INFLUENCIA DE DIFERENTES NIVEIS DE EXPLORACAO FLORESTAL EM UMA FLORESTA TROPICAL NA REGTAO DE NARABA-PA

AIIVAIRO GAIRCIA

Engenheiro-florestal

Orientador: PROF. DR. HILTON THADEU ZARATE DO COUTO

Dissertactio apresertada a Escola superior de Agricultura "Lliz do Queiroz", da universidade desto Paulo, para obtericto do titulo do Mestro sm ciencias Florelais.

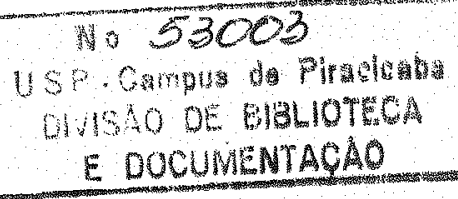

PI RACICABA

Estado de Sáo Paulo - Brasil

Novembro - 1990 
Ficha catalográfica preparada pela Seçăo de Livros da Divisão de Biblioteca e Documentação - PCAP/USP

Garcia, Alvaro

G216i Influência de diferentes níveis de exploração florestal em uma floresta tropical na regiăo de Marabá-PA. Piracicaba, 1990.

$149 \mathrm{p}$.

Diss. (Mestre) - ESALQ

Bibliografia.

1. Floresta tropical amazônica - Exploração 2. Floresta tropical amazônica - Exploraçäo - Método estatístico 3. Floresta tropical amazônica - Manejo Ensaio I. Escola Superior de Agricultura Luiz de Queiroz, Piracicaba 
INFLUEHCTA DE DIFERENTES NIVETS DE EXPLORAS.XO FLORESTAL EM UMA FLORESTA TROPICAL MA REGTXO DE MARABÁPA

AIVYARO GARCDA

Aprovado $2 \pi \overline{\bar{a}} 23.11 .70$

Conisรaัด juIgadora:

Frof. Dr. Hilton Thadeu Zarate do Couto ........ ESAlgiugF

Frof. Dr. Alvaro Fernando de Almeida .......... ESALQhuSF Frof. Dr. Agostinho Lopes de Souza $\ldots . \ldots . \ldots \ldots \ldots$. H.F.V.

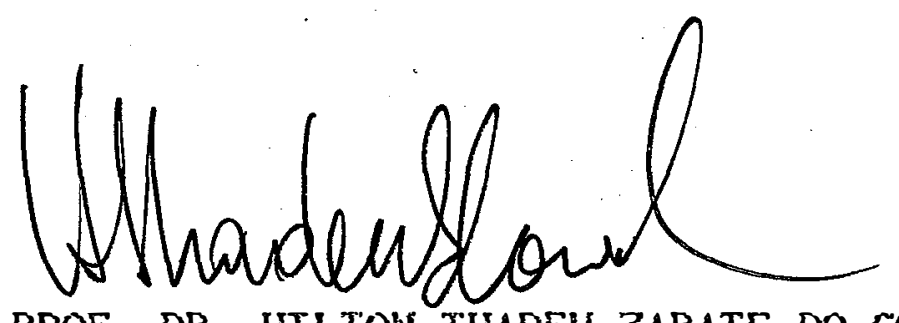

PROF. DR. HILTON THADEU ZARATE DO COUTO Oriertador 
ii.

Aos meus pais,

Arsemiro Garcia (in memoriun E

Anunciata Irene Garcia

DEDICO

AGRADEÇO

A mintza esposa.

Kitty

peio carinko, incentivo e apoio na execução dieste tratalino 


\section{AGRADECI HESTOS}

- A Escola Superior de Agricultura "Luiz de Gueiraz".

Ao Prof. Dr. Hilton Thadeu $Z$. do Couto pelo apoio, amizade $e$ incentivo durante a desenvolvimento do trabalho.

Ao Prof. Dr. Alvaro F. de: Almeida pelo convivio e aprendizado en prol do respeito e conșervação da Natu-

A CAPES/CNPG pela concessão da bolsa de estudas duranțe a fase de obtenção dos creditos.

Ao Engenheiro Florestal Fenato Moraes de Jesus - FRDSA, pelas interminâveis discussoses sobre o manejo de florestas tropicais.

Aos "Mestres Furais" "Sr. Lucival Radrigues a SF. Manol Cordeiro, do CPATU/EMERAPA pela colesa $e$ identificaçăo do macerial botanico.

Ao amigo Antonio Carlos Martins pela confecção das íguras e desenhos.

Aos Professores e funcionarios do DCF/USP. e IPEF pela colaboraça prestada.

Ao amigo Milton Cezar Fibeiro (Miltinfo\} do Laboratorio de Mécodos Runtitativos do Depto. de Ciencias Florestais - EsALe/USP, pela ajuda na análise dos dados e editoração deste trabalho.

- Aos colegas de colegas de pós-graduação pelo companheirismo e constantes trocas de ideias, em especial ao 3oão Luis F. Batista, Mauricio Ranzini, Tim F. Wehr, Vera Ley Engel e Naemi $V$. Leăa. 
Pagina

LISTE DE FIGURAS $\ldots \ldots \ldots \ldots \ldots \ldots \ldots \ldots \ldots \ldots \ldots \ldots \ldots$ vi.

LISTA DE TAEELAS $\ldots \ldots \ldots \ldots \ldots \ldots \ldots \ldots \ldots \ldots \ldots \ldots$.

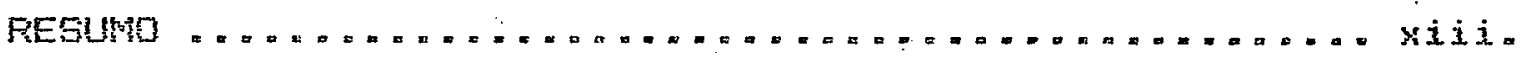

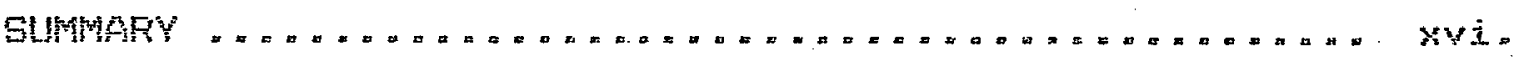

1 INTFODUÇAT $\ldots \ldots \ldots \ldots \ldots \ldots \ldots \ldots \ldots \ldots \ldots \ldots \ldots \ldots \ldots \ldots \ldots$. 1

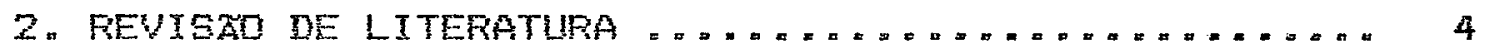

2.1 . Florestas Tropicais* Tmoortanciag Potencialidades E Taxas de Destruição ............ 4

2.2. Estudos Fitassorialogicos Em Florestas Tropi-.. Caj. $\ldots \ldots \ldots \ldots \ldots \ldots \ldots \ldots \ldots n=\ldots \ldots \ldots \ldots \ldots \ldots \ldots \ldots \ldots \ldots$ B

2.3. Crescimento de Arvores en Florestas Tropicais. 17

2.4. Manejo de Florestas Tropicais ............. 24

3. MATEFIAL E METODOS $\ldots \ldots \ldots \ldots \ldots \ldots \ldots \ldots \ldots \ldots \ldots$

Z.1. Caracterizaçăo da Area .................. 36

3.2. Descriça do Ensaí .................... 40

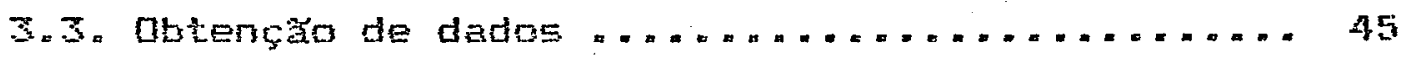

3.4. Arálise das Intormaçbes ................. 48

4. FESULTADDS E DISCUSSAD $\ldots \ldots \ldots \ldots \ldots \ldots \ldots \ldots \ldots \ldots$

4.1. Composiçăo Floristica ................... 57

4.2. Quociente de Mistura de IENTSCH (aM) ....... 74

4.3. Estrutura Horizontal .................. 77

4.4. Inventario Florestal inicial (1984) ........ 97

4.5. Inventario Florestal Fos-exploretorio (1984) - 102

4.6. Primeiro Inventario Contrnuo (1966) ........ 109 
Pagina

4.7. Segundo Inventario Continuo (1998) ......... 115

4.8. Análise do Crescimento ................. 126

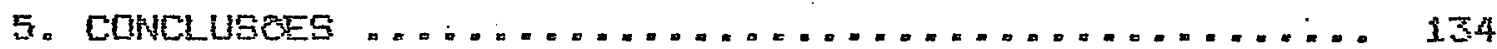

REFEFENCIAS EIELTOGRAFICAS $\ldots \ldots \ldots \ldots \ldots \ldots \ldots \ldots \ldots$

AFEUDICES $=\ldots \ldots \ldots \ldots \ldots \ldots \ldots \ldots \ldots \ldots \ldots \ldots \ldots \ldots \ldots \ldots \ldots \ldots \ldots$ 


\section{LISTA DE FIGURAS}

Figura

Pagina

1 Mapa de 1 coalização da Feserva Florestal de

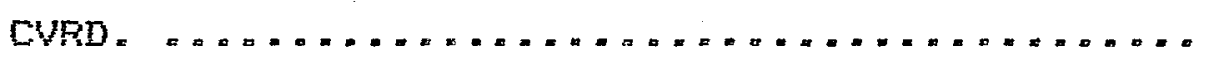

2 Localização dos biocas do Ensaio de Manejo Flaresta1.

3 Distribuifão dos tratamentos nos blocos do enseido

4 Distribuiça da area basal ( $\mathrm{m}^{2} / \mathrm{ha}$ ) no inventario inicial (1984).

5 Distribuica do numero de individucs por nectare no inventario inicial $\left\{1984^{4}\right\}_{\ldots \ldots \ldots \ldots \ldots \ldots} \ldots \ldots 2$

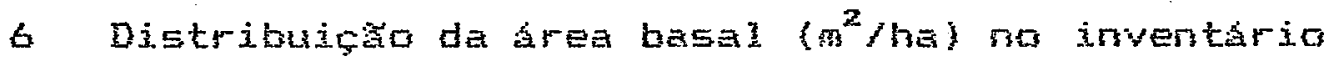

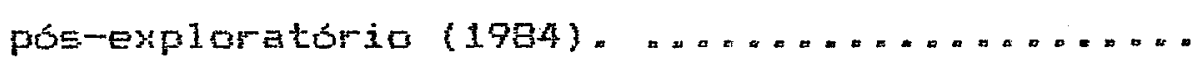

7 Distribuicão do numero de individuos por hectare no inventertio pos-eyploratorio (1984). ........ 108

B Distribuiça do numero de individua por hectare no primeiro inventario continuo (1996). ....... 110

9 Distribuição da area basal (m²/ha) no primeiro

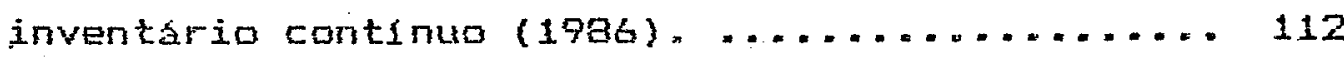

10 Distribuiçăo do número de individuos por hectare no segundo inventaria continuo (1998). ......... 
11 Distribuiçăc da area basal (m²/ha) no segundo inventário continuo (1989). .............. 117

12 Crescimento anual en area basal (m²/ha) no peri-

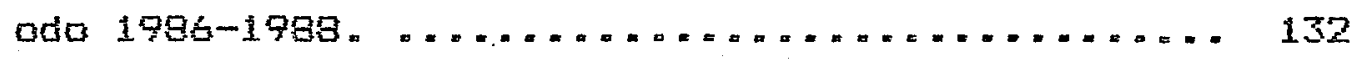


viii.

\section{LISTA DE TABELAS}

Tabe1a

Pagina

1 Descriçă das parcelas experimentais. ........

2 Distribuiça das classes de diametro. ........

3 Grdenação das familas botanicas generos e número de especies observados no inventario posexploratbrio (autubra-1984). ................

4 Numero de espécies, generos famílias botanicas observadas no inventálio pos-exploratorio coutu-

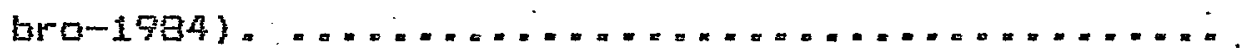

5 Núnerd de épécies, gêneros fanlizis botanicas observadas durante tados os inventarias flarestais reeiizados. $\ldots \ldots \ldots \ldots \ldots \ldots \ldots \ldots \ldots \ldots \ldots \ldots \ldots \ldots$

6 Composicăo flóristica geral. ..............

7 Número de especies gêneros e familias botanicas observadas no segundo inventario contrinu (Novembro-1998)

9 Composiça floristica do primeiro inventario continuo (0utubro-1986), por tratamento. ......

9 Composiça floristica do primeiro inventario continuo (Novembro-1988), por tratamento. .....

10 Evoluçăo do número de especies do ensaio. 
11 Quatiente de Mistura de JENTSCH (Gil) por tratamento, en todas as fases do ensaio. ......... 75

12 Indice de valor de importancia (IVI) das especies Estabeiecidas (SFi) g selecicmadas no primeirg inventario continuo (1986).

13 Indice de valor de importancia (IVI) das especies no estág de varas (SP2), selecionadas no primeiro inventario continu $(198 b) . \ldots . \ldots .$.

14 Indice de valor de importancia (IVI) das especies estabelecidas (SF1), selecionadas no segundo imventário continuo $(1998)$. $\ldots \ldots \ldots \ldots$

14 Indice de valor de importancia (IVI) das espocies ro Estagio de varae (SP2), Eelecionadas no segundo inventario contiruo $(1989), \ldots \ldots . . . \ldots$

16 Coeficiente de Variaça (CV\%) e número btimo de parcelas (n) para a variavel FEG HAs nas parce-

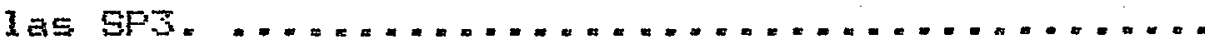

17. Numero de individuos (N/ha) no estagio de regeneracå natural (SPJ), observado no primeiro inventario continuo $(1986) . \ldots \ldots \ldots$

18 Analise de variáncia do número de individuos no estagio de regeneração natural (SP3) en 1986. .

19 Número de individuos (N/ha) no estagio de regeneração natural (SP3), observado no sequndo inventario continuo $(1998) . \ldots \ldots \ldots \ldots$ 
20 Analise de variârcia do número de individuos no estagio de reganeraça natural (SP3) em 1988. .. 94

21 Númera de espácies generos e fanilias botanicas da pegeneraça natural (SF3) em 1988. ......... 96

22 Distribuição da area basal ( $\mathrm{m}^{2} / \mathrm{ha}$ observada no inventario inicial $1984 . \ldots \ldots \ldots \ldots \ldots$

23 Analise de variancia dos dados coletados no inventario inicial (1984). ................. 100

24 Distribuiça do numero de individuas por hectare (N/ha cbservada no inventario inicial (1984). 101

25 Froduça de lenta $(s t)$ e madeira serravel (m)

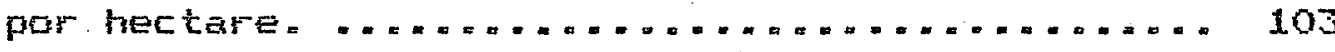

26 Volume nadeireiro inaproveitsvel (n⿳⺈冂䒑十⺝ . ..... 104

27 Distribuiça da Area basal $\left(\mathrm{m}^{2} / \mathrm{ha}\right)$ observada no inventapio pos-exploratorio (1984) = ..................

28 Distribuiça do número de individuas por hectare (Wha) observada ro inventario pos-exploratorio (1984).

29 Distribuição do numero de indiv1duos por hectare (N/ha) observada no primeiro inventario continuo (1986) 
30 Distribuiça da area basal ( ${ }^{2} /$ ha) observada no primeiro inventario continua (1986).

31 Efeito dos tratamentos na area basal (Ata_ha), número de individuos (N_Arvha) e diametro medio da parcela (MDAF), apbe 2 anos da implantaça dos tratamentos silvicusturais. .............

$\$ 2$ Distribuiça do número de individuos por hectare (W/ha) observado no segundo inventario continuo (1596)

33 Distribuigab da area basal $\left(m^{2} /\right.$ ha) observada no segundo inventario continuo (1989).

34. Efeito dos tratamertos na srea basal (Aba_ha), número de individuns (N_Arv_ha) e dianetro médio da parcela (MDAF), apos 4 anas da implantaçăo dos tratementos silviculturais nas parcelas $\left(S P^{2} 2\right)$.

35 Coeficiente de variaço (CV\%) = numero btimo de parcelas (n) para a variavel N_Arv_ha, nas

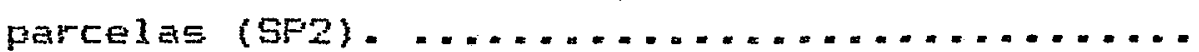

36 Incremento (\%) do numera de especies abservado no periodo $1786-1988$.

37. Efeito dos tratamentos na area basal (Aba-ha), número de individuas (N_Arv ha) e diámetro medio da parcela (MDAP), apos 4 anos da implantaçăo das tratamentos silviculturais nas parcelas

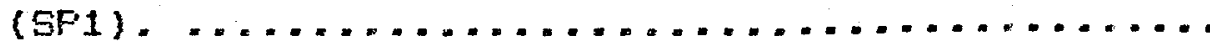


xis.

Tabela

Página

38 Ingresso (I) e mudanca da classe (T) de individuos, cbetrudo Em 198R. .............. 128

\$9 Crescimento periodico $e$ anual en area basal $\left(m^{2} / h a\right)_{5}$ apbe 4 aros da implantacáa dos trata-

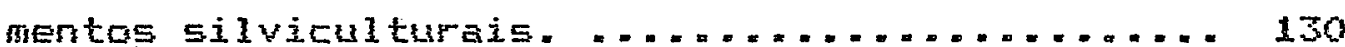




\section{INFLUENCTA DE DIFERENTES NIVETS DE EXPLORACXO FLORESTAL} EM UMA FLORESTA TROPICAL NA REGT XO DE MARABA-PA

\section{Autor: ALVARO GARCIA}

Orientador: PROF. DR. HILTON THADEU ZARATE DO COUTO

RESUMO

Com o abjetivo de avaijar o efeito de giferentes intensidades de evploração torestal en uma area de floresta tropical, foi instalado um ensaio de manejo sustentado na Reserva Florestal da Campantia Vale do Rio Doce-CVRD, localizada no muicipio de Haraba-Para.

Q delineamento estatistica do ensaio foi a de biacos ao acaso, com quatro repetiços e os tratamentos testados foram: 1) testemunha; 2) corte raso; 3) corte de todas os individuas com DAP $\geq 45 \mathrm{~cm} e$ 4) corte de tados os individuas cam $20 \geq 0 \mathrm{DF} \geq 60 \mathrm{~cm}$.

0 eneaio foi instalado em 1984 e as avaliaçbes foran efetuadas atraves dos dados coletados nos inventarios inicial (Agosto-19g4), pos-exploratorio (Qutubro-1984) continuos (1996 e 1989). Foram tomadas as medidas da circunferéncia à altura do peito (CAP) para todos as individuos com CAF $\geq 15,7 \mathrm{~cm}$ (varas e plantas estabelecidas), a 
xiv.

contagem dos individuas no estagio de muda $(H \leq 30 \mathrm{~cm})$ a identificaça botanica das especies presente nas parcelas do ensaio. Com os dados abteveres a Quaciente de Mistura de JENTSCH (an) e a Indice de Valar de Impartancia (IVI) en todos os tratamentos, assim como foram calculados os incrementos de novos individuos nas parcelas experimentais e o crescimento periodico e anual da area basal.

As principais conclusbes a nivel do ensaio forama a) no tratamento 2 roram obtidos os maiores volumes de produtos florestais (lanha e madeifa serravel) e com quatro anos de crescimento, cerca de $74 \%$ da area basal inicial foi alcançada porén a diversidade de especies no tratamento interior aos demais. No. Estagio atual ha a predoninância de especies pioneiras e secundarias iniciais b) a composiça floristica observade en 1909 , nos tratamen-

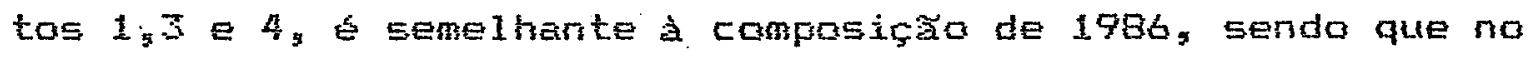
tratamento 2 houve uma intensa flutuação do número de especies presentes no periodo observado cl a número de amastras usadas para os individuos no estagio de regeneraçăo natural (SP2 S SPS) foi inferior ad necessario, no entanto foi possivel detectar diferengas qualitativas importantes entre as tratamentos testados; d) o incremento do numero de indiViduos. e o crescimento em area basal, em todos os tratamentos foi maior nas classes diametricas inferiores $(5-20 \mathrm{~cm}$ ) e) năo se recomenda nentum dos tratamentos utilizados, visto que o tempo de observaçăo (somente quatro anos) é pequeno em relação às possiveis mudanças que possam vir a ocorrer nas 
parcelas experimentais; f) recomenda-se a desenvolvimento de un sistema de amastragen especifico para o monitoramento da regeneraçăo natural em area submetida a diferentes intensiGades de exploraçăo, a implantaça de um programa integrado em unidades demonstrativos de manejo florestal. 
INFLUENCE OF DIFFERENTS LEVEL OF FOREST EXPLORATTON ON THE TROPICAL RATN FOREST AT MARABA REGION, PARA STATE OF

\section{Author: ALVARO GARCIA}

Adviser: PROF. DR. HILTON THADEU ZARATE DO COUTO

\section{SUMMARY}

Several. intensities of sustained yield management regimes were tested in an area of tropical forest at a Forest Reserve belonging to Cia Vale do fio Doce-cufo, located in the muncipality of Waraba, Fara State, Frazil. The statistical design for this test was Complete Randon Blocks with four replications, and the treatmens were: 1) No thinring: 2) clear cutting: 3 ) Thinning trees with $\mathrm{DEH}$ over $45 \mathrm{~cm}_{3}$ and 4 ) Thinning trees with DEH 1 ower then $20 \mathrm{~cm}$ and DEH above $60 \mathrm{~cm}$.

This test was installed in 1994 and data collected before and after thinning lAugust, 1994 and uctober, 1984), and in 19as and 1988. In each experimental plot, trees with circunference at over breast height (CHH) bark over $15,7 \mathrm{~cm}$ were measured. Seedlings from natural regeneration were counted in each plot. The species of each trees were identified by its botanical and popular names. 
With these data, the JEMTSCH mixture quacient and Importance Value Index (IVI) for each experimental plat were calculated, as well as the growth increment expressed as number of trees recruited and annual and periodic growth in basal area.

The main conclusions were: a) Treatment 2 showed the best wood valume after thinning (fuel waod and saw-wood) and after four years of growths $74 \%$ of the initial basal area were reached, but species diversity is lower than the other treatments. At this time there is numerical superiority of pioneer and early secondary species, b) Species composition observed in 198 a $_{3}$ at the treatments 1,3 and 4 is similar to that one observed in 1986. Treatment 2 showed an irregular unsteady pattern in the period under coneideration, c) The number of plats to study natural regeneration was lower than the necessary $110 \%$ sampling error with $95 \%$ probability level), but it was possible to get statistical significance among treatments, d) The growth increment expressed as number of tress and basal area, was greater in diameter class form 5 to $20 \mathrm{~cm}$, for all treatments, e) It was not possible to recommend anyone treatment, because the period of cbservation (four years) is not enough to reach stability, f) It is suggested a development of, a sampling scheme to monitor natural regeneration under several thinning intensities, and a demostration frogram for forest manegement in the Amazon. 


\section{INTRODUTXO}

A Amazonia Erasileira abrange uma brea de aproximadamente 5 milhoses de quilometras quadrados, incluindo-se neste vasto macico florestal, tipalogias caractorfsticas de campo natural, cerrado, florestas de varzeas florestas de terra-tirme e suas variaçes (FIFEs, 1976).

SEgundo FEARNSIDE (198B), cerce de $7 \%$ da Amazonia foram desmatados ate 1980, e caso prevalecan as tendencias atuais de uso de solo na Amazonia brasileira, serão desflorestados, anualmente, algo em torno de $27.000 \mathrm{~km}^{2}$ de área, cuja estimativa basequ-se nos dados disponlveis sobre oe dois últinos anos de desmatamentos en cada Estado e Territorio da Amazónia Erasileira. Somente no Estado do Fara, no ano de 1989 foram queimados cerca de $14.000 \mathrm{~km}{ }^{2}$ de área, dos quais cerca de $40 \%$ correspondentes a desmatamentos recentes (INPE, 1989).

Atualmente há várias formas de pressão sobre as areas florestadas na regiao Amazonica; dentre elas destacam-se a especulação com os preços da terra, a atividade pecusia extensiva, os programas de colonizaçăo mal conduzidos e, recentemente, a utilizaçăo de carvăo vegetal 
para o suprimento das usinas de ferro-gusa implantadas ao longo da Estrada de Ferro Carajas (FOMSECA, 1997 OFEN, 1985).

Diante da realidade acima expastā e das dificuldades, a curto prazo, de mudancas sociais e económicas do quadro atual amazonico, o manejo florestal en bases sustentadas surge como uma alternativa de produçăo promissora e capaz de. ordenar a esploraça dos recursos florestais em areas previamente destinadas a florestas.

Atraves do emprego do tecnicas de inventarios florestal e floristico, analises de variaveis ecologicas e conduça correta durante a exploraça florestal, é posstvel E 6 admiscivel, que parte das recursos florgstais existentes sejam transformados en diferentes frodutos e beneficios as populaçoses quer seja peío 450 difeto dos produtos fiorestais, ben cono pela projeçă futura das beneticios sociais e economicos a serem gerados pela utilizaça racional destes recurgas.

A Compantia Vale do Fio Doce - CVFD, atraves da sua subsidiaria, a Floresta Rio Dace S/A - FRDSA, desenvolve vários ensaios de manejo florestal sustentado na região amazónica (THIBAU, 18B7; JESUS \& MENANDFO, 1989). o ensaica de manejo florestal instalado na região de Marabá-PA, em área de floresta pluvial tropical, visa conhecer o potericial desta tipologia florestal para a producăo de lenha e madeira serravel, atraves de um modelo de manejo florestal sob rendimento sustentado. 
0 presente trabalho teve como objetivo analisar os efeitos de diferentes tratamentos silviculturais aplicados en uma area de floresta tropical umida na Amazónia, atraves de análises de crescimento da floresta e pelo estudo fitossociológico nos diferentes tratamentos, visando conhecer a capacidade de recuperação de uma floresta sutmetida a diferentes intensidades de exploraçă. 


\section{REVISAO DE LITERATURA}

2.1. Florestas Tropicais: Importancia, Potenclalidades e Taxas de Destruiçåo

As florestas tropicais das Americas, Africa e Asia, cobren cerca de 1.735 milhes de hectares, dos quais 1.200 milhbes de hectares $5 a 0$ de fiorestas densas e 735 milhos de hectares de florestas abertas. En adiçă, existem nos tropicos algo em torno de 410 milhos de hectares de áreas de agricul tura ou areas abandonadas (FAO, 1585).

A Amazónia Grasileira é constituida por oito Estados e dois Territorios da Uniăo, que somados formam uma area de aproximadamente $5 \mathrm{milhifes}$ de $\mathrm{km}^{2}$, que representam cerca de $20 \%$ das florestas tropicais do Mundo (sIQUeIRA, 1989).

Segundo a FAO (19B8) para os paises tropicais em desenvolvimento, as florestas e os terrenos arborizados såo essenciais ao bem estar economico e social de seus povos. Para a FAO, preciso intensificar as pesquisas, no entanto, acredita que a falta de conhecimento nao o o maior abstáculo, e sim a falta de apoio politico, financeiro e 
institucional para colocar en prática, as possiveis soluçơes. SOUZA (1989) afirma que as florestas tropicais ธăอ um dos maiores recursos naturais renovaveis, e que a utilizaรăo correta destas florestas proporcionan vários produtos e beneficios diretos e indiretos a população, tais como materia-prima para suprimento industrial, energia, produtas farmacalogicos, regulaçăo do fluxa e suprimento de água no solo, manutenção das chuvas, renovação e controle da qualidade do ar, recreaça e lazer, proteção a fauna, contrale de erosăo, etc.

A FAO (1989) precaniza que, as florestas tropicaiE ben utilizadas e manejadas, constituen uma ampla fonte de energia, um poderoso aliado contra a fome, uma base solida para criar o ben estar socio-economico e um imenso potencial de recureos geneticos capazes de assegurar e satisfazer as necessidades futuras. Todevia, reconhecem que a sua destruiçắ e depredaça continuam em un ti tmo alarmante. SEgundo FEAFNSIDE (1982) a extensăo a tana do desmatamento na floresta úmida da Amazonia Brasileira s objeto de discordancia entre os academicos e os tomadores de decisão no Erasil en outros palses.

Dados fornecidos pelo. INPE (TARDINI et ali $i$, 1580), obtidos de imagens do satelite Landsat em 1978, mostran que somente $1,55 \%$ da area da Amazónia brasileira, tinham sido desmatadas, o que representaria muito pouco em relação dos $4.795 .527 \mathrm{~km}^{2}$ da Amazonia Arasileira. Forem, FEARNSIDE (1984) afirma que as cifras do INFE 
subestimam a realidade, por causa da inabilidade da ténica para detectar derrubadas "muito pequenas" e da dificuldade de distinguir a vegetaçăo secundaria da floresta virgem. o autor cita o exemplo da interpretaça das imagens realizadas pela INPE para a regia da Zona Eragantina no Estado do Fara, onde a verdade terrestre contradiz os percentuais de area derubada e detectadas pelas imagens de satelite.

Recentemente, novas controversias surgiram a respeito da questão, quando foram divulgados, pela imprensa nacional, os indices oficiais atualisados sobre o desmatamento da Amazonia, envolvendo tecricos do Instituto Nacional de Pecquisas Espaciais - INPE e pesquisadores do Instituto Nacional de Fesquisa da Amazonia - INPA.

Fara FEARMSTDE (19gQ) cerca de $7 \%$ da cohertura florestal da Anazonia foran desmatadas ate 19a8, e estima, caso as tendencias de 450 atual da terra permanecan, un desmatamento de cerca de $27.000 \mathrm{~km}^{2}$, por ano, na Amazuia Erasileira.

0 INPE (1989) apontou no ano de 1988 , somente para a Estado do Fara, aproximadamente $14.000 \mathrm{~km}^{2}$ de areas queimadas, das quais cerca de $40 \%$ corresponden a desmatamentos rescentes.

FEAPNSIDE (1989) diz que as causas atuais do desmatamento podem ser agrupadas ens a) causas proximas $e$ b) causas subjacentes. Para o autor, as causas próximas sao os fatores que estimulam os proprietarios de terras e posseiros a dirigirem as seus esforcas para a derrubada da floresta o 
mais rapido poseive1. 0 autor enumera oito motivos presentes, dos quais destacam-se: (1) especulaçăo de terra; (2) incentivas tributários: (3) maiores impostos; cronograma para projetos incentivados (5) incentivo para culturas anuais (6) produçăo de produtos agricolas de exportasăo. For outro 1ado, as causas subjacentes do desmatamento são aquelas que ligam os processos na economia brasileira mais ampla, as motivaçoses proximas de cada desmatador individualmente ou a crescimento dos numeros de desmatedores presentes na regiăo. FEARUSIDE

identifica quinze causas, dentre elas destacam-se:

inflação: (2) crescimento populacional; (3) construgăo melhorias das estradas (4) baixo preco da terras polltica nacional e geopolitica internacional e (b) medo da floresta. Como prognose, o autor revela quatro motivos adicionais esperados para a futuro que săa: (1) esportaça de madeira; (2) produçăo de carvá vegetal; (3) suporte para as polas de desenvalvimento mineral e (4) projetos hidrelstricas.

FONSECA (1987) sintetiza em tres grandes fontes de pressáa sobre as áreas florestadas na regizo amazonica: (1) especulação com os preços da terra; programas de colonizaçăo mal conduzidos e (3) a atividade de pecuaria extensiva. CREN (1985) afirma que a utilização de carvăo vegetal para o suprimento das usinas de ferro-gusa a serem implantadas ao longo da Estrada de Ferro Carajas, poderá somar ds demais pressoses ja esistentes sobre as 
florestas tropicais amazonicas.

2. 2. Estudos Fitossociológicos em Florestas Tropicais

2.2.1. Consideraços sobre metodos de anáise estrutural

A vegetação e um sistema muito complexo, e que pode ser caracterizado por diferentes parametros, considerando ou năo alguns fatores do meid, tais como os climaticos, edaficos e bibticos (MONTOYA MAQUIN, 1966 ).

SEgundo MATOS MONTOYA MAGUIM $(1967)_{5}$ oS metodos fundamentados'en caracteristicas fisionsmica-estruturais da vegetaçă, să os que melhor atendem os requisitos de simplicidade de aplicaçă possibilidade de inclusăo de una amplitude de tipos de vegetagas de terminolagia aceitaça gera1.

Entende-Ee por fisionomia, a aparencia mastrada pela vegetaça, $e$ o seu estudo es feito através da análise de algumas de suas caracterlsticas, tais como as funcoses (caracteristicas morfobiologicas das especies que a formem) a a estrutura da vegetaça (distribuiça espacial das espeies).

Forster (1973), citado por LONGHI (1980), afirma que a análise estrutural se baseia no levantamento na interpretaçăo de criterios de conteúdo mensuravel, pois análises desta natureza permiten comparaçôses entre diferentes tipos de florestas. 
SOUZA (1973) define a estrutura de um povoamento como senda o número de srvores de cada classe de DAP ou de idade, existente en um hectare do mesmo povaamento.

FINOL (1971) afirma que os parametros da estrutura horizontal năo pernitem uma definiçăo real da orden de importancia ecologica das especies, assin sendo, propose a inclusác da estrutura vertical na análise global da Estrutura da vegetaçă.

A organização em agrupamentas de vegetais, através da análise totânica $E$ distribuiçăo espacial das especies, pode ser um criterio para a analise da estrutura da vegetaça e, segunda HUSCH (1963), a distribuiçăo de especies e quantidades de individuas por area, fo o resultedo dos habitos de crescimento e das condiçoses amientais, onde as especies se originaram e cresceran. Segundo a autor, Existen dois tipos de estrutura em relaçăa a idade dos individuos: (a) a estrutura equidnea $e$ (b) estrutura multianea, sendo esta ultima a Estrutura caracteristica de florestas naturais, onde há todas as gradaçbes de idade e tamanto.

Dutra forma de caracterizar a estrutura das florestas e adotar fómulas combinadas, simbolos ou pertis esquenaticos, como os exemplos apresentados por Matos \& MONTOYA MAGUIN (1967), onde roi usado o sistema de KüCHLER, que consiste de uma serie de combinaços de letras e números para designar os diversos tipos de vegetaçăo, ou entao, o sistema de DAHSEFEAU, que se baseia na combinaça 
de letras e números e mais uma serie de slmbalas para descrever representar graficamente a estrutura da vegetaçaัo.

LAMFRECHT (1564) afirma que dados Exclusivamente numericas e metados descritivos năo saa suficientes para caracterizar a estrutura da vegetaçăo, uma vez que as florestas să bastantes complexas. Para melhor compreender a estrutura da vegetaça, JARDIM (1985) afirma que s necessario desenvolver os perfis dos povaamentos, e que estes deven adaptar-se as caracterf sticas peculiares das forestas.

Fara qué un método de análise estrthural seja eficaz e correto, devem ser abservados as seguintes Pequisitos (LANFRECHT, 1964):

- Ler a capacidade e suficiencia para apresentar um quadro representalivo da estrutura da tipologia florestal estudada.

- ser aplicavel en qualquer tipa de florestaj

- não permitir que hajam influencias subjetivas, por parte do investigador, na interpretaça dos resultados, sendo desejavel que se expresse por cifras númeras;.

- permitir que os resultados de diferentes analises pracedentes do mesmo ou de distintos tipos de flarestas, sejam possiveis de comparaça;

- possibilitar aplicabilidade dos metodos estatisticos modernos, tanto na compilaçăo e avaliaça dos dados de campo, como na interpretaça e comparaçăo dos 
mesultados.

2.2.2. Análise quantitativa da vegetaça

\begin{abstract}
0 contecimento da estrutura da vegetaçă independente do metodo de analise empregado, requer a quantificação da vegetaร̆ă con o objetivo de obter informaçes fidedigfas dos aspectos quaitativos e quantitatiwoe da floresta.

AUEUSTIN (1981) afirma que QS inventarios florestais possuen caracteristicas proprias, definides segundo as condiçes e as ohjetivos para os quais exo planejados. Porem, todos possuen uma caracteristica comum e principal, que ch obter informaçßes, que deverão servir para tomada de decisoes sobre futuras aç3

Salvo Eituaçós peculiares, como florestas de alto valor ou pequenas parcejas de grande interesse cientifico, as avaliacoses florestais devem empregar as tecnicas de amostragen; posto que permiten que uma fraça da flaresta exaninada farneça, atraves do emprego de ténicas estatisticas, estimativas catisfatorias dentro de uma margem de erro previamente estabelecido.
\end{abstract}

2.2. 3. Procedimento para analise estrutural da vegetaçăo. 
utilizados na análise estrutural da vegetaçăo foram propostos inicialmente por CAINE CASTRO (1956) E atualmente, estao sendo usados, com relativo exito, na anaise estrutural das florostas tropicais e sub-tropicajs da América do Sul.

Em estudos fitossociolsgicas realizados na Amazonia (GARFD, 1986 JARDIM 1995: CAFVALHD, 1982; AUGUSTIN, 1981, VEGA, 1968), foram utilizados indices fitossociologicos para caracterizar a estrutura da vegetação. Segundo Hosckaha (158s), o fato das florestas tropicais apresentarem alta divereidade de esperies vegetais, o conhecimento do potencial presente e futuro das florestas deve ser obtido atravess de estudos que sejam capares de abranger os seguintes itens da analise estrutural: (1) estrutura horizontal; (2) estrutura verticals (3) estrutura parametrica e (4) Estrutura da regeneraşo natural.

\subsubsection{Parametros da analise estrutural}

a) Estrutura horizontal

A analise da estrutura horizantal mostra a participação de cada espécie em relaçăo às outras e verifica a forma de distribuição espacial de cada especie (HosokAwA, 1996). Os paranetros fitossociologicos da estrutura horizontal, estimados en ternos absoluto e relativo săo: abundância, dominância e frequencia. 
b) Estrutura vertical

A análise da estrutura vertical engloba estimativas dos parânetros: posição sociologica das especies E regeneração natural. A posiçăo sociológica informa sobre a composição floristica dos distintos estratos da floresta e sobre o papel que desempenham as diferentes especies em cada Estrato (HOSOKAWA, 1996).

o terma regeneraçăo natural se aplica, geralmente; ds fases infanto juvenis. das especies $E$ cada individuo pertencente a classe dianstrica pode ser considerada como regeneraçăo da 'fração do povoamento da mesna Especie com didametras superiorec a essa cizsse.

c) Estrutura parametrica.

Entende-se por estrutura paranstrica da vegetaçăo, a quantificaçă da fluresta em termos de volume; qualidade do fuste, vitalidade das arvares, comercializaçă etc. (HOSOKAWA, 1786).

d) Estrutura da regeneraça natural.

0 estudo da estrutura da regeneração natural es realizado por ocasião da determinaça da estrutura vertical e engloba a obtençăo das variaveis densidade e frequéncia para as especies presentes no tiasse e tamantio considerado como regeneraçăo natural (HOSOkAWA, 1986). 
e) Indices fitossociológicos.

- Indice de JENTSCH Du Guociente de Mistura.(GM)

Indice de JENTSCH au Guciente de Mistura foi utilizado pela primeira ver em 1911 (LOWGHI, 1990) e indica quantas apvores de cada especie să encontradas en media en um povoamento, permitindo assin uma primeira vicao, embora Emplrica, das condiçoes de mistura do povoamento.

Segundo FINOL $(1975)$, para florestas tropicais Q quociente de mistura é proxino de 1:7.

Nos estudos sobre regeneraxizo natural apresentado por CARUALHO (1982) E JARDIM (19a5), realizados en forestas trapicaij: as valores obtidos para o an foram 1:10 E 1:9, respectivamente. VIEIRA (1906) analisqu a regeneraräo natural de uma floresta tropical, un ano apos ter sido submetida a diferentes niveis de exploraça e obteve valores do OM proximos ao mencionado por Fingl (1575), em dais dos quatra tratamentas. BAFFOE (1990), afirma que dados recentes ten demostrado ume varizção muito alta na quantidade e qualidade da regeneraçăo natural nos primeiros tras anos, em areas submetidas a exploraçăd forestal.

- Gral de Homageneidade (H).

o grau do homogeneidade es um indice fikosEociologico desenvolvido para exprimir a homogeneidade de Lma ascaciaçăo vegetal, utilizando-se da variável frequencia (LONGHI, 1580$)$. 
- Indice do Vaior de Importancia (IVI).

DE dados estruturais de densidade, dominancia e frequencia, isoladamente, não fornecen as informaçöes requeridas sobre a estrutura florfstico-sociologica da vegetação - Fara efetuar analise da vegetação é importante que se encontre um valor que possibilite uma visão mais abrangente das especies, ou que caracterize a importancia ecologica de cada especie no conjunto geral do povoamento. (LAMFFECHT, 1964 ).

o indice do vaser de importancia

(IVI)

proposto. en 1951 por CURTIS \& McINTOSH e aplicado inicial-

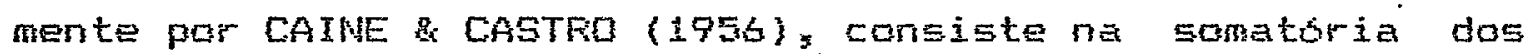
valores relativos de densidade, dominancia frequencia de cada especite.

Segundo VEGA (1968) a IVI \& usado para dar uma viฐăo do caracter de așociaçăo das espécies e para LONGHI (1980) ele serve para determinar a importancia ecologica de cada especie dentro da comunidade florestal, pois quanto maior o IUI, mais caracteristica sera a espocie dentro do complexo floristico do povoanenta.

- Indice do Valor de Importancia Ampliado (IVIA)

O Indice do valor de importancia ampliado (IVIA) foi utilizado Fela primeira vez por FINDL (1971) em substituição ao IVI, o qual, segundo o autor, não permite uma informaça completa sobre a estrutura da vegetaça, uma vez que considera somente a analise da estrutura horizontal 
e esta não reflete as caracteristicas reais das florestas, tendo en vista a grande heterogeneidade entre especies e estratos. FINOL (1971) sugere a inclusa da estrutura vertical, a qual irá contribuir para melhor caracterizar a importancia fitossociolbgita de cada especie dentro da f1aresta.

f) Estrutura diamétrica

A estrutura diamética da floresta descreve a distribuição das espócies, sequndo classes de dismetro pré-estabelecidas, e serve para orientar o manejo racional da fioresta

Năo f facil a interpretaça da estrutura diametrica de uma flaresta tropical e, segundo FINOL (1969) - conitecimento e o significado fitossociologico da acorrencia de especies tipicas dos menores estadias sucessianais até as condiçses climax da floresta, devem ser estudados profundamente.

A amplitude de classes diambiricas adotada na descriçăo da estrutura diametica das florestas tropicais, e definida segundo criterias subjetivas. LAMFRECHT (1968), VEILLOW Et aliz (1976), LONGHI (1980), HOSOKAWA (1981), entre outros, utilizaram intervalus de classe iqual a $10 \mathrm{~cm}$. Entretanto, EAFROS (1992), investigou a efeito de tres diferentes amplitudes de classes diamstricas no ajuste de funç8es de distribuiçőes diametrica, na Floresta Nacional do 
Tapajos ( PA), e optou pela escolha da amplitude de classe de $10 \mathrm{~cm}$.

g) Perfil estrutural

Qs perfis estruturais Eăo informaços auxiliares importantes no entendimento e exploraça das florestas. Un perfil completo da floresta deve abranger sempre uma planta horizontal e a projeça vortical desta planta, arim de proporcionar uma visão espacial da floresta e da posição de cada arvore individualmente na "sociedade" (HOSOKAHA, 1986).

2.3. Crescimento de Arvores em Florestas Troplcals.

\subsubsection{Constueraços gerals}

Os estudas sobre a dinamica de crescimento das flarostas tropicais săo escassos; devido, principalmente, an Fouco conhacimento dos diferentes fatores que intiuencian o crescimento das esperies, assim como pela compleyidade inspente de florestas tropicais.

Guinandeau (1969), citado por GUTIERREZ (1970) atribuiu as carzcteristicas das eftias $e$ as fatores geneticos proprios das especies, como sendo as aspectos determinantes para o entendimento da alta diversidade e dos diferentes ritmos de crescimento coservados em tlorestas tropicais.

0 crescimento das arvores pode ser explicado 
como sendo o aumento irreversivel em tamanho, ou seja, a formaçăo e diferenciaçăo de celulas, tecidos e orgãos da planta. Essa diferenciaçăo resulta no incremento e acúmulo de tecidos do floema e xilema, formando assim córtex e o alburno.

As medidas de altura, diametro, area basal, volume e peso săo na verdade, mensuraç̧es do acumulo de tecidos diferenciados, sendo o tronco a parte do vegetal que mais recebe atengão durante as avaliaços dentrongtricas (HUSCH, 1963).

o desenvolvimento e arquitetura das arvores såo bactantes heterogengos em uma floresta tropical, e essa variaça de crescimento e forma e atribuida, principalmente, as caracteristicas da especie, local e idade. Do ponto de vista global, o crescimento de povanmentas florestais sao influenciados, principalmente, pela idade, condiçes edáticas locais, posição sociologica das ávores e fatores geneticos de cada Especie (VEILLOM, 1967).

PHILIF (1707) menciona que antes de mensurar a crescimento a producăo em florestas tropicais, deve-se definir o objetivo das estimativas a seren obtidas e quantas e quais medidas devera ser tomadas. Diz ainda que existen problemas nos metodos usuamente empregados a que novos modelas estao senda desenvolvidas, porém as problemas de origen humana superam as problemas derivados das arvores ou da floresta. 
avaliaçăo do crescimento e produça en florestas tropicais, FHILIP (19a7) chama atença para os seguintes aspectos: (a) necessidade de uma major conscientizaçăo, de alto nivel, de autoridades e profissionais emvolvidos, para o valor dos recursos naturais, de tal sorte que haja investimentos continuos para execução de trabalhos de campo e para analises de dados (b) desenvolvimento de sistemas refinados de amostragen e procedimentos analiticos (c) mantutercăo de um programa de treinamento intensivo para tecnicas de campo, especialmente para identificaça de especies, mediça com eparelhos oticos, coletas de dados, e (d) emprego de tecnicas de mediça simples en unidades de enostras selecichadas.

2. 3.2. Fatores ambientais gue influenciam o cresclmento das arvores.

De fatores do meio ambiente que afetam o crescimento das arvores podem ser classificados en estavis e transitorias (HUSCH, 1963). Os fatares estaveis să aqueles que năo causan mudanças bruscas durante o cílo de vida da árvore, tais como, a mudança ne textura do solo e o nivel de rutrientes. Por sua vez, os fatores transitorios, clclicos ou esporadicos, tais como mudangas no tempo, 5ăo, do ponto de vista do crescimento das arvores, de suma importancia, principaimente, se os dados anteriores de crescimento serăo utilizados na prediço do creacimento futuro das arvores. Todavia, éstido que as variaços na 
taxa de crescimento anual das árvores săo atriburdas en parte, ds flutuaçoses ciclicas, sendo que na protica é dificil segregar estes efeitas do crescimento total da arvore (GUTIEFREZ, 1970 ).

Dentre os fatores do meio ambiente, a distribuiçăo das chuvas durante o ano, em rejação ao crescimento total, mais importante do que a quantidade de chuvas no mesmo periodo (GOLFAFI, 1967 ).

Nas regi ¿es de clima tropical, a temperatura do ambiente influi decisivamente no fltmo de crescimerto das ávores e, segundo NiCHCLSON (1560), é possivel abter altas taxas de fotossiftese sem a luz completa do dia.

MUFAEs $(1570)$ Estudou o crescimento en dianetro do tronco en varias especies de floresta tropical. mencionou que, provavelmente, en anos diferentes, os crescimentos maximos para cada especie se situamg em meses diferentes.. Deduziu, ainda, que a acorrencia de maiores taxas de croscimento do tronco em epoca chuvos indica que a luz nå fator 1 imitante para a crescimento do tronco para as especies que ocupan a teto da floresta já que esta fpoca do ano coincide com as menores taxas de radiaçao solar e as de maior nebulosidade.

GUTIERFEZ (1970) afirma que, dentre os fatores do meio que afetam o crescimento e forma das arvores, o controle do espaço de crescimento e o unico que pode ser manejado facilmente, una vez que a manipulaçao do espaço requerido pelas plantas pode proporcionar um crescimento 
mais uniforme assin como uma maior eficiência de utilização do sltio.

\subsubsection{Ref I namento}

As florestas tropicais săo caracterizadas pela alta densidade de plantas por ábea, com uma grande diversidade. de espécies, cujas ritmos de crescimento nem sempre să iguais.

A produtividade de florestas naturais ou forestas implantadas pode sep incrementada atraves de praticas silviculturais adequadas. Dentre estas, o refinamento termo usado para florestas naturais, e dasbastes. para as florestas implantadas şo ume deo mais importantes.

0 refinamento consisce na reducia gradual do número de spvores de un povanmento en crescimento, ato atingir un numerc ideal por. unidade de área, de onde se obtem a mélhor rentabilidade (EUTIEFFEZ 1970).

A definicăo das caracterisaticas do perinamento e funça do objetivo do manejo, pois, existe uma enorme possibilidade de alternativas, desde retiradas brandas. ciclicas, ate o corte unico e raso, que nem sempre है adequado ds condiçBose tropicais GUTIERREZ (1970).0s refinamentos dependen da definiça de alguns critérios tais camo:

a) regime do refinamento = indica o numero de arvores, 
area basal ou volume a deisar por unidade de aroa depois da exploração, pode ser expresso em porcentagem.

b) grau do refinamento: indica a intensidade de remosão das arvores em diferentes classes diamétricas em toda a exploração.

c) ciclo do retinamento: o intervalo medio, en anos, entre uma sucessăo de refinamentos; o qual pode ser constante ou variável.

d) peso do refinamento: indica o volume ou area basal removido en un só refinamento.

a) intensidada do refinamento e uma medida de quantidade removida (nㅇ de drvorec, area besal ou volume) en um perfodo de tempo especifico. Isto é intensidade = pesoleiclo.

As variaçoes do crescimento de arvores individuais ou do conjunto delas, em funçăo das caracteristicas do rerinamento adotado, săo pequenas a variaveis, quando comparadas as variaçőes do crescimento devido às mudanças clináticas anuais, ds diferenças de sitio e a lacalidade, mesmo que sejam dentro de um povarmento florestal aparentemente homogeneo (GUTIEFREZ, 1970). 
2.3. 4. Crescimento de espécies da floresta troplcal

PIRES (1981) afirma que te possivel estabelecer um sistema racional para definir tipos de vegetaça florestal e nåa-florestal, tomanda-se por base a avaliaçăo da biomassa e atraves da mediçăo do incremento em circunferencia ou dianetro das arvores. Fara o autor, no geral, as arvores da floresta tropical tem baixa longevidade e cita as observaçóses de Heinsdjk, a qual estimucu que una árvore media da floresta Amazonica fárvore teoricaly pertencente à classe de diametro entre $25-35$ cm incremento de diametro do tronco em torno de $0,8 \mathrm{~cm}$ por ano. Por sua vez PHILlifg (1969) afirma que, con excescå das especies pioneiras, o incremento en valume é lento, podendo considerar como uma taxa normal de crescimento, valores de 1 a $3 \mathrm{~m}^{3}$ /ha por ano.

MORAES (1970) mediu a crescimento mensal da circunferência do stonco em 21 espocies da flaresta Amazonica e verificou que dezessete delas apresentaram periodicidade estacional de crescimento, com fases de maior intensidade correspondendo a spoca chuvosa. Verifica ainda que as velocidades de crescimento foramg em geral para cada especie, maiares para as. individuas de parte media, can excessão de Theobrona subincanum, $e$ que individuas com diametro proximo a 10 cm cresceram mais rapidamente do que os de classes diametricas mais altas.

ALVIM (1964) estudou a crescimento en diametro 
do tronco do cacaueiro e otservou uma correlaçăo positiva entre o crescimento $e$ a temperatura do ar, porém năo encontrou, para a especie estudada, correlaça positiva entre a precipitaçăo pluviometrica e o crescinento do tronco.

2. 4. Manejo de Florestas Tropicals

2. 4.1. Sistemas silviculturals

A grande diversidade biologica observada nas florestas tropicais, fez com que fossem propostos difermates sistemas silviculturais para manejo destas florestas. Estes sistemas foram elaborados, considerando as caracteristicas proprias de cada tipo de flaresta. Varias autoreg descrevem diferentes sistemas de maneja silvicultural (ALVES, 1982; FAO, 1958; CATINOT, 1965: 5TOHF \& IPDUE, 1776: SMITH, 1962 ; TROUP, 1952; TANG, 1787; ASAGERE; 1987; WWOEOSHX, 1987 WADSWOFTH, 1987).

Segundo SMITH (1962) a termo sistema Eilvicultural e mais compreans1vel e designado para programas planejados de tratamentos silviculturais durante o citio de vida dos povomentos ("Etand"), e isto inclui, não somente 
os cortes de reproduçäo, mas tambem as cortes intermediarios.

o Manejo Florestal s conceituado pela "The Society of American Foresters" como sendo a aplicaça de metodos comerciais e princlpios tecnicas florestais na operacionalização de uma propriedade florestal (MISRA, 1982).

SHITH (1962) agrupou os sistemas Eilviculturais em quatro metodos, chamando-os de: (a) método de corte raso; (b) motodo da srvore porta-semente; (c) mitodo do abrigo temporário e (d) método seletivo.

QS ensaios de manejo florestal existentes na Amazonia så na sua naioria, segundo Hatista ${ }^{1}$ variaçöos ou adaptaçoes especticas dos sistemas propostos por SMITH $(1962)$.

2. 4.2. A importancia do manejo florestal para a Anazonia

0 enorme potencial biologico da floresta tropical Amazonica, evidencia uma posição de destaque no Mundo 
cientifico e economico, tendo en vista a existencia de um amplo e diversificado banco generico de especies vegetais e animais.

A exploração das florestas amazónicas vem sendo realizada há muitos anos, de forma seletiva e, mais recentemente, de forma seletiva e predatiria.

FEARNGIDE (1989) diz que a acupaz̧a territorial da Amazonia esta estreitamente ligada aus sistemas humanos de uso das fiorestas. Diz tambem. que estas sistemas, incluindo as forças sociais, 5 que levam a determinadas traneformaças do uso de terra, sendo portanto. a raiz do athal padrão de uiำizaça da floresta.

SOUZA (1989) acredita que o crescimento populacional das regibes tropicais sub-desenvolvidas e en desenvolvimento, que for ironia situan-ce en solos pobres que posstiem as maicres rlorestas tropicais do Mundo aliado as crescentes pressozes de demanda de mercado por parte dos paises ricos, eque ven provocando a depredaça e pertubaça das florestas tropicais.

HOSOKAWA (1986) afirma que o principio fundamental da atividade flarestal consiste en proporcionar beneficios múltiplos e continuos a humanidades sen contudo esgotar os neios produtivas. Afirma ainda, que os sistemas produtivos e de consumo devem estar em equilibrio harmbnico, 
e que a continuidade da existencia dos seres vivos depende muito do equilibrio entre os dois sistemas. Para o autor a adoço efetiva do principio de rendimento sustentado deve ser tomado como um princlpio de vida.

2. 4. 3. Modelos experimentais de manejo florestal sustentado em desenvol vimento na Amazonia.

Face aos danos cjusadas pala exploraça tradicional empregada, era de se esperar que houvesse en andamento um grande numero de pesquisas capazes de indicar, seguramente, novas ceminhos e ảternakivas para a litiłizaçăo. do potencial madereiro disponivel na Amazonia (STQUETfA, 1999). 
a) Cronograma dos estudos de manejo sustentado na Amazónia.

EVENTO

1955

Firmado convenio entre o Brasil e a F.A.Q., e comecam os estudas sobre manejo florestal em Curua-Una, na regiáo do fía Tapajós-PA.

1963

Implantaçăo por peritos da F.A.Q. de um ensaio de manejo florestal pare testar a Sistema de Abrigo de Madeira ("Tropical Shelterwood System-TSS"), na Estaçă Esperimental da SUDAN em Curub-Una-PA.

1963-73 Faralizaça do comvenio. Abaruono total das pesquisas.

1973

Firmado novo convenio entre a SUDAM $e$ a F.A.O. para analises dos ensaios existentes na Estarăo de CurLk-Una-PA:

1980

Implantado um ensaio de manejo florestal em uma hacia-modelo, perto de Manaus, atravós de um convenio entre o INFA/GIDJFINEF.

1982 . Implantaçăo de un ensaio de manejo flarestal na Floresa Nacional do Tapajos (PA) pelo IEDF lhoje IEAMAI.

1983 Implantaça de um ensaio de manejo tlorestal em area do Frojeto Jari; no Territorio do Amepá, atraves de UA Convenio entre a EMBRAPA/CFATU/IBDF.

1983 Implantaça de um ensaio de manejo tiorestal na. Feserva Florestal da Cia. Vale do fín Dace (CVFD), En Euricicupu (MA).

1984 Implantajo um ensaio de manejo florestal na Feserva Florestal da Cia. Vale do Fio Doce (EvFD): em liaraba $(P A)$.

1984 Implantado un ensaio de manejo florestal em area pertencente a Mineraçăo fio do Norte (MRN), Em Oriximina-PA.

1987 Implantado um ensaio conercial piloto na Feserva Florestal da CVFD, En Euriticupu (MA). 
b) Descrição principais resultados cfe alguns ensaios de manejo florestal sustentado instalados na Amazonia.

\section{1.) Manejo Florestal en Curua-Una (PA)}

En 1963, a F.A.D. e a Governo Brasileiro, através da SUDAN, implantaram ne Estaça Experimental de Curua-Una, um ensaio de manejo florestal visando testar o Sistema de Abrigo de Madeira ("TSS") (DUEOIS; 1971 ).

o Sistema inclui a corte de cipós e de arvoretas não económicas e o ervenenamento de algumas das maiores árvores de esperies não economicas (abertura do doseal), algune anos antes da exploraça soguido pela colheita seletiva e remogano peribdica de cipos e das "madeiras da atrigo", ou seja, de sivores que crian momentaneamente condiçes microclimáticas favoraveis ao crescimento da regeneraçăo natural de especies vaiiosas (FEAFMsIDE, 1989 ).

Neste ensaio, aOs 25 anos de idade, a furesta manejada experimentalmente produziu $20 m^{3} / h a$ de madeira comercial, com DAP maior ou igual a $45 \mathrm{~cm}$ (Jankauskis, ig7日 citado por. CARVALHO, 1989 ).

2:) Manejo Sustentado na Floresta-Nacianal do Tapajos (FA).

Aposs a reakizaçăo do reconhecimento da área, inventario florestal comercial invertario diagnostico da regeneraça natural, foi efetuada a oxploraça experimental de uma area de 64 ha. En 39 hactares, foram derrubadas 
árvores com DAP igual ou superior a $45 \mathrm{~cm}$ e nos 25 hactares restantes, foram retipadag arvores con DAP igual ou superior a $55 \mathrm{~cm}$.

a volume modio retirado foi de $72 \mathrm{~m}^{3} / \mathrm{ha}$ correspondendo a cerca de 20 arvores/ha fCARVALHO et ali 1989).

Após a exploraçăo experimental mecanizada, observou-se intensa regeneraçă inclusive de espécies de valor comercial, tais como: parapara (jocaranda copaic), maratato (Didynopana $x$ morototoni), cupiuba (Coupia slabra), que ocorrem mais frequentemente en grandes clareiras es jutal-acu (Mymened courbaril) e faveira-tolha fina (Piptadenia suaveolens), que aparecen en clareiras menores ramais secundarias.

Quatro anos apos a exploraça, existiam cerca de 16.000 plantas/ha la partir de $30 \mathrm{~cm}$ de altura ate $2,4 \mathrm{~cm}$ DAP). Deses total, 4.200 eram constituidas por especies comerciais e/au potenciais. Entre o primeiro e quarto ano a sobrevivencia media das plantas, considerando todas as Especies, foi de $75 \%$ (CAPVALH et ali 1997 ).

A taxa de atmento da area basal foi taior sob exploraça mais leve, quando apenas as especies comerciais foran consideradas, mas apresentou a tendencia opcsia quando a comparaçă foi feita para todas as esfocies (FEARNSIDE, $1999)$.

0 ciclo esperado entre as colheitas of de 20-25 anos, tratamentos silvilculturais deverao ser aplicados 
durante esse periodo, que inclui o corte de ciposs, eliminação de arvores de espescies comerciais que cao mal formadas ou com outros defeitos, e a elimiança de algumas árvores năo comerciais (CAFUALHD, 1987).

Os danos causados pela exploraçăo foram: $6,9 \%$ correspondentes a constirução das ramais secundárias e referentes ds areas dos patios de estocagen e ramais principais. Segundo os pesquisadores do CPATU/EMARAPA, coneiderando una area de corte anual de 1.000 hectares, haveriam 45 rectares de patios e ramais principais que poderian ser reflorestados, apos a exploragă con espócies de rápido crescimento.

3.) Manejo Florastal na JAFI (AP).

Fai realizado un inventario florestal comercial, para todas as arvores com DAP igual ou superior a 50 cm, antes da marcaçăo, exploração exiraçăo das árvores (CARVALHO et alii, 1999).

De poses doe dados do inventario, foram testados tres niveis de exploração:

a) retirada de $15 \%$ do volume total $\left(26 \mathrm{~m}^{9} / \mathrm{ha}\right)$ ou 3 individuos/ha. 
b) retirada de $25 \%$ do volume total (43 $\mathrm{m}^{3} / \mathrm{ha}$ ) ou 5 individuos/he.

c) retirada de $35 \%$ do valume tatal (61 $\mathrm{m}^{3} / \mathrm{ha}$ ) ou 7 individuos/ha .

Os custos de exploraça florestal, considerando: construção de estrada principal $(2,5 \mathrm{~km})$, vias secundáias $(4,8 \mathrm{~km})$, patios de estocagen $(29$ und), ramais de arraste $(17 \mathrm{~km})$, derrubada e extraçăo, carregamento e traneporte ainda, gastos com administraça $(15 \%)$ e imprevistos $(10 \%)$ foi de USt 10.10 por $\mathrm{m}^{3}$ (marco de 1996).

A produça por motosserrista foi de 15 arvorestha ou $75 \mathrm{~m}^{3} / d i a$. Foi avaliado 0 equipamento TSS Muller (fatricaça nacional) fara arraste de toras e que demonstrou eficiencia e adequaça as florestas tropicais com uma capacidade de arraste de $119 \mathrm{~m}^{3} / d i a$, ama distancia de arraste de 210 m na trilha principal, 54 metros na Eecundaria 25 metros sem triatha (CAFVALHO 1769).

Os danos causados pela exploraça forama
a) patios de estocagen
7,75 ha $(1,95 \%)$
b) Estradas principais
1,50 ha $(0,4 \%)$
c) estradas secundarias/ranais
a, 72 ha $(2,2 \%)$

4:3 Manejo Florestal da CVFD en Euriticupu (MA).

o erisaio foi instalado em uma area de floresta 
tropical, derominado por GOLFARI (1990) de Floresta Mesotila Perenifolia do rio Findare, localizada no municlpio de Santa Luzia (MA). A vegetação \& caracterizada pela presença abundante de cipos e fica situada na faixa de transiçăo entre a Floresta Amazónica e a Floresta de Babacús.

0 madelo experimental constitui-ce de 4 blocas aq acaso com 5 tratamentos. Freviamente a aplicaça dos tratamentos, foi feito um inventario florestal, através da enumeração completa de todos os individuos com DAF igual ou superior a $10 \mathrm{~cm}$, em todos os blocos de ensaio. A area de cada parcela experimental foi de $\dot{0}_{3} 5$ ha $(50 \times 100 \mathrm{~m})$, esparados entre $5 i$ de $50 m$ atactadas $75 m$ da estrada de acesso.

Os tratamentos foram escoltidos de modo a representar diferentes tipos de interferencia, Variando de un sistema de exploraço mais brando ate un sistema mais drastico (corte raso). Os cinco tratamentos forama

\footnotetext{
Trat. O1 - Testemunha (sen interferencia)

Trat. Oz - Elininaçăo de cipos

Trat. 03-Corte raso

Trat. 04 - Exploraçăo de todas arvores com DAP y $45 \mathrm{~cm}$

Trat. O5 - Exploraçăo de todas arvores com DAF $610 \mathrm{~cm}$ e DAF $>60 \mathrm{~cm}$. Wo povoamerto remanescente foram deiradas somente os individuas com ba formaçăo fenotipica.
} 
Nos tratamentos 3,4 e alem das prescriçßes acima, foram deisadas até duas arvores por parcela para que possam funcionar como porta-sementes. Da mesme forma, nestes. tratamentos, foram retirados todos os individuos que sofreram danos na ocasião da exploração.

YAFED et ali (19a9) afirman que os coniecimentos disponiveis para o manejo da floresta para producão sustentada estao ainda aquem das exigencias raqueridas devido a complexidade $e$ a numero de variáveis envolvidas. Fessaltam portem, que as informaçes exietentes permiten traçar rumos e estabelecer diretrizes basicas para seron incorporadas aos planos de manejo. Fara os pesquisadores, alén dos probiemas tecnicos envolvidos na questao do manejo das florestas tropicais, o que tem realmente dificultado qualquer aça mais profunda, 5ăo os aspectos pollticos, cono - processo de ocupaçăo a estrutura fundiaria da regiao e ate mesno a propria legislaçă florestal. os autores preconizam como basico e fundamental, a zoneamento ecológico do espaco territorial amazonico e sugerem a criacăo e implantaça das fiorestas nacionais, Estaduais 9 municipais, onde enţo seriam definidas areas para serem utilizadas atraves do manejo florestal suctentado.

Fankin (1985) citado por VIAHA (1997) entende que uma das raxbes da năo oristencia de informaços tásicas sobre a capacidade e possibilidade da reganeraça e manejo 
das florestas tropicais e sub-kropicais, o fato de que os inventarios realizados anteriormente pelo FADAM $E$ IBDF, Em area da florestas naturais do Erasil, limitaram-se aos levantamentos estatisticos do volume de madeira e a descriçao das comuniandes florestais.

SEgundo JANkAUSKIS (1979) a exploraça florestal na Amazonia 6 um fato irreversivel, sendo que a explaraçăo năo é incompativel com a sua regeneraçăo, desde que a exploraçăo florestal seja tecnicamente planejada e conduzida.

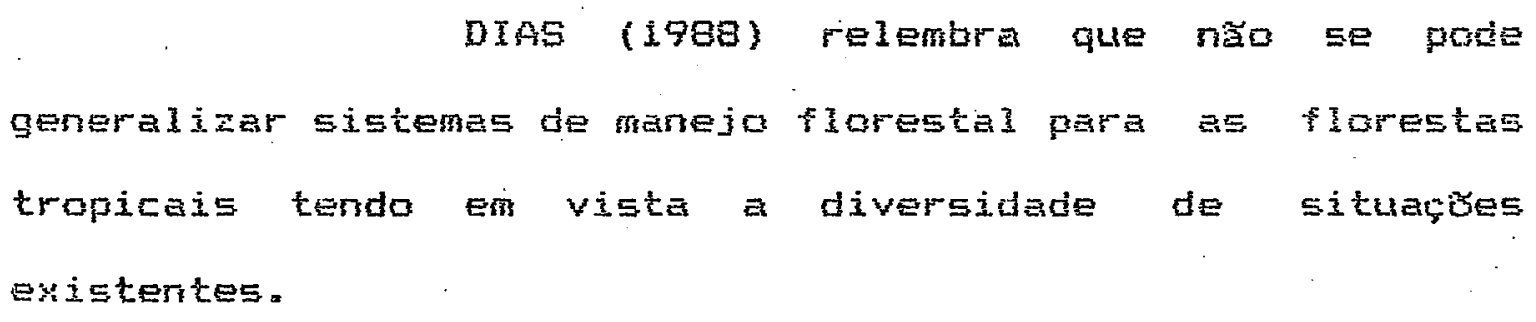

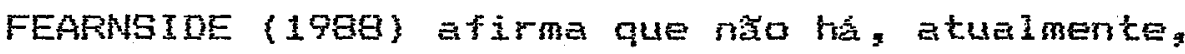
nentum sistema de menejo florestal sustentado operando en escala comercial en terras baixas da Amaxunia e que o deservolvimento de sistemas experimentais e incipiente quando comparados com os programas de eneaio existentes na $\bar{A} E \mathrm{i} a$ Africa. 
3. MATERTAL E METODOS

3.1. Caracterizaçá da Area

a) Localizaçáo

A Reserva Florestal da CURD Esta localizada no municlpio de Maraba. Estado do Fara, nas coordenadas geograficas de $05^{\circ} 21^{\circ} \mathrm{s}$ e $49^{\circ} 09^{\prime} \mathrm{w}_{3}$ e una altitude molia de $70 \mathrm{my}$ distante da sede do Maraba de aproximadamente $40 \mathrm{~km}$ fFigura 1).

0 acesso ate a Feserva se da peia rodovia PA-150, partindo-se de Maraba no entido da Serra de Carajas. Nas proximidades do km 497 desta rodoviag a cerca de $35 \mathrm{~km}$ de Maraba, toma-se a entrada da Fazenda Cabaceiras, a esquerda, por onde percorre-se cerca de 5 kn até o portao de entrade da Reserva. Na época chuvos, quando o acesso por via terrestre f dificultado, este pode ser feito por via fluvial, atraves do rio sorors, que serve de linite natural Em todo o lado ocidental da Reserva. Partindo-se do porto do DNER, na ponte do fio Sarors com a Fa-150, na altura do kim 499, a viagem dura cerca de 4 horas para "subir" o rio $E 3$ horas para "desce-10" (GARCIA, 19aB). 


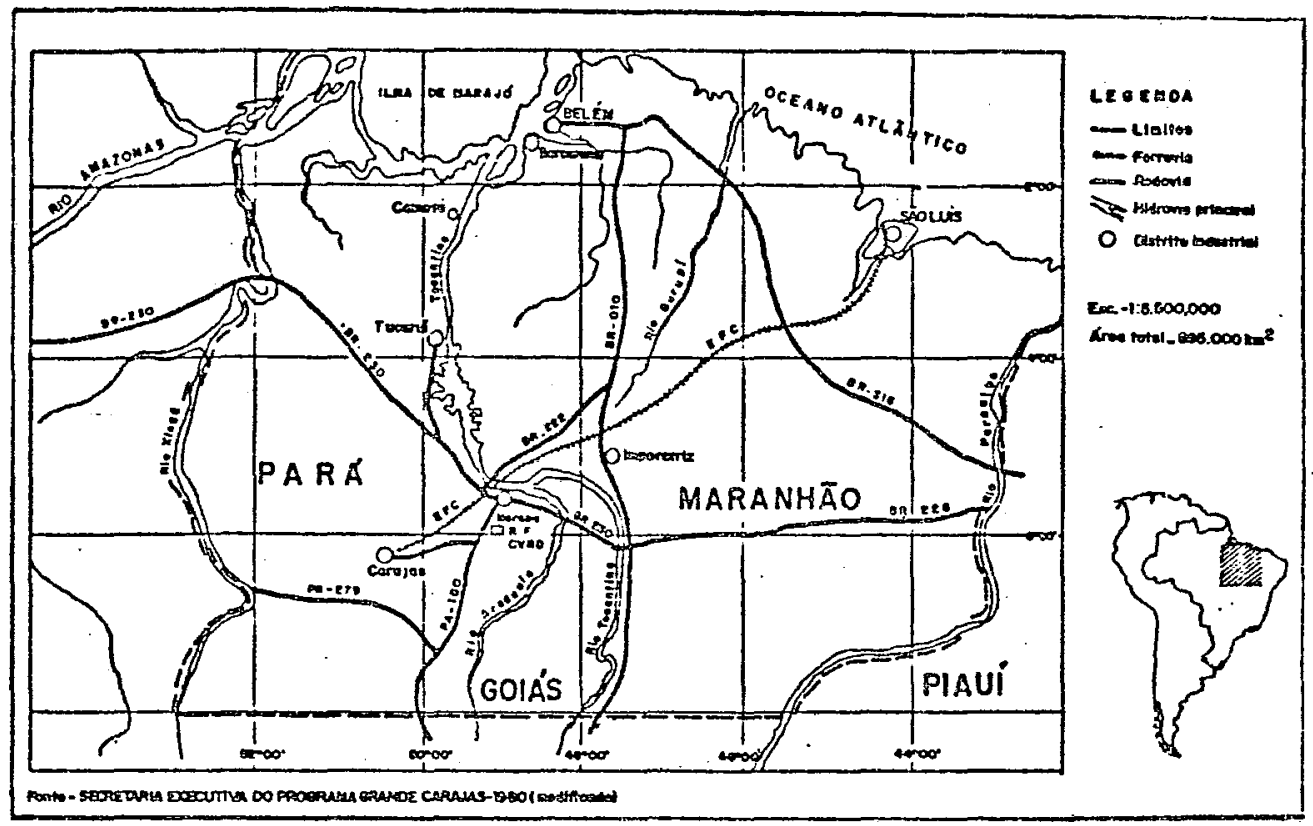

Figura 1 - Mapa de latalizacăo da Feserva Florestal da CVRD, Em Maraba, PA.

\section{b) Cilima}

Segundo FALEST et aliz (199A) o clima da região e do tipo Aly tropical chuvoso que en nentum mes do ano a temperatura modia é inferior a $10^{\circ} \mathrm{C}$. 0 s invernos săo secos e, no minimo, en um més do ano a precipitacão pluviometrica e inferior a $60 \mathrm{~mm}$. A precipitaça pluvionetrica é em torno de $1450 \mathrm{~mm}$ anuais, sendo a trimestre mais chuvoso o de fevereiro a atril e o mais seto de setembro a novembro. A temperatura media anual varia de $26,7-18,8^{\circ} \mathrm{C} e$ a ascilaça média da temperatura ar e proximo de $79 \%$. A regiăo apresenta deficit hidrico moderado nos meses de maio a novembro, totalizando 446 mm (DINIZ \& HASTOS, 1974). 


\section{c) Relevo e Solos}

o relevo da regiăo varia de plano a suavemente ondulado, com altitudes moderadas. Litologicamente, a constituiçå e de rochas fillticas do mesoproterozóco com relativa abundancia de niveis quartiticas, ds vezes com carater itabirltico ou jasperoides e lentes calcareas (FALESI OL ali 1906 ).

05. solos predominankes na regiag, segundo FALESI et alii (1996), constituem-se de ascoriaçoses de 1 atossolo vermelho-amarelo alica plintico e moderado, textura média, mais areia quartzosa alica e fraca, mais Glei pouco unido distrofico com textura indiccriminada da Fase Floresta Densa Submontana Aglainada e Floresta Aberta Mista, de relevo plano.

DANTAS (1997) clasEificou as EoloE ocorrentes na area experimental da Fessrva Fiorestal de CVRD, como sendo podzdico vermelho-amarelo alico, originado por intenperismo da formaçăo Pedra de Fogo.

d) Vegetaçăo

A vegetaço caracterlstica da regiăo segundo PIRES (1972), abrange extensas areas do Estado do Para, a ceste dos rias Araguaia E Tocantins e a norte e sul do ria Itacaiunas, e Eå denominadas de "mata-de-cipo" ou "Floresta de cipoal"; as quais GOLFART (1980) denominou de "Floresta mesofila perenifolia do rio Itacaiunas". 
SEgundo RADAMEFASIL (1973), essa formaçăo florestal e classificada como sendo do tipo FD-2: Florestas Densas com menos de $120 \mathrm{~m}^{3} /$ ha e caracteriza-se pelo porte relativamente reduzido, raramente $u$ ltrapassando $20 \mathrm{~m}$ de altura, com um emarantado de lianas que sobem pelas árvores e se embaraçam a pouca altura do chăc da mata.

GOLFARI (1990) diz que alternadamente com as matas de cipo, aperecen faixas de matas densas onde să frequentes a cedrorana (Cedrelinga spp), jutal ou jatobs (Hymenec spp), tatajuba (Bagussa spp), magno (Swietenia spo), ainda a castanheira (Bertholletid excelsa HEk), ávore que caracteriza a região de Maraba como pertencente ao "poligono dos castanhais" (KITAWURA, 1794).

A vegetaça ocorrente ne Reserva e predoninantemente florestal, com uma pequena area de vegetaçăo arbustive e/ou graminea en torno da sede "Piranheiras" a ds margens do rio Sororb, alen das imediaçbes da sede "Ponta de Pedras", com areas ja exploradas $e$ em frocesso de revegetaça nas zonas perifericas (EHGEl et aliig 1797). Segundo GOLFAFI (1780), a área apresenta uma fitotisionomia de matas mais densas do que a "mata-de-cipo" trpica, e un sub-bosque mais leve do enaranhado das lianas.

БALOHAO (1789) analisou a composiçăo floristica da Reserva Florestal da CVFD en Marabs, atraves de b parcelas retangulares de 1,0 ha cada, distribuldas aleatoriamente pela área. Foram registrados 3.147 individuos com DAP igual ou superior a $10 \mathrm{~cm}$ nos 6 hectares, distribufdos em frb 
famlias, 157 generose 237 especies.

3.2. Descriçáo do Ensaio

a) Localização

0 ensaio foi instalado en uma area de floresta tropical fluvial, localizada no muicipio de Marabs-PA, pertencente a Companhia Vale do Fio Doce - CVRD.

Os blocas foram distribuidos na area da reserVa, conforme mostra a Figura 2 .

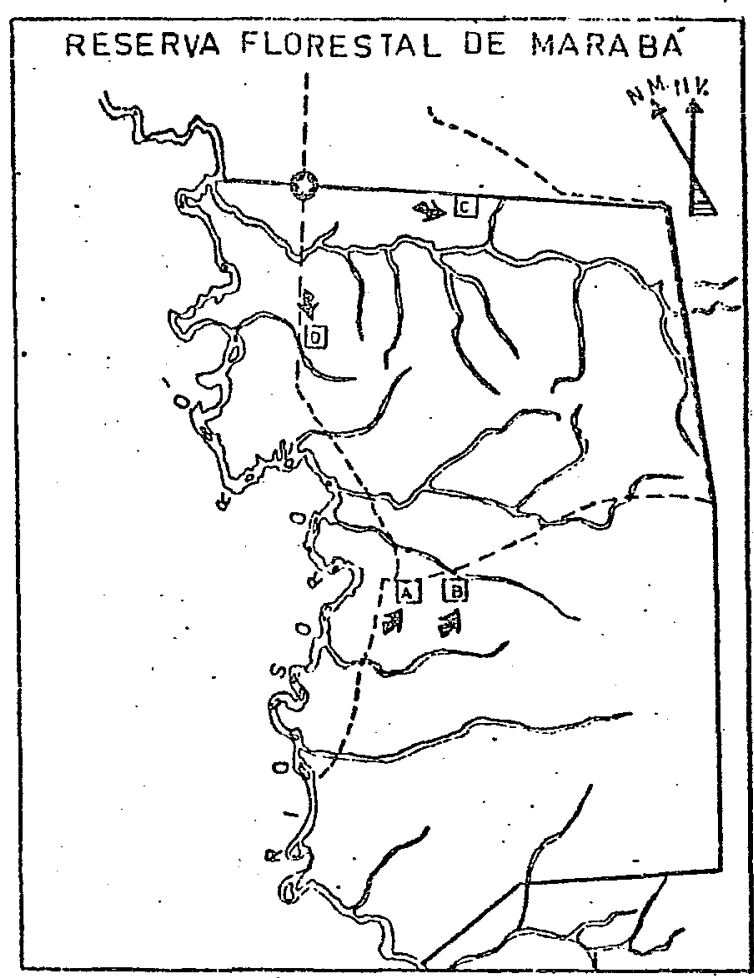

Figura 2 - Localização dos blacos do Ensaio de Manejo Florestal

Legenda: A.B.C.D. = Blocos de Ensaio. 
b) Delineamento estatistico

O Ensaio foi instalado Em Blocos ao Acaso, com quatro tratamentos em quatro repetiçơes.

Cada parcela mede $2.500 \mathrm{~m}^{2},(50 \times 50 \mathrm{~m}), \mathrm{con}-$ forme a Figura 3 , perfazendo $10.000 \mathrm{~m}^{2}$ de area experimental.

c) Descriço dos tratamentos

Ds tratamentos s3o caracterizados como diferentes formas de intervençăo ne floresta, assin descritos:

- Tratamenta n으 01

Nas parcelas sorteadas com o tratananto no 01 nă foi realizada nenhuna forma de intervençă portanto foi considerado como a testemunte do ensaib.

- Tratamento $\pi^{\circ}$ oz

Mas parcelas con o tratamento $n^{\circ}$ oz foi aplicado o corte raso, onde foram abatidos todos os individuos de todas as especies, com exceça dos individuos de castanteira, que să protegidos por Lei Federal fFortaria no 499-P de 0a/10/67 do IEDF).

- Tratamento no 03

Este tratamento, consiste en retirar tadas as individuos com DAF (diametro a atura do peito) maior ou igual a 45 cr encetuando-se os individuos de castanhesras. Dentre os individuos remanescentes; foram retirados todos 
aqueles quebrados por acasiăo das operaçbes silviculturais, assim como todos aqueles que apresentavam caracteristicas indesejaveis (morto-em-pé, mal formados e outros tipos de defeitos).

- Tratamento $\mathrm{n}^{\circ} 04$

Neste tratamento foram retirados todos os individuos com DAP menor ou igual a $20 \mathrm{~cm}$ com DAP maior OL igual a $60 \mathrm{~cm}$. Independentemente do DAF, tos individuos de castanheiras foram protegidos de corte. Da mesma forma que o tratamento $n$ 으 03 dentre os individuos remanescentes foram retirados todos aqueles con ferotipos indesejaveis.

d) Descriça da implantaço do ensalo

SEgundo JESUS \& MENANDFO (19G8) foran realizadas, durante a implantaça dos tratamentos, as seguintes operaços:

1) Locação dos Hacos e Farcelas

Na locaço dos Elacos procurou-se popresentar a cobertura florestal primariag sendo feito para isso varias incursoses na mata. Na marcaça das parcelas traçava-se uma picada perpendicular a estrada de acesso e en seguida demarcavam-se os retangulos correspondentes a cada tratamentos. Construiu-se un caminho equidistante entre as parcelas experimentais, de modo a permitir o escomento do produto llarestal retirado e distribuir os efoitos provocados por ele. 


\section{2) Inventário Florestal}

Foram avaliados por Bloco e Tratamento, antes das interferencias, didmetro a alura do peito (OAP) de todos individuos com DAF maior ou igual a 10 cma Essa avaliaçăo foi realizada por um Engenheiro. Florestal, auxiliado por un "mateiro" e um trabalhador bracal. Apos as interferencias erecuou-se um novo inventirio, para quantificar o material remanescente.

\section{3) Corte Manual}

Inicialmente com o auxilio do machado e da foice, 0 individuas com Dap inferiores a 10 cm eran abatidos e os com dianetros suricientes para lenha eram desdobrados tambem manualmente. Ess. operaça toi imprescindivel antes do corte das arvores com Dap maior s luma vez que ela abre espacos suticientes para permitir a queda desses individuos e minimizar os dance de abate.

\section{4) Corte Mecanizado}

Apos 9 corte manual, procedau-se o abate das arvores de maior diametro com a ausilio de moto-serras. Nessa etapa é ideal que o operador da motoserra tema uma boa pratica, năo so para efeitos de rendimento, mas, principalmenteg na orientaça da queda dos individuos, evitando danos exagerados nos individuos pemanescentes. 


\section{5) Desdobro Mecanizado}

Depois de efetuados as cortes manual a mecanizado, a lenha não desdobrada manualmente e os toros não madeiráveis eran seccionados de metro en metro con o uso de moto-serras. Ja as tora de serraria tinham comprimento Variado, en funçăo da esporcie e da sua sanidade.

6) Empilhamento-Cubagen

Apus o desdobra, toda lenta era empicihada e de imediato determinava-se o volume, en estereo. As toras madeiraveis eram medidas, posteriormente ao seu desdobro, Ltilizando-se para isso a cubagen rigorosa de "gmalian".

7) Rexirada do Produto Florestal

Essa operacă toi efetueda rigorosamente no mécino ate 30 dias apos a interterencia nas parcelas. A lenha era baldeada, dependendo do diametro, manuelmente ou En Larretas tracionadas por um trator agricola. As toras con utilizacão industrial foran petiradas com guincho ecoplado a un trator MF-g5x.

8) Acabamento

Após a retirada da biomassa en cada parcelag fez-5e o aviamento dos seus limites através de uma capina manual efetuada muma faisa de 1 m de largura que circundava cada parcela. 
3. 3. Obtençáo de dados

0 ensaio de manejo florestal sol regime sustentado foi instalado en diferentes etapas conforme o cronograma de atividade do projeto, a saber:

a) Inventario florestal inicial

En agosto de 1984 foi realizado, en agosto de 1984, um inventario florestal nas areas onde foram instalados os blocos do experimento. Antes da aplicaga dos tracamentos, todas as parcelas experimentais foram inventariadas por una equipe formada por um tecrica. un mateiro (identificador botanico local) e un tratalhedor de campo. As áreas onde foram instalados os blocos foran inventariadas 100\% onde todas as individuos con CAF (circunferbicia al alura do peito) maigr ou iquel a 30 Em foran medidos e anotaco o nome vulgar regional da especie.

\section{b) Inventario florestal pemanescente}

En outubro de 1994 , todas os individuos remanescentes das intervençes Eilviculturais; foram medidos a CAP E anotado o nome vulgar regional da especia.

\section{c) Inventario florestal continuo}

En 179 a $_{\text {g }}$ apos dois anos de implantaço do ensaio, foram instaladas ae Farcelas Permanentas visando monitorar os processos de dinamica de crescimento 
de sucessăo das especies ocorrentes nas areas do ensain.

0 metodo adotado para monitorar o ensaio fundamentado no modelo recomendado por SILVA \&QFES (1994) para a Amazonia Erasileira.

d) Dístribuiça dos Blocos e Tratamentos.

Os blocas etratamentos forem distritudas na area conforme a Figura 3.

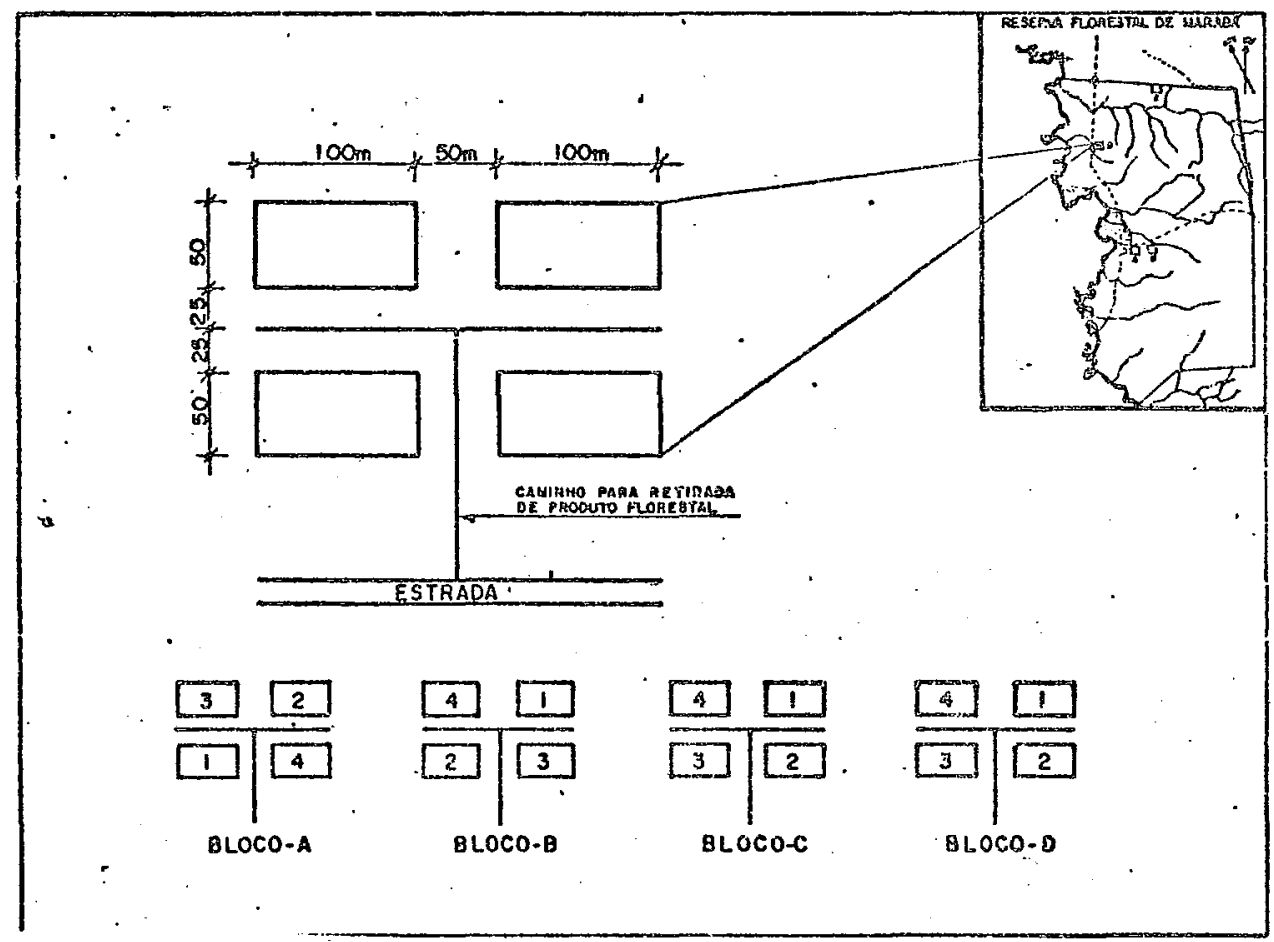

Figura 3 - Distribuiça dos tratamentos nos blocos do ensain. 
e) Medicáo e marcaçăo dos individuos remanescentes

As mediçóes e marcaçßes dos individuos rema-

nescentes nas parcelas permanentes de observaço foram realizadas conforme o Tabela 1.

Tabela 1 - Descrica das parcelas experimentais.

\begin{tabular}{|c|c|c|c|}
\hline \multicolumn{3}{|c|}{ DESCFIÇAO DAS PAFCELAS } & \multirow{2}{*}{$\begin{array}{c}\text { DESCFIÇAD DAS ATIVIDADES } \\
\text { REAL I ZADAS }\end{array}$} \\
\hline TIPQ & $\begin{array}{l}\text { DIMENGOES } \\
(\mathrm{m})\end{array}$ & $\begin{array}{l}\text { AFEA } \\
\text { (ha) }\end{array}$ & \\
\hline $5 P .1$ & $10 \times 10$ & 0,01 & $\begin{array}{l}\text { Mediçăo de todos os indivi- } \\
\text { duas com DAF igual ou maior } \\
\text { a } 5 \text { cm. } \\
\text { Marcarăo dos individuos com } \\
\text { DAF igual ou maior a } 10 \text { cm. }\end{array}$ \\
\hline $5 F .2$ & $5 \times 5$ & 0,0025 & $\begin{array}{l}\text { Mediça de todas as indivi- } \\
\text { duOS com DAP igual au maior } \\
\text { a } 2,5 \text { cm E DAF igual ou me- } \\
\text { nor a } 4.9 \text { ch. }\end{array}$ \\
\hline $5 P \cdot 3$ & $5 \times 3,52 \times 3,52$ & 0,000625 & $\begin{array}{l}\text { Contagen de todos os indi- } \\
\text { viduos com altura superior } \\
\text { a } 30 \mathrm{~cm} \text { DAP inferior a } \\
2,4 \mathrm{~cm}\end{array}$ \\
\hline
\end{tabular}

f) Datas de mediça

De acordo com a sequencia de implantaçăo do ensaio, foram realizadas as sequintes mediços:

- Inventario inicial

- medidas todos os individuos com DAP maior ou igual a $\pm 0 \mathrm{~cm}$.

- realizado em agosto de 1984 
48.

- Inventário remanescente

- medidos todos os individuos remanescentes en cada tratamenta.

- realizado em outubro de 1984

- Inventario continuo - ia mediça

- medidos todos os individuos en cada tipo de parcela

- realizado em agosto de 1986

- Inventirio contruo - zá mediça

- medidos todos os individuos en cada tipo de parcela

- realizado en novenoro de 1998

3.4. Anallso das Informagies

Ds dados coletados durante as etapas de campo \{1984, 1984, 19a9\} foram tabulados e analigados em tres fases:

a) Ideritificaçăo e classificaçăo botanica, paisizada con auri 1 io dos identificadores Hotanicos da EMBRAFA/CFATU de Eelem-PA.

b) Transformaça dos dados primarios en expreseå de crescimento.

c) Analise estatistica das variáveis de interesse. 


\subsubsection{Analise Estatistica}

0 ensaio foi instalado e analisado segundo o delineamento em blocos ad acaso (STEEL \& TORFIE, 19ó); conforme o modelo matemático:

$x_{i j}=\bar{x}+T_{i}+B_{j}+E_{i j}$

ande:

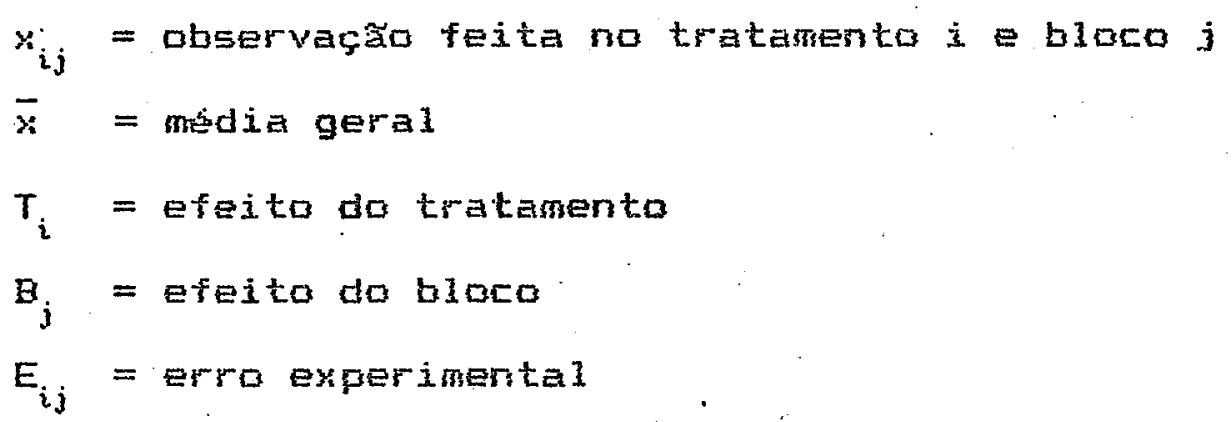

Para: $i=(1,2,3,4) \in j=(1,2,3,4)$

A analise de variarciag foi efetuada para as Variaveis DAP (dichetro medio a alura do Foito) basal) $N$ (numero de individuas), conforme a equema

FONTE DE VARIAGAO GL

\begin{tabular}{ll}
\hline Hlocos & $r-1$ \\
Tratanentos & $t-1$ \\
Erro Experinental & $(r-1)(t-1)$ \\
\hline Total & $r t-1$ \\
\hline
\end{tabular}


a) Composicá floristica

Ds dados coletados foram ordenados sequndo os nomes cient1 ficos e vulgares, assim como por ordem de generos e familias. Fai utilizado a Indice JENTSCH ou Quociente de Mistura, afim de explorar o grau de complexidade da tipologia florestal estudada.

- Quociente de Mistura (om) foi obtido pela seguintes expressån:

$$
\mathrm{QM}=n^{\circ} \mathrm{de} \text { especies/no de individuos }
$$

b) Estrutura horizontal

\section{b. 1 Abundancia ou Densidade}

A densidade mede a participara das diterentes especies na fioresta.

De acordo com FONT-GUEF $(1975)$; "dencidade" है - numero de individuas de cada especie dentro de una associaç̃o vegetal, e sempre e referido en uma unitade de superticie.

HOSOKAWA (1706) define densidade absoluta como Eendo o numero total de individuos pertencentes a uma determinada especie, ediz que a abundancia resativa indica a participaça de cada espécie, em porcentagen da numero total de srvares levantadas na parcela respectiva, considerando o numero total igual a 100. Assim sendo: 
Onde: $A B_{-} a b s=n / h a$

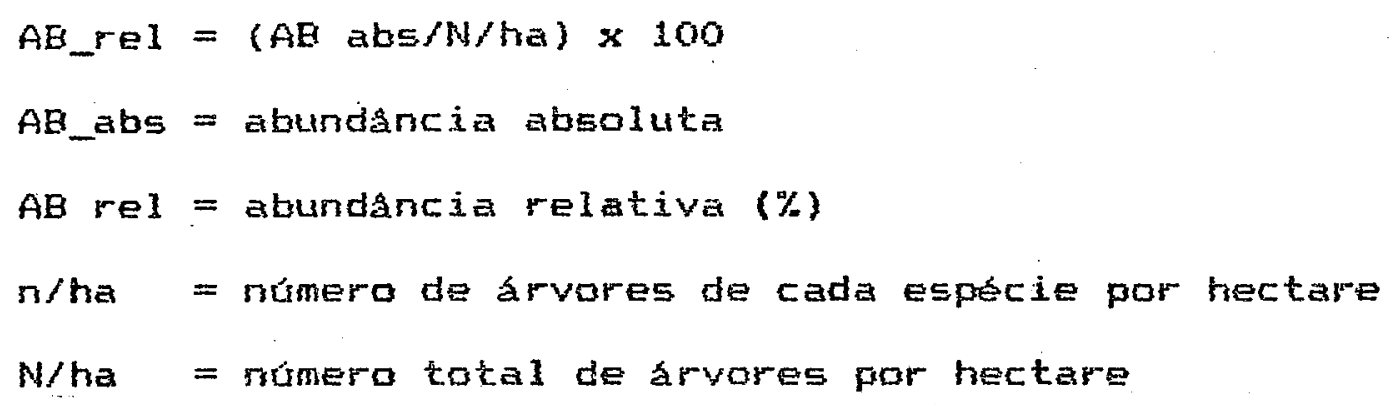

b. 2) Dominância

Gegundo FONT-GUER $(1975\rangle$ a dominancia é tida como uma superficie do solo, projetada por um feixe de projefăo horizontal da planta, o que vale dizer, a analise da projeça horiaontal das copas das arvores.

En florestas tropicais, é dificil determinar a dominancia devido aos diterentes estratos que forman uma estrutura horisontal e vertical muito complexa (HoSOkAwA, 198a).

CAINE \& CASTRO (1956) propusoram a uti1izaçă da area basal das arvores em substituiçăo a projeçăo das copas, uma vez que há estreita correlaça entre as dinensobes da copa e o diametro do ruste (HOSOKAWA, 1986).

A domingneia absoluta é calculada atravé da soma das areas basais dos individuos pertencentes a uma determinada especie. For sua vez a dominância relativa se obtem através da porcentzgen da soma total das ciominancias absolutas e seu valor corresponde a participaçă en porcentagem, de cada espécie ra expanga horizontal total (HOSOKAWA, 1986). Assim sendo: 
Onde: $D_{\text {_abs }}=\mathrm{g} / \mathrm{ha}$

$$
\begin{aligned}
& \text { D_rel }=(0 \text { abs/G/ha) } \times 100 \\
& \text { D_abs }=\text { dominancia absoluta }\left(m^{2}\right) \\
& \text { D rel = dominancia relativa }(\%) \\
& \text { g/ha = area basal de cada especie por hectare } \\
& \text { G/ha = area basal total for hectare }
\end{aligned}
$$

b. 3) Frequencia

$$
\text { LAMPFECHT (1964), Eitado pOF HOSOKAWA (1794), }
$$
diz que a frequencia mede a reqularidade da distribuicão horizontal de cada especie sobre a terreno, ou seja, a Eua diธperธão média.

SOUZA (1573) afirma que a frequêneia है un conceito estatistico relacionedo com a uniformidade da distribuiçă das especies, $E$ define-a como sendo uma medida de areas de iqual tamanho, dentro da comunidade. Fara determiná-la divide-se a parcela en un número conveniente de sub-parcelas de igual tamanto entre si, onde se controla a presenca ou ausencia das especies en cada sub-parcela. A frequencia absoluta se expressa en porcentagem das sub-parceles em que acorre determinada especie, sendo o número total de sub-parcelas igual a $300 \%$. De outro modo, a frequencia relativa se obtém com base na soma total das frequencias absolutas de luma parcela, que se cansidera igual a 100\%. Assim Sendo: 
Onde: $F R_{\text {_abs }}=\%$ de sub-parcelas que ocorre uma espécie

$$
\begin{aligned}
& F R \_r e l=F R \text { abs/2 FR abs } \times 100 \\
& \text { FR_abs = frequencia absoluta } \\
& \text { FR_rel = frequencia relativa (\%) }
\end{aligned}
$$

b. A) Indice do valor de importancia CIVIS

A importancia de uma especie se caracteriza pelo número de arvores e suas dimeneses (abundancia e dominàncial, as quais determinam o seu espaço dentro da biofeñse florestal, năo se importando se as arvores aparecam iso1 adas ou em gripos.

FCRSTER (1973), Citado pOT HDSOKAWA (1984); afirma que o IVI e uma grandeza relativã.

O indice do valor de importancia para uma especie é determinado pela scmatoria dos valores resativos de abundincia dominancia e frequencia (HoSOKAHA 1994 ).

\section{4. 3. Estimativas do crescimento}

A determinaço do crescimento anuel en area basal durante o periodo de monitoramento do ensaio foi obtido por classes diametricas, conforme a Tabela 2. 
Tabela 2 - Distribuição das classes de diametro.

\begin{tabular}{|c|c|c|c|}
\hline \multicolumn{4}{|c|}{ INTEFUALO } \\
\hline \multicolumn{2}{|c|}{ CLASSE DIAMETTRICA } & $\begin{array}{l}\text { DIAMETFO } \\
\text { (cm) }\end{array}$ & $\begin{array}{c}\text { CIRCUMFERENCIA } \\
(\mathrm{Cm})\end{array}$ \\
\hline & $A A$ & $5-9.9$ & $15,7-31,3$ \\
\hline & $A$ & $10-19,9$ & $31,4-62,7$ \\
\hline & B & $20-29,9$ & $62,6-94,2$ \\
\hline & $\mathrm{C}$ & $30-39.7$ & $94.5-125,6$ \\
\hline & $D$ & $40-49,9$ & $125,7-156,9$ \\
\hline & $E$ & $50-59,9$ & $157,0-100,3$ \\
\hline & $F$ & $60-$ & $198,3-$ \\
\hline
\end{tabular}

A brea basal de cada individuo foi calculada a partir da medição da circunterencia a altura do peito (CAP) o os resultados foram agrupados por especie, classe dianotrica a nivel de slacos e tratamentos.

A comparaçăo entre o erescimento inicial (1996) e o final (1988) foi efetuada agrupando-se todos os resultados obtidos, a nivel do tratamento, ens

a) povoamento florestal no instante $t_{i}$ (inventario continuo - 1996). 86).

- Para o instante $t$, obteve-se a somatoria da area basal de todos os individuos com DAF igual ou maior a 5 cin.

b) povoamento florestal no. instente $t_{2}$ inventario contíno - 1988). (38).

- Para o instante ${ }_{2}$ " obteve-se a sometoria da area basal de todos os individuas com DAF igual au maior a $5 \mathrm{~cm}$, 
menos a mortalidade natural abservada no instante $t_{2}$ " acrescido aos individuos que ingressaram na classe diamétrica igual a $5 \mathrm{~cm}$.

A mortalidade natural foi definida como sendo todas as individuas que foram medidos no instante $t_{2}$ (1986) e que por causas naturais, como idade avangada, enfermidadas ou danos sofridos na explarasăo, năo atingiram o instante $t_{2}$ (1988).

Desta forma, com os hados obtidas em cada remediçă sucessor, foram calculados os crescimentos bruto da area basal por classe diametrica for tratanentos utilizando-se da seguinte expressag:

$$
Y=G_{i}+M-G_{i}-1 \text { (GUTIERRE, } 1970 \text { ). }
$$

Onde:

$$
\begin{aligned}
& Y=\text { crescimento peribdico bruto } \\
& G_{f}=\text { area basa }\left(m^{2} / \text { ha }\right) \text { no instante } t+1 \\
& M=\text { mortalidade natural } \\
& G_{i}=\text { area basal no instante } t-1 \\
& I \quad=i n g r e s s o s \text { no periodo estudado }
\end{aligned}
$$

0 ingresso de novos individuas (I) nas parcelas experimentais foi obcido pela expressă

$$
I=N_{i}-N_{i}+A
$$

Onde:

$$
\begin{aligned}
& I=\text { ingressos de individuos no partodo de } 1796-1989 \\
& N_{i}=\text { numero de individuos na classe AA em } 1989 \\
& N_{i}=\text { numero de individuos na classe AA en } 1986
\end{aligned}
$$


$A$ = mortalidade natural observada en 1988 na classe $A A$

Para obtençãa dos transpassos (T), Ou seja, 0

numero de individuos que mudaram de classe diametrica no perlodo 1986-1988, inicialmente tomou-se a maior classe diametrica na qual nă houve transpassas. A partir desta classe, em direçăo ds classes de menor tamanho, foram obtidos, sucessivamente, os transpassos, de acordo com a seguinte expressão:

$$
T_{x-1}=M_{r_{x}}-N_{i_{x}}+A_{r_{x}}
$$

Bnde:

$$
\begin{aligned}
& T_{x-1}=\text { numere de individuos que migraram da classe } x-1 \\
& \text { para } x \\
& N_{f_{x}}=\text { numero de individuos presentes na classe } x \text { em } 1998 \\
& N_{i_{x}}=\text { numero de individuas presentes na classe } x \text { em } 1986 \\
& A_{f_{x}}=\text { mortalidade natural observada na classe } x \text { en } 1788 \\
& \text { Para } X=A A, A_{3} E_{3} \text { C, D, E, F. }
\end{aligned}
$$




\section{RESUL tados e DISCUSSAO}

\subsection{Composiça Floristica}

A composică floristica do ensaio foi analisada a partir dos dados do inventsrio inicial (1984), inventario pos-exploratorio (1994) e inventarios continuos $(1986$ e 1989$)$.

A composigão foristica dos inventarios iniCial e pos-exploratorio nao abrangenteg pois a metodologia empregada năo contemplou todas as classes de tamantio existente nas parcelas experimentais. Desta forma, uma analise comparativa profunda entre a composiço florfstica iniciale * Partir dos inventarias continuos năo foi realizadas tendo em vista as diferenças qualitativas existentes entre as duas Etapas do ensaio.

As espocies amostradas nos inventerios torestais realizados ate o ano de 1998 estao listadaspelo nome vulgar fegional de acordo com a classe de tamanho observada (Apendice 1 ).

No inventario inicial foram medidas 4.644 plantas, destas, 3.727 pertencentes a 97 espercies, 75 generos 2 ib famlias. Dentre os individuos amostrados, 717 
(19,7\%) nå foram identificados a nivel de especies botanicas e nem pelo nome popular. 0 número de especies identificadas por genero familia é apresentado na Tabela 3.

o inventario poss-esploratorio foi realizado imediatamente apos as intervençees silviculturais teren sido efetuadas. O identificador botănico (mateiro) fai a mesmo que realizou a inventario inicial. Nesta ocasiăo foram medidos a79 indivi- duas, dos quais 205 não foram identificados nem a nivel de nome vilgar regional, representando $23,3 \%$ do total dos individuos amostrados 0 número de especies por generos e fandias botanicas b apresentado na Tabela 4.

O número total de especies identificadas pelo nome vulgar regional, nos quatro inventarios florestais realizados, foi 249 das quais 235 foram identificadas taxonomicamente - 0 número de generas e familias botanicas identifica- dos săo apresentadas na Tabela 5 . 
Tabela 3 - Ordenação das familias botanicas, genercs e numero de especies observados no inventario inicial (Agosto-1984).

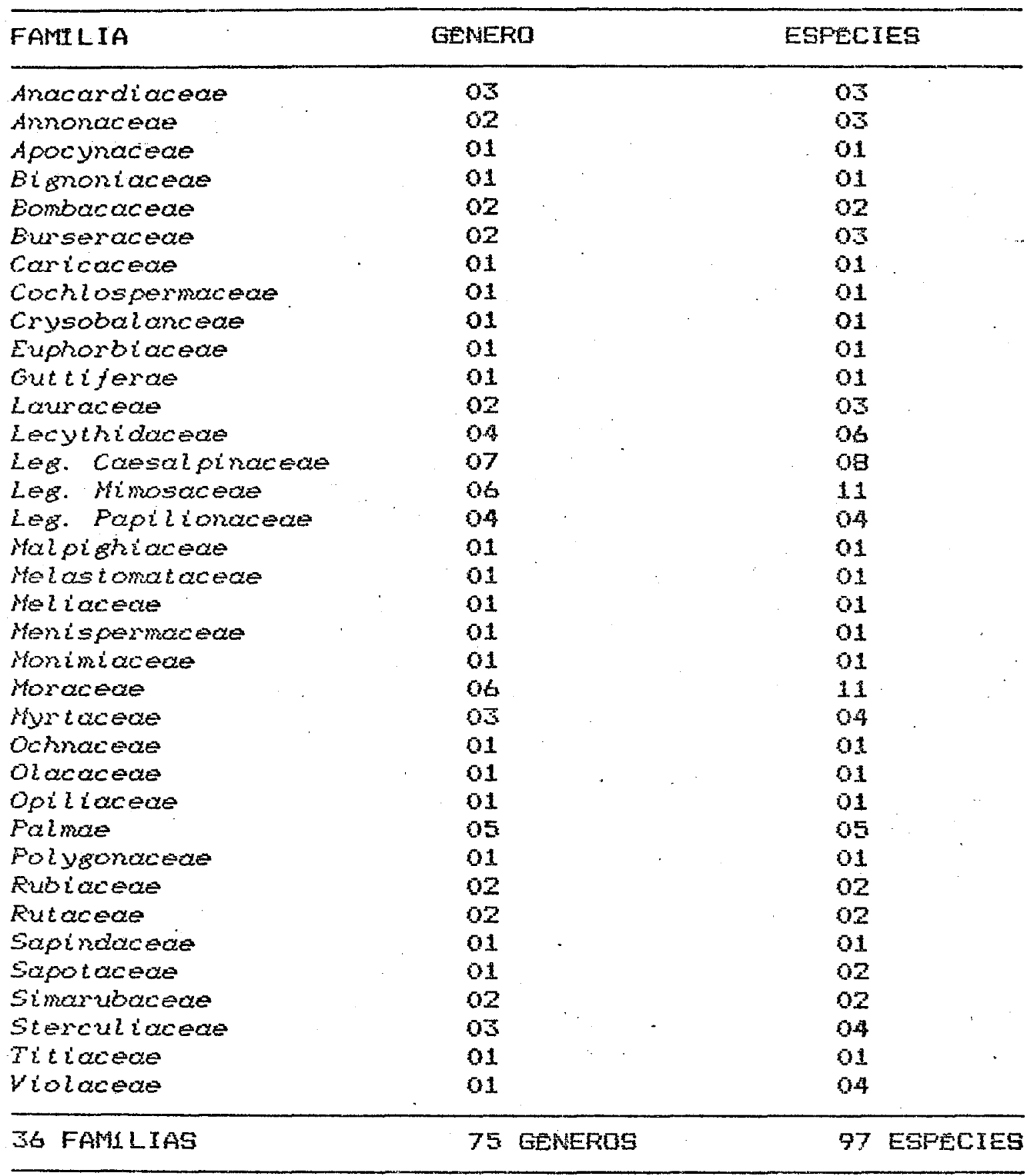


Tabela 4 - Ordenação das faml lias botanicas, generos e número de especies observadas no inventario pos-exploratorio (Qutubro-1984)

\begin{tabular}{|c|c|c|c|}
\hline FAMII LA & GENERO & ESFECIES & \\
\hline Anacardiaceae & $\$ 4$ & .05 & \\
\hline Annonaceae & 05 & 06 & \\
\hline Apocynaceae & 03 & 03 & \\
\hline Eignoniaceae & 01 & 01 & \\
\hline Eombacaceae & 02 & $0^{2}$ & \\
\hline Eorraginaceae & $a 1$ & 01 & \\
\hline Burseraceae & $\$ 2$ & 03 & \\
\hline Caricaceae & 01 & 01 & \\
\hline Cochlospermaceae & 01 & o1 & \\
\hline Crysobal ancede & 01 & 01 & \\
\hline Ebenacede & 01 & 01 & \\
\hline Euphorbiaceare & $0 z$ & 02 & \\
\hline Guttiferae. & 01 & 01 & \\
\hline Icacinerceas & 01 & 01 & \\
\hline Lauraceae & 02 & 03 & \\
\hline Lecythidacede & 04 & 06 & \\
\hline Leg. Cuesal pinacear & $\infty 6$ & $0 B$ & \\
\hline Leg. Mimosacear & 07 & 12 & \\
\hline Les. Papilionaceas & 04 & 0 & \\
\hline Ital pighiouede & ol & 01 & \\
\hline He las tomataceae & 01 & 01 & \\
\hline Hel iaceae & 03 & 03 & . \\
\hline Henis permacease & 01 & 01 &. \\
\hline Honimiaceae & 01 & 01 & \\
\hline Moracede & 05 & 10 & \\
\hline ifyntaceare & 02 & 02 & \\
\hline Ochnacede & 01 & 01 & \\
\hline olacaceae & 01 & 01 & \\
\hline opiliacede & 05 & 05 & \\
\hline Palmare & 01 & $a 2$ & \\
\hline Folygonacedie & 02 & 02 & \\
\hline Rubiacecue & 02 & $0 z$ & \\
\hline Futaceae & 01 & 02 & \\
\hline Sapindaceae & 03 & 05 & \\
\hline Sexpotacear & 02 & 02 & \\
\hline Simarubaceae & 01 & 01 & \\
\hline Solanacear & 03 & 06 & \\
\hline Sterculiaceae & ot & 01 & \\
\hline Titiaceae & 01 & $\phi 1$ & \\
\hline Violacear & 01 & 03 & \\
\hline 40 FAMILIAS & BQ GENEFOS & $114 \mathrm{ES}$ & EIES \\
\hline
\end{tabular}


Tabela 5. - Ordenaça das familias botanicas, generas e número de especies abservados durante todos os inventarios florestais realizados.

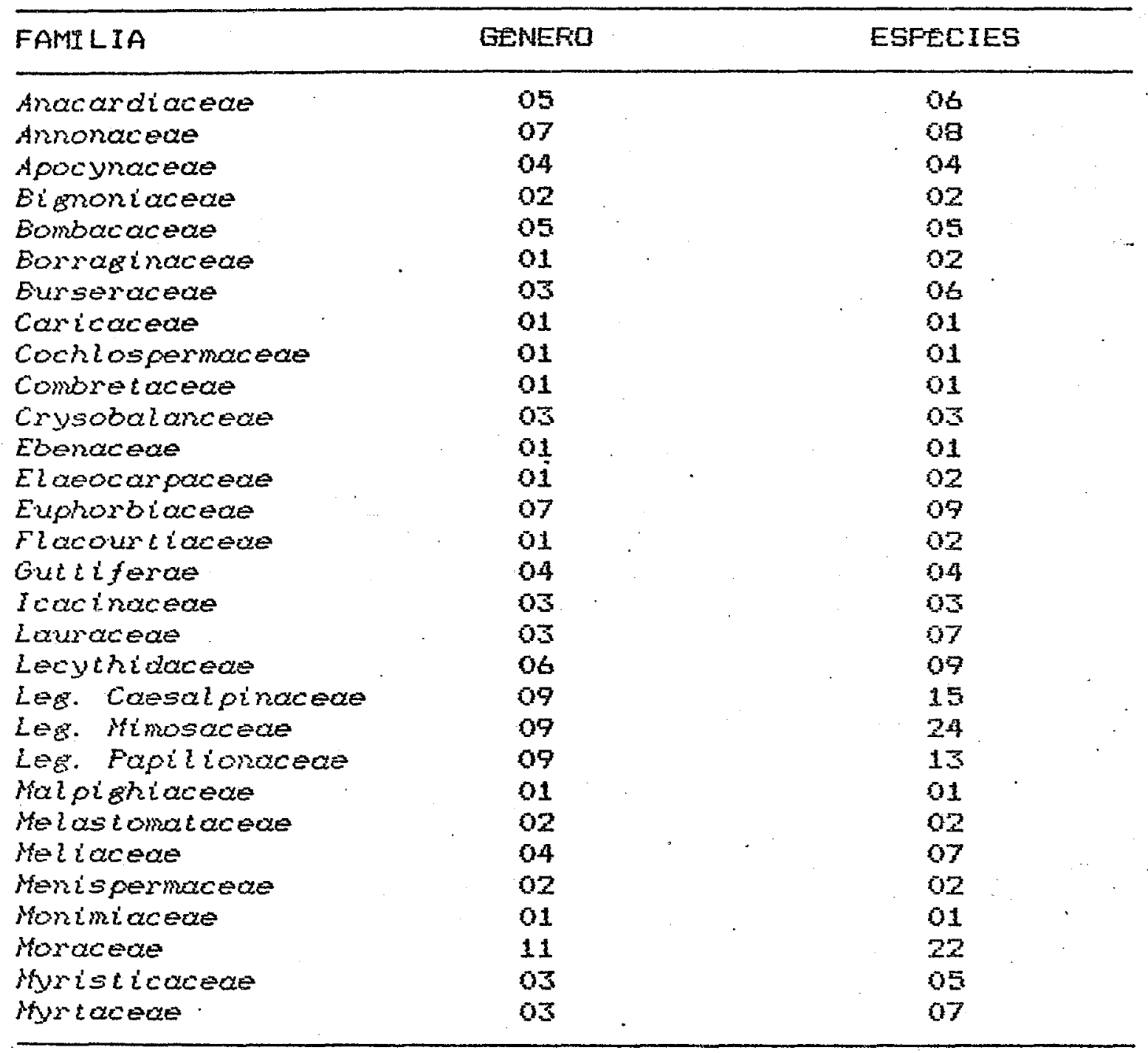


Tabela 5 - Continuaça.

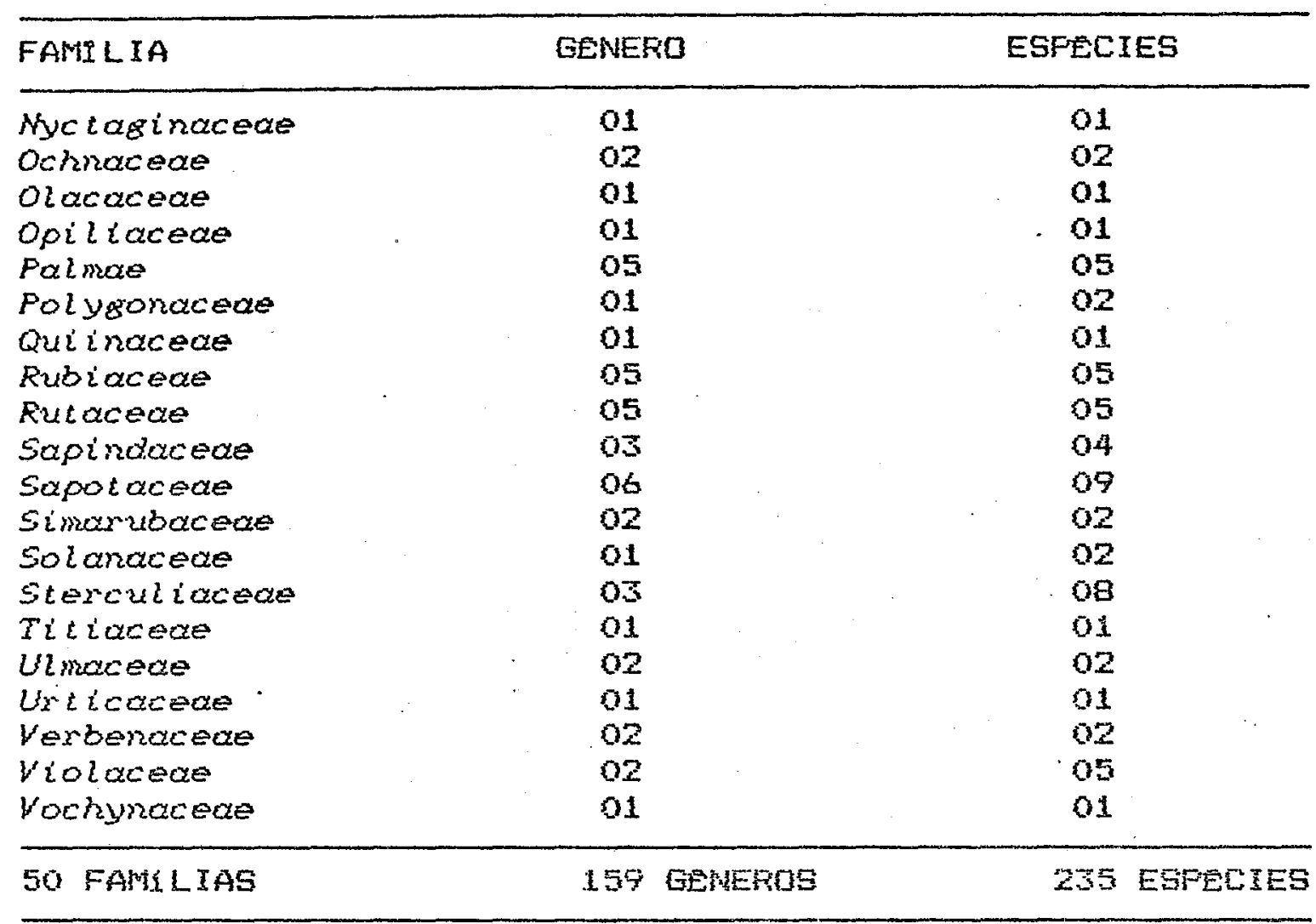

A composiçăo florfstica do ensaio, incluindo as especies observadas nos inventurios realizados em 1994 (inicial e pos-ejploratorio), 1986 e 1989 , apresentado na Tabela 6.

No inventario realizado em 1998 foram identificadas botanicamente 197 especies, distribuidas entre 45 famlias e is generas, canforne mostra a Tabela 7. 0 nunero de individuos nă identificados foi igual a. \$6, ou seja, Q,6\% do total de plantas inventariadas.

Nas Tabelas 6 e 7 encontran-se a distribuifă das especies por familias, de acordo com os tratamentas aplicados, respectivamente para os anos de 1786 e 1799. 
Tabela b - Composição florlstica geral.

\begin{tabular}{|c|c|c|c|}
\hline $\mathrm{COD}$ & NOME COMUM & MOME CIENTIFICO & NOWE FAWTLIA \\
\hline 001 & Abiu cabeça macaco & Labatia spp & Sapotaceae \\
\hline 002 & Abiu cutite & Richardel la macrophyl $l a$ & Sepotaceas \\
\hline 003 & Abiu seco & Fouteria laurifolia & Sapotaceae \\
\hline 004 & Abill vernelho & Franchetel ia ambifolia & Sapotaceae \\
\hline 005 & Abiurana & Lucuma lasiocurpa & Sapotaceae \\
\hline 006 & Abiurana torande & Eucuna dissepala & Sapotaceae \\
\hline 007 & Abiurana f. fina & Lucund $5 \rho p$ & Sapotaceae \\
\hline 009 & Abuta & Abuta grandifolia & Menicpermaceae \\
\hline 009 & Apai & Euterpe oleraceae & Palinae \\
\hline 010 & Acariquara & Minguartia guianensis & Olacaceae \\
\hline 011 & Agarra branca & Descontrecida & Desconhecido \\
\hline 012 & Amapá amargoso & Parahancornic andpa & Aporynaceae \\
\hline 013 & Amapa doce & Brosimum parirariodes & Momeceat \\
\hline 014 & Anapai & Brosinum lactescens & Moraceae \\
\hline 015 & Amaparana. & Thyrsodium paraenese & Anacardiacede \\
\hline 016 & Amesela branca & Frotium $s p \rho$ & Eurseraceat \\
\hline 017 & Amesc $1 \cong 0$ & Protium paraense & Eutremaceae \\
\hline 018 & Andirobarana & Guarea guidonia & heliaceae \\
\hline 019 & Angelim branco & Hynenolonium heterocarpus & 1. -minosaceas \\
\hline 020 & Angelim rajado & Pithecslobirm racenosum & L himbsacea \\
\hline 021 & Angico branco & Piptadenia $s \rho p$ & L. Wimosacea \\
\hline 022 & Anani & Symphonier globuitifexa & Guttiforate \\
\hline 023 & Araçarana & Psidium $\equiv p \rho$ & Wyrtaceas \\
\hline 024 & Araracanga & Aspidosperma desmantum & Apocynaceae \\
\hline 025 & Aratacia & Sagotia racenosa & Euphorbiaceae \\
\hline 026 & Aroeira & Astronium leicontei & Anacardiaceas \\
\hline 027 & Arraceira & Conceveiba guianensis & Euphorbiaceae \\
\hline 028 & $A x i x a$ & Sterculict pruriensis & Sterchliaceas \\
\hline 029 & Eabacu & Orbignya martiana & Palmae \\
\hline 030 & Elabaca & oenocarpus distichus & Falmae \\
\hline 051 & Eacuripari & Fheedie nacrophyl la & Guttiferae \\
\hline 0.32 & Elarrote. & Tatragastris altissima & Eutros raceas \\
\hline 0,3 & Erreu Freto & Protium tenutifolium & Eursoraceae \\
\hline 034 & Ereu sucuruta & Trattinickia ribifolia & Eurserecear \\
\hline 035 & Ereu vermel ho & Protium decandrum & Eursereceae \\
\hline 056 & Eurangige branca & Desconhecido & Desconhecido \\
\hline 037 & Eurangiga preta & Descomhecido & Desconhecido \\
\hline 038 & Gurra leiteira & Sopium marmieri & Euphorbiaceas \\
\hline 039 & Cabeca de arara & Mauc leopsis caloneura & hotaceas \\
\hline 040 & Cabelo de cotia & Desconhecido & Desconhecida \\
\hline 041 & Cacau bravo & Theobroma speciosum & Sterculiaceae \\
\hline 042 & Cacau da mata & Theobrond spp & Sterculiaceae \\
\hline 043 & Cacau jacare & Theobroma mariae & Sterchliaceae \\
\hline 044 & Cachuá & Triehilia lecointei & Meliacoae \\
\hline
\end{tabular}


Tabela 6 - Continuação.

\begin{tabular}{|c|c|c|c|}
\hline $\operatorname{COD}$ & NOME COMLM & NOME CIENTIFICO & NOME FAUII $L I A$ \\
\hline 045 & Cachuá grande & Trichilia grandifolia & Meliaceae \\
\hline 046 & Café bravo & Golipea jasminifilora & Eutaceae \\
\hline 047 & Caferana & Dendrobangie boliviana & Icacinacoae \\
\hline 048 & Caja & Spondias moni & Ariacardiaceae \\
\hline 049 & Cajú de janeiro & Anacardium giganteum & Anacardiaceae \\
\hline 050 & Cajuçara & Solanum rugosum & Solanaceae \\
\hline 051 & Camurim & Farkia spo & L.Mimosaceae \\
\hline 052 & Canatistula & Pelophorum vogel ianum & L. Caesalpinaceae \\
\hline 053 & Canela de jacamim & Finorea racemoea & Viclaceas \\
\hline 054 & Canela de velho. & Rinorea possoura & Violaceae \\
\hline 055 & Canela preta & Rinored spp & Violaceae \\
\hline 056 & Caneleiro & Toulicic guiar & Sapindaceae \\
\hline 057 & Camudeira & Desconhecido & Desconh \\
\hline 059 & Capitiu & Sipuruma gutiansensis & Monimiaceae \\
\hline 059 & Caqui & Diospyzus guianensis & Ebenaceas \\
\hline 060 & Ceraiperana & Hirtel la racenosa & Crysobalanaceas \\
\hline 061 & Casca preciosa & Aiba canelilla & Lauraceas \\
\hline 062 & Castanha de macaco & Courcupite subsessi & Lecythidace \\
\hline 063 & CaEtanha periquito & sterculia pruriens & Stercul iaceae \\
\hline $0 \leq 4$ & Castanheira & Berthol letia axcelsa & Lecythidac \\
\hline 065 & Cauzçu & coccoloba spp & Folygonacrae \\
\hline 06 & Caucho & Castilloa ulei & Muracease \\
\hline 067 & Cedro manso & Sinotod cedron & Sinarboaceae \\
\hline $06 \mathrm{~B}$ & Cedro vermeiho & Cedreta odorata & MeI iaceae \\
\hline 065 & Cedrorana & Cedrel inga catanceformis & L. Himotacear \\
\hline 070 & Chapeu de 501 & Cordia nodos $\alpha$ & Ecrraginaceas \\
\hline 071 & Comida de pombo & Citharexylum macrophyl lum & Vertennaceas \\
\hline 072 & Copaiba & Copaijera mulet iuga & L.CaEsalpinarene \\
\hline 073 & Copeibaraba & Copezifera spp & L.Caesalpinacean \\
\hline 074 & Coraçăd de negro & Lollemia paraensis & L.Fapilionaceae \\
\hline 075 & Couro de sapo & Desconhecido & Descomhecido \\
\hline 076 & Cumaru & Dipterix odorata & L.Fapilionaceae \\
\hline 077 & Cupú de janeiro & Theobrond subincanum & Sierculizaceae \\
\hline 078 & Cupuaçu & Theobroma erandiflom & Sterculiacease \\
\hline 079 & Curupita & Supiun cumupita & Euptiarbiaceae \\
\hline 080 & Drypetes & Drvpetes vaniabitis & Euphorbiaceae \\
\hline $\operatorname{ag} 1$ & Drypetesa & Erypeies cuncizonica & Euphorbiaceae \\
\hline 682 & Erivira branca & Ephedranthus parviflorus & AmTanaceaE \\
\hline 083 & Envira cana & Duguetia cadaverica & Anronateate \\
\hline 084 & Envira preta & Guatteria poeppeiana & Amonoteae \\
\hline
\end{tabular}


Tabela o - Continuaçãa.

\begin{tabular}{|c|c|c|c|}
\hline $\mathrm{COD}$ & NOME COHUM & NOME CIENTIFICO & NOME FAVII LIA \\
\hline 085 & Envira taia & Eocageopsis mullifiora & Annonaceae \\
\hline og6 & Escorrega macaco & Capirona huberiana & Fubiacean \\
\hline 087 & Espetorana & Cupania serobiculata & Sapindaceae \\
\hline 089 & Esponjeira & Fithecolobum acacioides & L.Mimosaceae \\
\hline & Estopeiro & Cariniand estrellansis & Lecythidaceae \\
\hline 090 & Farinta seca & Farineriam rodophi & Crysobalanaceae \\
\hline 091 & Fava amarga & Watairea spp & L.Fapilionaceae \\
\hline 092 & Fava bolota & Vatairea guianensis & L.Fapilionaceae \\
\hline 093 & Fava de anta & Eellucia grossularioides & Melastomataceae \\
\hline 094 & Fava de porca & Desconhecido & Desconhecido \\
\hline 095 & Fava f.fina & Piptadenia suaveolens & L.Mimosaceae \\
\hline 096 & Favao & Fexrazicz $5 \rho \rho$ & L. Mimosaceae \\
\hline 097 & Freijo branco & Cordia bicolor & Eorraginaceae \\
\hline 098 & Gameleira & Ficus spp & Moraceate \\
\hline 099 & Eena de ovo & Foect lanthe effusa & L.Fapilionaceae \\
\hline 100 & Goiaba brava & Psidium spo & Myrtaceae \\
\hline 101 & Goiaba branca & Fsidium spp & Myrtaceas \\
\hline 102 & Goiabarana & Fsidium acutangulum & Hyrtaceas \\
\hline 103 & Goiabeira & Psidium guayava & Myrtaceae \\
\hline 104 & Guiabinha & Mreiaria fioribunde & Myptacea \\
\hline 105 & Gräo de Cachorro & Tabernaemontana angulata & Aporynaceae \\
\hline 106 & Guariuba & Clarisia racenosa & Moracoae \\
\hline 107 & Unbauba & Cecropia spp & Woraceae \\
\hline 108 & Imbauba branca & Cecropia abtusifolia & Moraceae \\
\hline 109 & Imbaba da mata & Cecropia seydaphyt la & Moraceaz \\
\hline \pm 10 & Imbauba vermel ha & Cecropia distachia & Foraceze \\
\hline 111 & Imbaubăo & Pourouna spp & Moraceae \\
\hline 112 & $\operatorname{Inaja}$ & Maximilizana maripa & Falmä \\
\hline 113 & Inejarana & Cuararibea lasyocalys & Eombacaceae \\
\hline 114 & Inga & InECE $s \rho \rho$ & L. Mimosaceae \\
\hline 115 & Inga amarelinho & Inga auristel lae & L. Mimosaceae \\
\hline 116 & Inga branco & Inger intbaridiana & L. Minosaceae \\
\hline $1 \pm 7$ & Inge chato & Inera nobilis & L. Wimosaceae \\
\hline 118 & Inga cips & Inga edulis & L. Mimosaceae \\
\hline 119 & Inga faça & Inga capitata & 1.Mimosaceas \\
\hline 120 & Ingá peludo & Inga rubiginosa & L. Mimosacear \\
\hline 121 & Inga pretinho & Inga heterophylia & L. Nimosaceae \\
\hline 122 & Ingat vermel ho & Inegex spp & L. Wimosacear \\
\hline 123 & Irga xixica & Irega alba & L.Mimosaceae \\
\hline 124 & Ingarana & Pithecelobium caulithorum & L.Mimosaceas \\
\hline
\end{tabular}


Tabela 6 - Continuaça.

\begin{tabular}{|c|c|c|c|}
\hline $\mathrm{COD}$ & NOME COHUM & MOME CIENTIFICD & MOME FAMILIA \\
\hline 125 & Janita & Erosimum gui & \\
\hline 126 & Ips amarelo & Tabebuia serratifolia & Eignoniareae \\
\hline 127 & Jangada & Ochroma Lagopus & Bumbacaceae \\
\hline 128 & Inthare & Brosimum $5 p \rho$ & Moracea \\
\hline 129 & Jataúba preta & Guarea syluatica & Mel iaceae \\
\hline 130 & Joæo mole & Need $s p P$ & Myctaginaceae \\
\hline 131 & Jurubeba & Solonum crinitum & Solaracoae \\
\hline 132 & Jutai & Hymenaed courbaril & L. CaEsalpinaceac \\
\hline 133 & Jutal branco & hymenaed parvifolia & L. Caesa 1 pinaceae \\
\hline 134 & Jutal pororoca & Dialium gutanensis & L. Caesalpinacean \\
\hline 135 & Lacre & Vismic Eutanensis & Gutiforen \\
\hline 136 & Laranjinha & Citrus $s p \rho$ & Futaceae \\
\hline 137 & Louro amarelo & Ocoted spp & $L z$ \\
\hline $13 \theta$ & Louro branco & ocoter gloner & $L=$ \\
\hline 139 & Louro cravo & Ocoted caudutzu & Le \\
\hline 140 & Lourg preto & Hec tandre cuspida & LE \\
\hline 141 & LoLPO roEa & Deotea costutata & $L_{2}$ \\
\hline 142 & Louro vermel ho & Mectandrà mura & Latiracs \\
\hline 143 & Macueu de Eangue & Licanid heteromos & Crysobalanaceas \\
\hline 144 & Mamorana & Bombar longipedicel lat um & Eombacaceae \\
\hline 145 & Mamul & Jacaratia spinosa & Caricac \\
\hline 146 & Maniva de veado & Munihot guinge & Euphorbiaceate \\
\hline 147 & Mapatirana & Pouround guian & Moracane \\
\hline 148 & Marfim & Agonandra brasiliensis & Dpili.aceas \\
\hline 149 & Marirana & Poragueiba gutanensis & Icacinaceae \\
\hline$\$ 50$ & Marupa & Simaruba amara & Simarubaceae \\
\hline 151 & Massararduba & Marelteara huberi & Sapotacaae \\
\hline 152 & Massarandubinha & Manilkara anazonic & Sapotaceae \\
\hline 153 & Matamata amarelo & Eschweilera spo & Lerythidaceae \\
\hline 154 & Watamata branco & Eschweilera coriacea & Lecythidactas \\
\hline 155 & Matamata preto & Esehweilera grandiflora & Lecythidaceae \\
\hline 156 & patamata vermelho & Eschweilera spp & LeEythidacade \\
\hline 157 & Melancieira & Alexce grandifilora & L.Papilionaceae \\
\hline 158 & Fagno & Sutietenta macrophylia & Meliacease \\
\hline 159 & Muiracatiara & Astronium eracile & Anecardiaceae \\
\hline 160 & Muirachimbe & Emmotum acuminatum & Icacina \\
\hline 161 & Muirajuba & Apuleia spo & L. Caesalpinacea \\
\hline 162 & Muiratinga & Magaira coriace & Moreceap \\
\hline 163 & Muiratinga poluda & reticostylis peduncr & Moraceae \\
\hline 164 & Murta & Eugenia spp & Myrtaceae \\
\hline
\end{tabular}


Tabela 6 - Continuaçao.

\begin{tabular}{|c|c|c|c|}
\hline $\mathrm{COD}$ & NOME COMUM & NOME CIENTIFICO & NOME FAMTLIA \\
\hline 165 & Muruci da mata & Byrsinima aerugo & Malpighiaceas \\
\hline 166 & Murure & Pseudolmedia murure & Horaceas \\
\hline 167 & Murures amarelo & Brosimum spp & Moraceae \\
\hline $16 \theta$ & Mururé branto & Erosinum spp & Moraceae \\
\hline 169 & Mururé preto & Erosimum spp & Moraceae \\
\hline 170 & Mutamba & Quazuma ulmor fol ia & Sterculiaceae \\
\hline 171 & Mututi duro & Pterocarpus rohrii & L.Papilionaceae \\
\hline 172 & Megramina & Desconhecido & Desconhecida \\
\hline 173 & Orelha de Macaco & Enterolobium schomburgkit & L. Minosaceat \\
\hline 174 & arelha de anca & Cissompers ovalifolia & Menispermacea \\
\hline 175 & Pajeú & cocooloba latifolia & Folygonaceae \\
\hline 176 & Faliteira & Cassia lucens & L. Mimosaceae \\
\hline 177 & Fapo de mutum & Lacumaxia jenmani $i$ & Guinaceas. \\
\hline 178 & Farapara & Jacaranda copata & Eignoniaceae \\
\hline 179 & Farica & Schizolobium ancuzonicum & 1. Caesalpiñanae \\
\hline 180 & Fau de cotra & Oumarea castandejolia & Gohinacere \\
\hline 181 & Pau de jacaré & Laetia procera & Fiacourtiaceas \\
\hline 192 & Pau de serra & Leetia spP & Flatourtiacede \\
\hline 183 & Pau doce & olycydendron amazonicum & Euphorbiaceae \\
\hline 194 & Pau mulato & Cul ycophyi zum spruceanum & Fubiacene \\
\hline 185 & Fau preto & Cenostignu tocantinum & L-Cagsalpinaceas \\
\hline 196 & Fau roso & Peltogyne conferitifora & L.Caeselpiraceas \\
\hline 187 & Faxiluba & Socrated exhorriza & Falmae \\
\hline 198 & Peito de porca & Dosconhecido & Desconhecida \\
\hline 189 & Pente de macaro & Apeiba echingta & Tisierea \\
\hline 190 & Fimenta de jecú & Anowagorea dol ichocarpa & Anmonetras \\
\hline 191 & Pinenta branca & xylopia spp & Annonaceae \\
\hline 192 & Pimenta preta & Xylopia spp & Anmonaceae \\
\hline 193 & Firanheira & Firanhea trifoliata & Annonaceae \\
\hline 174 & Periquiteira & Cochlospermum orinocenis & Cochlospermaceat \\
\hline 195 & Fitomba & Talista esculenter & Sapindaceas \\
\hline 196 & Pitomba de leite & Toulicia spp & Sapindaceae \\
\hline 197 & Fracumbarana & Trichilia micrentha & Meliacrae \\
\hline 178 & Puthis & Euroia eriopila & Fubiaceae \\
\hline 199 & Furuizinto & Amaiona guianensis & Fubiaceae \\
\hline 200 & Quarubarana & Exisnod uncinatum & Vochysiaceae \\
\hline 201 & Quina & Quitina $s p \rho$ & ochnaceae \\
\hline 202 & Quinarana & Geissospermum sericeum & Apocyracear \\
\hline 203 & Fosina de czo & Desconhecido & Desconhecido \\
\hline 204 & Rinorea & Finorea ricurnes & Violaceae \\
\hline
\end{tabular}


Tabela 6 - Continuaçao.

\begin{tabular}{|c|c|c|c|}
\hline $\mathrm{COD}$ & NOME COMUM & NOWE CIENTIFICO & NOME FAMIIIA \\
\hline 205 & Saboeiro & Pithecelobiun jupumba & L. Mimosaceae \\
\hline 206 & Sangue de cavalo & Desconthecido & Desconherido \\
\hline 207 & Sapota & Matisia cordata & Bambacaceae \\
\hline 208 & Sapucaia & Lecythis paraensis & Lecythidaceae \\
\hline 209 & Spirantera & Spiranthera guianensis & Rutareae \\
\hline 210 & Sucupira & Bowdichia nítida & L.Papilichareae \\
\hline 21.1 & Sucupira preta & Diplotropis purpurea & L. Papilionaceae \\
\hline 212 & Samauma & Ceiba pentandra & Eumbacaceas \\
\hline 213 & Tachi branco & Sclerolobium purcunse & L. Caesalpinacea \\
\hline 214 & Tachi prata & Sclarolobium paniculata & L.Caesalpinacens \\
\hline 215 & Tachi preto & Tachiealia mymercophyl la & L.Caesa 1 pinatede \\
\hline 216 & Tachi vermeltro & Sclerolobium melanocurpum & L. Caesalpinaceae \\
\hline 217 & Tachirana & siyphinodendron ponicul. & L. WinosaceaE \\
\hline 218 & Tamengueira & Zanthoryl lum rhoifotia & Futacean \\
\hline 219 & Tamaquare & Caraipa erandiflora & Guthiferate \\
\hline 220 & Tanibuca & Terminalia guianensis & Combretaceae \\
\hline 221 & Taquari & Mabea caudata & Euphorbiacear \\
\hline 222 & Taruma & Witex tinifolia & Verbenaceza \\
\hline 223 & Tatajuba & Bagussa guianensis & Moracene \\
\hline 224 & Tatapiririca & Tepirira gutanenses & Anacardi.ac \\
\hline 225 & Tauari $t=\pi \dot{i}$ Lida & Couratari oblongifolia & Lexthidate \\
\hline 226 & Tento amarelo & Ormosicy excelsa & L.Papilionanteae \\
\hline 227 & Tento $f$. grande & Ormosia nobilis & L.Fapilionanceae \\
\hline 228 & Tento f. mista & Onmosid paraensis & L.Papilimanceae \\
\hline 229 & Tento preto & Ormosiopsis flava & LoFapilionanceas \\
\hline 230 & Tinteiro & Miconia minuitilora & He 3 accomatacose \\
\hline 231 & Trapiara & Leonia glyeicarpa & Vial areare \\
\hline 232 & Trapiarana & Ampe beera edentula & UImaceae \\
\hline 233 & Trema & Trema mierantha & Unaceas \\
\hline 234 & Ucumba charona & Osteophloeum ptatispermum & Myristicac \\
\hline 235 & Ucumba $f, p \in$ luda & Virola sebifera & Myristicaceae \\
\hline 236 & Leumba f. firme & Firota mel inonit & myristicacoas \\
\hline 237 & Ucumbe prota & Wirola micheli $i z$ & Myristic \\
\hline 239 & Ucumbaraba & Iryanthere paraensis & Myristicaceas \\
\hline 239 & Unhe de gato & Uncaria suianensis & Rubiaceas \\
\hline 240 & Urtiga & Urexa caracasana & aceae \\
\hline 241 & Urucurana & sloranea spp & El ezocarpac \\
\hline 242 & Urucurana figrande & Slouned grandiflora & Elas \\
\hline 243 & Visqueiro & Fardica perciula & Lat \\
\hline 244 & Muirapinima & Erosimum $s p p$ & Mar \\
\hline 245 & Amarelã & Apuleia molaris & Esalpinaceae \\
\hline 246 & Caranjimba & solorea flavida & Ea \\
\hline 247 & Pindaiba branca & Descontecido & Desconthe \\
\hline 248 & Findaiba preta & Desconthecido & Desconhecido \\
\hline
\end{tabular}


Tabela 7. - Númera de generos e especies por familia botanica observados no segundo inventário continuo (Novembro-1989).

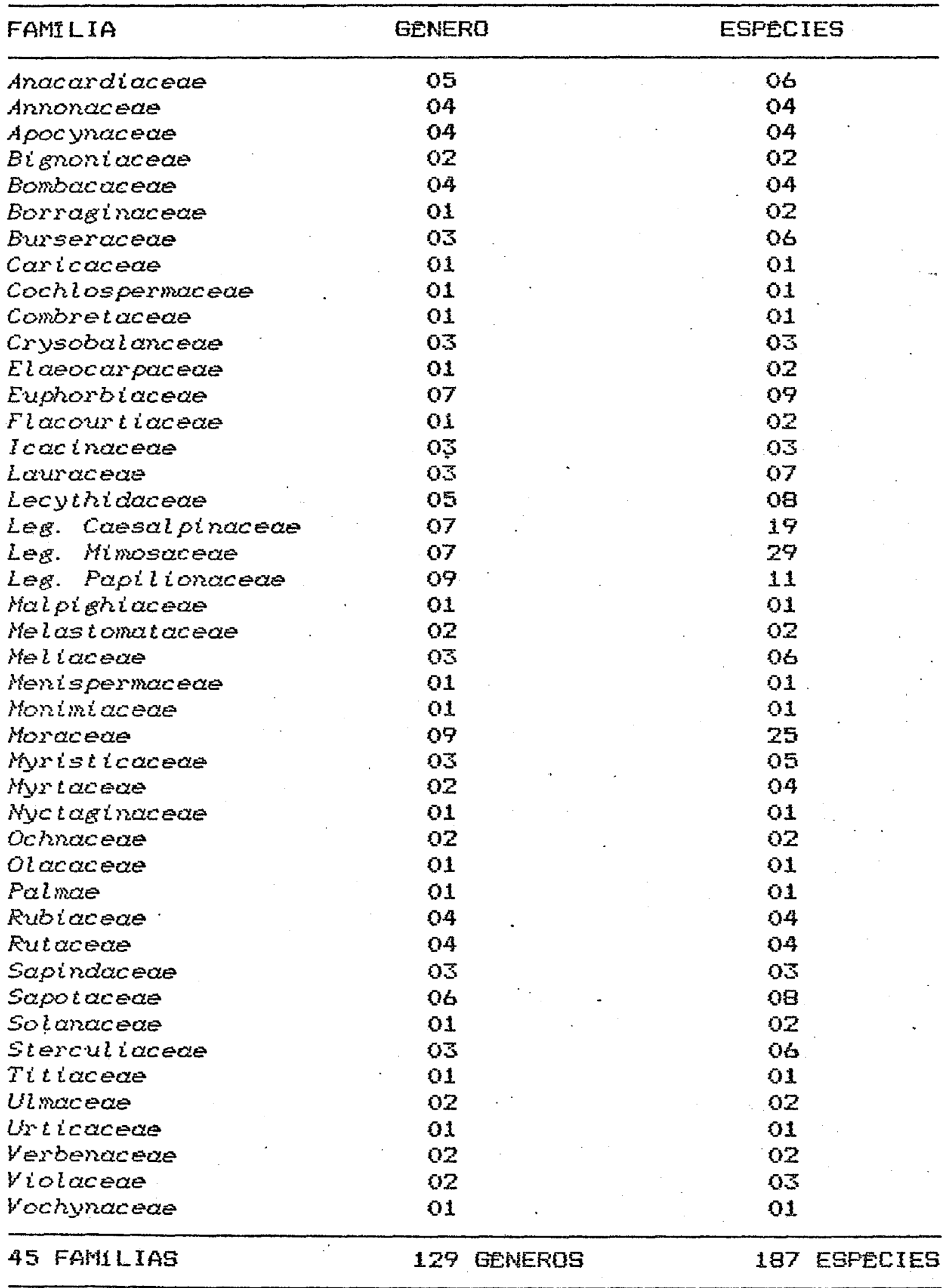


Tabela 8 - Composição florlstica do primeiro inventário continuo (Outubro-1996), por tratamento.

\begin{tabular}{|c|c|c|c|c|c|c|c|c|}
\hline \multirow{2}{*}{ FAMILIA } & \multicolumn{2}{|c|}{ TRAT . 01} & \multicolumn{2}{|c|}{ TFAT .0Z } & \multicolumn{2}{|c|}{ TRAT.OS } & \multicolumn{2}{|c|}{ TRAT.04 } \\
\hline & $n \leq p$ & $\%$ & $n \subseteq p$ & 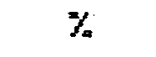 & $n \equiv p$ & $\psi$ & nsp & $\%$ \\
\hline Anacardiaceae & 4 & 3,03 & 1 & 1.45 & 2 & 1,57 & 1 & 1,20 \\
\hline Annonaceae & 4 & $\Xi, 05$ & 3 & 4,34 & 5 & 3.93 & 3 & 3,61 \\
\hline Apocynaceae & 4 & 3,03 & - & - & 2 & 1,57 & 1 & 1,20 \\
\hline Eignoniaceae & 1 & 0,75 & 1 & 1,45 & 2 & 1,57 & 1 & 1,20 \\
\hline Bombacaceae & 3 & 2,27 & - & - & $z$ & 1,57 & 2 & 2,41 \\
\hline Boraginacede & 2 & 1,51 & 2 & 2,89 & 2 & 1,57 & 2 & 2,41 \\
\hline Eurseraceae & 6 & 4,54 & 2 & 2,09 & 4 & 3,15 & 3 & 3,01 \\
\hline Caricaceae & 1 & 0,75 & 1 & 1,45 & 1 & 0,79 & 1 & 1,20 \\
\hline Cochlospermaceae & - & - & 1 & 1,45 & 1 & 0,79 & 1 & 1,20 \\
\hline Combretacear & 1 & 0,75 & - & - & - & - & - & - \\
\hline Crysobal ancede & 3 & 2,27 & 1 & 1.45 & 2 & 1,57 & 3 & 3,61 \\
\hline Ebenaceae & 1 & 0,75 & - & - & - & - & - & - \\
\hline Elcyeorar pacere & 1 & 0,75 & 1 & 1,45 & 2 & 1,57 & 1 & 1,20 \\
\hline Euphorbiacear & 3 & 2,27 & 3 & 4,34 & 4 & 3,15 & 4 & 4,82 \\
\hline Flacour t ideae & 2 & 1,51 & 2 & 2,89 & 2 & 1,57 & 1 & 1,20 \\
\hline Guttiferade & 3 & 2,27 & 2 & 2,99 & 3 & 2,36 & $\overline{3}$ & 3,61 \\
\hline I cac inuceas & 3 & 2,27 & 1 & 1.45 & 3 & 2,36 & 1 & 1,20 \\
\hline Lauraceas & 5 & 3,79 & 2 & 2,89 & 3 & 2,36 & 1 & 1,20 \\
\hline Lecythidezerede & 6 & $4,5,4$ & $\exists$ & 4,34 & 4 & 3,15 & 3 & 3,61 \\
\hline I. Caesul pinaceae & 6 & 4,54 & 2 & 2.99 & 5 & 3,94 & 5 & 6,02 \\
\hline L. Mimosaceae & 14 & 10,60 & 11 & 15.94 & 13 & 10,24 & 14 & 16,86 \\
\hline 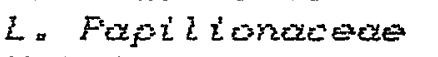 & 7 & 5,30 & 1 & 1,45 & 9 & 7.09 & 2 & 2,41 \\
\hline Halpiehtacede & - & - & - & - & 1 & 0,79 & - & - \\
\hline He las tomat aceare & 1 & 0,75 & 1 & 1,45 & 2 & 1,57 & - & - \\
\hline SUE-TOTAL & & & & & & & & \\
\hline
\end{tabular}


Tabela $\theta$ - Continuação.

\begin{tabular}{|c|c|c|c|c|c|c|c|c|}
\hline \multirow{2}{*}{ FAMILIA } & \multicolumn{2}{|c|}{ TFAT . O1 } & \multicolumn{2}{|c|}{ TFAT .02 } & \multicolumn{2}{|c|}{ TRAT.03 } & \multicolumn{2}{|c|}{ TRAT.OA } \\
\hline & $n \leq p$ & $\%$ & $n \in p$ & $\%$ & $n \leq p$ & $\%$ & nep & $\%$ \\
\hline Meliaceae & 4 & 3,03 & 1 & 1,45 & 5 & 3,93 & 1 & 1,20 \\
\hline Manispermuzede & 1 & 0,75 & - & - & 1 & 0,79 & - & - \\
\hline Monimicaneas & 1 & 0,75 & 1 & 1,45 & 1 & 0,79 & 1 & 1,20 \\
\hline Storacede & 11 & 8,35 & 6 & 8,67 & 12 & 9,45 & 7 & 8,43 \\
\hline Myristicacease & 2 & 1,51 & 2 & 2,89 & 4 & 315 & 2 & 2,41 \\
\hline Mretacean & 2 & 1,51 & 3 & 4,34 & 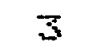 & 2,36 & - & - \\
\hline Myc taginaceae & 1 & 0,75 & 1 & 1,45 & 1 & 0.79 & 1 & 1,20 \\
\hline Dohnacede & 1. & 0,75 & - & - & 2 & 1,57 & 1 & 1,20 \\
\hline olcreacear & 1 & 0,75 & 1 & 1.45 & 1. & 0,79 & - & - \\
\hline Palmate & 1 & 0,75 & 1 & 1,45 & 1 & $0_{3} 79$ & - & - \\
\hline Polyernacear & - & - & 1 & 1945 & - & - & 1 & 1,20 \\
\hline Qui inaceve & - & - & - & - & 1 & 0,79 & - & - \\
\hline Rubiaceare & 2 & 1,51 & - & - & - & - & 1 & 1,20 \\
\hline Rit & 4 & 303 & 2 & 2,89 & 4 & 3,15 & 2 & 2,41 \\
\hline supindacede & 3 & 2,27 & $i$ & 1,45 & 3 & 2,36 & 2 & 241 \\
\hline Sapotaceae & 6 & $4: 54$ & 2 & 2,69 & 4 & 3.15 & $\$$ & 361 \\
\hline Solanacear & - & - & 2 & 2,89 & 1 & 0,79 & 2 & 2,41 \\
\hline Sterculicecoe & $b$ & 4,54 & 1 & i. 45 & $\Xi$ & 2,36 & 9 & 4,02 \\
\hline Titiaceae & 1 & 0,75 & \pm & 1,45 & 1 & 0.79 & $\underline{1}$ & 1.20 \\
\hline Ut maxeace & - & - & - & - & 1 & 0,79 & - & - \\
\hline Luticacede & - & -- & 1 & 1,45 & - & - & - & - \\
\hline Verbenaceae & 1 & 0,75 & - & - & 1 & 0,79 & - & - \\
\hline Violacede & 2 & 1,51 & 1 & 1,45 & 3 & 2,36 & 1 & 1,20 \\
\hline Vochysiaceae & 1 & 0,75 & - & - & - & - & - & - \\
\hline & & & & & & & & 3 \\
\hline
\end{tabular}

nsp $=$ rúmero do espécies 
Tabela 9 - Composição florlstica do segundo inventario contrnuo (Novembro-1989), por tratamento.

\begin{tabular}{|c|c|c|c|c|c|c|c|c|}
\hline \multirow{2}{*}{ FAMILIA } & \multicolumn{2}{|c|}{ TRAT.OI } & \multicolumn{2}{|c|}{ TRAT.OZ } & \multicolumn{2}{|c|}{ TFAT.03 } & \multicolumn{2}{|c|}{ TRAT .04 } \\
\hline & $n s p$ & $\gamma$ & nep & $\gamma$ & $n s p$ & $\%$ & $n \leq p$ & $\%$ \\
\hline Anacardiacede & 5 & 3,73 & 4 & 4,49 & 3 & 2,07 & 2 & 2,04 \\
\hline Annonaceae & 3 & 2,24 & 3 & 3,37 & 4 & 2,76 & 3 & 3,06 \\
\hline Apocynaceae & 4 & 2,98 & 1 & 1,12 & 2 & 1,38 & 1 & 1,02 \\
\hline Eignonicucece & 1 & 0,75 & 1 & $1 ; 12$ & 2 & 1,38 & 1 & 1,02 \\
\hline Eonbacaceae & 2 & 1.49 & 1. & 1,12 & 2 & 1,38 & 1 & 1,02 \\
\hline Borarinacecer & 2 & 1.49 & 2 & 2,25 & 2 & 1,38 & 1 & 1,02 \\
\hline Bursercaceare & 5 & $3: 73$ & 2 & $2: 25$ & 6 & 4,14 & 4 & 4,08 \\
\hline Caricaceae & 1 & 0,75 & 1 & 1,12 & 1 & 0,69 & 1 & 1,06 \\
\hline Cochlospermeta acie & - & - & 1 & 1,12 & 1 & 0,69 & 1 & 1,02 \\
\hline Combretcuede & 1 & 0,75 & - & - & - & - & - & - \\
\hline Crysobalaracece & 4 & 2,78 & 2 & 2,25 & 2 & 1,38 & 3 & 3,06 \\
\hline Ebenaceae & - & - & - & - & - & - & - & - \\
\hline Elcyecocar pacede & 1 & 0,75 & 1 & 1,12 & 2 & 1,38 & 1 & 1,02 \\
\hline Euphorbiacede & 3 & 2.24 & 4 & $4 ; 49$ & 5 & 5,45 & 6 & 3.45 \\
\hline Flacourticlesece & 2 & 1,49 & 1 & 1,12 & 2 & 1,38 & 1 & 1.02 \\
\hline 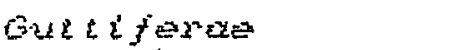 & 3 & 2,24 & 2 & 2,25 & 4 & 2,76 & 3 & 3,06 \\
\hline Icacineycerae & 3 & 2,24 & 1 & 1,12 & 3 & 2,07 & 1 & 1,02 \\
\hline Lawacere & 5 & 373 & 4 & 4.49 & 4 & 2,76 & 4 & 4,08 \\
\hline Eecythidrocade & 7 & 5,22 & 2 & 2,25 & 5 & 3,45 & 4 & 4,08 \\
\hline L. Caesulpiruceas & 6 & 4,49 & 5 & 5.62 & 7 & 4,83 & 5 & 5,30 \\
\hline L. Himosacene & 11 & 10,45 & 14 & 15,73 & 15 & 10,34 & 16 & 16,33 \\
\hline L. Fupilionciedecte & 6 & $4 * 48$ & 4 & 4,49 & $1 \pm$ & $7=59$ & 4 & $4.6 \mathrm{~B}$ \\
\hline Mey pighicaceze & - & - & - & - & 1 & 0.69 & - & - \\
\hline Helas tomay acese & 1 & 0,75 & 1 & 1,45 & 2 & 1,38 & - & - \\
\hline SUE-TOTAL & & 7 & & 56 & & 96 & & 63 \\
\hline
\end{tabular}


Tabela 9 - Continuação.

\begin{tabular}{|c|c|c|c|c|c|c|c|c|c|}
\hline \multirow{2}{*}{ FAMILIA } & & \multicolumn{2}{|c|}{ TRAT.01 } & \multicolumn{2}{|c|}{ TRAT. 02} & \multicolumn{2}{|c|}{ TRAT.OS } & \multicolumn{2}{|c|}{ TRAT . OA } \\
\hline & & $n s p$ & $z$ & $\pi 5 p$ & $\%$ & $n \leq p$ & $\%$ & nsp & $\%$ \\
\hline Meliaceae & & 4 & 2,79 & 1 & 1,12 & 4 & 2,76 & 2 & 2,04 \\
\hline Henispermaceae & & 1 & 0,75 & - & - & 1 & 0,69 & - & - \\
\hline Honimiaceae & & 1 & 0,75 & 1 & 1,12 & 1 & 0,65 & 1 & 1,02 \\
\hline Moraceae & & 11 & 8,21 & $\mathrm{~B}$ & 8,99 & 13 & 8,76 & 9 & 9,18 \\
\hline Myristicaceae & & 2 & $1 ; 51$ & 2 & 2,25 & 5 & 3,45 & 1 & 1,02 \\
\hline Murtaceae & & 2 & 1,51 & 2 & 2,25 & 2 & 1,58 & 1 & 3.02 \\
\hline Nye taginaceae & & 1 & 0,75 & \pm & 1,12 & 1 & 0,69 & 1 & 1,02 \\
\hline Ochnaceas & & 1 & 0,75 & - & - & 1 & 0.69 & - & - \\
\hline Olacaceae & & 1 & 0,75 & - & - & 1 & 0,69 & - & - \\
\hline Palnae & & 1 & 5,75 & - & - & - & - & - & - \\
\hline Polyzonacede & & - & - & 1 & 1,12 & 1 & 0,67 & 1 & 1,02 \\
\hline Quilinoceae & · & 1 & 0,75 & - & - & 1 & 0,69 & 1 & 1,02 \\
\hline Rubiaceae & & 2 & 1,49 & - & - & 1 & 0.67 & 1 & 1,02 \\
\hline Rutcreas & & 4 & 2,98 & 3 & 3,37 & 4 & 2,76 & 2 & 204 \\
\hline Sapindedceae & & 3 & 2,24 & 2 & $2 \neq 25$ & 3 & 2.07 & 3 & 3,06 \\
\hline Supotacece & & 7 & 5,22 & 3 & 3,37 & 5 & 3.45 & 3 & $3,0 b$ \\
\hline Solaricyedera & & - & - & 2 & 2,25 & 2 & 1,30 & 2 & 2704 \\
\hline stercul zacece & & 6 & 4,49 & 3 & 3,37 & 4 & 2,76 & 4 & $4,0 \mathrm{a}$ \\
\hline Tŕcicaede & & 1 & 0,75 & 1 & 1,12 & + & 0,69 & $i$ & 1.02 \\
\hline Ulmoceare & & - & - & - & - & 2 & 1,38 & 1 & $+1,02$ \\
\hline brticaceae & & - & - & 1 & 1,12 & 1 & 0,69 & - & - \\
\hline berbenacear & & 1 & 0,75 & 1 & $1=12$ & 2 & 1,75 & - & - \\
\hline Wiolacede & & 1 & 0,75 & \pm & 1,12 & 3 & 2,07 & 1 & 1.02 \\
\hline Yochysiacear & & 1 & $0_{7} 75$ & - & $\div$ & - & - & - & - \\
\hline & & & & & & & & & \\
\hline
\end{tabular}

nsp = numero de especies

AE familias com maior numero de especies identificadas no imventario de 1904 forama Leg. Mimosaceaeg Moraceae $e$ Leg. Papiliondcede, que juntas representaram $24,2 \%$ do total de especies. a tratamento 3 eqresentou 0 maior numero de especies, seguido pelo tratamento 1.

En 19ad, as famli 1 iss com o maior número da espécies forams Leg. Mimosacede; Horacede, Sapotaceae E Lecythidacede, que juntas somaran $26,7^{\%}$ do total de espocies. 
Nos tratamentos 1 e 3 , da mesma forma que no ano de 1986, foram registrados as maiores numeros de especies identificadas.

A evolução do número de especies durante $a$ periodo 1986-1988 pode ser vista na Tabela 10.

Tabela 10 - Evoluça do número de especies do ensaio.

\begin{tabular}{|c|c|c|c|c|c|c|c|c|}
\hline \multirow{2}{*}{ CLASSE DE TAWANHO } & \multicolumn{4}{|c|}{1796} & \multicolumn{4}{|c|}{1999} \\
\hline & $\mathrm{T} 1$ & $T 2$ & 35 & $T 4$ & $T 1$ & $T 2$ & $\mathrm{T3}$ & $T 3$ \\
\hline Fegeneragão (5P2 + 5PS) & $40^{\circ}$ & 51 & 39 & 51 & 55 & 69 & 61 & 62 \\
\hline Estabelecidas (SF1) & 128 & 37 & 122 & 61 & 132 & 60 & 139 & 69 \\
\hline
\end{tabular}

En todos os tratamentos e nos dois estagios de crescimento, foi observado un aumento Etbstancial do numero de esperise novas. Para as especies agrupadas no estagio de regeneraça natural, o aumento percentual de especies novas observado no tratanento 3 foi superior aos demais, representando um acrescimo de $37,0 \%$ En rejação ao ano anterior. Fara as especies estabelecidas, a maior aumento foi cbeervado no tratamento 2 , en torno de $39,0 \%$ en relaçăo a ano de 1986.

\subsection{Ouociente de Mistura de JENTSCH COM}

o Quaciente de Mistura foi calculado em todas as parcelas experimentais e durante todos os inventsrias Horestais realizados. A Tabela 11 mostra os valores do aM 
calculado para todos os individuos nos estagios de plartas estabelecidos (SP1) e varas (SP2).

Tabela 11 - Quociente de mistura de JEMTSCH (GN) por tratamento, en toda as fases do ensaio.

\begin{tabular}{|c|c|c|c|c|c|c|c|c|}
\hline \multirow{2}{*}{ AND } & \multicolumn{4}{|c|}{ TRATAHENTO OI } & \multicolumn{4}{|c|}{ TRATAPENTO 02} \\
\hline & $\begin{array}{c}\text { BLOCD } \\
01\end{array}$ & $\begin{array}{c}\text { ELDCO } \\
\text { OZ }\end{array}$ & $\begin{array}{c}\text { BLOCO } \\
\text { OS }\end{array}$ & $\begin{array}{c}\text { ELOCO } \\
04\end{array}$ & $\begin{array}{c}\text { ELDCO } \\
01\end{array}$ & $\begin{array}{c}\text { El.OCO } \\
02\end{array}$ & $\begin{array}{c}\text { ELDCO } \\
03\end{array}$ & $\begin{array}{c}\text { ELCCO } \\
04\end{array}$ \\
\hline $198^{(1)}$ & $1: 9,5$ & $1: 11,8$ & $1: 9_{7} 1$ & $1: 10,5$ & $1: 8,9$ & $1 \equiv 9,4$ & $1: 9,1$ & $1=8,9$ \\
\hline $1984^{(2)}$ & $1: 9,5$ & $1: 11,8$ & $1: 9,1$ & $1: 10,5$ & 䄅 & H & $*$ & w \\
\hline $1786^{69}$ & $1: 5 * 4$ & $1=4,3$ & $1=4,1$ & $1: 4,9$ & $1: 10 \%$ & $1: 7: 6$ & 106,2 & $1: 27,2$ \\
\hline $1988^{(6)}$ & $1: 5,9$ & $1: 4,2$ & $1: 5,4$ & $1 \equiv 4,6$ & $1=10,3$ & $1: 956$ & $1: 9 ;=$ & $1=21 ; 2$ \\
\hline
\end{tabular}

\begin{tabular}{|c|c|c|c|c|c|c|c|c|}
\hline \multirow{2}{*}{ AMO } & \multicolumn{4}{|c|}{ TRATAHENTD OB } & \multicolumn{4}{|c|}{ TRATAHENTO OA } \\
\hline & $\begin{array}{c}\text { ELCLO } \\
01\end{array}$ & $\begin{array}{c}\text { ELOLO } \\
02\end{array}$ & $\begin{array}{c}\text { ELOCO } \\
03\end{array}$ & $\begin{array}{c}\text { ELOCO } \\
04\end{array}$ & $\begin{array}{c}\text { BLOCO } \\
\text { ot }\end{array}$ & $\begin{array}{c}\text { FLLCO } \\
02\end{array}$ & $\begin{array}{c}\text { ELDCD } \\
0 \mathrm{~s}\end{array}$ & $\begin{array}{c}\text { aLOCO } \\
04\end{array}$ \\
\hline $1784^{(1)}$ & $1: 9,1$ & $1=12,3$ & $1: 12,5$ & $1: \theta g$ & $1=10,2$ & $1=7,4$ & $1: 11,3$ & $1: 12,0$ \\
\hline $1984^{(2)}$ & $1: 7,8$ & $1: 10,0$ & $1: 12 \times 7$ & $1: 7,5$ & $1: 6,0$ & $1: 4,5$ & $1: 7,5$ & $1: 31,4$ \\
\hline $1786^{(3)}$ & $1: 5^{\circ} 1$ & $1: 5,5$ & $1: 6: 4$ & $1: 4,3$ & $1: 6,1$ & $1.5,5$ & $1: 35:$ & $\pm: 3,7$ \\
\hline $1989^{(4)}$ & $1: 5,1$ & $1: 5,9$ & $1: 6,0$ & $1: 4,4$ & $1=8,2$ & $4: 4,9$ & $1=599$ & 115,6 \\
\hline 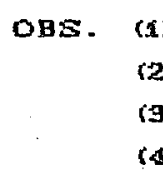 & $\begin{array}{l}\text { - Inve } \\
\text { - Irve } \\
\text { - Irve } \\
\text { - Irve }\end{array}$ & $\begin{array}{l}\text { mário co } \\
\text { mtário co }\end{array}$ & ontiruo & $\begin{array}{l}\text { ds-axplor } \\
1 \frac{a}{a} \text { modi } \\
2-\text { medi }\end{array}$ & der & & & 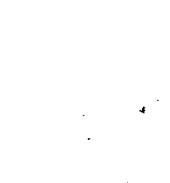 \\
\hline
\end{tabular}

0 valor medio do Guoriente de Mistura obtido do inventario inicial roi de 139,6 revelando que a composiçăo floristica inicial de araa era proxima aos valores. 
observados por outros autores en regibestropicais ifINOL, 1975; CARVALHO, 1982), ou seja, 9 individuos para cada especies, caracterizando assim uma alta heterogeneidade de esperies.

Após a implantação dos tratamentos, os valores medios do GM foram. substancialmente alterados, en todos os tratamentos, excluindo-se o tratamento ol. Mo tratamento 4 , as intervençoses Eilviculturais provocaram Lma diminuiçäo do grau de heterogeneidade media das especies. A nivel dos blocos, este efeito foi drástico no biaco 4 , paseando de 12 para 31 individuas por especie, indicando elevada heterogeneidade floristica. D efeito irverso foi observado no bloco 2 do mesmo tratamento, onde a Quociente de listura inicial era semelinante ao atribuido as formaçes florestais tropicais e que teve un aumento signiticativo, passando de 9 individuas por especie para apenas 4 individuos, indicando uma alta heterogeneidade floristica.

Os resultados observados nos inventurios de 1986 e 1980 diferen dos daquelesobservados em 1994, principalmente pare o tratamento 1 (testemuna), onde 0 inventario inicial apresentou um Duociente de Mistura de $1: 10,2 \mathrm{e}, \mathrm{Em}, 1988$ este valor foi reduzido para $135,0$. Apenas diferenças observadas, os valores sao semelhante ao obtido por SAlonã (1999), cuja media geral ficou en torno de 1:4,9. Da mesma forma nos tratementos 3 e 4 compartamento do aM foi semelhante ao observado no tratamento 1. Nas remediçరes sucessivas er̃etuadas, 
respectivamente, en 1986 e 1999, as maiores alteraçBes do am verificaram-se nas unidades. Experimentais pertencentes ao tratamento 4 .

For outro lado, os valares dos EN observados no ano de 1988, comparativamente aos de 1996, demostram uma tendsncia coerente. 0 ingresso cingrowthlde novos individuos, favoreceu a o desempenho do am, fato ete observado na evoluça dos valores do tratamento 2 (corte raso), durante o periado de 1904 (poss-exploratoria) a 1989.

Afenas nas parceias experimentais relativas ao traka- mento 2 , o Guociente de Mistura atingiugem 1998, valores pronimos aos observados no inventario inicial. Entretanto, a conposiçáo florstica observada em $19 a 9$ e completamente diferente daquela cbservada no inventario inicial. Nos demais tratamentos, inclusive no testemunhas houve diminuição acentuada da heterogeneidade thorietica das parcelas, es a partir de 1986, observa-se um leve aumento da heterogeneidade de todas as demais parcelas experimentais.

\section{3. Estrutura Horizontal}

A estrutura horizontal das espacies arbormas । parcelas experimentaisj foi caracterizada através dos calculos dos valores relativos de densidade (N/ha), dominancia ( $\left.\mathrm{m}^{2} / \mathrm{ha}\right)$ e frequencia de pspeies, discriminando-as en dois estagias de deservolvimenta: varas (SF2) e plantas estabelecidas (SP1), b nivel de blocos e 
78.

tratamentos.

Nos Apendices 2 e estao listäbas as estimativas dos parametros da estrutura horizontal para as especies mais represen- tativas observadas no ano de 1986, nos estagios de varas e plantas estabejecidas. Ja ros Apendices 4 e 5 acham-se as estimativas dos parametros da estrutura horizontal para as especies mais representativas observadas na avaliaçao efetuada en 1998.

4.3.1. Indice do Valor de Importancia (IVI)

Os resultados correspondentes aas mainres Indice do Valor de Importancia, por especies da classe (SF1), no ano de 1796, acham-se na Tabela 12. Segundo estes resultadosno tratamento 1 (testemuma) as Esperies gcologicamente mais importantes foram: Protium decandrum swart (breu vermelha). Sagotia racenosa Baill (arataciú), Cenostigma tocantinum Ducke (pau-preto) e Cedrelinga catanaeformis Ducke (cedrorana) g respectivamente para os blocos 1, 23 e 4. Dentre as esperies mais importante observadas, apenas Guarea guidonea (L.) Sleum (andirabarana), Dendrobangia boliviana Rusty (caferana) e Protium decandrum Shart (breu vermelha), ocorreram nos quatro blocos. 
Tabela 12 - Indice do Valor de Importsncia (IVI) das especies estabelecidas (SP1), selecionados no primeiro inventario continua (1996).

\begin{tabular}{|c|c|c|c|c|c|c|c|c|c|}
\hline \multicolumn{5}{|c|}{ TRATAMEMTO 1} & \multicolumn{5}{|c|}{ TFATAMENTO 2} \\
\hline \multirow{2}{*}{$\begin{array}{r}c o d \\
d a \\
\text { spp }\end{array}$} & \multicolumn{4}{|c|}{ FLOCOS } & \multirow{2}{*}{$\begin{array}{r}\operatorname{cod} \\
\mathrm{da} \\
\mathrm{\rho PP}\end{array}$} & \multicolumn{4}{|c|}{ ELOCOS } \\
\hline & 01 & 02 & 03 & 04 & & 01 & $o z$ & 03 & 04 \\
\hline 016 & 13,71 & - & - & - & $03 \mathrm{~B}$ & 13,32 & 14,98 & 35.57 & 10,61 \\
\hline 017 & 9,76 & 21,03 & 24,61 & - & 064 & 4,32 & 9,00 & 57,53 & 2,38 \\
\hline 018 & 22,93 & 1.6 .77 & 12,94 & 9,86 & 065 & - & 2,71 & 2,74 & - \\
\hline 025 & - & 21,24 & 32,23 & 45,01 & 066 & - & 4,50 & - & 2,37 \\
\hline 028 & - & 10,99 & - & 17,24 & 079 & - & $a_{y} 53$ & - & 6,54 \\
\hline 035 & 25,88 & 14,01 & 30,16 & 21,44 & 108 & 24,79 & 7,90 & - & 8,44 \\
\hline 047 & 21,15 & 17.09 & 23.29 & 10,41 & 110 & 130,59 & 121,32 & 5.79 & 235,32 \\
\hline 053 & - & - & 10,42 & 12,83 & 117 & 6,11 & - & - & - \\
\hline 064 & $-\cdot$ & - & 25,52 & - & 119 & - & 9,11 & - & 4,37 \\
\hline 069 & 12,47 & - & - & 16,62 & 121 & 10,55 & 4,07 & - & - \\
\hline 109 & 8,49 & 9,57 & - & - & 131 & 42,04 & 29,25 & - & - \\
\hline 113 & - & 14,58 & $\theta_{9}^{4}$ & - & 145 & 29,15 & 35,52 & $9 ; 57$ & 5,21 \\
\hline 118 & - & - & - & 10,37 & 176 & - & 7,06 & - & - \\
\hline 122 & 15,37 & - & - & - & 179 & 3,57 & - & 60,54 & 6,37 \\
\hline 124 & 7,73 & 7,01 & - & 7,01 & 199 & 3,37 & 4,17 & 2,80 & - \\
\hline 147 & - & $B, 06$ & - & 11,25 & 205 & 7,37 & 4.91 & 113,02 & - \\
\hline 166 & 9790 & 8,96 & - & - & 218 & - & 9,35 & - & 7,50 \\
\hline 185 & - & - & 26,62 & - & 241 & 4,83 & - & - & - \\
\hline
\end{tabular}


Tabela 12 - Continuação.

\begin{tabular}{|c|c|c|c|c|c|c|c|c|c|}
\hline \multicolumn{5}{|c|}{ TRATAMENTO 3} & \multicolumn{5}{|c|}{ TRATAMENTO 4} \\
\hline \multirow{2}{*}{$\begin{array}{r}\text { cod } \\
d a \\
5 p p\end{array}$} & \multicolumn{4}{|c|}{ BLOCOS } & \multirow{2}{*}{$\begin{array}{r}c o d \\
\text { da } \\
\text { spp }\end{array}$} & \multicolumn{3}{|c|}{ BLOCOS } & \multirow[b]{2}{*}{04} \\
\hline & 01 & 02 & 03 & 04 & & $o 1$ & $a z$ & 03 & \\
\hline 016 & $12,3 \theta$ & 7,40 & - & - & 017 & $7_{x} 48$ & - & 14,92 & - \\
\hline 018 & 26,87 & 23,28 & 7.91 & 13991 & 018 & - & - & 10,82 & 21,85 \\
\hline 025 & - & $7,2 \theta$ & 60,11 & 42,01 & 025 & - & - & 14,94 & 6,24 \\
\hline 028 & 10,43 & - & - & 7,84 & 035 & - & 42,69 & 19,27 & 20,51 \\
\hline 035 & 20,12 & 34,73 & 32,91 & 22,91 & $0 \mathrm{SB}$ & - & 19,01 & $\theta_{0}, 0$ & 27,39 \\
\hline 047 & 17,95 & 24,23 & 13,66 & - & 064 & $77: 29$ & - & 27.03 & - \\
\hline 058 & - & - & - & $\theta, 03$ & $069^{\circ}$ & 8,98 & - & - & 19,54 \\
\hline 064 & 7,51 & - & 21,45 & - & 110 & 82,17 & $19, \mathrm{ga}$ & - & 37,45 \\
\hline 084 & 10,40 & - & - & - & 118 & 9,54 & 15,36 & - & 18,69 \\
\hline 087 & 11,71 & - & - & - & 131 & 24,78 & 13,09 & - & - \\
\hline 099 & - & 19,99 & - & - & 145 & 15,49 & 69,36 & - & 21,04 \\
\hline 113 & 11,95 & 14,34 & - & - & 147 & - & - & - & 16,76 \\
\hline 118 & - & - & - & 11,83 & 166 & - & 15,74 & - & - \\
\hline 130 & - & - & - & 9,80 & 170 & - & - & $15_{9} 98$ & - \\
\hline 154 & 9,34 & 16,98 & - & 13,91 & 179 & - & - & 41,24 & - \\
\hline 166 & - & - & - & 15,52 & 185 & - & - & 52,28 & - \\
\hline 179 & - & - & 11,70 & - & 189 & - & - & 6,77 & 14,12 \\
\hline 185 & - & - & 15,65 & - & 205 & - & 16,45 & - & - \\
\hline
\end{tabular}

Somente duas espécies importantes do ponto de vista economico, foran observadas dentre as 19 especies com maiores IVI, que foram as castanteiras (Berthollecia excelsa HBK) as cedroranas (Cedrelinga catanaeformis Ducke).

AE espécies mais importantes observadas no tratamento 2 (corte raso) foram Sapium marmieri Huber (burra 
leiteira), Eertholletio excelsa HEK (castanheira), Cecropia distachia Willd (imbauba vermelta) e Jacaratia spinosa A.DC (mamul), todas elas, tfpicas das condiçôs ambientais geradas pelo tratamento silvicultural.

No tratamento 3 (corte seletivo), as especies com os maiores IVI foram Guarea guidonia (L.) Sleun (andirobarana), Protium decandrum Swart (breu vermelto) e Sagotia racemosa Baill (arataciú). Destas especies, as andiraba ranas e os treus vernelhos ocorreram em todos as blacos.

Mas parcelas com o tratamento 4 (corte seletiva) as especies gue se destacaram ecologicamente forama Cecropia distachia Wilid (imbauba vermelta) Jacaratia spinosa A.DC (mamu) a Cenostigna tocantinum Duche (pas pretol, sendo que neste tratamento nentuma especie ocorret simultaneamente en tados os blacas.

As especies classificadas no estagio de vara (SP2) E que alcançaram os IVI mais altos acham-se egrupadas na Tabela 13.

No tratamento 1 , as especies mais pepresenta-

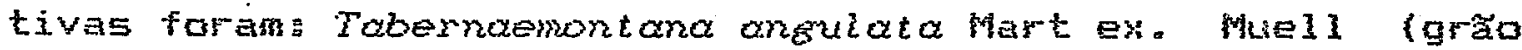
de cachorro): Guatleria poeppgiana Mart (envira preta), Rinorea racemosa (hart) kuntz (Canela de jacamim) e Pseudolmedia murure starid (mururs).

Inga edulis Mart (ings Eipo), Cecropia distachic lilld (imbauba vermelha) e schizolobium amozonicum (Huber) Ducke (parica) foram as especies que apresentaram os maiores IVI no tratamento $z$. 
Tabela 13 - Indice do Valor de Importancia (IVI) das especies no estágio de varas (SF2), selecionadas no primeiro inventario continuo (1986).

\begin{tabular}{|c|c|c|c|c|c|c|c|c|c|}
\hline \multicolumn{5}{|c|}{ TFATAMEMTO 1} & \multicolumn{5}{|c|}{ TFATAMENTO 2} \\
\hline \multirow{2}{*}{$\begin{array}{r}\text { cod } \\
d a \\
\text { spp }\end{array}$} & \multicolumn{4}{|c|}{ ELDCOS } & \multirow{2}{*}{$\begin{array}{l}\text { cod } \\
\text { da } \\
\text { spp }\end{array}$} & \multicolumn{4}{|c|}{ EILOCOS } \\
\hline & 01 & 02 & 03 & 04 & & 01 & 02 & 03 & 04 \\
\hline 004 & 30,89 & - & - & - & 016 & - & - & 14,59 & - \\
\hline 005 & - & - & 26,03 & - & ose & - & 69,24 & - & 14,59 \\
\hline 022 & 41,74 & - & - & - & 079 & - & 29,91 & - & 13,75 \\
\hline 025 & 29,91 & - & - & - & 100 & 21,72 & - & 14,26 & - \\
\hline 031 & 19,49 & 30,97 & 24,39 & - & 110 & 39,44 & $8 n, 95$ & - & 181,84 \\
\hline 055 & 22,20 & 56,86 & 20,16 & - & 118 & 56,36 & - & - & - \\
\hline 047 & 26.41 & - & 19,43 & - & 120 & - & - & - & 12,24 \\
\hline 053 & - & - & 71,69 & - & 121 & 29,52 & - & - & - \\
\hline 058 & - & 23,83 & - & 49,32 & 131 & 23,31 & 11,70 & - & - \\
\hline 084 & 19,49 & 78,18 & - & $29: 29$ & 135 & - & - & 16,00 & - \\
\hline 105 & 46.97 & - & . - & - & 137 & - & 11,4 & - & - \\
\hline 120 & - & - & - & 31,79 & 140 & 17,36 & - & - & - \\
\hline 130 & - & - & 24,39 & 32,69 & 178 & 54,97 & - & 14,57 & - \\
\hline 139 & 24,87 & - & - & - & 179 & 15,16 & - & 91,20 & - \\
\hline 166 & - & - & - & 54,26 & 189 & - & - & - & 21,26 \\
\hline 238 & - & - & - & 33,63 & 205 & - & 10,05 & 57,49 & 56,34 \\
\hline
\end{tabular}


Tabela 13 - Continuação.

\begin{tabular}{|c|c|c|c|c|c|c|c|c|c|}
\hline \multicolumn{5}{|c|}{ TRATANENTO 3} & \multicolumn{5}{|c|}{ TFATAMENTO 4} \\
\hline \multirow{2}{*}{$\begin{array}{r}\text { cod } \\
d a \\
\text { spp }\end{array}$} & \multicolumn{4}{|c|}{ ELOCOS } & \multirow{2}{*}{$\begin{array}{l}\text { cod } \\
\text { da } \\
\text { spp }\end{array}$} & \multicolumn{4}{|c|}{ ELCCOS } \\
\hline & 01 & or & $a z$ & 04 & & 01 & 02 & 03 & 04 \\
\hline 004 & - & - & - & 33,03 & 028 & - & 40,31 & - & 27,99 \\
\hline 006. & - & - & 13,62 & - & $0 \pi \theta$ & - & - & 102,37 & - \\
\hline 018 & 39,51 & - & - & - & 047 & - & - & - & 46,96 \\
\hline 035 & 25,41 & 32,99 & 46,91 & - & 050 & 40,01 & - & - & - \\
\hline $0 \sin$ & - & - & 53,61 & - & $\cos \theta$ & 39,73 & - & 16,95 & - \\
\hline 047 & - & - & 57,77 & - & 087 & - & 60,93 & - & - \\
\hline 053 & - & 15,09 & - & - & 097 & - & 64,20 & - & - \\
\hline 059 & 42,88 & - & - & - & 108 & 23,61 & - & - & - \\
\hline 084 & 51,37 & 135,31 & - & 61,02 & 110 & 37,26 & 29,16 & - & 42,00 \\
\hline 087 & - & - & 13,02 & $33=93$ & 118 & 32,73 & $F_{5} E_{1}, 51$ & - & 34,59 \\
\hline 117 & - & - & 11,75 & - & 121 & - & 41,43 & - & - \\
\hline 122 & 27,98 & - & - & - & 179 & - & - & 52,81 & - \\
\hline 137 & 24,51 & - & - & - & 195 & - & - & 34,39 & - \\
\hline 140 & - & - & 13,94 & - & 189 & - & - & - & 30,58 \\
\hline 166 & $-\cdot$ & 15,09 & - & - & 219 & - & - & 16.95 & 47,12 \\
\hline 194 & - & - & 22,81 & 40,07 & 241 & - & 30,46 & - & - \\
\hline
\end{tabular}

As especies mais importantes ecolagicamente do tratamento I foram Guateria poeppetana Mart (envira preta) e Dendro- bangia boliviana Fusby (carerana), assin como Solanum rugosum Dunal (cajuagara), Cupania scrobiculata L.C Rich (espetorana), Sapium marmieri Huber (burra leiteira) e Zanthoxyllum rhoifolia Lam (tamanqueira) foram as especies de maior importancia ecológica no tratamento 4. 
A Tabela 14 mostra; a nivel de blocos e tratamentos, as especies estabelecidas (SP1) com as maiores IVI no ano de 1989.

Tabela 14 - Indice do Valor de Importancia (IVT) des espétics estahelecidas (SP1), selecionados no segundo inventario continuo (1988).

\begin{tabular}{|c|c|c|c|c|c|c|c|c|c|}
\hline \multirow{3}{*}{$\begin{array}{r}\text { cod } \\
\text { da } \\
\text { spp }\end{array}$} & \multicolumn{4}{|c|}{ TFATAMENTO 1} & \multicolumn{5}{|c|}{ TRATAHENTO 2} \\
\hline & & ELOC & 205 & & \multirow{2}{*}{$\begin{array}{r}\text { Ead } \\
\text { da } \\
\text { spp }\end{array}$} & \multicolumn{4}{|c|}{ DLOCOS } \\
\hline & 01 & $a z$ & 05 & 04 & & $a t$ & 02 & 03 & 04 \\
\hline 116 & 15,78 & $\cdot-$ & - & - & 038 & 15,45 & 23,79 & 65,54 & 9,12 \\
\hline $017=$ & 10,62 & 19,79 & 25,13 & - & 084 & 2,62 & 3,52 & 23,31 & 1.97 \\
\hline $018=$ & 22,57 & 16,50 & 13,19 & 11,97 & 065 & 1,17 & 4,06 & 1,43 & - \\
\hline 025 & $b .29$ & 22,13 & 33.67 & 43,64 & $0 b s$ & - & 2,63 & - & 2,00 \\
\hline 028 & 5,69 & $\theta_{7} 74$ & - & 17,53 & $0 \leqslant 8$ & $i, 50$ & - & 1,34 & - \\
\hline $035=$ & 27,24 & $14: 54$ & 32,42 & 18,36 & 079 & - & 4.90 & 1,54 & 5,63 \\
\hline 047 & 21,92 & 15,98 & 23,11 & 10,45 & 084 & - & 1,70 & 9,26 &, \pm 79 \\
\hline 049 & 9,22 & - & - & 6,22 & 108 & 19.47 & 5,42 & - & 7,59 \\
\hline 053 & - & - & 9,71 & 12,74 & 110 & 145,54 & 135,25 & 19,67 & $227 \times 53$ \\
\hline 164 & - & - & 25,06 & - & 116 & - & 5,35 & - & 1,90 \\
\hline 069 & 13,36 & - & - & 15,89 & 118 & 16,70 & 13,25 & 1,36 & 13,18 \\
\hline 109 & 8,21 & 7.49 & - & - & 121 & 16.96 & 6,70 & - & 1.77 \\
\hline 113 & 5.72 & 12,77 & $9,6 \theta$ & - & 131 & 6,91 & 4,22 & - & - \\
\hline 122 & 15,33 & - & - & - & 135 & 1,48 & 2,10 & \pm .40 & - \\
\hline 130 & 6,90 & - & - & 6,57 & 145 & 20,78 & 24,64 & 10,97 & 4,09 \\
\hline 147 & - & 8,83 & - & 11,77 & 179 & 3.93 & 1,97 & $50_{7} 08$ & 7,75 \\
\hline 154 & - & 6,35 & - & 9,94 & 189 & 2,43 & 5,56 & 1,37 & 3,61 \\
\hline 166 & 9,49 & 9,25 & 6.13 & - & 205 & 10,20 & 5.76 & 96,51 & 1,90 \\
\hline 195 & - & - & 25.92 & - & 218 & - & 4,14 & - & 3.98 \\
\hline 226 & - & 5,76 & - & - & 224 & 1,31 & - & 3,36 & - \\
\hline
\end{tabular}


Tabela 14 - Continuaçăo.

\begin{tabular}{|c|c|c|c|c|c|c|c|c|c|}
\hline \multicolumn{5}{|c|}{ TRATANENTO 3} & \multicolumn{5}{|c|}{ TFATAMENTO 4} \\
\hline \multirow{2}{*}{$\begin{array}{r}c o d \\
d a \\
\operatorname{spp}\end{array}$} & \multicolumn{4}{|c|}{ ELOCOS } & \multirow{2}{*}{$\begin{array}{r}\text { cad } \\
\text { da } \\
\text { spp }\end{array}$} & \multicolumn{4}{|c|}{ ELOCOS } \\
\hline & ol & 02 & 03 & 04 & & 01 & 02. & 03 & 04 \\
\hline 016 & 12,14 & $a_{3} 11$ & - & - & 017 & 7,13 & - & 12,11 & - \\
\hline 018 & 25,53 & 21,05 & 5,29 & 13.55 & 018 & - & - & 8,00 & 11,79 \\
\hline 025 & - & $7,4.4$ & 56,67 & 41,49 & 035 & - & 24,83 & 14,52 & 14,38 \\
\hline 028 & 10,00 & 5,67 & 0,17 & - & 038 & - & 18,77 & 25,37 & 28,03 \\
\hline 035 & 19,00 & 33,30 & 31,60 & 23,54 & 064 & 62,62 & - & 23,41 & - \\
\hline 047 & 17,19 & 20,27 & 11,96 & 6,35 & 069 & 6,19 & - & 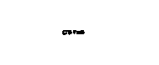 & $\pm 6,03$ \\
\hline 053 & - & $\theta, 34$ & - & 7,13 & 108 & 15,75 & - & - & - \\
\hline 064 & 9,24 & - & 18,67 & - & 10 & 77,31 & 4395 & - & 61,21 \\
\hline 087 & 11,33 & - & - & - & 119 & 17,99 & 39,25 & - & 44,40 \\
\hline 099 & - & 18,37 & - & - & 121 & 21,43 & $1.9,96$ & - & 12,34 \\
\hline 113 & 11,94 & 12,70 & 5.91 & - & 131 & $9: 48$ & 6,35 & - & - \\
\hline 118 & - & - & - & $1 ; x 87$ & 145 & 9.25 & 47,71 & - & 13,01 \\
\hline 130 & - & - & - & 10,65 & 147 & 5,75 & 5,59 & - & - \\
\hline 154 & 10,45 & 17,41 & 5,78 & 13,89 & 170 & - & - & 13,32 & - \\
\hline 166 & - & - & - & 14,49 & 179 & - & 9,31 & - & 8,23 \\
\hline 179 & - & - & 11,99 & - & 179 & - & - & 45,45 & - \\
\hline 185 & - & - & 14,95 & - & 185 & - & - & 43,17 & - \\
\hline 189 & - & - & - & 7,29 & 189 & - & - & 5,76 & 15,46 \\
\hline 199 & - & 7,58 & - & - & 205 & - & 12,11 & 5,89 & - \\
\hline 205 & - & - & - & 6,35 & 218 & - & 7,09 & - & 9,22 \\
\hline
\end{tabular}

As esperies ecologicamente mais importantes nas parcelas submetidas ao tratanento 1 (testemunha) foran as mesmas observadas no inventário de 1986 (Tabala 12), sendo que as especies Guarea Euindonia (La) sleum (andirobarana), Sagotia racemosa Bails (arataciús Frotium 
decandrum Swart (breu vermelho) e Dendrobangia boliviana Rusby (caferana), ocorreram en todos os blocos, entretanto em 1986, somente as andirobaranas, caferanas $e$ breus vermelhos ocor- reram, simultaneamente, nos quatro blocos.

No tratamento 2 (corte raso) destacaram-se as eEpócies: Cecropia distachia willd (imbauba da mata), Jacaratia spinosa A.DC (mamui) E Ingaedulis Mart (inga cipo) nos blocos 1, 2,3 4, respectivamente. Todavia, as especies que caracterizaram a composicăo floristica das parcelas experimentais foram as imbaubas, que obtiveram as maiores IVI nos blocos 1,2 e 4 .

As especies Sapium marmieri Huber lburra 1Eiteira), Eertholteito excelsa HEK (caEtanheira), Cecropia distachia Wild (imbaba da mata), Inga oducis mart (inga cipo) J Jacaratia spinosa A.DC (mamul, Schizolobium amazonicum (Huber) Durke (parica), Apeiba echinata Grati (pente de macaco) e Pithecelabium jupumba (hisid) Urb (saboeiro), ocorrefam simultaneanente Em todos os blacos.

Semelhante ao ano de $198 b_{\text {, as }}$ espécies mais importantes das parcelas submetidas ao corte raso foram aquelas com caracteristicas adaptativas favoraveis ds condiços ecoló gicas geredas pelo tratanento aplicado. Foi observado ainda, o surgimento de espócies silviculturalmente importantes, como os paricas tschizolobium amazonicum (Huber) Ducke), porem, as especies pioneiras constituen-se na maioria das especies presentes nas parcelas. 
As castaheiras que aparecem nas parcelas experimentais, em todos os blocos, nă să oriundas da regeneraçăo natural e 5 im, arvores que foram protegidas de corter determinação legal.

No tratamento 3 (corte seletivo), as especies Guarea guidonid (L.) Sleum (andirobarana), Protium decandrum Swart (breu vermelho) E Sagotia racemosa Bail1 (arataçú), foram as especies com os maiores lut semelhante ao observado no ano de 1786.

Ja no tratamento 4 (corte seletivo): destacaram-se ecologicamente, as seguintes especies: Cecropia distachia lilld (blacos 1 a 4). Jacaratia spinosaA.DC (b10cos 2) Eshizolobiun anazonicum (Huber) Ducke (bioco 3).

A Tabela 15 mostra as especies do estágia de Varas (SP2) com os maiores IVI.

No tratamento $1_{3}$ as especies mais representativas forama Tabernaemontana angulata fiat ex. Muell lgräo de cachorro), Protium decandrum swart (breu vermelno), Rinorea racemosa (bart) kuntz (canela de jacamim) e Franchetetla ambifolia Radli (abilu vermelho), respectivamente nos blocos 1, 2, 3 e 4. Comparativanente ab ano de 1986, apenas a especie grăo de cachorro manteve-se entre as mais importan- tes a cerca de $70 \%$ das especies com os maiores IVI, observadas em 1986, apareceram entre as mais importantes no inventário de 1998. 
89.

Tabela 15 - Indice do Valor de Inportancia (IVI) das especies no Estagio de vares (SPZ), Selecionados no segundo inventario continuo (1989).

\begin{tabular}{|c|c|c|c|c|c|c|c|c|c|}
\hline \multicolumn{5}{|c|}{ TRATAMENTO 1} & \multicolumn{5}{|c|}{ TFATAMENTD 2} \\
\hline \multirow{2}{*}{$\begin{array}{r}c o d \\
d a \\
s p p\end{array}$} & \multicolumn{4}{|c|}{ ELDCOS } & \multirow{2}{*}{$\begin{array}{r}\text { cod } \\
d a \\
s p p\end{array}$} & \multicolumn{4}{|c|}{ ELOCOS } \\
\hline & 01 & 02 & 03 & 04 & & $\infty 1$ & 02 & 03 & 04 \\
\hline 004 & 45,69 & 23,73 & 31,03 & 35,79 & 015 & - & 9,31 & - & $-\cdots$ \\
\hline 018 & - & 38,64 & - & - & $03 \theta$ & - & 20,58 & 147,93 & 10,77 \\
\hline 022 & 32,50 & - & - & - & 046 & - & 9,33 & - & - \\
\hline 025 & 43,35 & 23,73 & 35,62 & $27,1.9$ & 058 & 25,73 & 74,67 & - & $40_{4} 50$ \\
\hline 035 & - & 61,95 & - & - & 069 & 一 & - & 21,24 & - \\
\hline 047 & 37,86 & $14,5=4$ & 32,42 & 18,36 & 079 & - & 4,90 & 1,54 & 5,63 \\
\hline 053 & - & - & 75,01 & - & 110 & 109,25 & 78,95 & 16,59 & 136,68 \\
\hline 058 & - & 18,15 & - & 35,71 & 116 & - & - & 23,79 & 12,37 \\
\hline 063 & - & 57,36 & - & 27,19 & 117 & - & 8.95 & - & 12,91 \\
\hline 064 & - & - & 14,60 & - & 118 & 70,77 & - & - & 10,24 \\
\hline 084 & 29,00 & 17,66 & - & - & 135 & - & - & - & 10,97 \\
\hline 305 & 75.64 & - & - & - & 154 & - & 8,63 & - & 15,13 \\
\hline 130 & - & - & 20,56 & 23,62 & 179 & 42,61 & - & 15,28 & - \\
\hline 139 & 35,92 & - & - & - & 179 & - & 10,15 & - & 10,41 \\
\hline 143 & - & - & 30,49 & - & 189 & 25,73 & - & - & 19,73 \\
\hline 166 & - & - & - & 35,72 & 235 & - & 9,33 & - & - \\
\hline
\end{tabular}


Tabela 15 - Continuação.

\begin{tabular}{|c|c|c|c|c|c|c|c|c|c|}
\hline \multicolumn{5}{|c|}{ TFATAMENTO 3} & \multicolumn{5}{|c|}{ TRATAMENTO 4} \\
\hline \multirow{2}{*}{$\begin{array}{l}\text { cod } \\
d a \\
\text { spp }\end{array}$} & \multicolumn{4}{|c|}{ ELOCOS } & \multirow{2}{*}{$\begin{array}{r}\text { rod } \\
d a \\
\text { spp }\end{array}$} & \multicolumn{4}{|c|}{ BLOCOS } \\
\hline & 01 & 02 & 03 & 04 & & $0 \pm$ & 02 & 03 & 04 \\
\hline 012 & - & - & - & 41,86 & 014 & 15,62 & - & - & - \\
\hline 014 & 21,52 & 15,28 & - & - & 016 & - & - & $13 \times 27$ & - \\
\hline 016 & $22,6 \theta$ & 39,89 & - & - & 028 & - & 32,58 & - & - \\
\hline otg & 22,68 & - & 11,71 & - & $0 \pi \theta$ & - & - & 100,92 & 30,21 \\
\hline 025 & - & 34,78 & 29,20 & 28,00 & 053 & - & - & - & 17.44 \\
\hline 035 & 22,68 & $17: 99$ & 39,65 & 26.44 & 058 & 49,81 & 45,98 & 22,79 & 86,22 \\
\hline 058 & - & - & 95,99 & - & 070 & $17: 45$ & 60,16 & 11,79 & - \\
\hline 047 & - & - & 22,51 & - & 094 & 14,63 & 24,35 & - & - \\
\hline 053 & - & 15,28 & 10,64 & - & 110 & 18,51 & - & - & - \\
\hline 058 & 42,06 & - & - & - & 117 & 15,21 & - & 21,09 & - \\
\hline 063 & - & $12 \mathrm{a}, 42$ & $10_{9} 64$ & 91,36 & 119 & $30_{9} 05$ & - & - & 30,21 \\
\hline 064 & 32,52 & - & - & - & 121 & - & 50,67 & - & - \\
\hline 116 & - & - & - & 21,35 & 176 & 45,97 & - & - & - \\
\hline 137 & 22,69 & - & 11.71 & - & 185 & - & - & 58,42 & - \\
\hline 130 & 33,04 & - & - & $20, \$ 7$ & 218 & - & - & 13,97 & 126,43 \\
\hline 228 & 49,62 & - & - & - & 241 & - & 86,25 & - & - \\
\hline
\end{tabular}

Wo corte raso, (tratamento 2) as especies que se destacaram foran as imbedbas (Cecropia distachic Wilid) e burra leiteira (Scupium narmieri Huber). Observa-se nestas parce- las, em releçăo ao ano de 1996, alteraços substanciais na composiçă floristica, sendo que das 16 esperies mais importantes registradas em 1966 , apenas $\mathrm{B}$ constam da lista de esperies mais importantes no ano de 1789. 
As espocies Ormosia paraensis Ducte (tento folha fina), Duguetia cadawerica Huber (envira cana) e Sapiun marmieri Huber (burra leiteira), obtiveram os maiores IVI nas parcelas com o tratamento 3. For sua vez, apenas $50 \%$ das especies selecionadas em 1786 mantiveram-se entre as especies mais importantes Em 1988, e dentre Elas, nenhuma - repetiu o desempenho apresentado em 1989, demonstrando a ocorroncia de mudanças intensas na composiça fororstica destas parcelas.

No tratamento 4 , as especies mais representativas da composiça floristica das parcelas foram siparumo guianensis Albl (capitiús. Siconea spp (urucurana) sapizm marmieni Huber (burra lejteira) Eanthoxyl tum rhotfolta Lam (tamanqueifa), respectivamente nos blocos 1,2, 3 , 4 . Dentre as especies acima mentionadas, apenas os capitius ocorreram en todas os blocos. Da mesma forma que nos demais tratamentas, cerca de $50 \%$ das espbcies mais importantes en $176 b_{\text {na }}$ apareceran entre as mais importantes en 1968.

\section{3. 2. Regeneracio natural}

A regeneraçăo nathral foi analisada quantitativamente e qualitativamente atraves dos dados ctidas nas inventarios realizados en 1986 e 1938, d nivel de blocos e tratamentos, con e sem transformacăo. A expressa matematica usada para transformar os dados originais raia in $x=N_{3}$ onde $x$ o valor observado e $N$ a resultado da trensformaça. o uso da expreseão reduzil o coeficiente de variaçăo do 
ensaio (CV) de $29,1 \%$ para $2,9 \%$ em 1986 e de $31,1 \%$ para $3,2 \%$ em 1989, porem a ANOVA não detectou diferences estatisticas significativas entre as medias dos tratamentos testados. 0 CV entre as variancias das parcelas mencuradas e o número de parcelas necessarias para homogeneizar a distribuicão dos dados \& apresentado na Tabela 16.

Tabela 1s - Coeficiente de Variaça (CV\%) e numero stimo (n) de parcelas para a varisvel REG_HA.

\begin{tabular}{|c|c|c|c|c|c|c|c|c|}
\hline \multirow{2}{*}{ ANO } & \multicolumn{2}{|c|}{ TFAT 1} & \multicolumn{2}{|c|}{ TRAT 2} & \multicolumn{2}{|c|}{ TRAT 3} & \multicolumn{2}{|c|}{ TRAT 9} \\
\hline & $\mathrm{CV}$ & $W$ & $\mathrm{CV}$ & $N$ & $C V$ & N & CV & $\mathrm{W}$ \\
\hline 1986 & 33.9 & 50 & 41,6 & 76 & 35,9 & 56 & $53_{8} 1$ & 323 \\
\hline 1988 & 49,2 & 106 & $57 \times 4$ & 144 & $41 ; 8$ & 76 & $5 b_{7} 7$ & 141 \\
\hline
\end{tabular}

A Tabela 17 apresenta. o numero de individuos. por hectare, chservados no inventirio de 190 .

Tabela 17, - Numero de individuos (W/ha), no estagio de regeneraça natural (SF3), amostrados no primeiro inventario contíno - 198 á.

\begin{tabular}{ccccc}
\hline & \multicolumn{5}{c}{ TRATAWENTO } \\
\cline { 2 - 5 } & 1 & 2 & 3 & 4 \\
\hline 1 & 19.560 & 13.760 & 16.320 & 29.900 \\
2 & 16.000 & 17.280 & 24.000 & 12.900 \\
3 & 19.560 & 17.280 & 29.160 & 27.200 \\
4 & 19.940 & 25.280 & 19.840 & 15.040 \\
\hline
\end{tabular}

As analises da variancia efetuda para as Variaveis numero de individuos por hectare (REG HA) $P$ media 
de individuos por parcelas (MFEG), com dados observados a transformados (LREG_HA) mostraram que näo houveran diferencas significativas entre bloros e tratamentos testados a nIvel de significancia o \% .

Os resultados da Analise de Variancia são apresentados na Tabela 19, de acordo con as variaveis testadas.

Tabela 19 - Analise de variancia do número de individuos no estagio de regeneraçäo natural (SP3) em 1996.

TFATAMENTO

VARIAVEIS

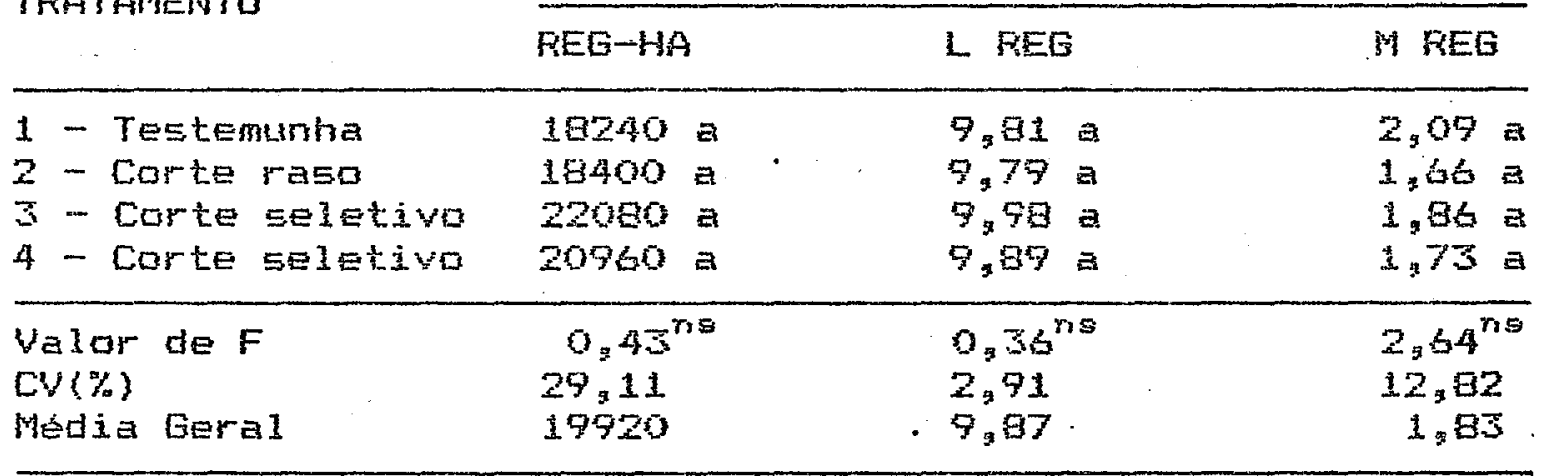

ns: diferenca náa sigrificativa

Nota: médias seguidas pela mesma letra nés diferem eritre si estatsticamorite pelo teste de Tricti.

A composiçăo tlorítica da regereração natural observada en 190 ab abange 94 espócies botanicas distribuldas entre 5 gi gêneros e 39 familias.

As famlias mais abundantas foram: Leg. Mimosacede, Moracede e Leg. Cesalpinacede, que juntas somaran cerca de $2 \%$ do tatal de Especies. No Apendice $a$ estão listadas as espécies identiticadas e o numerg de individuas por parcelas experimental.

As especies mais abundantes no tratamento 1 
foram: Guatteria poeppgiana Matt (envira pretal, Rinorea racemosa (Mart) Kunta (canela de jacamim), Protiun decandrum Swartz (breu vermelta) e Dendrobangia boliviana Rusby (caferana), as quais somaram $60,3 \%$ do total de individuos, sendo que estas especies ocorreram en todos os blocos do ensaio.

As especies que predominaram no tratamento 2 foram: Protium Epp (amescla branca), Cecropia distachia Willd (imbauba vermelta) 'Inge heterophylla billd (inga pretinhol, as quais acorreran tom todos os blokos e representaram cerca de $22 \%$ do total de individuos.

No tratamento 3 a a especies Protium $5 p$ (ames- cla branca) y Protiun decandrum Swat (breu vernelbo), Rino- rea racenosa (Mart) Kuntz (canela de jacamin): Guatteria poppiana Mart (envire preta) E Anoragorea dolichocarpa Ducke (pimenta. de jacú), foram as que apresentaram maiores valores de densidade, sendo que juntas representam cerca de 5o\% do total de individuos.

No tratamento 4, as Especies maja abundantes foram: Protium spp (amescla bmanca), bendrobangia boliviana Fusby (caferana), Rinored rocemoso (mart) Kuntz (canela de jacamim), siparuma guiarensis Aubl (cagitio), Ouatieria poeppiana Mart (envira preta) e inga edul is Mart (inga cipo), as quais somaram carca de $58 \%$ do total dos individuos. o número de individuos no estagio de regeneraço, abegrvado en 1989, por bloco etratamento, fopresentado re Tabela 19. 
Tabela 19. - Núnero de individuos (W/ha), no estagio de regenerarăo natural (SFS), observado no segundo inventario continuo (1989).

\begin{tabular}{ccccc}
\hline & \multicolumn{4}{c}{ TRATANENTO } \\
\cline { 2 - 5 } BLOCO & 1 & 2 & 3 & 4 \\
\hline 1 & 31.360 & 11.840 & 17.600 & 32.640 \\
2 & 15.040 & 15.200 & 24.000 & 14.720 \\
3 & 22.400 & 16.960 & 25.920 & 25.280 \\
4 & 19.520 & 17.280 & 21.440 & 13.120 \\
\hline
\end{tabular}

Semelhante aos resultados obtidos en 1986, a andise de variancia para as variaveis testadas nă detectou nenhuma diferença Eignificativa entre blocos e tratanentos Lestados, conforme mostra a Tabela 20.

A modia geral de individuas por hectare em 1989 fai superior a media chservada en 1996, porem, nos tratamentos 2 e 4 as medias observadas em 1989 foram inforiores as medias de 1796 .

Tabela 20, - Ansise de variancia do numero de individucs no estagio de regeneraça natural (SPz) en $190 \mathrm{~d}$.

TRATAMENTO

VARIAVETS

\begin{tabular}{|c|c|c|c|}
\hline 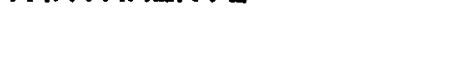 & REG-HA & 1 FEG & M FEG \\
\hline 1 - Testemuntra & 22000 & $9.97 \mathrm{a}$ & $2,04 \approx$ \\
\hline 2 - Corte raso & 16320 a & $7,67 a$ & $1,47=$ \\
\hline $3-$ Corte seletivo & 22240 a & $10,00=$ & $1,71 \mathrm{~A}$ \\
\hline 4 - Corte seletivo & $22060=$ & $9,90 a$ & $1,72 \mathrm{a}$ \\
\hline $\begin{array}{l}\text { Valor de F } \\
\text { CV(\%) } \\
\text { Hedia Geral }\end{array}$ & $\begin{array}{l}0,70^{n 5} \\
31,11 \\
20520\end{array}$ & $\begin{array}{l}0,92^{r 9} \\
3.16 \\
9,97\end{array}$ & $\begin{array}{c}3,99^{n 9} \\
15,50 \\
1,73\end{array}$ \\
\hline
\end{tabular}

ne: difereriga ná sigrificaliva

Nola: médias seguidas pela mesma letra ná diferem entre si estatsticanerite fello teste de TUKaY. 
A composiçăo florl stica da regenerarăo b composta por 34 familias botanicas, 71 generos e 91 especies, conforme mostra a Tabela 21 . Observa-se que en $1986_{y}$ houve um aumento da diversidade de especies a nivel de gereras, poreng ocorreu uma dininuigão do número de fani- lias botanicas.

AS familias mais aburdantes nesta ocasiă de avaliaçăforam : Leg. Mimosaceae, Moracede, Leg. Caesalpinaceae, Euphorbiaceae e sapotacede, que itutas somaram $57 \%$ do total das espocies e cerca de $26 \%$ da tola 1 de individuos presentes no ensaio. Mo Apendice 7 estao lietades as espocies que acorreran no inventario de liag o o número de individuos por hectare por bloco e tratamento.

As esperies mais abundantes no tratamento 1 faram: Protium spp (anescla branca), Sagotia rabanosa gaili (aratasiu), Dendrobangia boliviana Fusby (caterana) , Rinorea racemosa (Mart) kuntz (Eanela de jacamin) D Dureuetia cadaverica Huber (envira cana), que juntas representam cerca de $47 \%$ do total de individuos, $e$ se acham presentes en todos as blacos.

No tratamento 2 as especies que predominaram Toiram; Protium spo (amescla branca); Rinorea racemosa (Mert) Kuntz (canela de jacamim), Dendrobangia boliviana Fusty (caferana), Duguetia cadaverica Huber (envira cana) Inga nobilis Willd (inga chato), Eschwoilera coriccea hartius ex-Berg (matamata branco) e siporuma Buianensis Aubl (capitiú) com aproximadamente $42 \%$ do total de individuos. 
96.

sendo que apenas as especies amescla branca e canela de jacamim ocorreram en todos os blocos.

Tabela 21 - Numero de generos e especies por tamilias botanicas da regeneração natural en 1998.

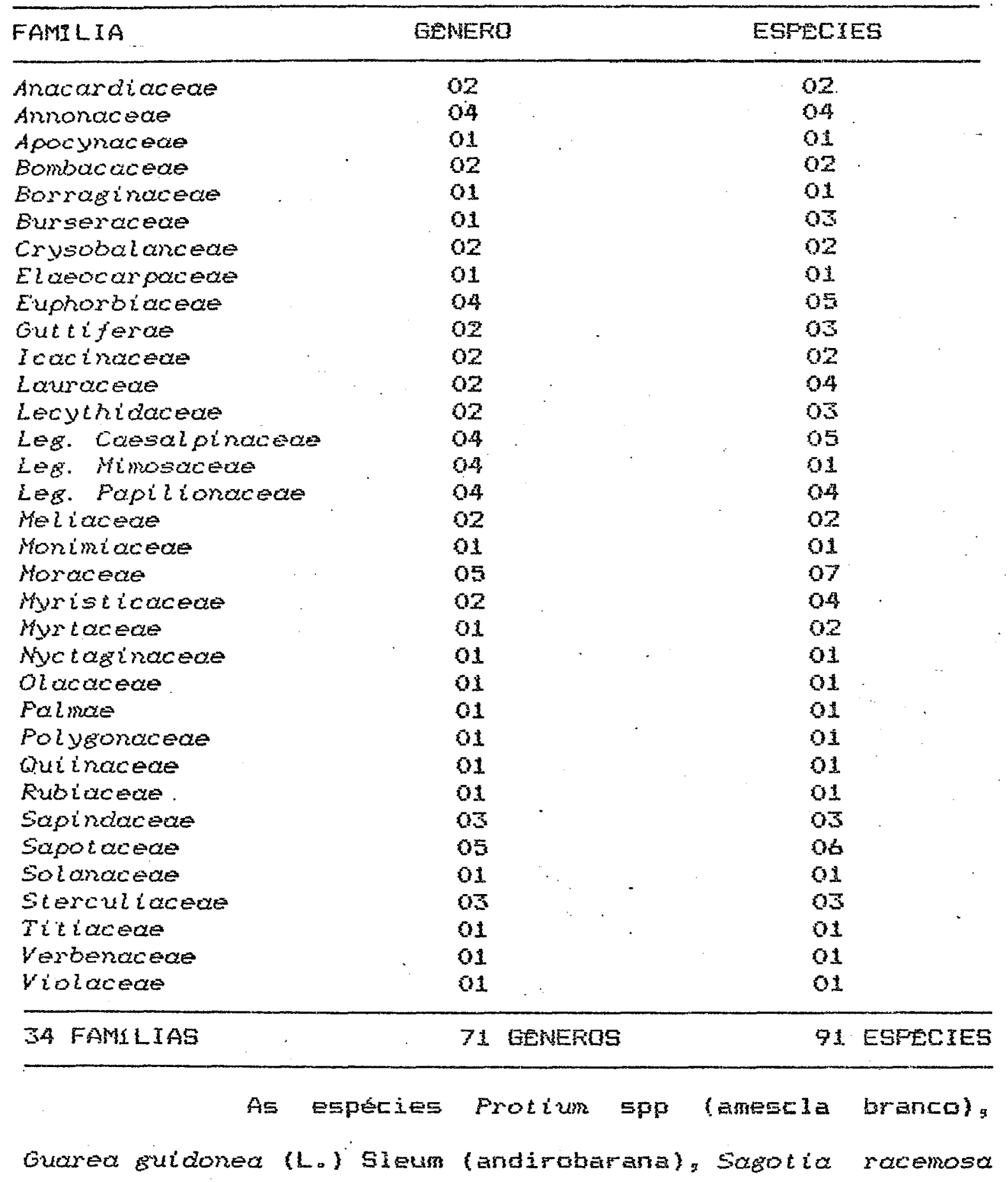


Raill (arataciú), Dendrobangia boliviana Rusty (caferana), Rinorea racemosa (Mart) Kuntz (canela de jacamim) Dusuetia cadaverica Huber (envira cana) e Cenostigna tocantinum Ducke (pau preto), foram as mais abundantes no tratamento 3 , com cerca de 60\% do total de espécies. Neste tratamento. as espécies amescla branca, andirobaranag cafera- na e envira Eana ocorreram en todos as blocos.

No bratamento 4 as espacies mais abundantes foram: Frocium spp (amescla branca), Sagotia racenosa Bail1 (arataciú, Dendrobangia boliviand Fusby (caterana) g Rinorea racemosa (Mart) kuntz (envipa cana), siparuma guianensis Aubl (capitid), Frotium decundrum Swart (breu verselho), Cupania scrobiculata L.C.Rich (espetarana), Inga edulis Willd (inga chato) Ingo edulis Mart (inga cipos e Cenostigna tocantinum Ducke (pau preto), que juntas repreentaram cerca de $70 \%$ do total de individuos. Destas especies. apenas amescla branca e ingá chato ocorreram en todos os blocos.

\section{4. Inventario Florestal Inicial}

Com as dados coletados no inventario inicial foram cotidas estimativas de a srea basal por hectare (Aba_ha), diametro medio da parcala (MDAF) $a$ o númepo de individuos por hectare (N_Arv_ha), em todas as unidades Experimentais.

Inicialmente foi determinado o número de blocos (n) necessarios para a caracterizago do enseio, consi- 
derando as sequintes variaveis: Aba_ha, M_Arv_ha MDA, e os valores (n) ottidos foram: 23,4 e 2 , respectivamente.

A Tabela 22 mostra a distribuiça por bloco. tratamento e classe diamstrica da area basal fonal das parcelas antes das interven- çEs Silviculturais. Na Figura 4 acha-se a distribuiço da area basal por tratamento e classe diametrica.

Tabela 22 - Distribuiçăo da area basal $\left(m^{2} /\right.$ ha, por bloco. tratamento e classe diambtica. Inventario inicial - 1964.

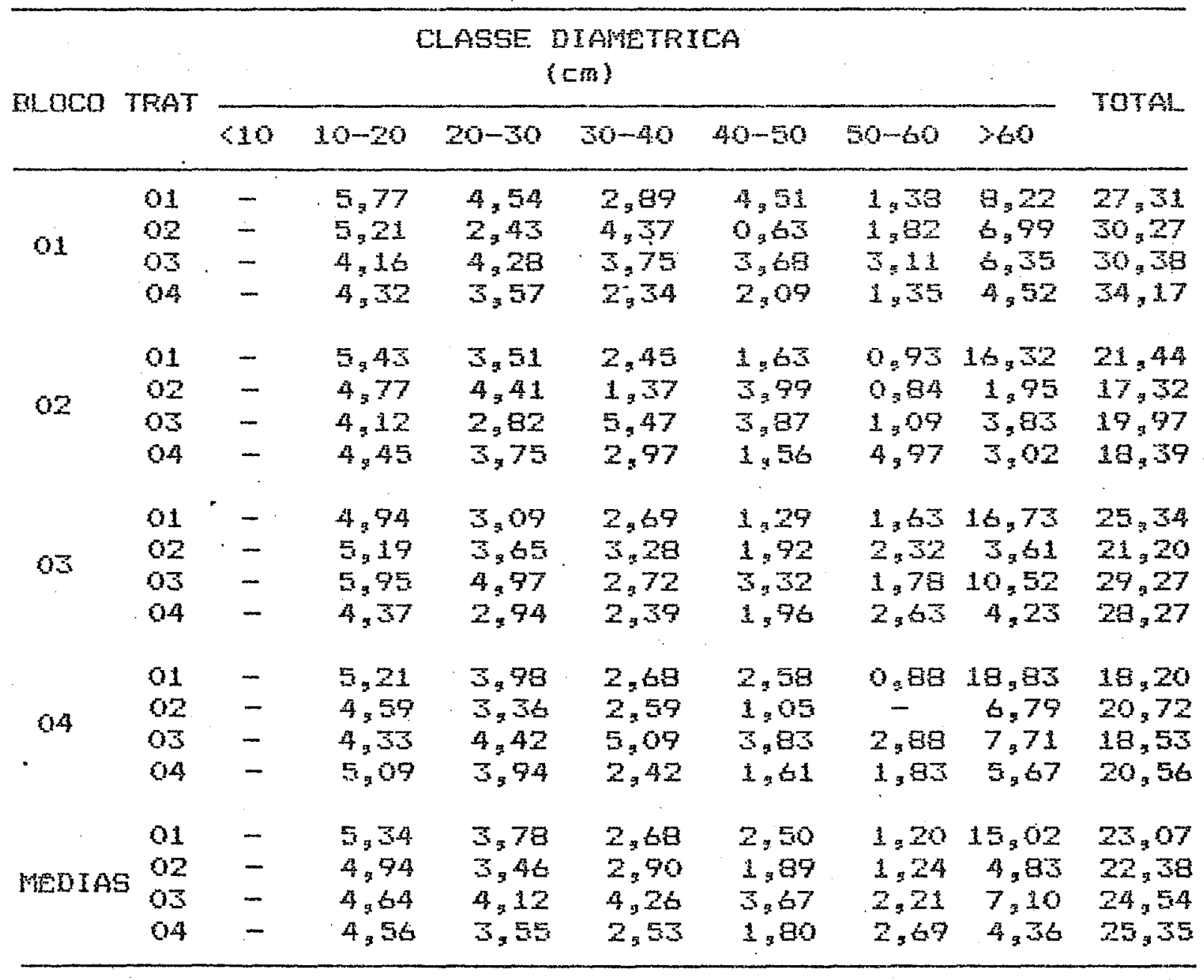




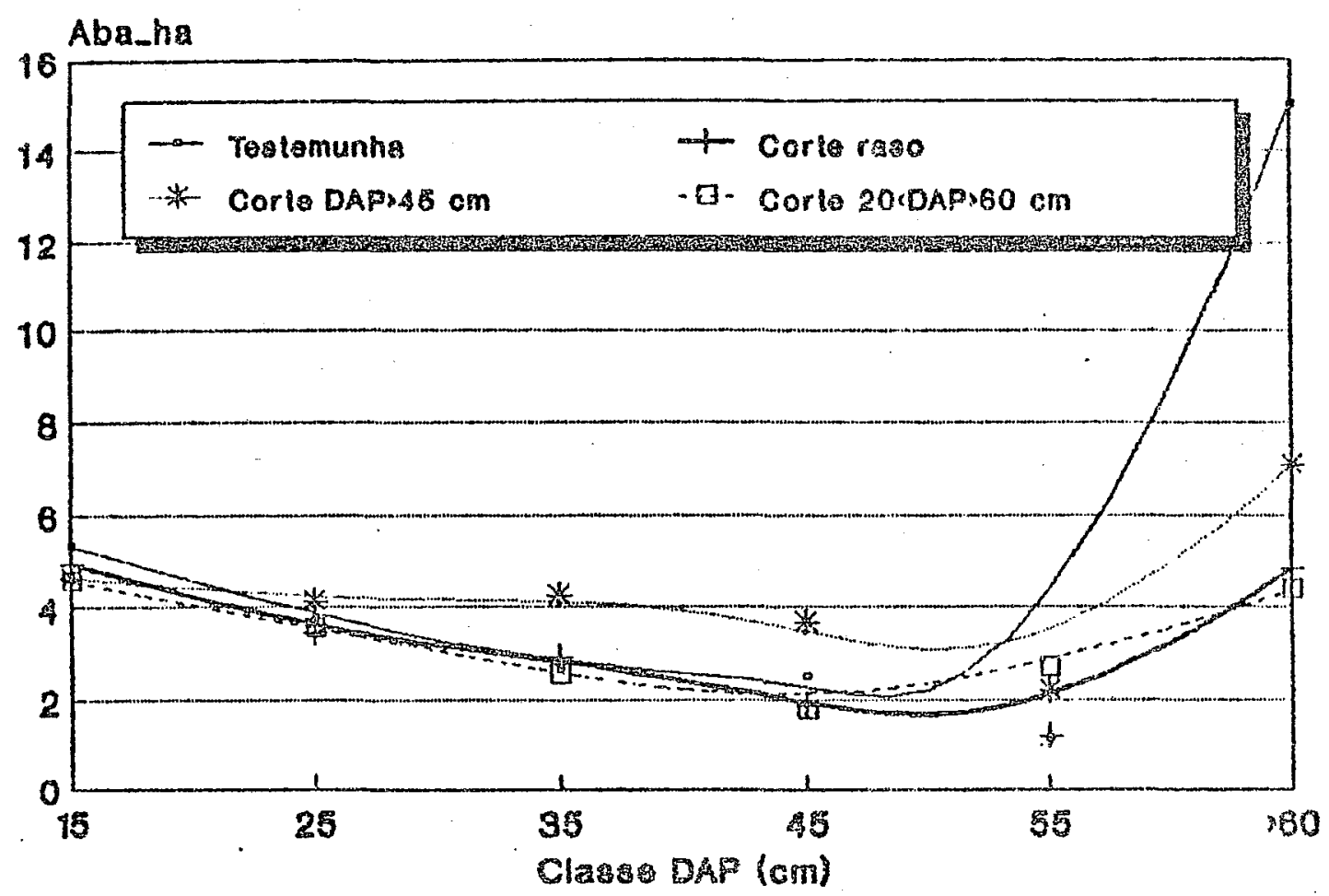

Figura 4 - Distimbiça da srea basal (mª) por thatemento Classe de dismetro observeda no istrentario inicial (1998)"

A andise da variancia revelou dicerengas significativas entre blacos somente para as variaveis area basal e dismetro medio. A nivel de tratamentos nă foi encontrada diferenças significatiwas entre as stedias das Variaveis estudadas (Tabela 23 ).

Q teste de Tulay efetuado para a variável area basal (Aba_ha) mostrou que as nedias doservadas nos blocos 1 e 3 săo superiores as medias dos blocos 2 f 4 por outro 1ado, as medias do tratamento nă diferiram entre si. 
Tabela 23 - Analise da Varidncia doe dados coletados no invertario inicial (1984).

\begin{tabular}{|c|c|c|c|c|c|c|}
\hline \multirow{3}{*}{ TFATAMENTO } & \multicolumn{6}{|c|}{ VARTAVEIS } \\
\hline & \multicolumn{2}{|c|}{ Aba-ha } & \multicolumn{2}{|c|}{ MDAF } & \multicolumn{2}{|c|}{ H_Ary_ha } \\
\hline & ELICO & TFAT & ELOCO & TRAT & - EllaCa & TFAT \\
\hline $\begin{array}{l}\text { 1-Testemunha } \\
\text { 2-Corte raso } \\
\text { 3-C.seletivo } \\
\text { 4-C.seletivo }\end{array}$ & $\begin{array}{l}30521 a \\
19280 b \\
26019 a \\
19502 b\end{array}$ & $\begin{array}{l}23074 a \\
22375 a \\
24536 a \\
25345 a\end{array}$ & $\begin{array}{l}20901 \mathrm{a} \\
17007 \mathrm{~b} \\
21791 \mathrm{a} \\
20223 \mathrm{a}\end{array}$ & $\begin{array}{l}20740 a \\
20326 a \\
20496 a \\
20545 a\end{array}$ & $\begin{array}{l}4990 a \\
4650 a \\
4770 a \\
4265 a\end{array}$ & $\begin{array}{l}4725 a \\
4495 a \\
4715 a \\
4675 a\end{array}$ \\
\hline $\begin{array}{l}\text { Valor de } F \\
\text { CV(\%) } \\
\text { Media Geral }\end{array}$ & $\begin{array}{r}19,07^{* * *} \\
10 \\
23\end{array}$ & $\begin{array}{l}1,17^{n s} \\
47 \\
83\end{array}$ & $\begin{array}{r}9,93^{*} \\
5 y \\
20\end{array}$ & $\begin{array}{l}0_{3} 19^{n s} \\
5\end{array}$ & $\begin{array}{r}1,56^{n 5} \\
10 \\
46\end{array}$ & $3^{4}: 21^{n s}$ \\
\hline
\end{tabular}

ns: diferencas nato significativas

*: diferencas sigrificativas do nivel de 580 yolo taste de

* diferericas gigrificalivas ao nivel de 1 to pelo testo do Nota: midias sequidas pela mesma leira ribo diferem erire si estatlsticamerte pelo teste de TrkeY.

Fara a variavel diametro medio (moff); o teste de Tukey identificou superioridade das médias des blocos $\mathbb{Z}_{3}$ 1 e 4 en. relaçă a media do bloco 2 enquanto que; entre medias de tratamentos năo houve diferenca signi- ficativa.

A distribuigano do rumero de individuas (N_Arvha) por blacogtratamento e classe diametrica o apresentada na Tabela 24.

A distribuiçăo diametrica cbservada nat parcelas experimentais (tratamenta) e que carrosponde a estrutura diametrica inicial da floresta considerada no ensaid fFigura 5) a asemelha-se a distribuiçă em J-invertido, conceituada por De LIOCOURT (1998) e MEVER (1933) para caracte- rian a frequencia de individuas por hectaredas florestas naturais.

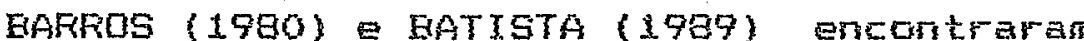
distrizunges 
101.

semelhantes quando estudaram a distribuica diametrica da floresta tropical, através de modelas de distribuicão diametricas.

Tabela 24 - Distribuiçăo do número de individuos por bloco, tratamento e classe diamstrica por hectare (W/ha): Invertario Inicial - 1994.

\begin{tabular}{|c|c|c|c|c|c|c|c|c|c|}
\hline \multirow{2}{*}{ ELOCO } & \multirow{2}{*}{ TRAT } & \multicolumn{7}{|c|}{$\begin{array}{c}\text { CLASSE DIAHETRICA } \\
(\mathrm{cm})\end{array}$} & \multirow{2}{*}{ TOTAL } \\
\hline & & $<10$ & $10-20$ & $20-30$ & $30-40$ & $40-50$ & $50-60$ & 700 & \\
\hline \multirow{4}{*}{01} & 01 & - & 370 & 94 & 32 & 30 & $\theta$ & 19 & 550 \\
\hline & $\alpha$ & - & 342 & 80 & 26 & 10 & 4 & 10 & 472 \\
\hline & 03 & - & 310 & 66 & 30 & 9 & 8 & 19 & 440 \\
\hline & 04 & - & 336 & 72 & 26 & 16 & $A$ & 20 & 1394 \\
\hline \multirow{4}{*}{02} & 01 & - & 352 & 54 & 48 & 4 & $\Xi$ & 16 & 492 \\
\hline & 02 & - & 309 & 90 & 16 & 26 & 4 & 4 & 456 \\
\hline & 03 & - & 350 & 82 & 36 & 12 & 10 & 8 & 498 \\
\hline & 04 & - & 320 & 74 & 30 & $\theta$ & 0 & 4 & $436^{\circ}$ \\
\hline \multirow{4}{*}{03} & $a 1$ & - & 266 & 94 & 40 & 24 & 14 & 12 & 450 \\
\hline & $a z$ & - & 269 & 62 & 56 & 28 & a & 8 & 424 \\
\hline & $0 ;$ & - & 374 & 100 & 30 & 22 & $B$ & 12 & 554 \\
\hline & 04 & - & 286 & 90 & 54 & 24 & 12 & 14 & 480 \\
\hline \multirow{4}{*}{04} & 01 & - & 274 & $7 \theta$ & 26 & 14 & 6 & 10 & .009 \\
\hline & 02 & - & 286 & 90 & 32 & 10 & 22 & 6 & 436 \\
\hline & 03 & - & 270 & 66 & 24 & 14 & 12 & $\theta$ & 394 \\
\hline & 04 & - & 316 & 89 & 26 & 10 & $a$ & 10 & 458 \\
\hline \multirow{4}{*}{ MEDTAS } & 01 & - & 315 & 80 & 36 & 18 & $\mathrm{~B}$ & 14 & 472 \\
\hline & 02 & - & 301 & 92 & 32 & 18 & 8 & 7 & 436 \\
\hline & 03 & - & 326 & 80 & 30 & 14 & 9 & 11 & 471 \\
\hline & 04 & - & 314 & 96 & 34 & \pm 4 & 7 & 12 & 467 \\
\hline
\end{tabular}


o número de individuos por classes diamstricas sucessionais segue, aproximadamente, una serie geometrica decrescente.

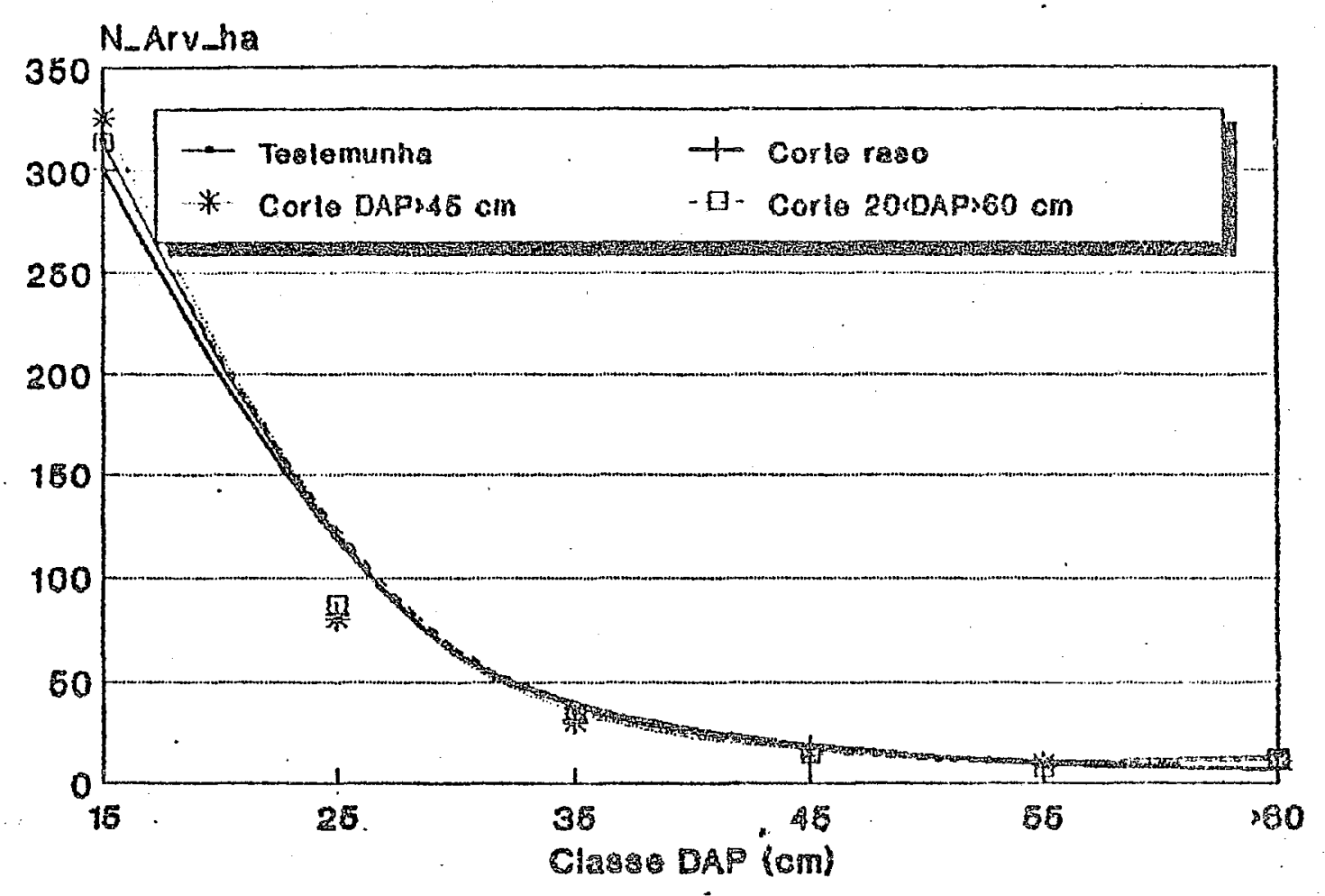

Figura 5 - Distribuicăo do numero de individuo (N_Arv_ha); obeervada no inventario inicial (1994).

4. 5. Inventario Florestal Póswexploratorio

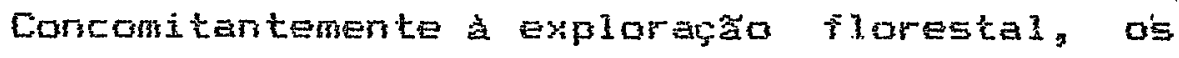
produtos obtidos da tloresta foran mensurados a an de caracterizar os tratamentos Eilviculturais aplicados. Os

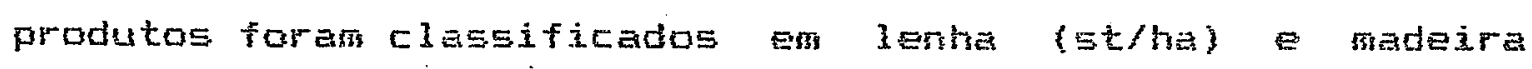
serravel ( ${ }^{3}$ /ha) , conforme mostra a Tabela 25. 
Tabela 25 - Froducta de lenha (st) e madeira serravel ( $\mathrm{m}^{3}$ ) por hectare, por bloco e tratamento.

\begin{tabular}{|c|c|c|c|c|c|c|c|c|c|c|}
\hline \multirow{2}{*}{ TRAT } & \multicolumn{2}{|c|}{ ELOCO OL } & \multicolumn{2}{|c|}{ ELLOCD OR } & \multicolumn{2}{|c|}{ ELACO OJ } & \multicolumn{2}{|c|}{ EL_OCO O4 } & \multicolumn{2}{|c|}{ MEOIA } \\
\hline & LEN. & MAD. & LEN. & MAD. & LEN. & WAD. & LEN. & MAD. & LEN. & MAD. \\
\hline 02 & 597 & 38 & 385 & 36 & 592 & 35 & 501 & 36 & 466 & 36 \\
\hline 03 & 387 & 34 & 199 & 30 & 242 & 28 & 161 & 29 & 245 & 30 \\
\hline 04 & 247 & 30 & 129 & 25 & 177 & 27 & 211 & 26 & 191 & 27 \\
\hline
\end{tabular}

Ds maicires rendimentos, tanko para a lenha cono para madeira serravel, a nivel dos blocos e na modia geral do ensaio, form cbtidos no tratamento ol loore rasol.

En experisneias conduzidas na Amazonia Feruana (HARTSORN et ali , 1787), o corte raso foi utilizado em un sistema de menejo florestal, onde a exploraça foi realizada en fainas com largura entre 50-75 metras. Os resutados obtidos ate 1997 foram considerados satisfatorios, poren resultados mais conclusivassera conheridos no final, do ciclo, ocasiăo em que todas as faimas de corte raso serao novamente exploradas. A expectativa para a realizaço de um novo corte, na primeira faina explurada, ef de 30 anos.

As estimativas de volume comercial das tipologias tlorestais da fimazonia geralmente gão superestimadas en relaçăo ao volume realmente aproveitavel. Qs inventarios florestais ja realizados estimam altos volumes de madeira conercializaveis por unidade de brea, mas estes representem menos de $50 \%$ do volume pera processamento 
industrial. A Tabela 26 mostra o volume inaproveitavel de madeira para a industrializaçăo (desdobro), que comparados aos valores aproveitáveis (Tabela 25), revelam um aproveitamento em torno $24 \%$ do total de madeira disponivel. Esta diferença pade ser atribufda a dois fatores: o reduzido número de especies comercializáveis (conceito mercadologico) e grande numero de causas naturais, tais como os defeitos da arvores e danos causados durante a exploraçăo florestal.

Tabela 26 - Volume madeireiro inaproveitavel (mª).

\begin{tabular}{ccccccc}
\hline TKAT & ELDCO O1 & ELOCO O2 & ELOCO OS & ELOCO 04 & MEDIA \\
\hline 02 & 242 & 76 & 168 & 132 & 155 \\
03 & 183 & 66 & 131 & 84 & 116 \\
04 & 68 & 47 & 62 & 57 & 58 \\
\hline
\end{tabular}

Apos a implantaçăo dos tratamentos silviculturais es consequentemente, com a reduçăo da srea basal e do número de individuos das parcelas, foi executado outro inventario florestal, visando avaliarqualitativamente e quantativainente o estoque remanescente.

A composição floristica remanescente das parcelas experimentais e apresentada no Apendice 1 e na Tabela 3. A distribuiçáo da area basal $\left(\mathrm{m}^{2}\right.$ /ha por bloco, tratamento e classe diametrica encontra-se na Tabela 27 e Figura 6. 
Tabela 27 - Distribuiça da area basal $\left(\mathrm{m}^{2}\right.$ hal por bloco, tratamento e classe diametrica. Inventario pós-exploratorio de 1934.

\begin{tabular}{|c|c|c|c|c|c|c|c|c|c|}
\hline \multirow{2}{*}{ BLCCO } & \multirow{2}{*}{ TFAT } & \multicolumn{7}{|c|}{$\begin{array}{c}\text { CLASSE DIAMETFICA } \\
\text { (cm) }\end{array}$} & \multirow{2}{*}{ TOTAL } \\
\hline & & $<10$ & $10-20$ & $20-30$ & $30-40$ & $40-50$ & $50-60$ & 360 & \\
\hline 01 & $\begin{array}{l}01 \\
02 \\
03 \\
04\end{array}$ & $\begin{array}{l}- \\
- \\
- \\
-\end{array}$ & $\begin{array}{c}5,77 \\
0,06 \\
3,31 \\
-\end{array}$ & $\begin{array}{c}4,54 \\
2,58 \\
\pm, 26\end{array}$ & $\begin{array}{c}2,89 \\
- \\
1,80 \\
2,23\end{array}$ & $\begin{array}{l}4,51 \\
- \\
0,51 \\
1,65\end{array}$ & $\begin{array}{c}1,38 \\
- \\
0,39 \\
1,27\end{array}$ & $\begin{array}{c}0,22 \\
- \\
11,08\end{array}$ & $\begin{array}{r}27,31 \\
0,05 \\
9,99 \\
17.49\end{array}$ \\
\hline 02 & $\begin{array}{l}01 \\
02 \\
03 \\
04\end{array}$ & $\begin{array}{l}- \\
- \\
-\end{array}$ & $\begin{array}{l}5,43 \\
0,11 \\
4,35 \\
0,05\end{array}$ & $\begin{array}{c}3,51 \\
5,06 \\
1,52\end{array}$ & $\begin{array}{c}2,45 \\
- \\
2,35 \\
2,68\end{array}$ & $\begin{array}{c}1_{5} 63 \\
- \\
0,26 \\
0,52\end{array}$ & $\begin{array}{c}0,95 \\
- \\
-\end{array}$ & $\begin{array}{c}16,32 \\
3,67 \\
- \\
6,12\end{array}$ & $\begin{array}{r}21,48 \\
3,79 \\
10,02 \\
19,71\end{array}$ \\
\hline 03 & $\begin{array}{l}01 \\
02 \\
03 \\
04\end{array}$ & $\begin{array}{l}- \\
- \\
-\end{array}$ & $\begin{array}{c}4,94 \\
- \\
4,82 \\
-\end{array}$ & $\begin{array}{l}5,09 \\
- \\
3.95 \\
3.94\end{array}$ & $\begin{array}{c}2,69 \\
2,71 \\
4,39\end{array}$ & $\begin{array}{l}1,29 \\
- \\
1,68 \\
3,25\end{array}$ & $\begin{array}{c}1,63 \\
- \\
1.97\end{array}$ & $\begin{array}{c}16,73 \\
1,01 \\
3,67 \\
2,26\end{array}$ & $\begin{array}{r}25,34 \\
1,01 \\
17,03 \\
15,90\end{array}$ \\
\hline 04 & $\begin{array}{l}01 \\
02 \\
03 \\
04\end{array}$ & $\begin{array}{l}- \\
- \\
-\end{array}$ & $\begin{array}{c}5,21 \\
0,02 \\
3,4.4 \\
-\end{array}$ & $\begin{array}{c}3,78 \\
- \\
2,43 \\
2,92\end{array}$ & $\begin{array}{c}2,69 \\
- \\
2,25 \\
1,75\end{array}$ & $\begin{array}{l}2.58 \\
- \\
1.19 \\
0.97\end{array}$ & $\begin{array}{c}0_{3} 8 B \\
- \\
0_{3} 83\end{array}$ & $\begin{array}{c}18 \times 83 \\
1,44 \\
-\end{array}$ & $\begin{array}{r}18,20 \\
0,02 \\
10,75 \\
6,50\end{array}$ \\
\hline HEDIAS & $\begin{array}{l}01 \\
03 \\
04\end{array}$ & $\begin{array}{l}- \\
- \\
-\end{array}$ & $\begin{array}{l}5,34 \\
0,02 \\
3,90 \\
0,01\end{array}$ & $\begin{array}{l}3,78 \\
0,03 \\
3,01 \\
2,41\end{array}$ & $\begin{array}{c}2,69 \\
- \\
2,52 \\
2,51\end{array}$ & $\begin{array}{l}2,50 \\
-1,01 \\
1,60\end{array}$ & $\begin{array}{c}1,20 \\
- \\
0,09 \\
1,03\end{array}$ & $\begin{array}{r}15,02 \\
1,17 \\
4,28 \\
4,57\end{array}$ & $\begin{array}{r}23,07 \\
1,22 \\
11,70 \\
14,93\end{array}$ \\
\hline
\end{tabular}

obs.: * Individuas de castariheira.

A bres basal remanescente no corte raso (tratamento 2) refere-se aos individuos de castenhejras pois o Codigo Florestal Brasileiro proite o equ corte e extraça. a năo ser en casos especiais, cono em areas de reservatorio de usinas hidreletricas. Com a retirada dos produtos rlarestais oriundos do tratamenta $3 ;$ a hrea basal das 
parcelas foi redurida, em media, de $51 \%$, sendo que no bloco 1 essa reduçăo foi mais alta, atingindo cerca de $70 \%$ da area basal inicial. Esea reduçăo pode ser explicada pela exploração de todas as arvorese com DAP igual ou maiar de 45 con que existiam na parcela. As reduçeses da area basal a do número de individuo do tratamento 3 geraram os produtos Plorestais presentes na Tabela $25^{.}$sendo que no bloco 1 foram obtidos os maiores rendimentos, tanto para lenha tomo para madeira Eerravel.

Nas parcelas com o tratamento 4, a reduça da area basal foi semeihante d do tratamerto $3151,09 \%$ e $51,87 \%$ respectivamente). A redugăo toi maior ro bloco 4 s gendo retirado cerca de be\% da srea basal inicial.

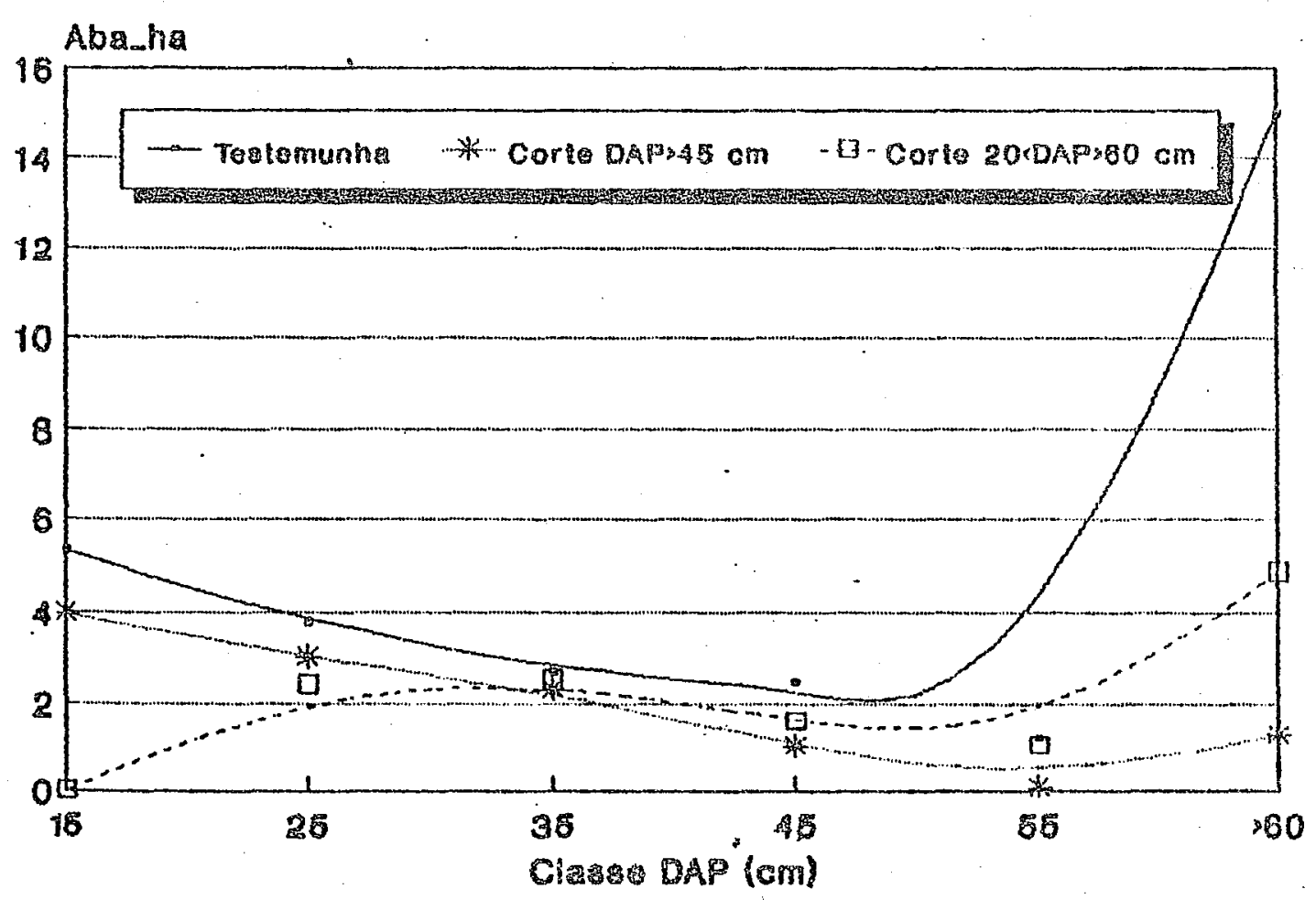

Figura b - Distribuiça da brea basal (Abaha) coservada no inventaria pos-exploratorio - i7ga. 
A distribuiça do número de individuos remanescente por blowa tratamento e classe diametrica acha-se na Tabela 28 Figura 7.

Tabela 28 - Distribuiça do numero de individuos por hectare por bloco,tratamento e classe de diametros observada no inventario pos-exploratorio de 1984.

\begin{tabular}{|c|c|c|c|c|c|c|c|c|c|}
\hline \multirow{2}{*}{ ELDCO } & \multirow{2}{*}{ TRAT } & \multicolumn{6}{|c|}{$\begin{array}{c}\text { CLASSE DIAMETRICA } \\
\text { (cm) }\end{array}$} & \multirow[b]{2}{*}{260} & \multirow{2}{*}{ TOTAL } \\
\hline & & 610 & $10-20$ & $20-30$ & $30-40$ & $40-50$ & $50-60$ & & \\
\hline \multirow{4}{*}{01} & 01 & - & 370 & 94 & 32 & 30 & 6 & 19 & 550 \\
\hline & 02 & - & 2 & - & - & - & - & - & $2^{*}$ \\
\hline & $a$ & - & 208 & 54 & 20 & $b$ & 2 & 0 & 270 \\
\hline & 0.4 & - & 0 & 23 & 22 & 10 & 6 & $g^{3}$ & 80 \\
\hline \multirow{4}{*}{02} & 01 & - & 352 & 54 & 48 & 4 & 8 & 16 & 482 \\
\hline & 02 & - & - & - & - & - & - & - & $2^{* 3}$ \\
\hline & 03 & - & 292 & 6日 & 26 & 2 & 0 & $0_{\text {制 }}$ & 379 \\
\hline & 04 & - & $2^{*}$ & 32 & 20 & 4 & 0 & $2^{3}$ & 50 \\
\hline \multirow{4}{*}{03} & 01 & - & 266 & 94 & 40 & 24 & 14 & 12 & 450 \\
\hline & 02 & - & - & - & - & - & - & $2_{2}$ & $z^{*}$ \\
\hline & 03 & - & 282 & 84 & 32 & 12 & 0 & $2^{3}$ & 412 \\
\hline & 04 & - & - & 80 & 46 & 20 & $\mathrm{a}$ & $2^{* 4}$ & 156 \\
\hline \multirow{4}{*}{04} & 01 & - & 274 & 78 & 26 & 14 & 6 & 10 & 408 \\
\hline & 02 & - & 2 & - & - & - & - & - & $2^{50}$ \\
\hline & 03 & - & 210 & 58 & 22 & $B$ & 0 & 0 & 300 \\
\hline & 04 & - & - & 64 & $1 \theta$ & 6 & 4 & 0 & 92 \\
\hline \multirow{4}{*}{ MEDIAS } & 01 & - & 315 & 80 & 36 & 19 & $\mathrm{~B}$ & 14 & 472 \\
\hline & 02 & - & 1 & 1 & - & - & - & 1 & $2^{3}$ \\
\hline & 03 & - & 245 & 66 & 25 & 7 & 1 & 1 & 345 \\
\hline & 04 & - & 1 & 51 & 26 & 10 & 4 & 2 & 97 \\
\hline
\end{tabular}

obs. * Individuos de costaringira.

No tratamento is a reduça do numero de arvores por hectare foi de $27 \%$ senda que no blaco 1 a reduça foi maior do que nos demais biacos $(34,1 \% 24,2 \% 25,6 \%$ e $23,7 \%$ 
respectiva mente). A reduça do numero de individuos foi masor na classe diametrica $10-20 \mathrm{cmg}$ devido aus denos causados nas árvores remanescente durante a exploraçăo forestal.

No tratamento 4 , as interferbncias geraram uma reduçăo media de $79,3 \%$ do numero inicial de individuos, sendo que no bloco 2 foram retirados cerca de $86 \%$ do total de individuos. Essa reduça pode ser explicada pelo fato do tratamento contemplar o corte de todos os individuos con DAF iqual ou inferior a $20 \mathrm{~cm}$ as quais compom a classe de maior frequencia de individuos na estrutura das florestas tropicais.

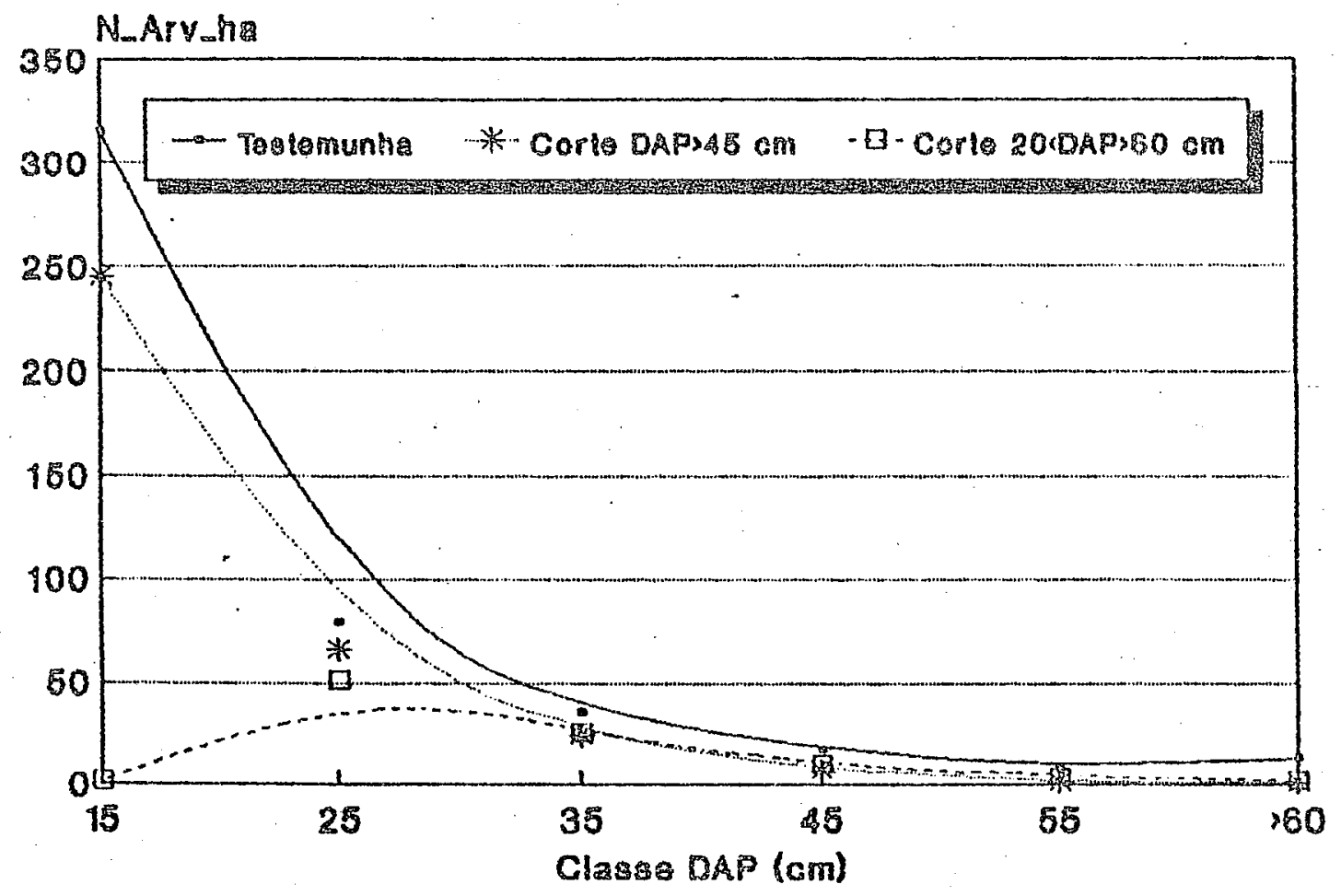

Figura 7 - Distribuiça do numero de individuos por hectare (N Arv_ha) observado no inventario pos exploratorio de 1984. 


\section{6. Primelro Inventário Florestal Continuo (1986)}

Em 1996, apos 2 anos da implantaça dos tratamentos silviculturais, foram instalados em cada unidade experimental, as parcelas de observaçes conforme desericăo ja apresentada na Tabela 1 , nos queis os dados do ensaio passaram a ser cojezados.

0 número de individuos (N/ha) por waco. tratamento e classe de diametro observado nas parcelas experimentais e apresentado na Tabela 29.

Tabela 29 - Distribuiça do numero de individuss (h/ha) por blocag tratamento e clasen diametrica otservada no inventsio contriou de 1986 .

\begin{tabular}{|c|c|c|c|c|c|c|c|c|c|}
\hline \multirow{2}{*}{ BLOCO } & \multirow{2}{*}{ TEAT } & \multicolumn{5}{|c|}{$\begin{array}{c}\text { CLASGE DIANETFICA } \\
\text { (CA) }\end{array}$} & & \multirow{2}{*}{ TTTAL } \\
\hline & & 410 & $10-20$ & $20-30$ & $30-40$ & $40-50$ & $50-60$ & 250 & \\
\hline \multirow{4}{*}{01} & 01 & 696 & 429 & 100 & 32 & 20 & 12 & 4 & .300 \\
\hline & 02 & 1204 & 88 & 4 & - & - & - & - & 4 \\
\hline & 03 & 1060 & 348 & 76 & -24 & $a$ & - & - & 1512 \\
\hline & 04 & 664 & $2 \theta$ & 24 & 20 & 9 & 4 & 9 & 756 \\
\hline \multirow{4}{*}{02} & 01 & 706 & 312 & 56 & 36 & 8 & 4 & 12 & 1130 \\
\hline & $a z$ & 1072 & 40 & - & 4 & - & - & - & 1136 \\
\hline & 03 & 724 & 390 & $8^{4}$ & 52 & 4 & - & - & 1244 \\
\hline & 04 & 344 & 48 & 28 & 12 & 4 & - & - & 436 \\
\hline \multirow{4}{*}{03} & 01 & EEg & 280 & 100 & 52 & 20 & 4 & 盖 & 1060 \\
\hline & 02 & 589 & 8 & - & - & - & - & 4 & 600 \\
\hline & 03 & 812 & 344 & 80 & 40 & $\theta$ & - & 4 & 2280 \\
\hline & 04 & 164 & $\exists$ & 68 & $4 n$ & 28 & 8 & 4 & 329 \\
\hline \multirow{4}{*}{04} & $0 x$ & 640 & 272 & 100 & 16 & $\mathrm{~B}$ & 8 & 36 & 1060 \\
\hline & $O 2$ & 2960 & 96 & - & - & - & - & - & 3056 \\
\hline & 03 & $40 \mathrm{O}$ & 272 & 60 & 20 & 4 & - & - & 784 \\
\hline & 94 & 292 & 8 & 52 & 16 & 8 & $\theta$ & - & 384 \\
\hline \multirow{4}{*}{ MEDIAS } & 01 & 558 & 323 & 91 & 34 & \pm 4 & 7 & 12 & 1139 \\
\hline & 02 & 1456 & 58 & 1 & 1 & - & - & 1 & 1517 \\
\hline & 03 & 751 & 336 & 75 & 34 & 5 & - & 1 & 1202 \\
\hline & 04 & 366 & 23 & 43 & 25 & 12 & 5 & 3 & 475 \\
\hline
\end{tabular}




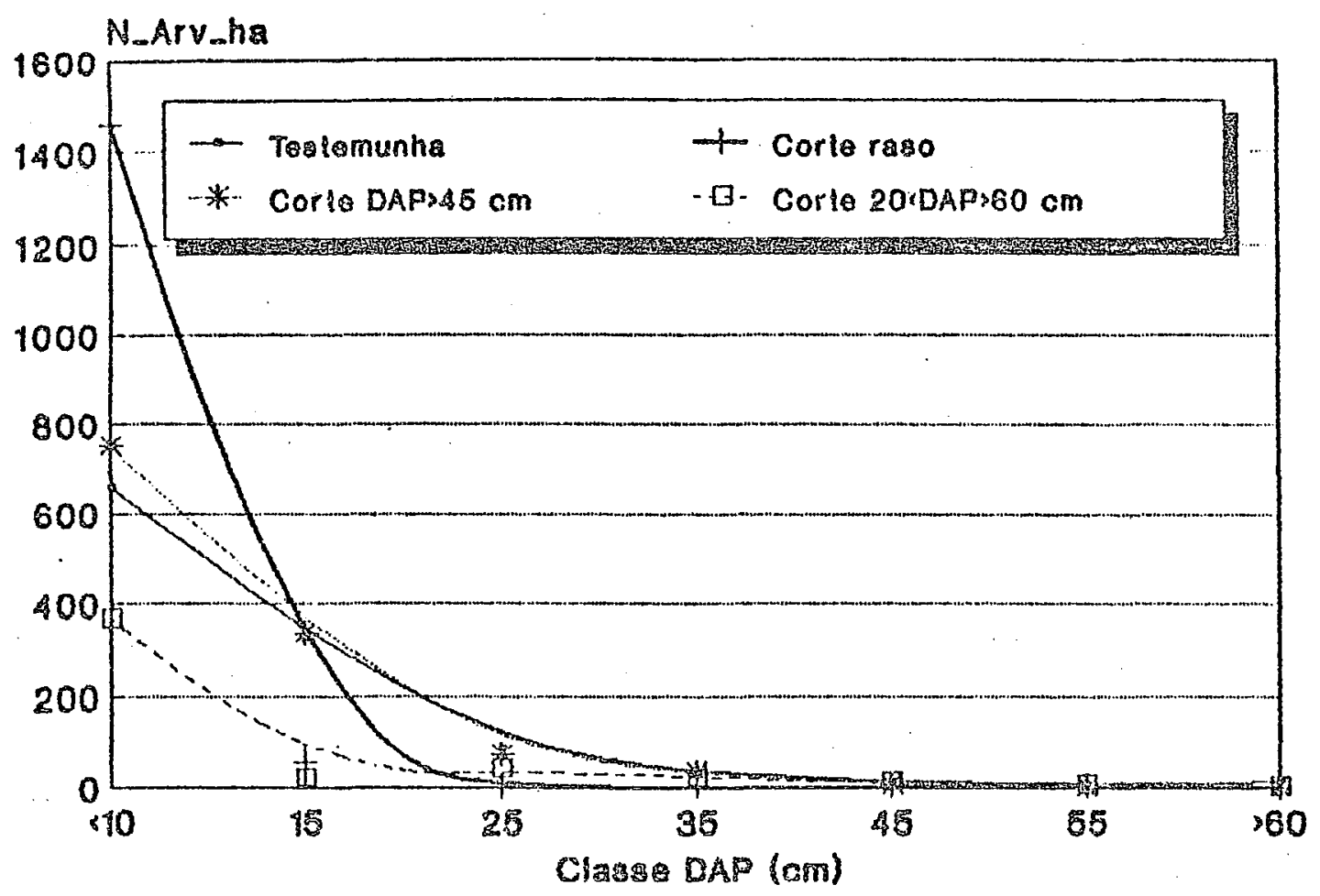

Figura $\theta$ - Distribujăa do numero de individus for hectere (N_Arv ha) oberervada no primeiro irventario continuo (178b).

A área basal $\left(m^{2} /\right.$ ha) das parcelas experimentais é apresentada ne Tabela 30 e Figura 9 . A ankise de Variancia (ANOVA) para as variaveisa area basal por hectare (Aba_ha); numero de individuos por hectare (N_Arv_ha), no estagio de varas (SF2) não mostrou diferenças significativas entre as medias dos blocos e tratamentos. 
111.

Tabela 30 - Distribuição da área basal $\left(m^{2} /\right.$ ha por bloco, tratamento a classe diametrica observada no Inventario continua de 1986.

\begin{tabular}{|c|c|c|c|c|c|c|c|c|c|}
\hline \multirow{2}{*}{ EILOCO } & \multirow{2}{*}{ TFAT } & \multicolumn{6}{|c|}{$\begin{array}{c}\text { CLASSE DIAMETICA } \\
(\mathrm{Cm})\end{array}$} & \multirow[b]{2}{*}{260} & \multirow{2}{*}{ TOTAL } \\
\hline & & 610 & $10-20$ & $20-30$ & $30-40$ & $40-50$ & $50-60$ & & \\
\hline 01 & $\begin{array}{l}01 \\
02 \\
03 \\
04\end{array}$ & $\begin{array}{l}2,63 \\
4,15 \\
4,09 \\
2,28\end{array}$ & $\begin{array}{l}6,40 \\
0,85 \\
5,06 \\
0,29\end{array}$ & $\begin{array}{l}5,51 \\
0,14 \\
3,47 \\
1,13\end{array}$ & $\begin{array}{c}2,84 \\
- \\
2,42 \\
1,99\end{array}$ & $\begin{array}{l}3,16 \\
- \\
0,58 \\
1,26\end{array}$ & $\begin{array}{c}2,71 \\
- \\
0,98\end{array}$ & $\begin{array}{c}1,25 \\
- \\
21,92\end{array}$ & $\begin{array}{r}24,51 \\
5,14 \\
15,62 \\
29,94\end{array}$ \\
\hline 02 & $\begin{array}{l}01 \\
02 \\
03 \\
04\end{array}$ & $\begin{array}{l}2,79 \\
3,39 \\
2,54 \\
1,01\end{array}$ & $\begin{array}{l}4,95 \\
0,37 \\
5,71 \\
0,63\end{array}$ & $\begin{array}{c}2,42 \\
- \\
3,67 \\
1,65\end{array}$ & $\begin{array}{l}3,24 \\
0,29 \\
4,62 \\
1,04\end{array}$ & $\begin{array}{l}1,15 \\
- \\
0,52 \\
0,55\end{array}$ & $\begin{array}{c} \pm, 02 \\
- \\
-\end{array}$ & $\begin{array}{c}4359 \\
- \\
-\end{array}$ & $\begin{array}{r}19,96 \\
4,04 \\
17,06 \\
4,98\end{array}$ \\
\hline $0 \Omega$ & $\begin{array}{l}01 \\
02 \\
03 \\
04\end{array}$ & $\begin{array}{l}2,04 \\
1,61 \\
2,67 \\
0,29\end{array}$ & $\begin{array}{l}4,57 \\
0,07 \\
5,41 \\
0,13\end{array}$ & $\begin{array}{c}4,32 \\
3,68 \\
3,47\end{array}$ & $\begin{array}{c}4,72 \\
- \\
3,78 \\
4,03\end{array}$ & $\begin{array}{c}3,19 \\
1,05 \\
4,04\end{array}$ & $\begin{array}{c}1,11 \\
- \\
- \\
1,95\end{array}$ & $\begin{array}{l}9.91 \\
1.95 \\
4,31 \\
4,12\end{array}$ & $\begin{array}{r}29,76 \\
3,63 \\
21,30 \\
17,92\end{array}$ \\
\hline 04 & $\begin{array}{l}01 \\
02 \\
03 \\
04\end{array}$ & $\begin{array}{r}2,43 \\
10,01 \\
1,51 \\
0,76\end{array}$ & $\begin{array}{l}4,09 \\
0,94 \\
4,24 \\
0,09\end{array}$ & $\begin{array}{c}4,61 \\
- \\
2,57 \\
2,47\end{array}$ & $\begin{array}{l}1,79 \\
- \\
2,06 \\
1,59\end{array}$ & $\begin{array}{c}1,29 \\
0,54 \\
1,11\end{array}$ & $\begin{array}{l}1.77 \\
- \\
1.96\end{array}$ & $\begin{array}{l}7 \pm 25 \\
- \\
-\end{array}$ & $\begin{array}{r}23,25 \\
10,87 \\
10,92 \\
7,98\end{array}$ \\
\hline NEDIAS & $\begin{array}{l}01 \\
02 \\
03 \\
04\end{array}$ & $\begin{array}{l}2,47 \\
4,79 \\
2.70 \\
1.00\end{array}$ & $\begin{array}{l}5,00 \\
0,54 \\
5,10 \\
0,28\end{array}$ & $\begin{array}{l}4,21 \\
0,04 \\
3,39 \\
2,19\end{array}$ & $\begin{array}{l}3,15 \\
0,07 \\
3,27 \\
2,16\end{array}$ & $\begin{array}{c}2,19 \\
0,67 \\
1,74\end{array}$ & $\begin{array}{c}1,66 \\
- \\
1,19\end{array}$ & $\begin{array}{l}5,67 \\
9,48 \\
1,08 \\
6,51\end{array}$ & $\begin{array}{r}24,37 \\
5,73 \\
16,17 \\
15,14\end{array}$ \\
\hline
\end{tabular}

Das 80 parcelas experimentais onde foram coletados os dados sobre as espécies no estagio do varas 1 . (12 parcelas) näo epresantaran renhun individuog sendo que no tratamento 4 a percentagen foi de $25 \%$ 


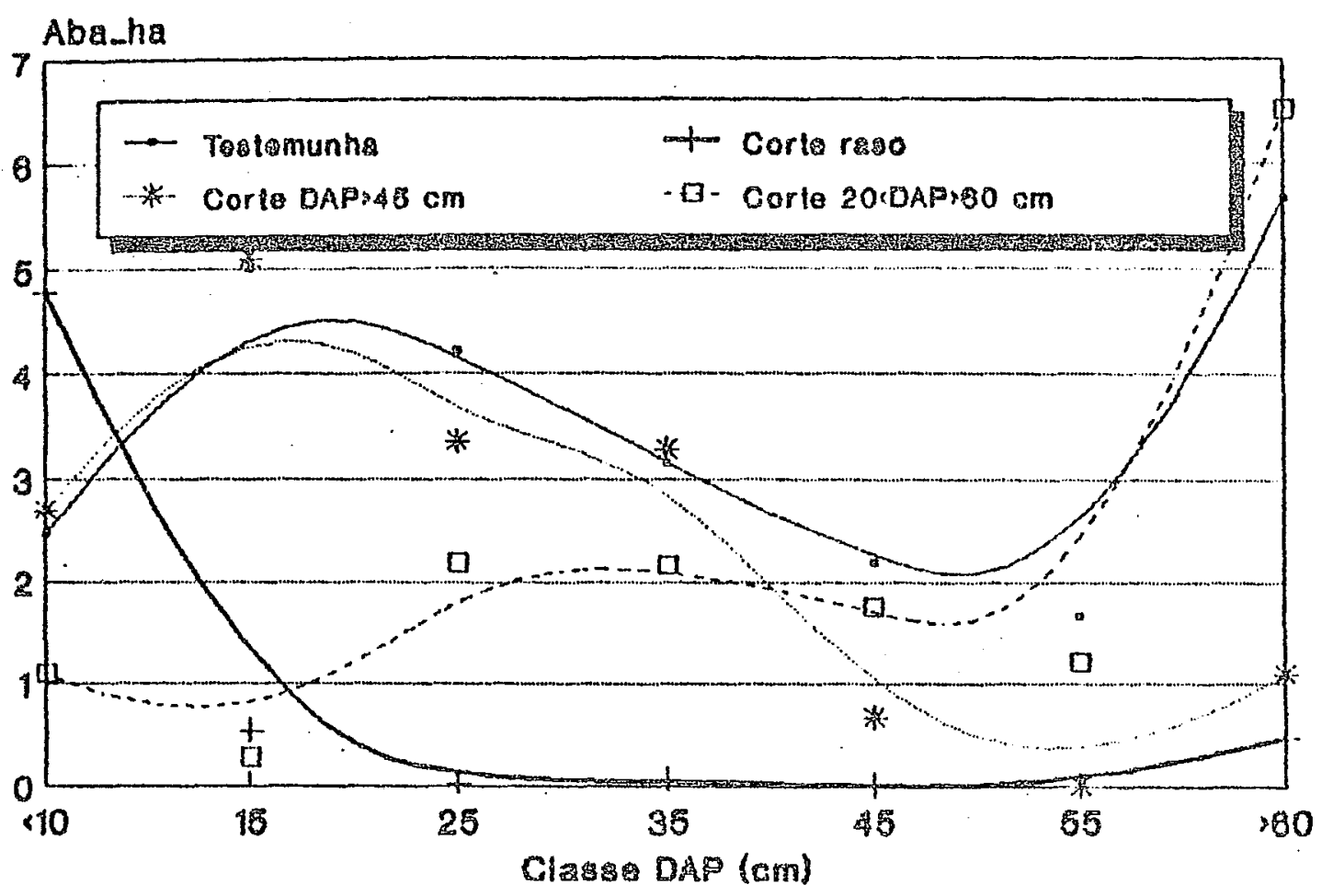

Figura 7 - Distribuiçă da área basal (Aba_ta) duy ante o primeipo inventario continus - 19ab.

0 coeficiento de variaga (CV) calculado para o número de individuos por parcelas. ea cada tratamentos mostrou uma alta amplitude nos valores observados, de tal sorte que a ANAVA nă detertou diferencas significativas entre as medias dos blocos e tratamentos. Os coeficientes de variaçãu forama $55,1 \%, 72,5 \%, \quad 82,7 \%$ e $57,0 \%$ para 05 tratamentos $1,2,3,4$, respectivamente.

Por sua veá a arálise de variancia realizada para os dados coletados nas parcelas experimentais para as arvores estabelecidas (SPi), indicou diferenças significativas entre tratamentos para as tres variaveis estudadas (Tabela 31). 
?

告

落

元

$\begin{array}{ccc} & -1 & 0 \\ -1 & 0 & 5 \\ 0 & 0 & 5 \\ 0 & 5 & \pm \\ 0 & 0 & 5 \\ 0 & 0 & 0\end{array}$

$\begin{array}{ccc}0 & 0 & -1 \\ 0 & 0 & 5 \\ 4 & 0 & -1\end{array}$

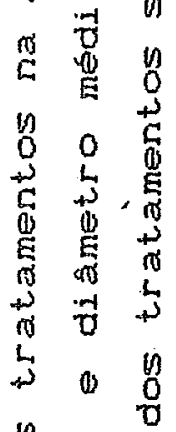

勋

$\begin{array}{lll}0 & 5 & 4 \\ + & 4 & 4 \\ 0 & 1 & 0\end{array}$

II $Z \frac{1}{a}$

मे

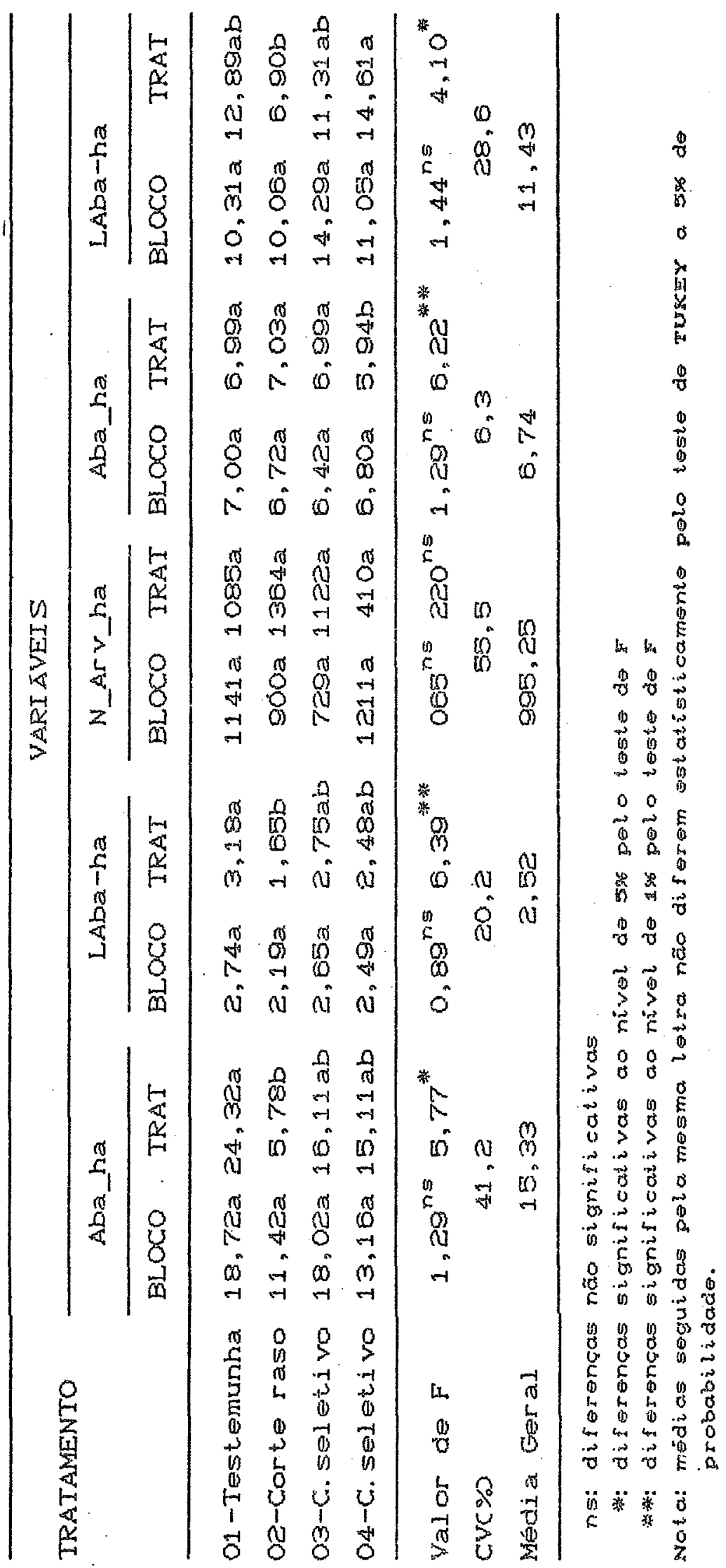


0 teste de TUKEY para comparar as medias dos tratamentos apontou, para a variavel area basal (Aba_ha), a superioridade do tratamento 1 (testemunha) sobre as demais tratamentos, e ainda, entre os tratamentos 3 e 4 , na houve diferenças significativas entro as medias observadas. Ressalka-se que, a reducăo da area basal dos dois tratamentos por ocasião da implantaça do Ensaib toi semeltrante is. o4\% e $51,97 \%$, respectivamentel.

En relação a variavel núnero de individuos (N_ArV_ha), a média do tratamento 4 foi inferior as demais medias, sendo que entre as medias dos tratamentos 1,2 3 , năo foi observado diferenças significativas. A inferioridade do tratamento 4 em relaça aos demais e explicada pala alta reduçăo do número de individuos apesar do ingresso de 366 individuos en módia, na classe de dimetro $5-10$ cm dumance o periado de 1994-19g6.

No tratamento 2 a ingresso de novos individuas nas classes dianstricas inferiores (menor do que 20 fm foi superior aos tratamentos 1,3 a 4 porkm en termes medias năo houve diferença significativa entre os tratamentos 1 e 3.

Para a varikvel diametro medio da parrela (MDAP) houve superioridade do tratamento 4 sobra os denais, pelo tato do tratamento favorecer a permanknaia dos individuas nas classes diametriras intermediarias (diametro maior do gue 20 cm e menor do que bo cm). For sua vez, a semelhança entre as medias dos diametros modios 
observados nos tratamentos 1 E pode ser explicada pela compensaça ocorrida no tratamento 3 pela antrada de novos individuos na classe de diametro 5-10 cm.

\subsection{Segundo Inventario Contínuo (1988)}

As distribuiçoes do número de arvores e area basal $\left(m^{2}\right)$ por hectare, por blotog tratamento e classe diametrica, achan-5e, respectivamente ras Tabelas 32 E 3 .

Tabela 32 - Distribuiça do numero de individuos (h/ha) por bloco, tratamento elasse diametrica doservada no inventátio continuo de 1989.

\begin{tabular}{|c|c|c|c|c|c|c|c|c|c|}
\hline \multirow{2}{*}{ ELCCO } & \multirow{2}{*}{ TFAT } & \multicolumn{7}{|c|}{$\begin{array}{c}\text { CLASSE MIAHETFICA } \\
\text { (CM) }\end{array}$} & \multirow{2}{*}{ TOTAL } \\
\hline & & $<10$ & $10-20$ & $20-30$ & $30-40$ & $40-50$ & $50-60$ & $\times 6 n$ & \\
\hline \multirow{4}{*}{01} & 01 & 672 & $42 \theta$ & 100 & 40 & 20 & 12 & 4 & 1284 \\
\hline & $0 z$ & 940 & 660 & 20 & - & - . & - & - & 1620 \\
\hline & 05 & 960 & 376 & 100 & 20 & 16 & - & - & 1480 \\
\hline & 04 & 794 & $\mathrm{SBA}$ & 34 & 20 & $\Xi$ & 4 & 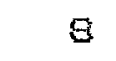 & 1244 \\
\hline \multirow{4}{*}{02} & 01 & 716 & 304 & 80 & 36 & 8 & 8 & 12 & 1164 \\
\hline & 02 & 1272 & $7 O B$ & 12 & 4 & - & - & - & 1976 \\
\hline & 03 & $B 40$ & 308 & 92 & 60 & 7 & - & - & 1300 \\
\hline & 04 & 404 & 252 & 30 & 20 & 4 & - & - & 716 \\
\hline \multirow{4}{*}{03} & 01 & 556 & 292 & 100 & 48 & 20 & 8 & is & 1048 \\
\hline & 02 & 1092 & 264 & - & - & - & - & 4 & 1360 \\
\hline & 03 & 798 & 404 & 96 & 36 & 16 & - & 4 & 1344 \\
\hline & 04 & 272 & 32 & 60 & 44 & 40 & 8 & 4 & 460 \\
\hline \multirow{4}{*}{04} & 01 & 640 & 292 & 100 & 16 & 12 & $\mathrm{~B}$ & 16 & 1084 \\
\hline & 02 & 1600 & 1376 & B & - & - & - & - & 3004 \\
\hline & 03 & 452 & 286 & 60 & 20 & 12 & - & - & 820 \\
\hline & 04 & 472 & 184 & 48 & 8 & 16 & 4 & - & 732 \\
\hline \multirow{4}{*}{ MEDIAS } & $a 1$ & 346 & 329 & 97 & $5 E$ & 15 & 9 & 12 & 1145 \\
\hline & 02 & 1226 & 757 & 10 & 1 & - & - & 1 & 1795 \\
\hline & 03 & 757 & 360 & 87 & 34 & 13 & - & 1 & 1258 \\
\hline & 04 & 485 & 213 & 45 & 23 & 17 & 4 & 3 & 708 \\
\hline
\end{tabular}


116.

Tabela 33 - Distribuiça da area basal $\left(\mathrm{n}^{2} / \mathrm{ha}\right.$ ) por bloco, tratamento e classe diamótrica no inventario continuo de 1989.

\begin{tabular}{|c|c|c|c|c|c|c|c|c|c|}
\hline \multirow{2}{*}{ ELOCO } & \multirow{2}{*}{ TRAT } & \multicolumn{7}{|c|}{$\begin{array}{c}\text { CLASSE DIANETRICA } \\
(\mathrm{cm})\end{array}$} & \multirow{2}{*}{ TOTAL } \\
\hline & & $<10$ & $10-20$ & $20-30$ & $30-40$ & $40-50$ & $50-60$ & 260 & \\
\hline 01 & $\begin{array}{l}01 \\
02 \\
03 \\
04\end{array}$ & $\begin{array}{l}2,58 \\
3,85 \\
3,59 \\
3,18\end{array}$ & $\begin{array}{l}6,22 \\
9,59 \\
5,29 \\
5,19\end{array}$ & $\begin{array}{l}5,26 \\
0,77 \\
4,58 \\
1,67\end{array}$ & $\begin{array}{l}3,59 \\
- \\
1,94 \\
2,10\end{array}$ & $\begin{array}{l}3,21 \\
- \\
2,29 \\
1,36\end{array}$ & $\begin{array}{c}2,99 \\
- \\
0,99\end{array}$ & $\begin{array}{c}1,56 \\
- \\
- \\
21,72\end{array}$ & $\begin{array}{l}25,41 \\
14,21 \\
17,78 \\
36,41\end{array}$ \\
\hline 02 & $\begin{array}{l}01 \\
02 \\
03 \\
04\end{array}$ & $\begin{array}{l}2,82 \\
4,75 \\
3,15 \\
1,73\end{array}$ & $\begin{array}{r}4,61 \\
10,22 \\
6,14 \\
3,45\end{array}$ & $\begin{array}{l}3,38 \\
0,56 \\
3,95 \\
1,79\end{array}$ & $\begin{array}{l}3,29 \\
0,42 \\
5,54 \\
1,94\end{array}$ & $\begin{array}{c}1,59 \\
1,04 \\
0,64\end{array}$ & $\begin{array}{c}1,89 \\
- \\
-\end{array}$ & $\begin{array}{c}4.54 \\
- \\
-\end{array}$ & $\begin{array}{r}21,92 \\
36,15 \\
19,95 \\
9,45\end{array}$ \\
\hline 03 & $\begin{array}{l}01 \\
02 \\
03 \\
04\end{array}$ & $\begin{array}{l}1,91 \\
4,50 \\
3,03 \\
0,90\end{array}$ & $\begin{array}{l}4,81 \\
3,29 \\
6,62 \\
0,39\end{array}$ & $\begin{array}{c}4,79 \\
- \\
4,69 \\
3,24\end{array}$ & $\begin{array}{c}4,41 \\
3,61 \\
3,89\end{array}$ & $\begin{array}{c}3,06 \\
- \\
2,21 \\
6,02\end{array}$ & $\begin{array}{c}1,73 \\
- \\
1,87\end{array}$ & $\begin{array}{l}9,91 \\
2,18 \\
4,33 \\
4,15\end{array}$ & $\begin{array}{r}30,82 \\
9,97 \\
24,49 \\
20,34\end{array}$ \\
\hline 04 & $\begin{array}{l}01 \\
02 \\
03 \\
04\end{array}$ & $\begin{array}{l}2,51 \\
6,90 \\
1,70 \\
2,14\end{array}$ & $\begin{array}{r}4,61 \\
19_{3} 23 \\
4,78 \\
2,34\end{array}$ & $\begin{array}{l}4,82 \\
0,27 \\
2,37 \\
2,54\end{array}$ & $\begin{array}{c}1,49 \\
-7,77 \\
0,76\end{array}$ & $\begin{array}{c}1,97 \\
1,67 \\
2,61\end{array}$ & $\begin{array}{c}1,87 \\
- \\
0.97\end{array}$ & $\begin{array}{c}7,33 \\
- \\
-\end{array}$ & $\begin{array}{l}24,50 \\
26,51 \\
12,81 \\
11,38\end{array}$ \\
\hline WEDIAS & $\begin{array}{l}01 \\
02 \\
03 \\
04\end{array}$ & $\begin{array}{l}2,46 \\
5,07 \\
2,74 \\
1,96\end{array}$ & $\begin{array}{r}5,06 \\
10,59 \\
5,71 \\
2,84\end{array}$ & $\begin{array}{l}4,56 \\
0,40 \\
4,03 \\
2,31\end{array}$ & $\begin{array}{l}3,19 \\
0,11 \\
3,22 \\
2,14\end{array}$ & $\begin{array}{c}2,39 \\
- \\
1,81 \\
2,66\end{array}$ & $\begin{array}{c}2,17 \\
- \\
0,76\end{array}$ & $\begin{array}{l}5,84 \\
0,55 \\
1,08 \\
6,52\end{array}$ & $\begin{array}{l}25,66 \\
16,71 \\
18,79 \\
19,79\end{array}$ \\
\hline
\end{tabular}

As Figuras 10 e 11 ilustram, respectivamenteg as distribuiçbes do número de individuos por hectare e a area basal dos tratamentos testados. 


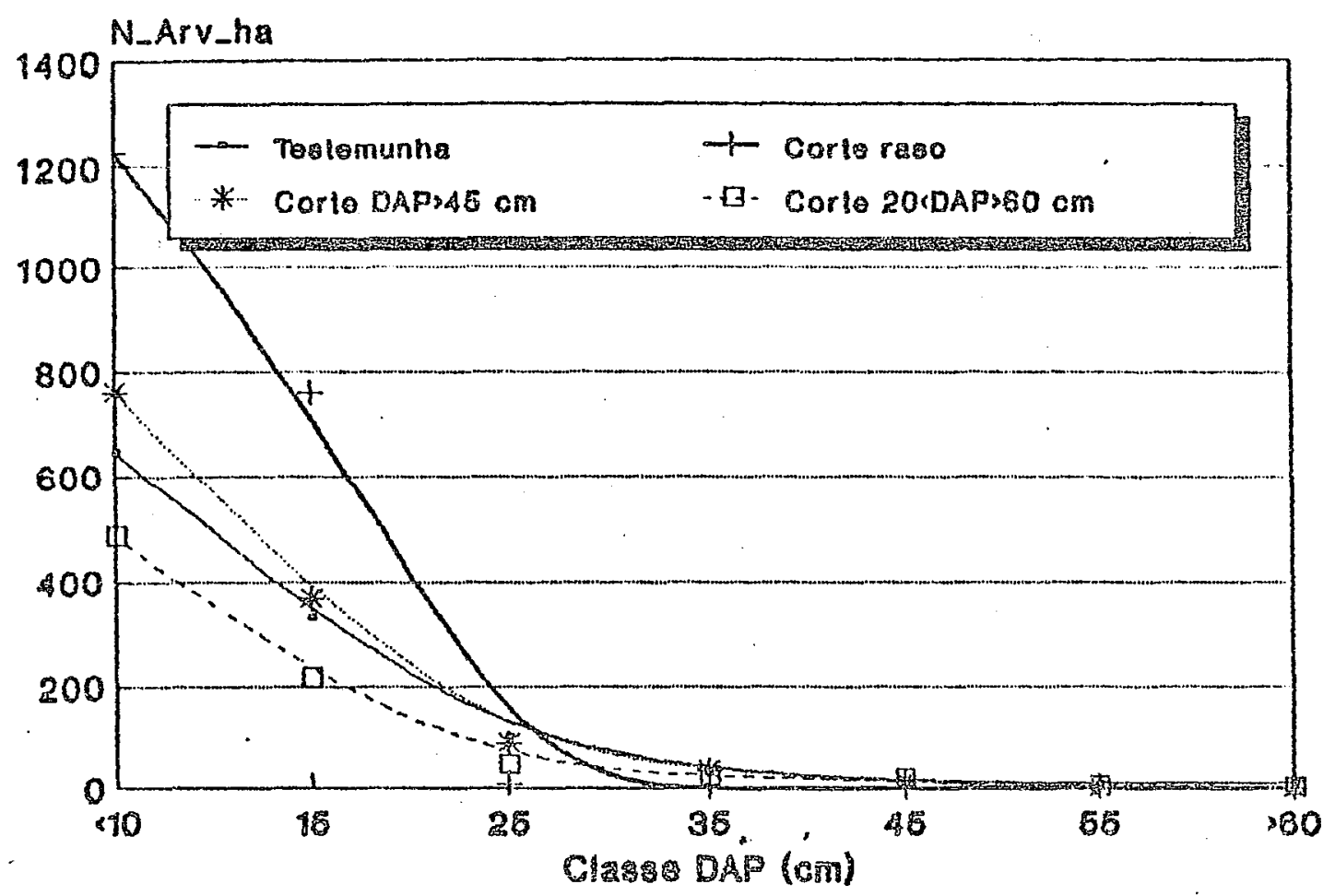

Figura 10. - Distribuição do núnero de individuos por hectare (N_Arv_ha) em 1998 .

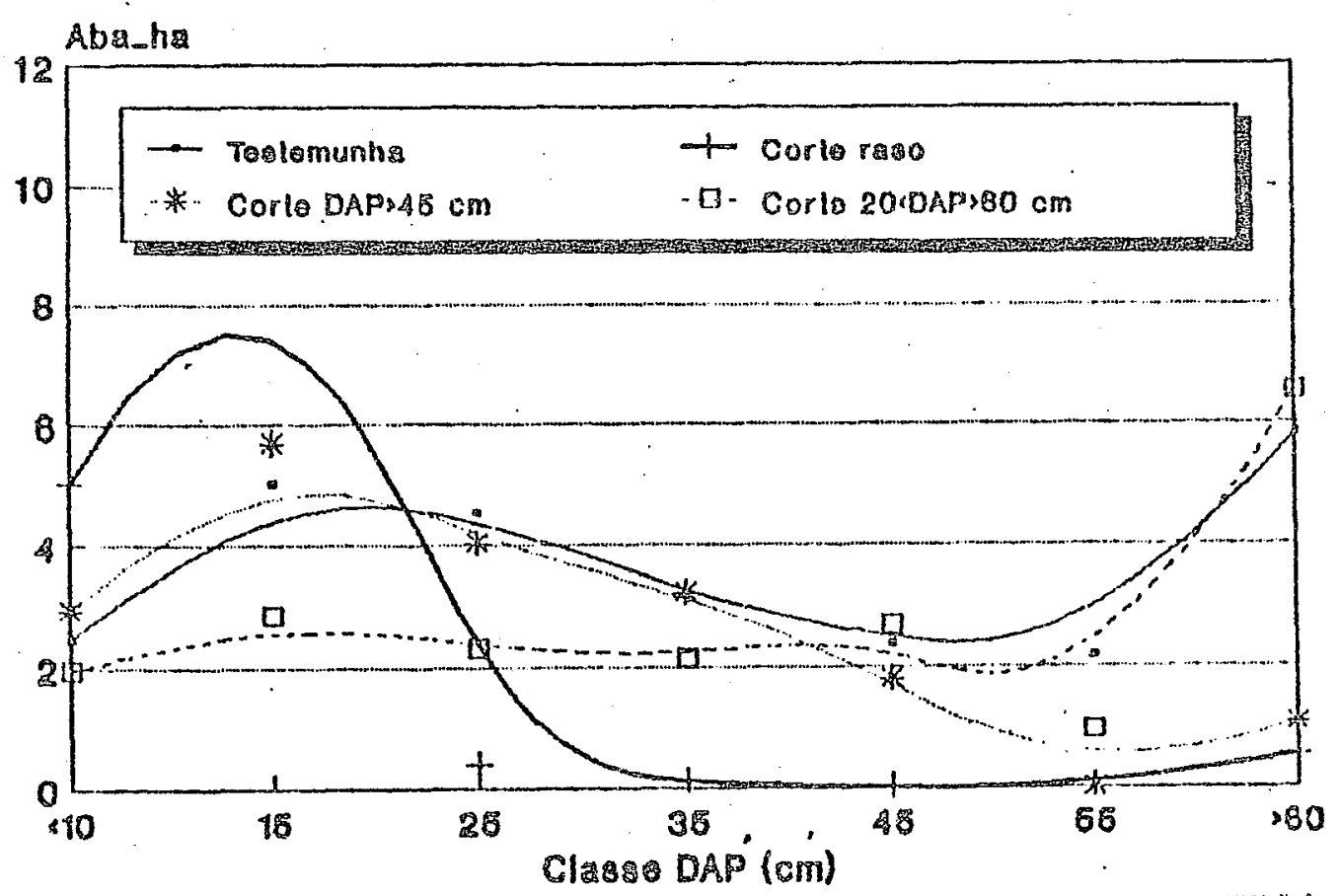

Figura 11 - Distribuiçă da area basal (Aba_ha) em 1989. 
4.7.1. Resultados obtidos para os indiriduos no estagio de varas cspes

A análise de Variancia (ANAVA) dos dados obtidos nas parcelas SP2 (Tatela 34 ), detectou, para a variável diametro médio das parcelas (MDAF), diferenças significativas ao nivel dos tratamentos. o teste de Tukey indicou a superioridade do tratamanto 2 sobre os demais, porem não detectou diferenças entre os tratamentas 1 e 4. Contribuiram para a superioridade do bratamento 2,0 ingresso, durante 0 periodo de 1706-1999, de S6o individuos na classe de diametro AA (5-10 cm), ben coma, o número de individuos que permaneceran ra classe diametrica AA (1226 individuas). Mas demais tratamentos os ingressos forama $16,40,140$, respertivamente nos tratamentos 1, 304.

Fara area basal e numera de individuos por hectare, os resultados da ANova denonstraran gue näa houveram diferengas significativas entre as medias dos tratamentos testados. A não existencia de dif̧erenças estatisticas entre as medias dos tratamentos é atribuda, em parte, ao alto coeficiente de variaçă (cV) entre o número de. individuos por parcela (5FZ), bem como, por outroe efaitos nă controladas pelos tratamentos famostragen e eventos biologicas inerentes às especies da flaresta). A Tabela 35 mostra os valores das coeficientes de variegáa (Cv\%) a a número stimo de parcelas (n) para os tratamentos, durante os anos de 1986 o 1989, calculados para a variavel N_ArV_ha. 
$n$
0
0
0
5
0
0
0
0
0
0
0
0
0

- $a$

की

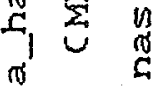

$\begin{array}{ccc}0 & n & \\ 0 & 0 & n \\ 0 & -1 & -1 \\ & 0 & 0 \\ -1 & 0 & 5 \\ 0 & L & 5 \\ 0 & 0 & \pm \\ 0 & 0 & -1 \\ 0 & 0 & 0\end{array}$

ø $\begin{array}{lll}0 & n & 0 \\ 0 & 0 & 5\end{array}$

40 0 in

व $\begin{array}{cc}0 \\ 0 \\ 0\end{array}$

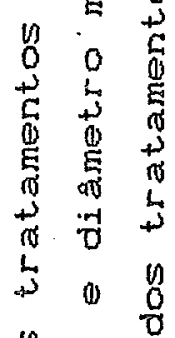

告

$0>0$

-1 द

红 $z \frac{1}{a}$

1

m

. $\begin{array}{r}0 \\ 0 \\ 0 \\ 0 \\ 0 \\ 0\end{array}$

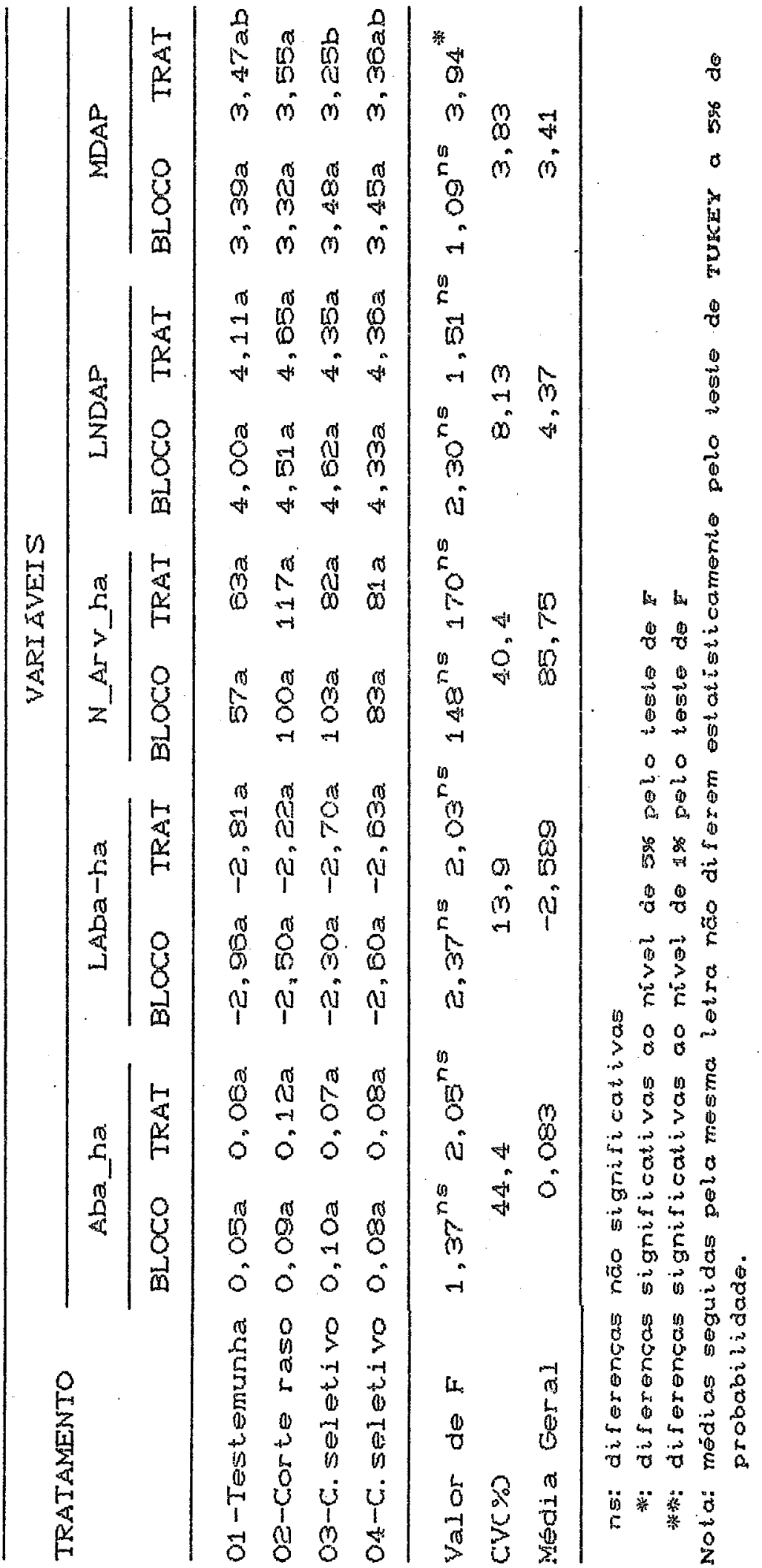


Tabela 35 - Coeficiente de Variaçăo (CV\%) e rumero otimo de parcelas (n) para a variavel N_Arv_ha.

\begin{tabular}{|c|c|c|c|c|c|c|c|c|}
\hline \multirow{3}{*}{ ANO } & \multicolumn{8}{|c|}{ TRATAMENTOS } \\
\hline & \multicolumn{2}{|c|}{01} & \multicolumn{2}{|c|}{02} & \multicolumn{2}{|c|}{03} & \multicolumn{2}{|c|}{04} \\
\hline & $C U(\%)$ & $\pi$ & $E V(\%)$ & $n$ & $C \cup\langle \%\rangle$ & $n$ & $C V(\%)$ & $n$ \\
\hline 1986 & 55,2 & 133 & 72,5 & 230 & $82_{3} 7$ & 300 & 87,0 & 331 \\
\hline 1988 & $6 \geq, 0$ & 168 & 60,3 & 159 & 76,7 & 256 & 82,3 & 286 \\
\hline
\end{tabular}

Diante da Tabela $35_{3}$ observa-sa que a emostragem pode ter intuenciado decisivamente sobre os resultadns da AUAva, pois o núners de parcelas utilizadas (20 pareelas) esta abaino do ideal de parcelas necescarias para cobrir a maior parte da variabilidade natural oxistente nos dados coletados.

$$
\text { Um estudo preliminar na tipologia florestal }
$$
estudata, poderia determinar, para o tratamento ol, o tananto ideal da parcela necessaria para inventariar os individuos na classe de diametro AA $(5-10 \mathrm{~cm}$, bem como o numero btimo de parcelas exigido para cobrir a maior parte da variabilidade natural Existente re foresta. For cutro 1ado. a determinaçăo do rumero e tamanto otimo das parcelas necessarios para o monitoramento dos tratamentos $2,3=4$, teria que ser obtida en areas extensas (t 50 ha), nas quais os tratamentos fossem aplicados. A metodologia empregada tamanho e núnero de parcélas, foi desenvolvida pejo cFatul ENEFAFA a adotada, sem modificaçBes, pela CVRD, visto ser un 
metodo recomendado e utilizado nos inventários da floresta tropical amazónica (SILVA LOFES, 1984).

Não obstante a AMOVA năo ter detectado diferenças estaristicas entre as medias das variaveis area basal e rúmero de individuos por hectareg no ano de 1980 foi observado um aumento no numero de especies en cada tratamento, en relaça a inventario realizado em 1986.

Os inventarios no numero de espécies, por tratamento, durante os anos de 1996-1788, säo epresentados na Tabela 36.

Tabela 3b - Incmemento $(\%)$ do numero de especies oberrvadas no periodo de $1986-1988$.

\begin{tabular}{|c|c|c|c|c|}
\hline \multicolumn{5}{|c|}{ TFATANENTAS } \\
\hline ANO & 01 & 02 & $O$ & $n$ \\
\hline 1756 & 20 & 20 & 19 & 23 \\
\hline 1988 & 25 & 25 & 28 & 25 \\
\hline
\end{tabular}

Indepondantamente do tratanenta, houve un incremento de $23,1 \%$ no numero total de especise, durante o pe-

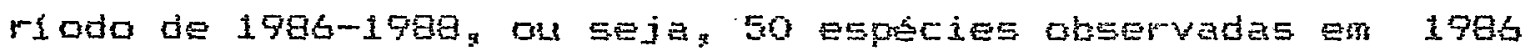
e 65 esperies observades em 1798. Esse increnento refere-Ee "entrada", no inventario de 1799 de 25 novas especies representadas por 19 fami ias 225 generos, e a "saida" da 10 especies distribuidas por 9 ramín

No tratamento ol dentre as 5 esperies que ingressaram em 1998, encontra-5e a castamheiras esperie con- 
siderada de dificil regeneração en condiçes naturais (KITAMURA, 1984). As especies que "salman" (ou morreram) das parcelas do tratamento 1 (testemunha), săo especies representativas do estágio inicial de regeneraça da foresta, tais como as caraiperanas (firtela sppis espetoranas (Cupania spp), Imbauba (Cecropia spp) Lcuubaranas (Sloanea spp).

No corte paso (tratamento 2), o incremento de novas especies foi iqual ao registrado no tratamento 1 ltestemunha). Surgimam no ano de 1998, especies da sucessă secundsiag. tais como as cedroranas (Cedrelinge spp) matamatas (Eschweleirc spp), paus-pretas (Cenostigma spo) =

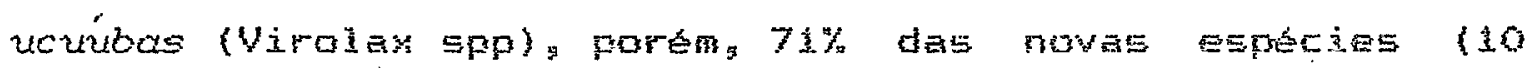
especies) Eão caracteristicas da sucesฐâ inicial da florasta (pioneiras elou secundarias iniciais). O numero de especies que "sairam" das partelas foi igual a 10, das quais bo\% 5ă dentre elas: Protium spp (breus), Sapium spp (burra laiteira) e Solanum spp (jumbeba).

O naigr incremento de especies roi cbtido na tratamento $\Xi_{3}$ sendo que $62,5 \%$ das especies novas sao carac-

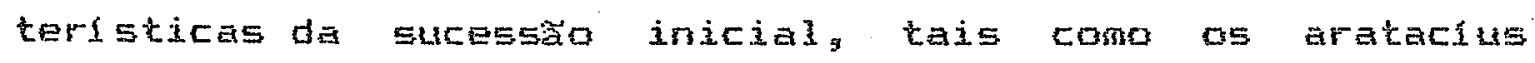
$($ Sagotia Spp), envires (Enguetia spo), imbauba (Cecropia spp), mutambas (oudzunc spp) e urucuranas (slodred skp). Ingressaran ainda esperies da sucessao secundaria inicial como os paraparas (Jacaranda spp), Leudbas (Virola spp) e tentos (Ormosia spp). Das E espraies que ocorperam en 19ab 
que nao foran registradas em 19ag, 3 pertencen ao estagio de sucessă inicial (imbaubas, mururss e periquiteiras) e sao tlpicas da sucessão secundaria inicial, os tentos lormosia spp) e abius (Pouteria spp).

0 menor incremento do numero de especies novas, foi observado no tratamento 4 (11 espeies que "entraram" contra 7 espécies que "selram" en 1998. Das especies que "entraram" no ano de 398 s ineluem as esperies pioneiras: enviras (Guatterie spp) s paliteiras (Cussia spp) periquiteiras (Cochlospermum spp) e taquaris (Habed spp), as quais juntan representan cerca de $37 \%$ do total de esperies novas. Dentre qutras epseies, foran obsorvadas. os tachis (Tachigalia spp), ingás (Inga spp), matematas (Eschweilera spp). As especies pioneiras forman certa te bo\% do total das Espécies, que "Eafram" no periodo de 19gb-1798, pepregentadas pelas especine: espetorana lCupania Espla treijólurua (Cordia spp), jurubeba (Solamum spo) e lacre (Visnid spo). As Especies de sucessa secumbria inicia que "sairam" forang ings (Ingd Epp) E natamata (Eschweilere spp).

A.7.2. Fesultados obtidos para os indlviduos estabew lecidos (SPI)

0 coeficiente de variaça (CVy) do ensaio, para as variaveis area basal (Aba_ha) E numero de individuas por hectare (N_Arv_ha) foi igual a $41,6 \%$ (alco) e $14,7 \%$ (medio), no entanto a honggeneizaca das variancias pola 
expresså logaritimica, In $X=N_{g}$ fez com que houvesse uma reduçăo nos coeficientes em torno de $75,6 \%$. Qs CV's para os dados transformados foram $14,7 \%=4,6 \%$ para as varibveis Aba_ha $e$ NArv_ha, respectivamente. 0 cV para a varisvel MDAF foi igual a $18,6 \%$ (dados sem transtormasao).

Dentre as variaveis testadas, a anklise de Variancia (ANOVA) detectou diferencas estatisticas significativas, ao nivel dos cratamentos), para varisvel N_Arv_ha (Tabela 37 ).

Entre as medias dos tratamentos, para a variavel NAry ha, o teste de Tukey indicou a superioridade significativa da media do tratamento 2 En relaço aus demais tratamentos. Näo houveram diferencas estati exicas Ejgrificativas, entre os tratamentas 1 a 3 . Ma tratanento 2 , no periodo de 1986-1989, houve o ingresso de 702 rovos individuos, que migraram da classe de diametro AA (5-10 cm) "Nos demais tratamentas, o incremento foi de 17540 a 140 individuas, nos tratamentos 1 ; 3 4, respectivamente.

No iratamento 2 , Ouociente de Mistura Medio (am) obsorvado en 1786 o igual a 1312,5, o que demonstra uma mistura de especies baixas porem semeltante ae on módio observado en 1986. 0 valor observado no tratamento 2 s superior aquele atribuido para as condicose neturais de mistura na sloresta tropical (FINOL 1971). En 1999 foram observados 149 especies, distribuidas por ne tamilias botanicas. Entre os anos de 1966 e 1989 houve um actoscimo de $38,3 \%$ no numera de ecteries (Tabela 10). 


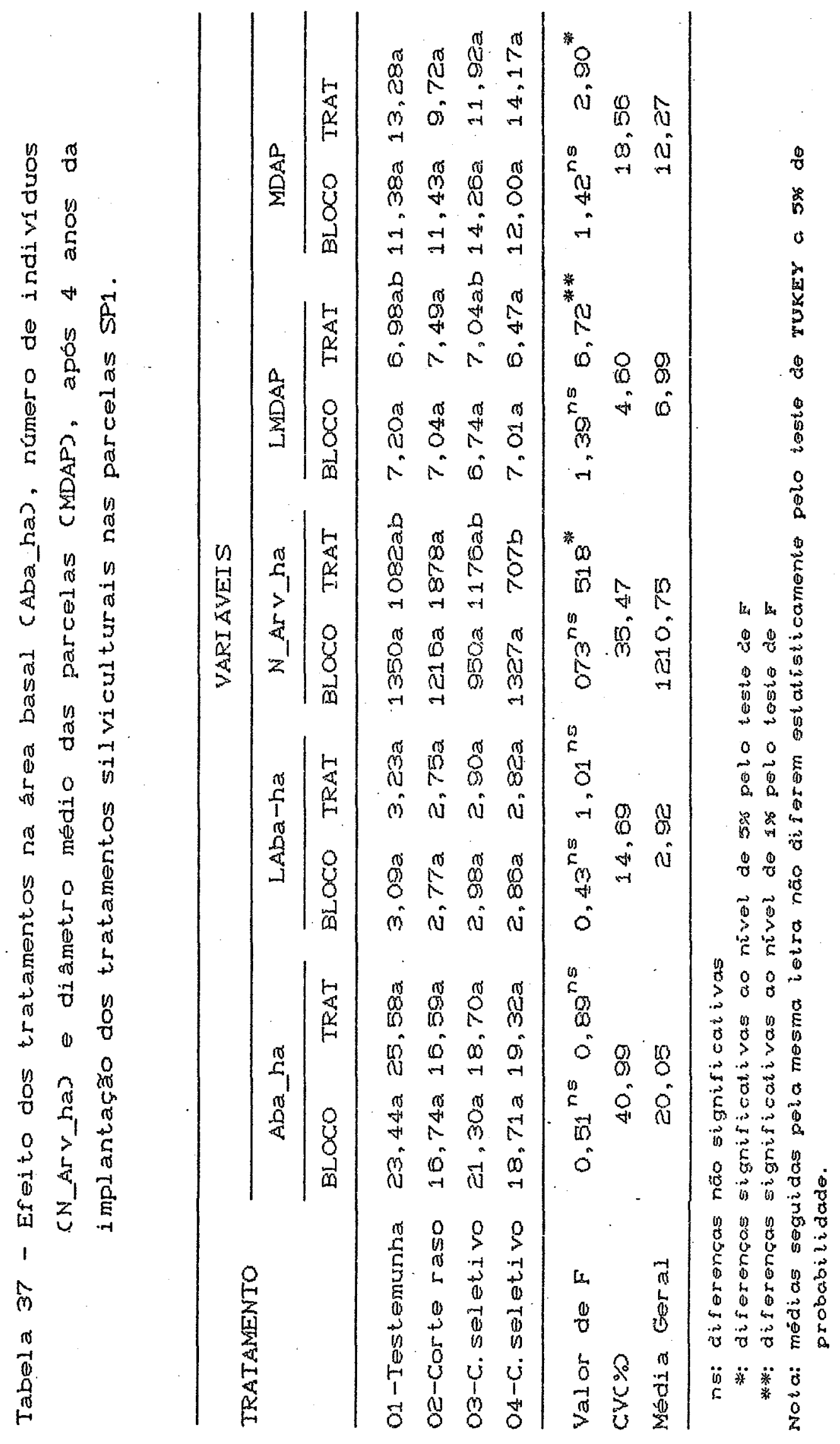


As especies pioneiras predominaram a composicăo florlstica das parcelas com o tratamento 2 as fami 1 ias botanicas mais abundantes foram Feg. Minosacede (14 especies) a Moracede (a especies).

Mesmo a ANOVA nå detectando diferencas Estatoticas significativas entre as medias dos tretamentos para as variaveis Ababa e MDAF ${ }_{3}$ dbsemou-se que para a area basal, o tratamento 2 (corte raso) atingiug en quatro anos de crescimento, 64 g $3 \%$ da (testemunha) , fato este favorecido pelo crescimento inicial das especies tipicas be tese inicial de regeneracä da

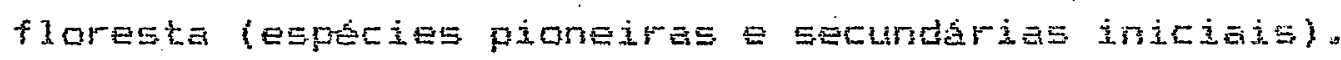

Nos tratamertos 3 a 4 à área besal media remanescente represanta $73,1 \%$ e $75,5 \% g$ respectivanente, en relaçăo d artea basal media das parcelas testemenhas.

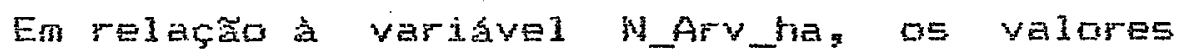
médios obseryados entre os tratamentas denungtram a Euperioridade numerica do tratanento 4 sobre ds tratamentos 2 e 3 assemelha-se mécia do tratamento 1 . Apesar de senelhanca entre as medias dos tratamentos 1 e 4, neste, o numero de especies é cerca de $27 \%$ inferior ad número de especies observadas nas parcelas com o tratanento 1.

4. 8. Análise do Creschmento

A determinagå do incremento de novos indivi- 
anual en area basal dos tratamentos testados, foram realizadas a partir dos dados comstante nas Tabelas 38 e 39.

\subsubsection{Incremento do número de individuos CNArv_ha}

A Tabela 39 mastra a evaltiga do numpro de individuos por hectares por tratamento e classe de dicmetro. A mortalidade natural (A) foi maior no tratamento 2, na classe de dismetro AA $(5-10 \mathrm{~cm})$. Ds individuos que morreram neste tratamento e classe de DAF pertecen as especies do estagio iniciel de sucessa da trafesta representados na sua thatoria por inbarbas (cecropic spo). Nos demais tratanatos a mortalidade tamborai maior nas classes de diametro $A A$ A $(5-20$ EN). A mortalidade das eEpécies nas classes de dianetro acima de 45 cm lchasese 0 , E E F) E reduzida, pois apenas i individuo, no tratamento 4. morreu ne classe E. Nas classes $E$ e $C$ a mortalirade nabural foi. bairag en torno de $9 \%$ o\% $0 \%$ a $17 \%$ do total dos tratamentos $1,2,3,4$, respectivanente. 0 ingresso de novos individios (I) nes parcelas experimentais foi maior nos tratamentos $4=2<140=130$ individuos, respectivamente) : cujos tratamentos contempiaran a abertura de clareiras grandes, no corte raso e pequenas e medias, no corte dos individuas com DAP $20 \mathrm{~cm} e$ DAFy $60 \mathrm{~cm}$. Nestes tratamentos foram favorecidas as especies pioneiras, as quais compon a maioria dos inoividuos que ingressaram nas parcelas experimentais. 
Tabela 39 - Ingressos (I) e mudancas de classe (T) de indiViduns, observado en 1988.

\begin{tabular}{|c|c|c|c|c|c|c|c|c|c|c|}
\hline \multirow{3}{*}{$\begin{array}{c}\text { CLASSE } \\
\text { DAP }\end{array}$} & \multicolumn{5}{|c|}{ TFATAMENTO $I$} & \multicolumn{5}{|c|}{ TFATAMENTO 2} \\
\hline & \multicolumn{2}{|c|}{$n^{\circ}$ ind } & \multirow[b]{2}{*}{$A$} & \multirow[b]{2}{*}{$I$} & \multirow[b]{2}{*}{$T$} & \multicolumn{2}{|c|}{ n: ind } & \multirow[b]{2}{*}{$A$} & \multirow[b]{2}{*}{$I$} & \multirow[b]{2}{*}{$T$} \\
\hline & 1986 & 1988 & & & & 1986 & 1980 & & & \\
\hline$A A$ & 659 & 646 & 28 & 16 & 17 & 1456 & 1226 & 360 & 130 & 702 \\
\hline$A$ & 323 & 329 & 11 & - & 9 & 58 & 757 & 3 & - & 7 \\
\hline B & 51 & 99 & 1 & - & 4 & 1 & 10 & - & - & 0 \\
\hline$C$ & 34 & 35 & 3 & - & 1 & 1 & 1 & - & - & 0 \\
\hline $\mathrm{D}$ & 14 & 15 & 0 & - & 2 & 1 & 1 & - & - & - \\
\hline$E$ & 7 & 9 & 0 & - & 0 & - & - & - & - & - \\
\hline \multirow[t]{2}{*}{$F$} & 12 & 12 & 0 & - & 0 & - & - & - & - & - \\
\hline & 1139 & 1145 & 43 & 16 & 33 & 1517 & $159 \mathrm{E}^{2}$ & 365 & 130 & 711 \\
\hline
\end{tabular}

\begin{tabular}{|c|c|c|c|c|c|c|c|c|c|c|}
\hline \multirow{3}{*}{$\begin{array}{c}\text { CLASSE } \\
\text { DAP }\end{array}$} & \multicolumn{5}{|c|}{ TFATARENTO 3} & \multicolumn{5}{|c|}{ TFATAWENTO } \\
\hline & \multicolumn{2}{|c|}{$n_{0}^{\circ}$ ind } & \multirow[b]{2}{*}{$A$} & \multirow[b]{2}{*}{$I$} & \multirow[b]{2}{*}{$T$} & \multicolumn{2}{|c|}{$n:$ ind } & \multirow[b]{2}{*}{$A$} & \multirow[b]{2}{*}{$I$} & \multirow[b]{2}{*}{$T$} \\
\hline & 1980 & 1909 & & & & 1706 & 1958 & & & \\
\hline$A A$ & 751 & 757 & 34 & 40 & 42 & 366 & 485 & 23 & 140 & 192 \\
\hline$A$ & 306 & 366 & 12 & - & 14 & 23 & 215 & 2 & - & 5 \\
\hline E & 75 & 87 & 2 & - & - & 43 & 45 & 3 & - & - \\
\hline $\mathrm{C}$ & 34 & 34 & - & - & 8 & 23 & 23 & - & - & 5 \\
\hline$D$ & 5 & 13 & - & - & - & 12 & 17 & - & - & - \\
\hline$E$ & - & - & - & - & - & 5 & 4 & 1 & - & - \\
\hline$F$ & 1 & 1 & - & - & - & 3 & $\Xi$ & - & - & - \\
\hline & 1202 & 1258 & 48 & 40 & 64 & 475 & 799 & 29 & 140 & 202 \\
\hline
\end{tabular}

Onde:
$A=$ mortalidade natural
$I=$ ingressos de individuos no perído $1996-1990$
$T=$ mudargas de classe do perfodo 19ab-19ag

A mudanga dos individuos das classes diametricas inferiores para as imediatamente suberiores (I) foi mais 
intensa nas classes $A A$ para $A \equiv A$ para $B$, sendo que no tratamento 2 houve a transferancia de 702 individuos da classe AA para A. Nos demais tratamentos esse valor fai igual a 17, 42 e 192, para os tratamentos 1, 3, E 4 respectivamente. No tratamento 1 (testemunha) houveram mudanças de individuos entre 6 das 7 classes diametricas da populaçang fato este que demonstra o dinămico crescimento das espócies da floresta tropical.

4.B.2. Crescimento en area basal $\mathrm{m}^{2} / \mathrm{ha}$.

A Tabela 39 apresenta os valores das areas basais abtidas en 1996 1998, pot tratanentas a classe diametrica, pelas quais toram calculados os efescimentos peribdico e anual da brea basal, sequndo classes de dismetro e tratamentos.

A Figura iz mostra o crescimento anuals por classe diamétrica, de todos as tratamentas testados.

Dentre ce tratamentos testados, a menor percentagen de crescimento anual foi obsarvada no tratamento 1 , basal do ano de 1989. Nas pareelas testemuntas foi obtido um valor medio de crescimerito de 0,6 sug $^{2}$ /halano. 
Tabela 39 - Crescimento periudico e anual em area basal $\left(\mathrm{m}^{2} / \mathrm{ha}\right)$, apos 4 anos da implantaça dos tratamentos silviculturais.

TFATAMENTO 1

\begin{tabular}{|c|c|c|c|c|c|c|}
\hline \multirow[b]{2}{*}{$\mathrm{CD}$} & \multicolumn{2}{|c|}{ AFEA BASAL $\left(m^{2} /\right.$ ha $)$} & \multirow{2}{*}{$\begin{array}{c}\text { MOFTAL TOADE } \\
\left(m^{2} / \text { ha }\right)\end{array}$} & \multicolumn{3}{|c|}{ CRESCIVENTO $\left(m^{2} /\right.$ ha $)$} \\
\hline & 1986 & 1799 & & PEFI ODO & ANO & $\%$ ANUUAL \\
\hline$A A$ & 2,47006 & 2,46011 & 0,00047 & $-0,00949$ & $-0,00474$ & $-0,2$ \\
\hline A & 5,00491 & 5,06220 & 0,00431 & 0,0616 & 0,0308 & 0.6 \\
\hline$\Xi$ & 4,21439 & 4,56042 & 0,00273 & $0_{3} 34976$ & 0,17438 & $3, a$ \\
\hline $\mathrm{C}$ & 3.14925 & 3,19632 & 0,03326 & 0,08135 & 0,04065 & 1,3 \\
\hline D & 2,15662 & 2,37897 & 0 & 0,19235 & 0.09117 & $\Xi_{8} \theta$ \\
\hline$E$ & 1.65510 & 2,16810 & 0 & 0.513 & $0,2 \div 65$ & 11,9 \\
\hline \multirow[t]{2}{*}{$F$} & 5,67552 & 5,92417 & $a$ & 0,15065 & $0,075,52$ & 1,3 \\
\hline & 24,36495 & $25_{3} 6523$ & 0,04077 & 1,52818 & 0,66405 & $2, a$ \\
\hline
\end{tabular}

TFATAHENTO 2

\begin{tabular}{|c|c|c|c|c|c|c|}
\hline \multirow[b]{2}{*}{$C D$} & \multicolumn{2}{|c|}{ AFEA FASAL $\left(m^{2} /\right.$ ha $)$} & \multirow{2}{*}{$\begin{array}{c}\text { MOFTALIDADE } \\
\left(m^{2} / \mathrm{ma}\right)\end{array}$} & \multicolumn{3}{|c|}{ CFESCINANO $\left(\mathrm{m}^{2} / \mathrm{ha}\right)$} \\
\hline & 1996 & 1908 & & FERI ODO & AND & F ARULAL \\
\hline$A A$ & 4,79001 & 5,07011 & 0,00106 & 0,28116 & 0,14059 & 2,9 \\
\hline A & 0.54229 & 10,5917 & 0,00034 & 10,04973 & $5_{3} 02498$ & 47,4 \\
\hline E & 0,03626 & 0,39992 & $a$ & 0,36354 & 0,15177 & 45,5 \\
\hline C & 0.07410 & 0,10522 & 0 & 0,0311 & 0,01555 & 14,8 \\
\hline \multirow[t]{2}{*}{$F$} & 0,48700 & 0.5462 & 0 & 0,0598 & 0,0294 & 5,4 \\
\hline & 5,93005 & 16,7130 & 0,00140 & 10,79436 & 5,39219 & 32,3 \\
\hline
\end{tabular}


Tabela 39 - Contimuação.

\begin{tabular}{|c|c|c|c|c|c|c|}
\hline \multirow[b]{3}{*}{$\mathrm{CD}$} & \multicolumn{6}{|c|}{ TFATANENTO 3} \\
\hline & \multicolumn{2}{|c|}{ XFEA BASAL ( $\mathrm{m}^{2}$ iha) } & \multirow{2}{*}{$\begin{array}{c}\text { MOFTAL IDADE } \\
\left(m^{2} / \mathrm{na}\right)\end{array}$} & \multicolumn{3}{|c|}{ CFESEIIIENTO $\left(m^{2} / \mathrm{ha}\right)$} \\
\hline & 1986 & 1908 & & PERI DDO & ANO & $\%$ ANUUAL \\
\hline$A A$ & 2,70001 & 2,9401 & 0,00062 & 0,24071 & 0,120355 & 4,1 \\
\hline$A$ & 5,10737 & 5,7064 & 0,00258 & 0,06161 & 0,30081 & 5,3 \\
\hline $\bar{E}$ & 3,34866 & 4,02532 & 0,00425 & $0_{5} 68099$ & 0,34044 & 8,4 \\
\hline$C$ & 3,27002 & 3.2179 & 0 & -0.05212 & $-0,02506$ & $-0,8$ \\
\hline$D$ & 0.67377 & 1,80457 & 0 & 1.13073 & $0,5,5537$ & 31,3 \\
\hline \multirow[t]{2}{*}{$F$} & 1.07767 & 1.08350 & 0 & 0,00583 & 0,00291 & 0,3 \\
\hline & 16.17750 & 19.7777 & 0,00745 & 2,60765 & 1,57206 & $9, a$ \\
\hline
\end{tabular}

TEATANENTO A

\begin{tabular}{|c|c|c|c|c|c|c|}
\hline \multirow[b]{2}{*}{$C D$} & \multicolumn{2}{|c|}{ AEEA BASAL $\left(m^{2} / \mathrm{ha}\right\}$} & \multirow{2}{*}{$\begin{array}{c}\text { WOFTALIDADE } \\
\left(\mathrm{m}^{2} / \mathrm{ha}\right)\end{array}$} & \multicolumn{3}{|c|}{ DFEOCIIENTO $\left(\mathrm{n}^{2} / \mathrm{ha}\right)$} \\
\hline & 1986 & 1560 & & PEFI UDO & $\mathrm{AuO}$ & $\%$ AWIAL \\
\hline$A A$ & 1,08001 & 1,5601 & 0,00031 & 0,96487 & 0,43843 & 22,1 \\
\hline$A$ & 0,28891 & 2,8364 & 0,00068 & $2,5,8317$ & 1,27508 & $4.4,9$ \\
\hline$E$ & 2,17958 & 2,3107 & 0,00796 & 0,13899 & 0,06949 & 3,0 \\
\hline $\mathrm{C}$ & 2,1591 & $z_{7} 1473$ & 0 & $-0,01100$ & $-0,00059$ & 0,3 \\
\hline$D$ & 1.73902 & 2,6608 & 0 & 0,52179 & 0,46089 & 17,3 \\
\hline$E$ & 1.19795 & 0,9601 & 0,00744 & $-0,31529$ & $-0,15764$ & 16.4 \\
\hline \multirow[t]{2}{*}{$F$} & 6,5107 & $6,5.65$ & 0 & 0.00500 & $0_{3} 0029$ & $a_{1}$ \\
\hline & 15,15527 & 17,3919 & 0,08629 & 4,32292 & 2.16146 & 11,3 \\
\hline
\end{tabular}




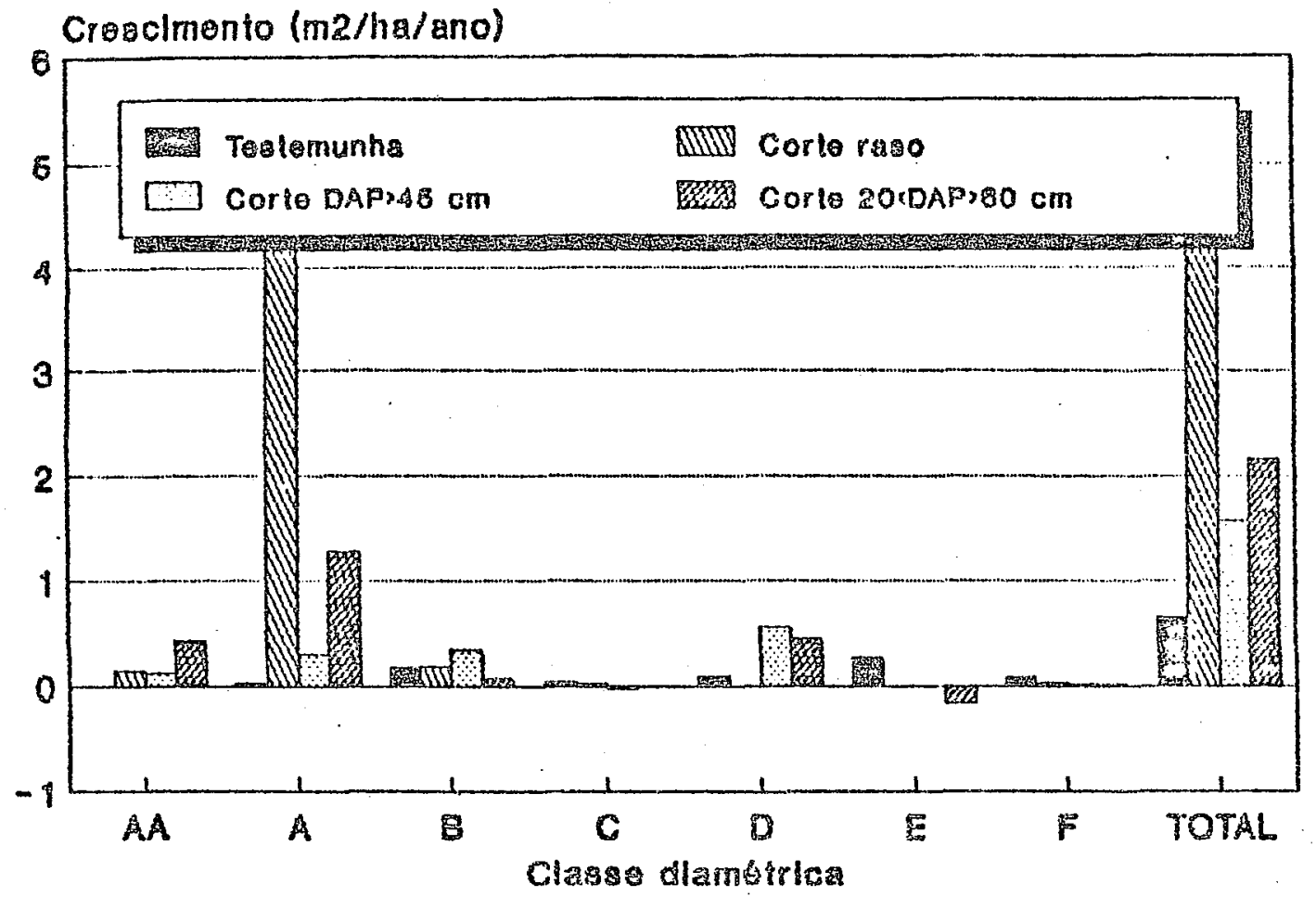

Figura 12 - Crescimento anual en Area basal $\left(\mathrm{m}^{2} / \mathrm{ha}\right.$ ) no pojriodo $1796-1789$.

O crescimento anual no tratamento 2 foi iqual a $32,3 \%$ da area basal de 1900 e foi maior nas classes de diâmetro AA $=A$ (96\% do total anual). $Q$ yalor total anual observado, $5,37218 \mathrm{~m}^{2} /$ had crescimento doservados nos demais tratamentos, porem, espera-5e que taja uma disinubça do ritmo de erescinento neste tratamentog visto que as especies que campon a maior parte do crescimento observado pertencen ao estágio de regeneraçă inicial da floresta, e que frequentemente irăo competir entre si por ejpaco e luzg Eendo substituidas posteriormente por outras espécies com caracteristicas ecologiCas adaptadas às novas condigcos ambientais do tratamento. 
Nos tratamentos 3 e 4, o creacimerto anual roi iqual a $1,57 \mathrm{~m}^{2}$ /he e $2,16 \mathrm{~m}^{2} /$ ha, respectivamente. No tratamento 3, o crescimento nas classes AA 2 A representaram $26,8 \%$ do total anual, encuanto que no tratamento 4 este valor atingiu cerca de $79 \%$ do total de crescimento amual. Estes valures coincidem con as arimativas de MofaEs (1970) de que, o creecimento periodico en circumfersncia do tronco proximo a $10 \mathrm{~cm}$ maior do que nas classes diametricas mais altas. 


\section{CONCLUSOEES}

Em face aos resultados obtidos, pode-se con cluir que, nas condiços do ensaio:

a) A implantaço dos tratamentos silviculturais reduziug nos tratamentos 3 e 4 , en modia, $50 \%$ da brea basal e $27 \%$ e $79 \%$ do numero de individuos, respectivamente. A producäo midia de lenha (st) a medeira serravel (m) por hectaro fai maior no tratamento 2, porem as aspectos gualitativos da regeneraça natural, ads quatro anos de idade, 5ão inferiores aos demais tratamentos.

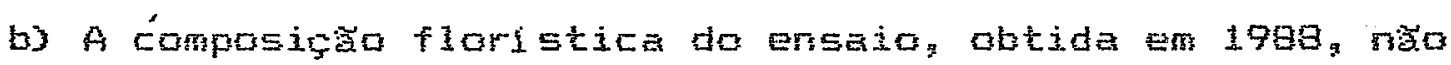
roi comparada con a composiço do imventario iricial (1504)* uma vez que as metodologias e condicbes empregadas nos inventarios räo foram as mesmes. No entanto em relaçăo ao inventario realizado en 1796, sob mesmas condiçes, abeervau-se um aumento medio de $27 \%$ no numero do especies novas, no estagio SPI y $16 \%$ no estagio SP2 e $23 \%$ no estagio SFs. 
c) O Quociente de Mistura (GM) medio obtido no tratamento (testemunha), em 1989 fai inferior ans valares atribuidos para florestas tropicais naturaiss porems semelnante aos resultados apresentados por SALOWAO (1999), revelando que a composiça floristica da tipologia florestal estudada relativamente pobre em rumero de especies arboreas. No tratamento 2 (corte raso), o an medio foi intluenciado pela ocorrencia das espécies piomeiras, fato este que contribuiu para a homogeneizạ̧o floristica das unidades. No tratamento 3 (corte dos individuos com DAF $\geq 45 \mathrm{~cm}$ ) 05 resultados indicam que, en ralaço a 190 , não houveram mudanças acentuadas na composiçăo floristica das unidades experimentais. Ho entartag o Guociente de Wistura medio obtido no iratamento 4 (corte dos individus con $20 \geq$ DAP $\geq$ $60 \mathrm{~cm}$, mostrou que entre 1996 e 1799, houve un axmento da diversidade floristica nas unidades experimentais..

d) a efeito dos tratamentos silviculturais gobre a composição das esperies ecolagicamente mais importantes lcom os maiores IVI), no estagio de veras (SFZ) e plantas estabelecidas (SP1), foi mais acentuado no tratanento 2. para 0 dois estágios. Nos demais tratamentos houve semel hanca entre a composiça das esproies mais impottantes en 1989 e 1796. No entanto, observou-se em 1798, o surgimento, nas unidades experimentais com o fratanento 4, de esperies con potencial silvicultural, cono os paricás 
(Schizolobium amazonicum e paraparas (Jacaranda copai $)$, assim como a regeneraça natural de Eertholletia excelsa (castanheira) nas parcelas experimentais com os tratamentos 123.

e) A regeneraçăo natural toi inventariada em un numero de parcelas (SF2 e SF3) abeixo do ideal, no entanto, con as dados obtidos foi possivel comparar o efeito dos tratamentos em relaçăo alguns aspectos qualitativos da regeneração natural. Houve un aumento de $23 \%$ no rumero total de especies no perrodo de $1786-1980$.

f) A floresta se regenere cresce en ritimos diferentes e de acordo con os tracamentos adotados. A andise de Variancia efetuda en 1989 nag detectou diferencas significativas entre as abdias da brea basal dos tratamentas, porbm, con puetro anos de erescimanto, a krea basal do bratamento 2 cerca de $74 \%$ da area basal inicial nos tratamentos 3 e 4 este percentual ef de $74 \%$ e $76 \%$ respectivamente. 0 crescimento en drea basa foi maior g em todos as tratamentos, nas clasess diambtricas infariores $(5-20 \mathrm{~cm})$.Por sua vez, para a variavel Nary ha (numero de individuas por hectare), a ANOVA detectou diferangas estatisticas significativas entre os tratamentos e pelo teste de TUKEY observau-se a superiorideda do frakamento 2 sobre os demais tratamentos e a igualdade estatistica entre as tratamentos 1 B. 
9) Com quatro anos apos terem sido realizadas as interferencias silviculturais, a ingresso de novos individuos, nos tratamentos 2, 3 4, foi constituido na maior parte, por especies do estágio inicial da regeneraça da floresta (pioneiras esecundarias iniciais), e a mortalidade natural foi acentuada entre as especies pioneiras na classe diametrica $5-20 \mathrm{~cm}$.

h Apesar dos valores dé crescimento da area basal e do incremento de novos individuos obervados no ensaiog a escolta de um modelo ideal para o manejo corpeto da floresta, beseado en un periodo de observaceses de apenas quatro anos, fe prematuro, uma ves que ha necessidade de obter informaços complementares sohre o ritmo de crescimento e o comportamento das especies da torrata quando submetidas à diferentes niveis de explaraçăo, ben como, a definição de um sistema de amostragem para a monitoramento das especies nos diferentes estágios de desenvolvimento existentes na floresta. For outro lado, a utilizaçäo do corte raso (tratamento 2) en regioes com florestas tropicais umidas, como modelo de manejo flarestal Eustentado atraves do uso múltiplo da floresta, nã deve ser adotado como pratica silvicultural, uma vez que o equilibrio -ecologico da floresta é drasticamente alterado $e$ a sustentabilidade do ecossistema, quando retomada, inviabiliza o manejo florestal sob a ponto de vista sócio-ecanomico. 
i) Os estudos sobre o manejo da floresta tropical amazónica sao escassos, e raros são aqueles que visam conhecer os efeitos de diferentes praticas silviculturais sobre a composicão floristica e o crescimento das espécies da floresta.

j) Os ensaias de manejo flomestal deven assumir Em regizes de grande pressão ambiental, alem do papal cientrfico e didatico, una funça demonstrativa, na gual se integram e interagem estudos basicos e outros Estudosy tais como a formaça de mäo-de-obra regional qualificada fidantificadores botanicos, trabalhador florestal, administradores florestais, ete.), economicos e Ergonomotricos. Areas com 50 a 100 ha 5 ă ideais para o desenvolyimento de programas integrados em unidades demonstrativas de manejo florestal. 


\section{REFERENCIAS BIBLIOGRAFICAS}

AGUSTIN, C.V. Avaliaçáo estrutural e quantitativa de una floresta tropical unida em Iquitos-Peru. Curitiba, 1981. 144p. (Tese-Mestrado-UFFr).

ALVES, A.A.M. TEcnicas de produçáa florestal, Lisboa, Instituto Nacional de Investigarăo Cientsfica. 1982. 331p.

AlUIM, P. de T. Tree growth periodicity in tropical elimates. In: ZIMMERHANH, W.H. The formation of wood in forest trees. New York, Acadenic Press, $1764,559 \mathrm{p}$.

ASABEFE, P.K. Attempts as sustained yield management in the tropical high forest of Ghana. In: MEFGEN, F. \& VICENT, 3.F. Natural managements of tropical moist forests. Yale University - New Haven, 1987, p. 47-70.

GARROS, P.L.C. Estudo das distribuiçôs diametricas da floresta do planalto do Tapajos - Para. Curitiba $1960.123 p$. (Tese-Yiestrado-UFFr).

EARROS, P.L.C. Estudo fitossociologico de una floresta tropical úmida no planalto de curuá-Una, Amazonia Brasileira. Curitiba, 1796 . 158p. (Tese-Doutoramento-UFPr).

BAFROS, P.L.C. de. Curso de reciclagem em manejo de flcrestas tropicais. Felem, FCAP/UAE, 1970. (Apontamentos). 
EATISTA, J.L.F. A funço Welbull como modelo para a distribuiçao de dímetro de especies arbóreas tropicals. Firacicaba, 1989, 125p. (Tese-Mestrada-ESALQ).

CAINE, S.A. \& CASTFD, G.M. de D. Aplication of some phytosocialogical techniques to Erazilian Rain Forest. Amer. J. Bot., $43(3): 205-17,1956$.

CAFVALHO, J.Q.P. Analise estrutural da regeneraçao natural em floresta tropical densa na regixo do Tapajós no Estado do Pará. Curitiba, 1782. 127p. (Tese-Mestrado-UFPr).

CAFVALHO, J.0.F. de. Fesultados de pesquisas da ENhrara/ IEDF-FWFF Sobre manejo de floresta no Tropico unido Erasizeiro. In: Seminario Internacional sobre Manejo em Flow resta Tropical, 1. Serra dos Carajas-PA, $1985.21 p$. (ñá publicado).

CAFVALHO, J.O.F. de. Subsidios para o manejo de florestas naturais na Amazonia Brasileira: resultados de pesquisas da EMBRAPA-CPATU.TBDF-CHPF. BE1Ém, EMBRAPA-CPATU, 1987. 35P. (ENTFAPA-CFATU. DOCumENTOS. 43).

CAFVALHO, 3.0.P. de. Manejo de florestas naturais na Amazom nia visando a utilização racional de seus recursos. Rio de Janeiro, 505 Wata Atiantica, 1989. 17p.

CARVALHO, J.Q.P dE = LUPES, J.C.A.5 SILVA; J.N.H.; COSTA, MALCHER, L.G.; CAFVALHO, M.S.F.de. Pesquisas com vistas ao manejo de matas nativas na regiäo do rio Jari. Helén, EMERAFA/CFATU, 1997. 21p. (EHERAFA-CFATU. DOEUmEntos, 45).

CATINOT, R. SyIviculture tropicale en foret dense africaine. Bois et Foret des Tropiques, $(100): 5-18,1765$. 
DANTAS, M. Estudos de sucessăo e produtividade primária em áreas desmatadas da Reserva Florestal de Maraba-cVRD: Oxford, Departament of Zoology, 1987. 3Bp. TRelatorio de pesquisa) -

DIAS, G.M.E. Manejo de renovales: el peligro de generalizar. Chile Forestal, Santiago, (156): 21-3, 1798:

DINIZ, T.D. de A.S. EASTOS, T.X. Contribuira a conhecimento do clima tipico da castanha-do-brasil. Eoletim Tecnico do IPEAN, EeIten, (64): 59-71, 1974.

DuEOIS, J.L.C. Silvicultural research in the Amazono FAO, Foma, 1971. 192p. (FAO.Technical Feport, 3 ).

ENGEL, VL: JESUS, F.H. R GAFCIA, A. A FESErva Flarestai de Marata. Ina Congresso Brasileiro de Derésa do Meio Ambiente, 1. Fio de Janeiro, 1997. Anaie, UFFJ, $1989 . p$. $901-39$.

FALESI, I.C. : FREIFE, E.M. da S. SILVA, L.G.T. Levantamento de reconhecimento de média interisidade dos solos e avam liaço da aptidáo agricola das terras da Estrada de ferro Carajás. Eejem, CUFD. 1984. 104p.

FAO. Troplcal siviculture. Foma 1958. 190p. (FAO. Forestry and forest products studies, 13 ).

FAD. Tropical Forestry Action Plan. Fome, 1795. 159F.

FAO. Plano de Aça: Floresta Tropical. Fona 198a. 3zp.

FEAFUSIDE, F.M. Desmatamento na Amazonia Erasileira: que intensidade ven ocorrendo. Acta Amazonica, flanaus, $12(3)$ : $579-90,1982$. 
FEARNSIDE, P.M. A floresca vai acabar? Ciencla Hoje, Rio de Janeiro, $2(10)$ : 42-52, 1984.

FEAFNSIDE, P.M. O carvăo de Carajas. Ciencla Hoje, fio de Janeiro, $8(49): 17-21,1988$.

FEARMSIDE, P.M. Causas do desmatamento da Amazonia Erasileira, Para-Desenval vímento, Eelém. 23: 24-33. 1998.

FINOL, U.H. Foseibilidades de mariejo silvicultural para 1 as reservas forestales de la region occidental. Rev. For Venez., 12(17): $81-107,1969$.

FINOL, U.H. Ruevos parametros a considerarse en el analises Estructural de las Eelvas virgines tropicales. Rev. For Venez., $14(21): 27-42,1971$.

FINOL, U.H. La silvicultura en 1 a Orinoquia Venezolana. Rev. For Venez., $18(25): 37-114.1975$.

FONSECA, F.F. de A, Consequencias ecologicas da implantaçăo da siderúrgica a carva vegetal na regiå da Ferrovia de Carajas. Para-Desenvol vímento, Belem; 2e: 31-34, 1997.

FONT-QUEF, F- Dicionário de botânica. Labor garceicna, 1975. $1244 \mathrm{p}$.

GAFCrA, A. A Reserva Florestal de Marabá, FFDSA/NFAL, Açailândia - MA, 1988, Gp. (ña publicado).

GOLFARI, L. El belance hidrico de Thomthuaite como guia para estabelecer analogia climaticas: algunos ejemplos en Pinus radiata D. Don. In: World symposium on manmade forest and their industrial importance, Roma, FAO, 1967. p. $981-92=$ 
GOLFAFI, L. Zoneamento ecologico para reflorestamento na área de influencia da Serra de Carajas, Revista cveo, Rio de Janeiro, (12): 2-19. 1980.

GUTIERREZ, A.M.R. Efecto del raleo sobre el crecimiento en area basal de un bosque secundario an el tropico humedo. Turrialba, 1970. 77p. (Tese-Mestrado-IICA).

HARTSHOFM, G.S.: SIMEONE, F. E TOSI, J.A. Jr. Manejo para rendimento sostenido de bosques naturales. Un sinopsis del projecto de desarrolio del falcazu en la selva central de la Amazonia Feruana. In: COLONg J.C.F. el dí.s ed. Management of the forest of tropical America: Projects and technologies. Fic Fiedra, ITF/SFES, 1907. p. $235-25 B$

HOSOKAWA, R.T. Maragement of humid tropical torest in supported yield system in Erazil. In: Reuniáo dos paises produtores de materiampima: madeira. FUFEF/TSC-JICA, Curitiba, 1981. 16p.

HOSOKAWA, F.T. Manejo e economia de florestas. FAD/ONU, Foma , 1786. 125p.

HUSCH, E. Forest mensuration and statistics. Mew York, Fionald Frese. 1763. 474p.

INPE aponta reduça da area de queimadas na Amazonia Legal. O Liberal, Eelem, 13 jun. 1999. p. 3.

JAKKAUSKIS, J. Recuperaça de florestas tropicais mecanicamente exploradas. EEl Em, SUDAl, 1979. $58 \beta$. 
JARDIM, F.C. da S. Estrutura da floresta equatorial timida da Estaçao Experimental da Silvicultura Tropical do INPA. Manaus, 1985. 198p. (Tese-Mestrado-IMFA).

JESUS, R.M. \& MENANDFO, M.5. Produção sustentada en florestas Amazonicas. In: Congresso Florestal Estadual, 6. Nova Frata-FS. 1988. Anais Nova Prata-RS, UFRS, 1898. P. $953-64$.

KITAHURA, F.C. Castanhais nativos de Maraba-PA: fatores de depredaça e bases para a sua preservaço. EMERAFA-CFATU, Eelèm, 1794. 32p. (ENGFAPA-CFATU, Documentos, 30).

LAMPRECHT, H. Ensaio Eabre la estructura floristica de la parte sur-oriental del Bosque Universitario "El caimital" - Estado de Earinas. Rev. For Venez., 7(10-11): 77-117. 1964.

LONEHT, 5.J. Estrutura de uma floresta natural de Araucaria angustifolia no sul do Brasil. Curitiba, 1980. 219p. (Tese-Mestrado-LFFr).

MATCS, G.F \& MONTOYA MAGUIN, J.M. E1 sistema Dansereau para 1 a descripción estructural de 1 a vegetacion. Turrialba, 16 (12) $=167-90,1966$.

MISFA, D.N. Current management concepts in forestry. Ina HALLSWOFTH; E.G. Socio-economic effects and constraints

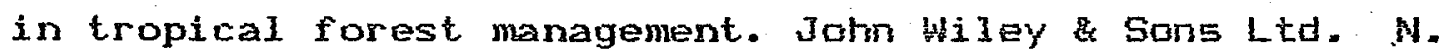
York, 1982. B. 191-201.

MONTQYA PAQUIN, J.H. E1 acuerdo de Yanganbi (195b) como base para une nomenclatura de tipos de vegetacion en el tropico americano. Turrialba, 18(12): 167-80, 1966. 
MORAES, V.H.F. Feriadicidade de crescimento do tromco em arvores da Floresta Amazónica. Boletin Tscntco do IPEAN, Eelem, 52(5): $312-20,1970$.

NICHOLSON, D.I. Lenght requiriments of seedlings of five species of dipterocarpaceae. Malayan Florester, 23(4): $344-56,1960$.

NWDROSHI, L,C. Fegeneration Success of natural managenent, enrichment planting and plantations of rative species in West Africa. In: MEFGEN, $F$. Q VICENT, J.F. Nateral managements of tropical molst forest, yale University. New Haven. 1987. p. $71-93$.

OREN, D.C. Uma reserva Eioligica para o Maranhöo. Cithela Hoje, rio de Janeiro, 8(44): $36-45_{g} 1985$.

FHILIP, W. S. Otstacles to measuring growth and yield in tropical rain forest. In: MEREEM, F. VICENTE, J.R. Natural management of tropical moist forest. Nex Haven; Yaje University, 1997 . Fa 135-48.

PHILlifs, J. villizacion de $10 s$ bosques troplcales centroam mericanos, plantaciones $y$ usos industriales de la madera. Turrialba, IICA, $1768.16 \mathrm{p}$.

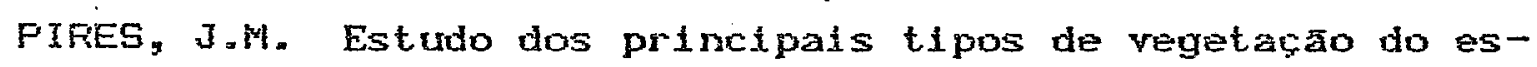
tuário do Anazonas. Firacicaba, 1972. 198.p. (TEse-Doutoramento. ESALG).

PIfES, J.H. Aspectos Ecologicas da floresta amazorica. In: Congresso Brasileiro de Florestas Tropicais, 3. Massoro, 1976. Anais. ESAM, 1776. P. 235-87. 
PIRES, J.M. a conceito de floresta tropical. Revista CVRD, Rio de Janeito, 2(5): 17-20, 1781.

RADAMERASIL, Folha SB-ZZ Araguala e Parte da Folha SC-Z2 Tocantins. ME. Fio de Janeiro, 1973. 175p. (Levantamento de Recursos Maturais 4 ).

SAlOMã R.de F. Composição floristica e a fitossociologla de florestapluvial tropical de terra firme, municipio de Marabá, Estado do Pará. Eelem; HFEG, 1989. $119 p$. (Felatório Finai. de Pesquiea).

STQUEIRA: J.D.P. Manejo Florestal sustentado na Amazonia: necessidade "versus" pesquisas. In: Amazonias Facts, problens and solutions, 5ão Faulag USF, 19ag. p. 109-132.

SILVA, J.N.M. \& LOPES, 3.E.A. Inventario florestal continuo em florestas tropicals: a metodologia utilizada pela EMBRAPA-CPATU na Amazonia Brasileira. Eelem, EMERAFACFATU, 1984. I6P. (EMEFAFA-CFATU. DOCumEntos, 33).

SMITH, D.H. The practice of silviculture. New York, John Wiley sons, 1962. 578p.

Squza. A.L. de. Analise multivariada para manejo de florestas naturais: alternativas de produço sustentada de nadeiras para serraria. Curitiba, $1989.245 \mathrm{p}$. (Tese-Doutoramento-UFPr).

SQUza, F.F. de, Terminologia florestal - glossário de termos e expressós florestais. Fundacăo IEGE, Fio de Janeiro, $1973.304 p$. 
STEEL, R.G.D. \& TORFIE, 3.H. Princlples and procedures of statistics with special reference to the biological sclences. New York, MeGraw Hi11, 1960. 481p.

STOHR, G.W.D. E INOUE, M.T. Sistemas silviculturais: sugestoes para uma nova classificaça. Floresta, Curitiba, $7(1): 58-63,1976$.

TANG, H.T. Froblems and strategies for regenarating dipierocarp forests in Malaysia. Ina MERGEN, F. \& VICENTE; 3.F. Natural manegements of tropical molst forests. Yale University, New Haven, 1987. 9. 23-46.

TARUTNI, A.T, LEE, D.C.L.; SANTUS, R.J.F.: ASSIS, O.R. de. EAREOSA, M.F. dOS 5.3 MORETRA, dE L. FEFEIRA, M.T. SILVA, D. : SANTOS FILHO, C.F. dos. Submprojeto desmatamento. Convenio IEDF/CHPq-THPE, 1979. Instituto Macional de Fesquisas Espaciais, 5ao José dos Campos-5P, 1980.

THIBAU, C.E. Frodução sustentada en fiorestas. Conceitos metodológicos. In: Simposio sobre silvicultura y mejoramento genetico de especies forestales. Euenos Aires, 1987. Anais, EuEnos Aires, CIEF, 1987. P. 194-225.

TROUF, F.S. Silvicultural systems. Dxford, claredon Fress, 1952. $216 \mathrm{p}$.

VEGA, C.L. La estructura y compdeicion de 10 bosques himedos tropicales del Carare, Colambia. Turrialba, 18(4): $416-36,1968$.

VEILLON, J.F. Frimeiros resultados de la medicion del crescimento de bosques naturales venezolanas. Boletim del IFLA, (2): 73-90, 1767 . 
VEILLON, J.P. : KONRAD, U.W. GAFCIA, N. Estudio de la masa forestal y su dinamismo en parcelas de diferentes tipos ecolsgicas de bosques naturales de las tierras bajas venozolanas. Rev. For Venez., $19(26)$ : 73-106, 1976.

VIANA, V.M. Ecologia de populaç̧es florestais colonizadoras e recuperaça de areas degradadas. Publicaça ACIESP, Sáo Faulo, 54(1): 29-39, 1987.

VIEIRA, G. Analise estrutural de regeneraço natural, apus diferentes niveis de exploraço en una floresta troplial úmida. Manaus, 17ab. 120p. (Tese-Mestrado-IMFA).

WADSWORTH, F.H. Applicability of Asian and African silviculture systems to naturaliy regenerated porests of the Neotropics. In: MERGEN, F. a VICENTE, J.R. Natural management of tropical moist forests. Yale University. New Haveng $1987.9 .93-112$.

YARED, J.A.G.: ERIENZA JR., 5.; CARVALHO, J.D.F. UE. LOFES, 3.C.A.g AGUIAR, G.J.R. de. COSTA FILHO, F.F. Sizvicultura como atividade economica ne regiao amasnica. Ins Encontro Erasileiro de Economia Florestal, 1. Curitiba, 1988 . p. $23-78$. 
149.

APENDICES 
APEADTCE 1

Rel açăo das espócies presentee nos inventários flarestais realizados 


\begin{tabular}{|c|c|c|c|c|c|c|c|c|c|c|c|c|c|c|c|c|c|}
\hline \multirow{2}{*}{ 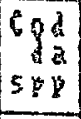 } & \multirow{2}{*}{ Hoge conas } & \multicolumn{4}{|c|}{$1984(1)$} & \multicolumn{4}{|c|}{$1984(3)$} & \multicolumn{4}{|c|}{$1986 \quad 131$} & \multicolumn{4}{|c|}{$1988 \quad 64$} \\
\hline & & II & 12 & 13 & 14 & 11 & 12 & 13 & Ia & 8.1 & I.2 & 7,3 & 7.4 & 1.1 & 1.2 & T.3 & $\longdiv { 7 . 4 }$ \\
\hline 061 & nsia cabeca racaco & & & & & & & & & $E$ & & $E$ & & $E$ & & EV & \\
\hline 982 & Abia catite & & & & & & & $x x$ & & & & & & $\bar{M}$ & & & \\
\hline 083 & Abia seco & & & & & & & & & $E$ & & & & E H & H & it & \\
\hline 064 & Abio veraeldo & & & & & & & & & EV & if & EUII & $\varepsilon$ & EVI & & $\sqrt{\varepsilon}$ & $E$ \\
\hline 905 & Abiarana & & & & & & & & & $E V$ & & & & En & $\pi$ & i & H \\
\hline 066 & Abiarana $1.9 r a n d e$ & & & & & & & & $x \times$ & $E$ & & is & $E$ & $E$ & & & $E$ \\
\hline 007 & Hojurana f.fina & & & & & & & $x x$ & & $\varepsilon$ & 4 & $E$ & il & $E$ & H & $E$ & \\
\hline 968 & Abeta & & & & & & & $x x$ & & $E$ & & $E$ & & $E$ & & $E$ & \\
\hline 809 & Acai & $x x$ & $x \times$ & $\times x$ & & $\forall x$ & & $x x$ & $x x$ & & & & & & & & \\
\hline 019 & Acariatasa & $x x$ & $\times x$ & & $x x$ & $x x$ & & $x x$ & & $E$ & ii & $E$ & & $E$ E & & $E$ & \\
\hline 011 & Agarra branca & $x x$ & $x x$ & $x x$ & $\times x$ & $x x$ & & $x x$ & $x \times$ & & & & & & & in & \\
\hline 012 & A tia a a a biargoso & & & & & $: x$ & & $8:$ & $x:$ & $E$ & & EH & $E$ & $E$ & $E$ & $E \cup M$ & $E$ \\
\hline 913 & A tha di doce & & & & & & & $x x$ & $x x$ & $E$ & & & & $E$ & & & \\
\hline 914 & A日 2 2a & & $x x$ & & & & & $8 x$ & & $E$ & & $E$ & & EV & if & EUH & VH \\
\hline 615 & Anaparana & & & & & & & $6 x$ & $x x$ & & & & & & V & & \\
\hline 916 & Aresclabsanca & & $x x$ & & & $x x$ & & & $n x$ & $E$ & EVH & $E$ in & EUA & $E$ & $E$ & EVII & EUI \\
\hline 917 & f nse $=180$ & $x x$ & $x x$ & & $8 x$ & $x x$ & & $8 x$ & & $E$ & & $E$ & $E$ & $E$ & & $E$ & $E$ \\
\hline 918 & Andirobarana & & & & & & & $x x$ & & EUA & 11 & EUH & $E n$ & EUA & E M & EUh & $E$ \\
\hline 819 & Angel if Branco & & & & & $x x$ & & $x x$ & $x x$ & & & & & & & & \\
\hline 023 & Angel in rajado & & & & & & & $x x$ & & & & & $E$ & & & & $E$ \\
\hline 621 & Angico branco & & $x x$ & 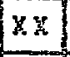 & & $H x$ & & & & & & & & $E$ & & & \\
\hline 022 & $\operatorname{An} a n i$ & & & & & & & & & EV & & $E$ & E & $E$ EV & H & $E N$ & $E$ H \\
\hline $6: 3$ & Araqzana & & & & & & & $k x$ & & $E$ & & & & $E$ & & & \\
\hline 624 & Araracanga & & & & & & & 88 & $\times x$ & $E$ & & & & $E$ & & & \\
\hline 925 & Asataciu & & & & & & & & 1 & EV & & $E$ & $E$ & EUA & i & EVI & E \\
\hline 026 & asoeira & & & & & & & $x x$ & $x x$ & $E$ & & $E$ & & EH & A & $E$ & H \\
\hline $92 \%$ & arsecira & & & & & & & $x x$ & & & & $E$ & & & & $E$ & \\
\hline 628 & $2 \times i \times i$ & $x x$ & & & $x \times$ & $x x$ & & & & $E$ & $E$ & $E$ & FUM & $E$ & $E$ & $E$ & EV \\
\hline 629 & Babaca & $x A$ & $x \times$ & $x \times$ & & $x x$ & & $x x$ & $x x$ & & & & & & & & \\
\hline 836 & Eaca3 & $x x$ & $\mathrm{xx}$ & $x x$ & $x \times$ & & & & $x x$ & $E$ & & & & $E$ & & & \\
\hline 831 & Bactipari & $x x$ & $\mathrm{xx}$ & Ke & $x \times$ & $x x$ & & $\pi x$ & & EUM & 旬 & E H & H) & EVH & & $E$ B & $\sqrt{E}$ \\
\hline 032 & Sarpote & $x x$ & $x x$ & $x x$ & $x x$ & $x x$ & & $x x$ & & $E$ & & $E$ & & $E$ & & $E$ & \\
\hline$\$ 33$ & Brea preta & & & & & & & & & $H$ & & & & & & M & \\
\hline 034 & Breu sacaraba & & & & & & & & & $E$ & & & & $E$ & $E$ & $E$ & $E$ \\
\hline 635 & Brell vereblio & & & & & & & & & EUM & 1 & EUH & $E \mathrm{il}$ & EUH & & $E \cup H$ & $E$ \\
\hline 036 & Burangiga branga & $x x$ & $x \times$ & $x x$ & $x \times$ & $x y$ & & $x x$ & $x x$ & & & & & & & & \\
\hline 937 & Barangiga gresa & $x x$ & $x \times$ & $x \times$ & $x x$ & $x x$ & & & & & & & & & & & \\
\hline 638 & Brya leitgina & $x x$ & $x x$ & $\mathrm{x}:$ & $x x$ & $x$ & & $\sqrt{\mathrm{x}}$ & $x x$ & & $E$ & EV & EV & $E$ & EUM & EV & $E V$ \\
\hline 633 & Cabega de arda & $x x$ & $\times x$ & $x x$ & $|x x|$ & IX & & $x x$ & $x x$ & & & & & & & & \\
\hline
\end{tabular}




\begin{tabular}{|c|c|c|c|c|c|c|c|c|c|c|c|c|c|c|c|c|c|}
\hline \multirow{2}{*}{$\begin{array}{r}60 ? \\
d a \\
58 \\
\end{array}$} & \multirow{2}{*}{ Honecotan } & \multicolumn{4}{|c|}{1980113} & \multicolumn{4}{|c|}{$1984: 23$} & \multicolumn{4}{|c|}{$1996 \quad 63$} & \multicolumn{4}{|c|}{1988643} \\
\hline & & II & 52 & 13 & T4 & (II) & 12 & 13 & 14 & 1.1 & [.8 & 1.3 & 1.9 & 7.1 & 9.2 & 9.3 & 9.4 \\
\hline 848 & Cabelo de colia & $5 x$ & $x \times$ & $x \times$ & $x x$ & $x \times$ & & $x \times$ & $x: x$ & & & & & & & & \\
\hline 041 & Cacall brano & $x x \mid$ & $5 x$ & $x \times$ & $x x$ & $x \times$ & & $\mathrm{x} \times$ & $x x$ & & & & & & & & \\
\hline 042 & Cacal da & & & & & & & $x \times$ & $x x$ & $E$ & & \begin{tabular}{|ll}
$E$ & 1
\end{tabular} & H & $E$ & it & E I I & 11 \\
\hline 843 & cacau jacare & & & & & & & & & 5 & & & & $E$ & & & \\
\hline 044 & $\operatorname{cacha}$ & & & & & & & $x \times$ & & $E$ & & $E$ & & $E$ & & $E$ & n \\
\hline 945 & Gacbaa grande & & & & & & & & & & & $E$ & & & & IE & \\
\hline 046 & cafe bravo & $x \times$ & $\% x$ & $x \times$ & $x:$ & $x \times$ & & $x \times$ & & $E$ & & E. & & $E$ & EV & $E$ & \\
\hline 647 & Gaferana & & & & & & & & $8 x$ & EU月 & in & EUH & EUM & EUN & Uni & EUII & EUH \\
\hline 048 & $6 a j a$ & $\times x$ & & & & $x \times$ & & $x \times$ & $x x$ & $E$ & & & & $E$ & $\pi$ & & \\
\hline 849 & Gaju de janeiro & $x \times$ & $x \times$ & $\times x$ & $x \times$ & $x x$ & & $x x$ & & $E$ & & $E$ & & $E$ & & $E$ & \\
\hline 950 & cajagara & & & & & & & $x \times$ & $x x$ & & EH & & Un & & $E$ & $E$ & EUH \\
\hline 351 & 6 and & & $x *$ & $x \times$ & & & & $x \times$ & $x:$ & & & & & & & & \\
\hline 952 & Ganafistala & & $x x \mid$ & & & $x x$ & & $x \times$ & $x x$ & & & & & & & & \\
\hline 953 & Canela de jacanin & $8 x$ & $x x$ & $x \times$ & $x x$ & $x \pi$ & & . & $x x$ & EUM & $\mathrm{HI}$ & EUH & H & EUit & $M$ & EUA & in \\
\hline $6, n$ & Cantia de velbo & & $x \times$ & $x \times$ & & & & $x x$ & $x x$ & 11 & & & & & & & \\
\hline 955 & Ganela preta. & $x x$ & & & & $\mathrm{xx}$ & & $x \times$ & $\times x$ & & & & & & & & \\
\hline 856 & Caneleiso & & & & & & & $x x$ & & $E$ & & $E$ & & E i & & $E$ & 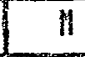 \\
\hline $95 \%$ & Carrudeiro & $x x$ & & & & $2 x$ & & & & & & & & $E$ & & & \\
\hline 658 & tayitiu & & $x:$ & & & & & $x:$ & & $E H$ & 10 & EUII & HUH & $E \cup M$ & EVH & EUn & EVI \\
\hline 859 & 6aga & & & & & & & $8 \mathrm{x}$ & $x x$ & $E$ & & & & & & & \\
\hline 968 & 6araigerana & & & & & & & & & EUH & i) & $E H$ & 8 & $E$ & in & $E$ II & E \\
\hline 061 & casca reciosa & & & & & & & & & $E$ & & & & $E$ & & & \\
\hline 062 & 625 tanha de acaco & & & & & & & & & $E$ & & & & E & & & \\
\hline 963 & castanga gerignito & & & & & & & & & $E$ & & & & $E$ & & & \\
\hline 964 & Gastandeita & $x x$ & $x x$ & $8 x$ & $x:$ & $x x$ & $y$ & $x 8$ & $x 8$ & $E$ & $E$ & $\varepsilon$ & $\varepsilon$ & $E U$ & $E$ & E & $E$ \\
\hline 665 & fallafu & & & & & & & & $x x$ & & $\begin{array}{lll}E & 11 \\
\end{array}$ & & $E$ & & $E$ : & $E$ & $E$ \\
\hline 966 & cancoso & $x \times$ & $x \times$ & $x \times$ & $x \times$ & $x x$ & & $x A$ & $x x$ & $E$ & $E$ & $e$ & E & $E$ & $E$ & E & $E$ \\
\hline 967 & Cedro benso. & & & $x:$ & & & & $x \times$ & & & & & & & & & \\
\hline 868 & Cedro vergelho & & & & & & & $x \times$ & $x 8$ & $E$ & & & & $\sqrt{E}$ & & & \\
\hline 869 & cedrosana & $x x$ & $x x$ & $x:$ & $x x$ & $x x$ & & 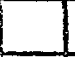 & & $E$ & & $E$ & $E$ : & $E$ & $E V$ & $E$ & $E$ \\
\hline 879 & Congea de 501 & & & & & & & $x x$ & $x x$ & $\varepsilon$ & UMI & $E$ & Un: & $E$ & E M & $E$ & EU \\
\hline 071 & Cogida de gobbo & & & & & & & $x \times$ & & & & & & & $E$ & $E$ & \\
\hline 922 & Copaiba & & & & & & & $x:$ & & $E$ & & & & $E$ & & & \\
\hline 673 & cogaibarana & & & & & & & $2 x$ & $x x$ & & & & & & & & \\
\hline 689 & Gorago de negro & $x:$ & & $x:$ & $x x$ & $x x$ & & $x \times$ & & & & $E$ & & & & $E$ & \\
\hline 975 & conxo de sayo & $x x$ & $x \times$ & & & $x \times$ & & $\mathrm{xx}$ & & & & & & & & & \\
\hline 876 & Callay & & & & & 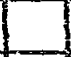 & & $x:$ & & $E$ & & $E$ & & $E$ & & $E$ & \\
\hline 677 & Capu de janeiro & & & & & & & & $x \times$ & & & & & & & & \\
\hline 678 & casuag & $x \times$ & $x x$ & $x:$ & $x x$ & $x x$ & & . & & $E$ & & $\bar{E}$ & $E$ & $E$ & & $E$ & $E$ \\
\hline
\end{tabular}




\begin{tabular}{|c|c|c|c|c|c|c|c|c|c|c|c|c|c|c|c|c|c|}
\hline \multirow{2}{*}{$\begin{array}{l}c 0 d \\
\text { da } \\
582\end{array}$} & \multirow{2}{*}{ NOBE COBOE } & \multicolumn{4}{|c|}{1984613} & \multicolumn{4}{|c|}{198423} & \multicolumn{4}{|c|}{$1986 \quad 63$} & \multicolumn{2}{|c|}{1988} & \multicolumn{2}{|c|}{$(4)$} \\
\hline & & $T 1$ & 12 & 13 & 34 & 11 & 12 & 13 & 19 & 9.1 & T.2 & 18.3 & $\longdiv { 1 . 4 }$ & 9.1 & 1.2 & 1.3 & $\longdiv { 9 . 4 }$ \\
\hline 979 & 6080183 & & & & & & & & & & EUH & & $E$ & & EH & E & $E$ \\
\hline 886 & Orypetes & & & & & & & & & $E$ & & & & $\varepsilon$ & & & \\
\hline 881 & Dryectesa & & & & & & & & & $E$ & & & & $E$ & & & \\
\hline 682 & Envira branca & & & & & & & $x x$ & & & & $E$ & & & & $E$ & \\
\hline 983 & Envita cana & & & & & & & & 28 & E & in & $E n$ & $E n$ & EUH & in & EUI & E \\
\hline 684 & Envira preba & & & & & & & & & EUA & UII & EUH & E M & EUM & EUI & EUH & EUA \\
\hline 685 & Envira taid & & & & & & & $x x$ & $x x$ & $E$ & & $E$ & & $E$ I & H & E II & मn \\
\hline 886 & Eccorrega vacaco & $x \times$ & $x \times$ & & & $\times x$ & & & & & & & $E$ & & & $n$ & $E$ \\
\hline 087 & Espetorana & & & & & & & & & EUiA & 11 & EUH & UH & 5 is & $E$ & $E V$ & i \\
\hline 688 & Esonjeira & & & & & & & & & & $E$ & $E$ & $E$ & & $E$ & $E$ & $E$ \\
\hline 689 & Estogeiro & & $\times 8$ & $x x$ & & $x \times$ & & & & & & & & & & & \\
\hline 096 & farinda seca & $x x$ & & $x:$ & & $x \times$ & & & & $E$ & & & & $E$ & & & \\
\hline 991 & Fava aharga & & & & & & & & & $E$ & $E$ & & & $E$ & EV & $E$ & \\
\hline 092 & fava $1010 t 2$ & & & & & & & & & $E$ & & & & $E$ & $E$ & $E$ & \\
\hline 693 & Fava de anta & $x \times$ & $x \mathrm{x}$ & $x:$ & $x x$ & $x x$ & & & & $E$ & H & $E$ & & $E$ & & $\varepsilon$ & \\
\hline 994 & Yava de porca & & $x x$ & & $x x$ & & & & & & & & & & & & \\
\hline 695 & Fava f. fina & & & & & & & & & $E$ & $E$ & $E$ & $E$ & $E$ & E & $E$ & $E$ H \\
\hline 996 & S2020 & $x x$ & $x x$ & $x x$ & & $x x$ & & & & & & & & & & & \\
\hline 697 & Freijo branco & & & & & & & & & $E$ & $E$ & $E$ & UM & $E$ & $E$ & $E$ & \\
\hline 698 & fagedeisa & & & $x x$ & & & & & & & & & & & & & \\
\hline 939 & fead de ovo & $x x$ & $x:$ & $x x$ & $x x$ & $x x$ & & $3 x$ & $x x$ & $E$ & & $E$ & $E$ & $E V$ & & EUH & $E$ \\
\hline 186 & 6oial soua & $x x$ & & & & $x x$ & & & & & & & & & & & \\
\hline 181 & 60133 bsanca & & & & & & & & & & & & & II & & & \\
\hline 102 & goiabarand & & & & & & & & & $E$ & M & $\sqrt{E}$ & & $E$ & $\mathrm{H}$ & $E$ & \\
\hline 103 & 6oingeira & & $x:$ & & $x y$ & & & & & & & & & & & & \\
\hline 104 & foidinga & $x \times$ & & & & $x:$ & & & & E II & H & $E$ & & $E$ & 4 & $E$ & H \\
\hline 195 & 6r:o de cachorro & & & & & & & & & $\mathrm{y}$ & & $E$ & & $v$ & & $E$ & \\
\hline 106 & taringa & & & & & & & & & & & $E$ & & & & $E$ & \\
\hline 187 & Iobaba & $x x$ & $x \times$ & $x z$ & $2 x$ & $x x$ & & & & & & & & & & & \\
\hline 168 & 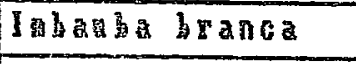 & & & & & & & & & EUn & $E$ & EUH & & & $E$ & $E$ & $\mathrm{E}$ \\
\hline 109 & I0batca da data & & & & & & & & & $E$ & & $E$ & & $E$ & & $E$ & \\
\hline 119 & 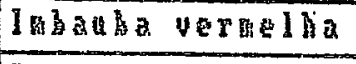 & & & & & & & & $\dot{-}$ & & EUH & $E$ & EUY & & EUI & $E V$ & EU. \\
\hline 111 & I thando & $x x$ & $x \times$ & $x:$ & $x x$ & $x x$ & & & & & & & & & & & \\
\hline 112 & $\ln 3 \mathrm{x}^{2}$ & $x x$ & & $x \cdot x$ & & $x z$ & & & & & & & & & $E$ & $E$ & \\
\hline 113 & Inajagana & & & & & & & & & $E \cdot H$ & & $E$ & & $E$ H & & $E$ H & हf \\
\hline 114 & $\operatorname{lng} \mathrm{a}^{\circ}$ & xi & $x x$ & & & $x x$ & & & & & & & $E$ & & & & $E$ \\
\hline 115 & Inya anarelingo & $x x$ & $x x$ & $x x$ & $x x$ & $x x$ & & & & $E$ & & & & & & & \\
\hline 116 & Inga branco & $x x$ & $x x$ & $x x$ & $x x$ & $x x$ & & & & E H & $E H$ & E H & EUA & $E V$ & EUI & EUA & $E$ H \\
\hline 117 & Ingá chato & & & & & & & & & $E$ & EU14 & EU\| & $E M$ & $E$ & EUH & E!M & EUM \\
\hline
\end{tabular}




\begin{tabular}{|c|c|c|c|c|c|c|c|c|c|c|c|c|c|c|c|c|c|}
\hline \multirow{3}{*}{ 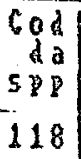 } & \multirow{2}{*}{ Home coOd } & \multicolumn{4}{|c|}{1984613} & \multicolumn{4}{|c|}{1984623} & \multicolumn{4}{|c|}{1986} & \multicolumn{4}{|c|}{$1988 \quad(4)$} \\
\hline & & 11 & 12 & 13 & 14 & 11 & 12 & 13 & 19 & I.1 & T.2 & 9.3 & 8.4 & 9.1 & 1.2 & 1.3 & $\longdiv { 7 . 4 }$ \\
\hline & $\operatorname{lngá}$ cipo & & & & & & & & & $E$ & EUH & $E$ & EUH & $E M$ & $E \cup M$ & $E$ H & EVH \\
\hline 119 & Inga faca & & & & & & & & & $E$ & $H$ & $E$ & $E$ & $E$ & in & E II & $E V$ \\
\hline 126 & $\operatorname{lnga}$ reloda & & & & & & & & & EUH & EUH & $E M$ & UM & EUA & $E M$ & $E$ H & $n$ \\
\hline 121 & brid pretinbo & & & & & & & & & & EUH & $E$ & EUM & & $E$ H & $E$ E & EUH \\
\hline 122 & Ingà vergel ho & $x x$ & $x x$ & $x x$ & $x x$ & $x x$ & & & & $E$ A & & EV & HI & $E$ & $E$ I & $E H$ & 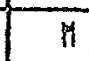 \\
\hline 123 & $\operatorname{lnga} x i x i c a$ & & & & & & & & & $E$ & & $E$ & & $E$ & & $E$ & \\
\hline 128 & Ingarana & & $x:$ & $x x$ & & $x x$ & & & & $E H$ & H & $E$ 月 & & $E$ H & H & $E H$ & H \\
\hline 125 & Janit $\bar{a}$ & $x x$ & $x x$ & $x x$ & $x x$ & $x x$ & & & & & & $\sqrt{E}$ & & & & $E$ & \\
\hline 126 & lpe aparelo & & & & $x y$ & $x x$ & & & & & & $E$ & & & & $E$ & \\
\hline 127 & Jangada & & $x x$ & & & $x$ & & & & & & & & & & & \\
\hline$[128]$ & $\operatorname{lng} 3 \mathrm{e}^{\circ}$ & $x x$ & $x x$ & $x x$ & & $x x$ & & & & $E$ & 14 & $\sqrt{E \pi}$ & $\bar{H}$ & E & h & $E$ E & n \\
\hline 129 & Jataliba preta & & & & & & & & & & & $E$ & & & & $E$ & \\
\hline $13 n$ & 1050 bose & & & & & & & & & EV & P & $E$ & $M$ & EUM & EU: & EUH & $\bar{M}$ \\
\hline 131 & Jarabeba & & & & & & & & & & EUH & $E$ & EUA & & $E$ & $E$ & E \\
\hline 132 & Jutai & (xx & $x x$ & $\sqrt{x x}$ & $x x$ & $x x$ & & & & & & & & & & & \\
\hline 133 & Jotai branco & $x x$ & $x x$ & $x x$ & & $\overline{x x}$ & & & & & & & & & & & \\
\hline 134 & datai pororoca & & & & & & & & & tE & & E & $E$ & $E$ & & $E$ & E \\
\hline 135 & Laces & & & & & & & & & & EUH & & EV & & EVII & $E$ & $E$ \\
\hline 136 & Laranjinda & $x 8$ & & & & $x x$ & & & & & & & & & & & \\
\hline 137 & Logro anarelo & $x x$ & $x x$ & $x x$ & $x x$ & $x:$ & & & & $E$ & EUH & EV & $E$ & $E M$ & $E$ 品 & EUII & $E$ \\
\hline 138 & Logro hranco & $x x$ & $x x$ & $x x$ & $x x$ & $x y$ & & & & $E$ & & $E$ & & EUH & $E$ & $E$ H & it \\
\hline 139 & 10080 cravo & & & & & & & & & EV & & & & EV & & $E$ & \\
\hline 149 & Lotro greto & $x x$ & $x x$ & $x:$ & $x \times x$ & ix & & & & E H & UH & EVH & E & $E$ & $E$ & EVH & $E M$ \\
\hline 141 & Logro rosa & & & & & & & & & & & & & & it & & \\
\hline 142 & Iouro vermelo & & & & & & & & & & & & $E$ & & & & $E$ \\
\hline 143 & Hacuon de sangue & & & & & & & & & & & $E$ & $E$ & EणI & $\pi$ & $E$ E & $E$ \\
\hline 148 & Hatorana & & & & & & & & & H & & & & & 11 & & \\
\hline 145 & fiasai & $\pi x$ & $x x$ & $8 x$ & $x \times$ & $2 x$ & & & & $\mathrm{E}$ & EUH & $E$ & E & $E$ & EV & $E$ & $E$ \\
\hline 146 & haniva de veado & & & & & & & & & & $E$ & & $E$ & & & & $E$ \\
\hline 147 & Hapatirana & & & & & & & & & $E$ & $E$ & EM & $\widehat{E 7}$ & $E$ H & $E M$ & $E$ & $E H$ \\
\hline 148 & harlin & & $x x$ & & & & & & & & & & & & & & \\
\hline 149 & hiarirana & & & & & & & & & $E$ & & $E$ & & $E$ & & $E$ & \\
\hline 158 & fiana & $x x$ & $\times x$ & $x x$ & $\pi x$ & $\mid x x$ & & & & & & & & & & & \\
\hline 151 & Mas5aranduba & $x x$ & & & & $x$ & & & & & & & & & & 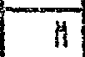 & \\
\hline 152 & Hassarandahinas & $x x$ & $x \times$ & $x x$ & $x x$ & $x \%$ & & & & & & & & & & & \\
\hline 153 & Watanata andrelo & $x \times$ & & $x x$ & & $x x$ & & & & & & & & H & & in & VII \\
\hline 154 & Hatanata braboo & $x x$ & $x x$ & $x x$ & $x x$ & $x x$ & & & & EH & H & E & EUn & $E$ H & EUH & $E H$ & $E$ \\
\hline 155 & Hatanata proto & $x x$ & $x x$ & $x x$ & $x x$ & $x x$ & & & & $E$ & & $E$ & & $E$ & & $E$ & \\
\hline 156 & Hatanata verstello & & & & & & & & & $E$ & M & & & $E$ & & & \\
\hline
\end{tabular}




\begin{tabular}{|c|c|c|c|c|c|c|c|c|c|c|c|c|c|c|c|c|c|}
\hline \multirow{2}{*}{$\begin{array}{c}60 d \\
9 \\
5\end{array}$} & \multirow{2}{*}{ Hose cOB } & \multicolumn{4}{|c|}{1984113} & \multicolumn{4}{|c|}{1986823} & \multicolumn{4}{|c|}{1986} & \multicolumn{4}{|c|}{1988643} \\
\hline & & II & 12 & 13 & 14 & 11 & 12 & 13 & 14 & I. & 7.2 & 8.3 & 9.4 & 1.2 & i.2 & 7.3 & 1.4 \\
\hline 157 & nelancieira & $x \times$ & $x x$ & & $x x$ & $x x$ & & & & & & & & & & & \\
\hline 158 & Hogno & & & & $x:$ & & & & & & & & & & & & \\
\hline 159 & neiracatiara & & & $x \times$ & $x x$ & $x \times$ & & & & $E$ & & & & $E$ & & & \\
\hline 1601 & forisactiobe & & & & & & & & & $E$ & & $E$ & & $E$ & & $E$ i & \\
\hline 161 & hoirajaba & & & & $x x$ & $x y$ & & & & & & & & & & & \\
\hline 162 & Hairatinga & & & & & & & & & & 5 & & $E$ & $E$ & $E A$ & $\varepsilon$ & EU \\
\hline 163 & Hajatinga peloda & & & & & & & & & $E$ & & $E$ & $E$ & $E$ & $E M$ & $E$ & $E$ \\
\hline 164 & Aarta & & & $x \times$ & $x x$ & & & & & & & & & & & & \\
\hline 165 & faraci da ata & & & $x \times$ & $x x$ & $x x$ & & & & & & $\varepsilon$ & & & & $E$ & \\
\hline 166 & Marare & & & & & & & & & $E V$ & & EUH & E & EV & & $E$ & 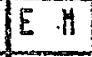 \\
\hline 167 & horure anarelo & $|x \times|$ & $x x \mid$ & $x x$ & $x:$ & $x \times$ & & & & & & & & & & & \\
\hline 168 & farase banco & $\mathrm{x} \times$ & $x x$ & & & $x:$ & & & & & & & & & & & \\
\hline 169 & Gingré greto & & $x:$ & & & & & & & & & & & & & & \\
\hline 176 & Hataba & $\mathrm{xx}$ & $\times x$ & $x x$ & $x x$ & $x:$ & & & & $E$ & & & $E$ & $E$ & Uก & EV & E \\
\hline 171 & Hetaic daso & & & & & & & & & & & E & & $E$ & & {$\left[\begin{array}{lll}E & 11 \\
\end{array}\right.$} & 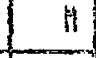 \\
\hline 172 & Hegramina & & $2 \times$ & & & $x x$ & & & & & & & & & & & \\
\hline 173 & frelha de racaco & $x x$ & & & & $x:$ & & & & & & & & & & & \\
\hline 174 & Orelba is onoa & & $x x$ & & $x x$ & & & & & & & & & & & & \\
\hline 175 & $\bar{P} a j u^{-}$ & $x:$ & $x x$ & $x:$ & & $x x$ & & & & & & & & & & & \\
\hline 176 & Paliteira & & & & & & & & & & $E$ & & $E$ & & EUA & $E$ & EUH \\
\hline 177 & Pago te otat & & & & & & & & & & & $E$ & & $E$ & & $E$ & H \\
\hline 178 & Parapara & & & & & & & & & E & EVA & E & $E$ & $\xi$ & $E V$ & EV & $E$ \\
\hline 179 & $82 \times i a$ & & & & & & & & & $E$ & EUS & $E$ & EUR & $E$ & EUH & $E$ & 50 \\
\hline 189 & $8 \mathrm{de}$ de cobra & & & & & & & & & $E$ H & & 11 & v & $E$ & & & \\
\hline 181 & Pan de jackre & & & & & & & & & $E$ & $E$ & $E$ & $E$ & $E$ & $E V$ & $E$ & $E$ \\
\hline 182 & Pan de sersa & & & & & & & & & $E$ & 1 & $E$ & & $E$ & & $E$ & \\
\hline 133 & Pan loce & & & & & & & & & $E$ & & & $E$ & E & & & $E$ E \\
\hline 182 & Pag ondato & & & & & & & & & $E$ & & & & $E$ & & & \\
\hline 185 & Pat is acto & $x x$ & $\times x$ & $x \times$ & $\times x$ & $x \times$ & & & & $E$ & H & $E$ & EUI & $E$ & EUH & $E H$ & EUh \\
\hline 186 & $8 \mathrm{at} \quad \mathrm{s} 0 \times 0$ & & & & $x x$ & & & & & & & & & & & & \\
\hline 187 & fasina & $x x$ & $4 x$ & $x: 1$ & $\mathrm{nx}$ & $x \times$ & & & & & & & & & & & \\
\hline 188 & Peiso de parca & $x \times$ & & $x x$ & $x x$ & $x x$ & & & & & & & & & & & \\
\hline 189 & Pente de racaco & $x x$ & $x \times$ & $x \times 1$ & $x y$ & $x \times$ & & & & $E$ & EUH & $\varepsilon$ & EV & EH & EUA & $E$ & EUH \\
\hline 198 & Pjonenta de jaci & & & & & & & & & M) & 11) & B] & 1 & & & & \\
\hline 191 & Binenta branca & $x:$ & & & & $x x$ & & & & & & & & & & & \\
\hline 192 & Eimenta preta & $x x$ & & & & $x y$ & & & & & & & & & & & \\
\hline 193 & Ditatina & $x x$ & $\pi x$ & $x x$ & $X 8$ & $x x$ & & & & & & & & & & & \\
\hline 194 & Eeriquitoira & $x x$ & & & & $x x$ & & & & & ENI & Evit & {$\left[\begin{array}{ll}E & H\end{array}\right.$} & & EV & $E$ & EV \\
\hline 195 & Pitobba & & & & & & & & & $E$ & & $E M$ & i) & EU & 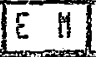 & $E$ h & i \\
\hline
\end{tabular}




\begin{tabular}{|c|c|c|c|c|c|c|c|c|c|c|c|c|c|c|c|c|}
\hline \multirow{2}{*}{$\begin{array}{r}60 \text { d } \\
\text { a d } \\
\text { sol } \\
\end{array}$} & \multirow{2}{*}{ HOAC COB } & \multicolumn{4}{|c|}{198161} & \multicolumn{3}{|c|}{1984623} & \multicolumn{4}{|c|}{$1986 \quad 63)$} & \multicolumn{4}{|c|}{$1988 \quad 143$} \\
\hline & & 71 & 28 & 83 & If & $1 1 \longdiv { 1 2 }$ & 13 & 14 & I. & 1.2 & 1.3 & $\mathrm{~T} .4$ & 1.1 & 1.2 & I.3 & T.4 \\
\hline 196 & Fitouba de leite & $x x$ & $\times x$ & $\times x$ & & $2 \times$ & & & & & & & & & & \\
\hline 197 & Eraconbarana & & & & & & & & $E$ & & $E$ & & $E$ & & & \\
\hline 198 & Parai & & & & & & & & $E$ & II & $E V$ & in & $E$ H & H & EUH & H. \\
\hline 193 & Paraizingo & & & & & & & & $E$ & & & & $E$ & & & \\
\hline 268 & $f 46507,2 x 4$ & & & & & & & & $E$ & & & & $E$ & & & \\
\hline 281 & Ooina & $\times x$ & $x \times$ & $x x$ & & $x x$ & & & & & $E$ & & & & $E$ & \\
\hline 282 & guinarana & $\mathrm{xx}$ & & $x x$ & & $x x$ & & & $E$ & & & & $E$ & & & \\
\hline 203 & Resina de cou & & $x x$ & & $x x$ & & & & & & & & & & & \\
\hline 204 & Binorea & & $x x$ & & & & & & & & $E$ & & & & $E$ & \\
\hline 295 & Saboeiso & & $x \times$ & & $x x$ & . & & & $E$ & EUH & $E$ & $E$ & $E$ & $E$ & $E$ & $E$ \\
\hline 296 & Sangue de cavalo & $x x$ & & & & $x x$ & & & & & & & & & & \\
\hline 297 & Sanota & & & & & 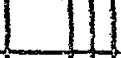 & & & $E$ & & & & $E$ & & & \\
\hline 280 & Sartata & $\times x$ & & & $x x$ & $\times x$ & & & & & . & $E$ & & & & $E$ \\
\hline 209 & Syirantera & & & & & & & & & & $E$ & & & & $E$ & \\
\hline 210 & Sacapira & & $x:$ & & & & & & $E$ & & $E$ & & $E$ & & $E$ & \\
\hline 211 & Sucupira greta & & & & & & & & TE & & $E$ & & $E$ & & $E$ & \\
\hline 212 & 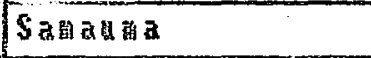 & $x x$ & & & & Ix & & & & & $E$ & & & & $E$ & \\
\hline 213 & Tachi hrango & & $x:$ & $x x$ & $x \times$ & & & & & & & & & & ii & \\
\hline 218 & Tathi graba & 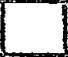 & & & & & & & $E$ & & 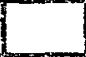 & & $E$ & & & \\
\hline 215 & Tachi preto & $x x$ & $x x$ & $x \times$ & $x x$ & $x \times$ & & & $E$ & & $E$ & M & $E$ & EH & $E$ & v \\
\hline 216 & TEChi VESBdico & & & & & & & & & & $E$ & & & EH & $E$ & \\
\hline 217 & Tachirata & & & & & & & & $\sqrt{E}$ & & $\sqrt{E}$ & & $E$ H & 4 & $E$ is & 3 \\
\hline 216 & 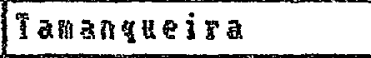 & & & & & & & & $E$ & E & $E$ & EUP & $E$ & $E$ & $E$ & EV \\
\hline 219 & 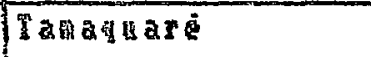 & & & & & & & & $\sqrt{E}$ & & $E$ & & $E$ & & $\bar{E}$ & \\
\hline 229 & Ianibaca & & & & & & & & $E$ & & 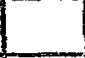 & & $E$ & & 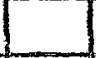 & \\
\hline 221 & Tagasti & & & & & & & & & & $E$ & & & it & $\sqrt{E}$ & VII \\
\hline 222 & Tarnas & & & & & & & & $E$ & & $E$ & & $E 0$ & & EUN & \\
\hline 223 & Tacajaba & & & & & & & & $E$ & & & & $E$ & & & \\
\hline 224 & Tatavirica & & & & & & & & 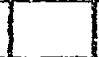 & $E$ & & $E$ H & $\xi$ & $E$ & $E$ & $E$ \\
\hline 225 & 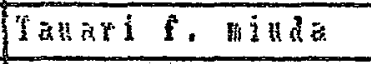 & & & & & & & & $E$ & & $E$ & & $E M$ & & $E$ & \\
\hline 226 & Tento atare 10 & & & & & & & & $E$ & & & & & & & \\
\hline 227 & Iento f.grande & & & & & & & & & & $E$ & $E$ & & . & $E$ & \\
\hline 228 & Tento f. oidda & & & & & & & & & & $E$ & & & i] & EV & \\
\hline 229 & Tento preto & & & & & & & & & & $E$ & & & $M$ & $E$ & H \\
\hline 239 & Tinteiro & & & & & & & & & & $E$ & & & & $E$ & \\
\hline 231$]$ & Iragiara & & & & & & & & & & $E$ & & & & $E$ & \\
\hline 232 & Iraciarana & & & & & & & & & & $E$ & & & & $E$ & \\
\hline 233 & Trefia & & & & & & & & & & & & & & $E$ & $E$ \\
\hline 234 & Ucunbe chorona & & & & & & & & & & $E$ & & & & $E$ & \\
\hline
\end{tabular}




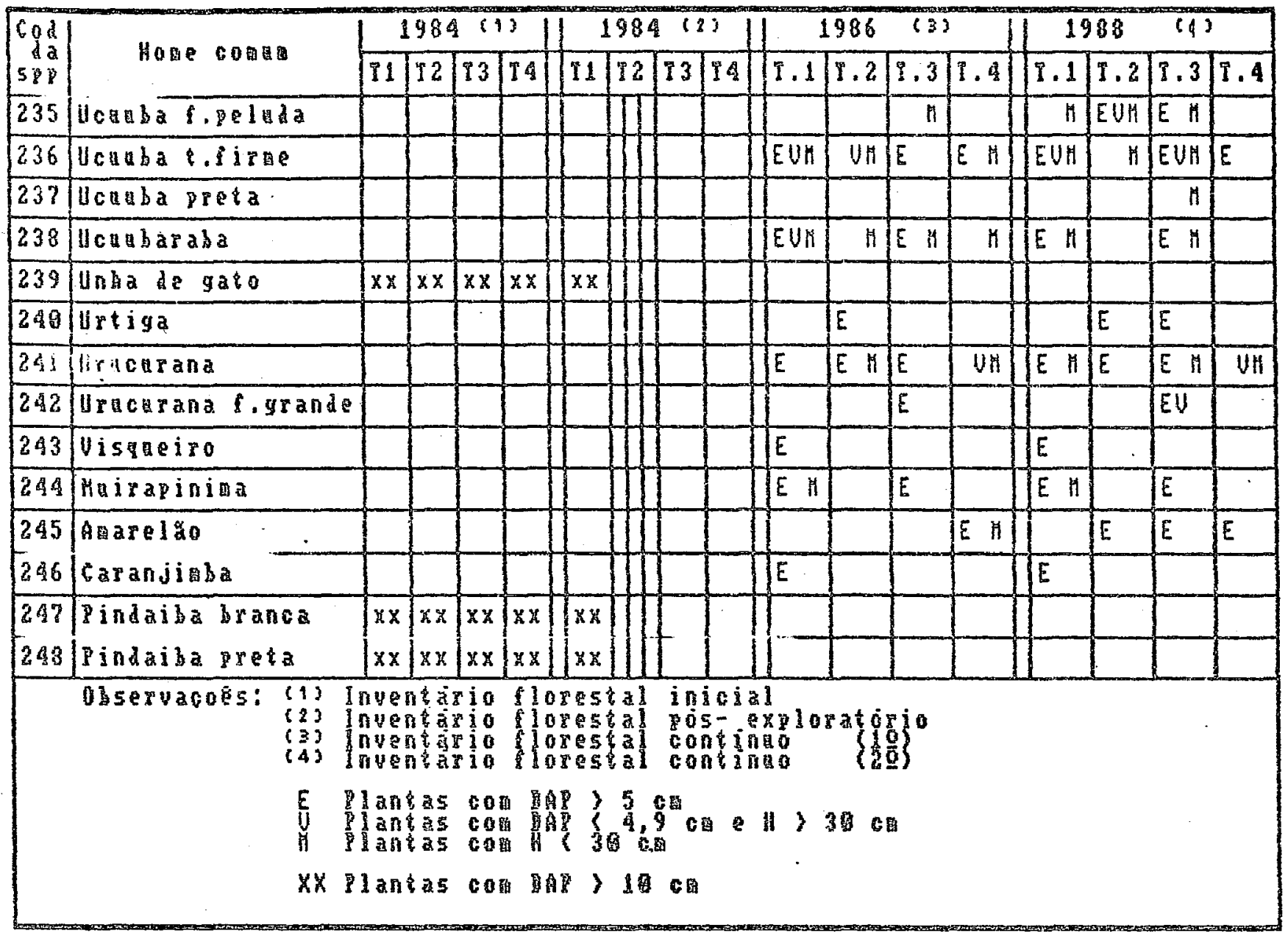


APEMDTCE ?

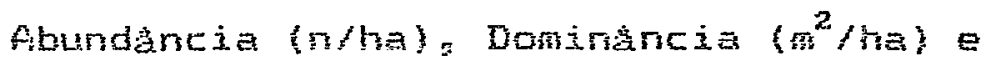

Frequencia $(\%)$ absoluta e relativas das especies selecionedas no estagio de plantas estabelecidos (SP1). Inventaria contrnad 1796. 
Page Ko I

$83 / 25 / 90$

A)undanc a (S/ha), Boninanc ia (wa/haterequencia (\%) absoluta

e relativa das especies selecionadas no estagio de

plantas estaúciecidas (GPi)

Inventario continuo - 1986

Codspp hove conda

Trat Bloco ab_abs Ab_rel Co abs Do_rel Freq_abs Frequel

\begin{tabular}{|c|c|c|}
\hline 16 & Anescla branca & $\mathfrak{1}$ \\
\hline $2 ! 7$ & Anescla & 1 \\
\hline 918 & Andirobarana & 1 \\
\hline 335 & Jreu ver meino & $\vdots$ \\
\hline 47 & Caferana & 1 \\
\hline 69 & Cedrorana & 1 \\
\hline 109 & illouba da tata & 1 \\
\hline 22 & inga veruelino & 1 \\
\hline$\$ 24$ & Ingar and & 1 \\
\hline 6 & Murure & 1 \\
\hline 7 & Anesclao & 1 \\
\hline$\theta$ & Ancirobarana & 1 \\
\hline 5 & Aratariu & 1 \\
\hline e & Axixa & 1 \\
\hline 5 & 3rell vernetho & 1 \\
\hline 7 & Cóterexta & 1 \\
\hline 9 & Injauba da nata & 4 \\
\hline 3 & anajarana & 1 \\
\hline 4 & Ingtrane & 1 \\
\hline 7 & Mapatirana & 1 \\
\hline 166 & Midrare & 1 \\
\hline bi7 & Anesclao & 1 \\
\hline $0 \leq 8$ & Anưvirobarana & 1 \\
\hline 025 & Arataciu & 1 \\
\hline 835 & Brel ver fielho. & 1 \\
\hline 947 & Cáfrana & $i$ \\
\hline 053 & Canela de jacanin & 1 \\
\hline$\theta 6 \dot{4}$ & Castanineira & 1 \\
\hline 113 & Iñajarane & $i$ \\
\hline 185 & Pali preto & 1 \\
\hline 818 & Anóirobarana & 1 \\
\hline 25 & Arataciu & 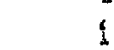 \\
\hline 028 & Axixa & 1 \\
\hline 935 & Bren ve: aelho & $i$ \\
\hline 047 & Caferand & i \\
\hline 953 & Canela de jacamia & 1 \\
\hline 869 & Cedrorana & 1 \\
\hline 18 & Inga cipo & 1 \\
\hline 30 & joad mole & 1 \\
\hline 47 & Papatirana & 1 \\
\hline 36 & -Eurra leiteira & 2 \\
\hline 364 & Castanheira & 2 \\
\hline 106 & indauba branca & 2 \\
\hline 10 & Igbaud veraelha & 2 \\
\hline & inga thato & 2 \\
\hline
\end{tabular}

\begin{tabular}{|c|c|c|c|c|c|}
\hline 76 & 4.13 & 0.49 & 1.99 & 52 & 5.58 \\
\hline 12 & 0.97 & 1.83 & 7.51 & 12 & 1.29 \\
\hline 1.2 & 9.03 & 1.82 & 7.46 & 60 & 6.43 \\
\hline 124 & 10.60 & 1.99 & 3.16 & 72 & 7.72 \\
\hline 120 & 9.69 & 1.23 & 5.94 & 60 & 6.84 \\
\hline 12 & 0.97 & 2.49 & 13.22 & 12 & 1.27 \\
\hline 28 & 2.26 & 1.21 & 4.95 & 12 & 1.2 \\
\hline 44 & 3.55 & 1.94 & 7.96 & 36 & 3.86 \\
\hline 36 & 2.91 & 9.39 & 1.59 & 32 & \\
\hline 36 & 2.91 & 0.97 & 3.99 & 28 & 3,00 \\
\hline 16 & $\{.47$ & 3.52 & 17.65 & 36 & 1.92 \\
\hline 34 & 7.75 & 9.65 & 3.28 & 48 & \\
\hline 128 & 11.81 & $\stackrel{1}{3} 983$ & 5.13 & 36 & \\
\hline 44 & 4.06 & 1.33 & 1.67 & 44 & 120 \\
\hline 48 & 4.43 & 1.05 & 5.28 & 36 & \\
\hline 88 & 8.12 & 1.55 & 2.76 & 52 & 6.22 \\
\hline 20 & 1.94 & 1.25 & 6.27 & 12 & 9.57 \\
\hline 69. & 5.34 & 0.47 & 2.35 & 56 & 6.70 \\
\hline 16 & $\{.47$ & 6.69 & 0.94 & 16 & 2.8 \\
\hline 26 & 1.85 & 0.88 & 4.31 & 16 & 1.81 \\
\hline 36 & 3.32 & 4.44 & 2.19 & 28 & 3.35 \\
\hline 44 & 4.46 & 4.63 & 15.62 & 32 & 4.59 \\
\hline 49 & 4.80 & 1.92 & 3.44 & 32 & 4.67 \\
\hline 176 & 17.60 & 1.78 & 6.81 & 66 & 8.62 \\
\hline 136 & 13.60 & 2,66 & 5.65 & 76 & 10.92 \\
\hline 198 & 10.80 & 0.98 & 3.29 & 64 & 9.19 \\
\hline 52 & 5.20 & 6.18 & 6.62 & 32 & 4.6 \\
\hline $\bar{B}$ & 0.89 & 6.99 & 23.57 & 3 & 1.15 \\
\hline 32 & 3.20 & 9.18 & 0.52 & 32 & 4.60 \\
\hline 68 & 6.80 & 3.84 & 12.93 & 48 & 6.70 \\
\hline 36 & 3.54 & 0.42 & 1.79 & 32 & 4.52 \\
\hline 212 & 20.86 & 2.98 & 12.85 & 83 & 11,30 \\
\hline 56 & 5.51 & 1.28 & 5.51 & 44 & 6.21 \\
\hline 56 & 5.51 & 2.79 & 11.97 & 28 & 3.9 \\
\hline 48 & 4.27 & 0.50 & 1.73 & 29 & 3. \\
\hline 72 & 7.09 & 9.29 & 1.23 & 32 & 4.5 \\
\hline 8 & 0.79 & 3.41 & 14.70 & 8 & 1. \\
\hline 16. & 1.57 & 4.05 & 0.20 & 16 & \\
\hline $28^{\circ}$ & 2.76 & 6.33 & 2.43 & 20 & \\
\hline 49 & 4.72 & 0.46 & 2.96 & 32 & $A$ \\
\hline 48 & 4.83 & 0.18 & 3.69 & 20 & \\
\hline 4 & 0.34 & 0.14. & 2.86 & 4 & \\
\hline 109 & 8.39 & 0.39 & 7.62 & 32 & \\
\hline $6 \overrightarrow{8}$ & 52.69 & 2.75 & 54.31 & 84 & \\
\hline 20 & 1.68 & 0.85 & 1.06 & 12 & \\
\hline
\end{tabular}


Tage tio. 2

$8=125 / 90$

Abuncancia (N/ha), Won rancia (aic/ha) Frequencia $(\%)$ ajsoluta

E reiativa cas especies selecionaras ro estagio de

Diantas estajelecidas (GP)

inventario continuo - 1936

Codspo Home conitis

Trat Bloco Ab_abs fio_rel Do_ấs Do_rel Freq_abs Ffeq_rel

\begin{tabular}{|c|c|c|c|c|c|c|c|c|c|}
\hline 121 & Inga pretinho & 2 & 1 & 20 & 2.35 & 0.07 & 1.46 & 24 & 6.74 \\
\hline 131 & Urubeba & 2 & $\mathfrak{1}$ & 172 & 14.43 & 0.66 & 13.01 & 52 & $\{4.61$ \\
\hline 145 & Mamui & 2 & 1 & 76 & 6.38 & 0.47 & 9.29 & 48 & 13.48 \\
\hline 179 & Parica & 2 & 1 & 9 & 6.67 & 0.83 & 0.65 & 8 & 2.25 \\
\hline 189 & Pente de macaco & 2 & 1 & 8 & 0.67 & 0.02 & 0.45 & 8 & 2.25 \\
\hline 265 & Saboeiro & 2 & 1 & 36 & 3.02 & 9.11 & 2,10 & 8 & 2.25 \\
\hline 241 & Uridcurana & 2 & $\mathfrak{s}$ & 16 & 1.34 & 0.06 & 1.24 & 8 & 2.25 \\
\hline 038 & Zurra leiteira & 2 & 2 & 36 & 3.69 & 9.13 & 3.35 & 28 & 7.45 \\
\hline 044 & Castanheira & 2 & 2 & 4 & 0.41 & 0.29 & 7.53 & 4 & 1.66 \\
\hline 065 & Cauacu & 2 & 2 & 8 & 9.82 & 0.63 & 0.82 & 4 & 1.06 \\
\hline 066 & Cauchò & 2 & 2 & 12 & 4.23 & 0.04 & 1.14 & 8 & 2.13 \\
\hline 179 & Curupita & 2 & 2 & 24 & 2.46 & 0.97 & 1.82 & 16 & 4.25 \\
\hline 108 & Injalba branca & 2 & 2 & 26 & 2.65 & 0.06 & 1.60 & 16 & 4.25 \\
\hline 110 & Imíauda vernelha & 2 & 2 & 492 & 50.41 & 1.91 & 48.57 & 84 & 22.34 \\
\hline 118 & Inga cipo & 2 & 2 & 29 & 2.87 & 9.06 & 1.99 & 16 & 4.23 \\
\hline 121 & inga pretinto & 2 & 2 & 12 & $\{.23$ & 2.03 & 0.71 & 8 & 2,13 \\
\hline 131 & Jurubetse & 2 & 2 & 9 & 8.19 & 0.28 & 7.22 & 52 & 13.83 \\
\hline 145 & Mainui & 2 & 2 & 96 & 9.84 & 4.51 & 12.72 & 48 & $\$ 2.77$ \\
\hline$\$ 7 t$ & Paiteira & 2 & 2 & 28 & $2.8 \%$ & 0.08 & 2.96 & $\theta$ & 2.13 \\
\hline 189 & Pente de alacaco & 2 & 2 & 12 & 1.23 & 0.63 & 0.81 & 8 & 2.13 \\
\hline 285 & Gaboeiro & 2 & 2 & 20 & 2.65 & 0.07 & 1.70 & 4 & 1.06 \\
\hline 218 & Tailanauzira & 2 & 2 & 32 & 3.28 & 9.11 & 2.94 & 8 & 2.13 \\
\hline 038 & Burra Ieiteira & 2 & 3 & 69 & 13.39 & 0.17 & 4.94 & 49 & 37.24 \\
\hline 664 & Castanheira & 2 & 3 & 4 & 6.79 & 1.95 & 55.92 & 4 & 1.72 \\
\hline 965 & Canacu & 2 & 3 & 4 & 0.23 & 0.78 & 6.23 & 4 & 1.72 \\
\hline 110 & Indauba veraelha & 2 & 3 & 8 & 1.57 & 0.03 & 0.78 & 8 & 3.45 \\
\hline$\{45$ & Marani & 2 & 3 & 26 & 3.94 & 0.08 & 2.16 & $g$ & 3.45 \\
\hline 179 & Parica & 2 & 3 & 120 & 23.62 & 0.33 & 9.33 & 64 & 27.39 \\
\hline 189 & Pente de nacaco & 2 & 3 & 4 & 0.77 & 0.91 & 0.29 & 4 & 1.72 \\
\hline 205 & Saboeiro & 2 & 3 & 264 & 51.97 & 0.91 & 25.64 & 84 & 36.21 \\
\hline 836 & Burra leiteira & 2 & 4. & 20 & 6.72 & 0.07 & 0.63 & 20 & 9.26 \\
\hline 064 & Castanteira & 2 & $4^{\circ}$ & 4 & 0.14 & 0.04 & 7.37 & 4 & 1.86 \\
\hline 066 & Cenicho & 2 & 4 & 8 & 9.29 & 0.02 & 0.23 & 4 & 1.86 \\
\hline 979 & Curupita & 2 & 4 & 16 & 0.57 & 0.04 & 0.41 & 12 & 5.56 \\
\hline 108 & Intabuba branca & 2 & 4 & 16 & 0.57 & $0.40^{\mathrm{r}}$ & 0.46 & 16 & 7.41 \\
\hline 110 & Inbauba veraelha & 2 & 4 & 2620 & 94.25 & 10.93 & 94.78 & 1 19은 & 46.29 \\
\hline 118 & Inga cipó & 2 & 4 & $\frac{4}{3}$ & 0.14 & 0.01 & 0.69 & 4 & 1.85 \\
\hline 145 & Fanusi & 2 & 4 & 20 & 9.72 & 0.08 & 9.78 & 8 & 3.71 \\
\hline 179 & Parica & 2 & 4 & 12 & 0.43 & 0.64 & 0.41 & 12 & 5.56 \\
\hline 218 & Taภaกิ queira & 2 & 4 & 20 & $\{.91$ & 9.09 & 8.93 & 12 & 5.56 \\
\hline 016 & Afriescla branca & 3 & 1 & 64 & 4.42 & 0.68 & 4.39 & 40 & 3.52 \\
\hline 918 & findirobarana & 3 & 1 & 140 & 9.64 & 1.75 & 11.25 & 58 & 5.99 \\
\hline 028 & Axixz. & 3 & 1 & 56 & 3.86 & 0.37 & 2.35 & 49 & 4.22 \\
\hline 935 & Breu vermelho & 3 & 1 & 68 & 4.68 & 1.84 & 11.56 & 44 & 3.87 \\
\hline 047 & Caferana & 3 & 1 & 100 & 6.89 & 0.89 & 5.76 & 60 & 5.22 \\
\hline
\end{tabular}


Dise lio. 3

$09 / 25 / 79$

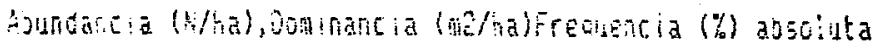

e relativa das esnecies seiecionaras no estagio de

piantas astabeiecicas (C?

inventario continuo - 1936

Codspp Hoge compa

Q64 Castanimeira

aet Envira preta

097 Espet or ana

113 inajarana

154 idutariata granco

Q16 Ariescla branca

Q18 Andirobarana

Des Aratacius

Q35 Ereu vernelio

Q47 Caferana

099 Gerae de ovo

$\$ 13$ inajarana

154 Hotaniata branco

- 18 Andirobarana

Q2: Arataciu

a3s Breus veralko

047 Ca?erana

364 Castanteira

170 Parica

¿95 Pau preto

- Q18 Andirobar ana

325 Aratacils

028 Axika

035 breu veraelho

050 Capitiu

118 inga cipo

130 juan mole

$\$ 54$ Matanata branco

166 Murure

017 Anesclaso

064 Castanheira

969 Cedrorana

110 Inouba vernelha

118 Inga cipo

131 Jurubéza

145 Ma科

035 Bren vermelio

Q38 Eurra ieiteira

i10 Inbauba vermellia

148 inga cipo

131 Jur ubeba

$\$ 4$ Magui

166 Murure

205 Saboeiro

017 Aniesclao
Trat Bjoco Ab_abs Ab_rel Do_abs Do_rel Freq_aus Freq_el

\begin{tabular}{|c|c|c|c|c|c|c|c|}
\hline 3 & 1 & 24 & 1.66 & 0.75 & 4.50 & 20 & 1.76 \\
\hline 3 & 1 & 52 & 3.58 & 0.54 & 3.30 & 40 & 3.52 \\
\hline & 1 & 76 & 5.23 & 0.29 & 1.29 & 52 & 4.58 \\
\hline 3 & 1 & 72 & 4.96 & 0.32 & 2.06 & 56 & 4.93 \\
\hline & 1 & 26 & 1.93 & $0.7 i$ & 4.95 & 80 & 2.47 \\
\hline & 2 & 32 & 2.79 & 0.29 & 1,72 & 24 & 2.97 \\
\hline 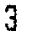 & 2 & 109 & 8.74 & 0.96 & 5,62 & 72 & 8.91 \\
\hline 3 & 2 & 36 & 3.45 & 0.37 & 2.15 & 16 & 1.90 \\
\hline 3 & 2 & 148 & 12.94 & 2.22 & 13.68 & 72 & 8.91 \\
\hline 3 & 2 & 124 & 10.84 & 0.93 & 5.47 & 64 & 7.92 \\
\hline 3 & 2 & 96 & 8.39 & 1.04 & 6.15 & 44 & 5.44 \\
\hline 3 & 2 & 68 & 5.95 & 0.51 & 2.96 & 44 & 3.44 \\
\hline 3 & 2. & 36 & 3.15 & 1.76 & 16.37 & 28 & 3.46 \\
\hline 3 & 3 & $2^{4}$ & 2.95 & $\{.66$ & 3.85 & 24 & 2.81 \\
\hline 3 & 3 & 392 & 28.43 & 3.74 & 17.65 & 104 & 14.65 \\
\hline 3 & 3 & 112 & 9.59 & 3.22 & 15.36 & 56 & 7.86 \\
\hline 3 & 3 & 60 & $5 \times 14$ & 9.49 & 2.34 & 44 & 6.13 \\
\hline 3 & 3 & 4 & 7.34 & 4.32 & 20.54 & 4 & 0.56 \\
\hline 3 & 3 & 72 & 6.16 & 9.39 & 1.61 & 29 & 3.93 \\
\hline 3 & 3 & 36 & 3.98 & 1.69 & 8.47 & 32 & 4.49 \\
\hline 3 & 4 & 49 & 5.52 & 0.31 & 2.87 & 32 & 3.52 \\
\hline 3 & 4 & $11 \dot{t}$ & 16.82 & 1.76 & 15.65 & 60 & 10.35 \\
\hline 3 & 4 & 106 & 2.21 & 9.46 & 4.26 & 3 & 1.38 \\
\hline 3 & 4 & 64 & 8.84 & 9.93 & 8.55 & 32 & 5.52 \\
\hline 3 & 4 & 28 & 3.87 & 0.98 & 9.72 & 20 & 3,45 \\
\hline 3 & 4 & 16 & $2.2 !$ & 9.75 & 6.07 & 26 & 2.76 \\
\hline 3 & 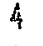 & 24 & 3.31 & 0.33 & 3.94 & 20 & 3.45 \\
\hline 3 & 4 & 32 & 4.42 & 0.50 & 4.57 & 28 & 4.83 \\
\hline 3 & 4 & 28 & 3.87 & 0.74 & 6.83 & 28 & 4.63 \\
\hline 4 & 1 & 8 & 1.18 & 1.71 & 5.74 & 8 & 2.50 \\
\hline 4 & 1 & 8 & 1.18 & 21.92 & 73.55 & 8 & 2.56 \\
\hline 4 & 1. & 20 & 2.94 & $\theta .62$ & 2.89 & 12 & 3.84 \\
\hline 4 & 1 & 348 & 51.47 & 1.59 & 5.35 & 86 & 25.64 \\
\hline 4 & 1 & 27 & 2.94 & 0.06 & 0.19 & 20 & 6.41 \\
\hline 4 & 1 & 64 & 9.41 & 0.44 & 1.47 & 44 & 14.10 \\
\hline 4 & $\underline{1}$ & 48 & 7.06 & 0.22 & 9.73 & 24 & 7.69 \\
\hline 4 & 2 & 20 & 5.85 & 1.47 & 30.50 & 20 & 7.14 \\
\hline 4 & 2 & 28 & 7.97 & 9.39 & 1.94 & 28 & 10.00 \\
\hline 4 & 2 & 28 & 7.67 & 0.21 & 4.24 & 24 & 8.57 \\
\hline 4 & 2 & 16 & 4.204 & 0.27 & 5.61 & 16 & 5.71 \\
\hline 4 & 2 & 24 & 6.96 & 9.06 & 1.32 & 16 & 5.71 \\
\hline 4 & 2 & 132 & 33.32 & 9.77 & 16.93 & 56 & 20.90 \\
\hline 4 & 2 & 8 & 2.02 & 0.52 & 10.86 & 8 & 2.85 \\
\hline & 2 & 8 & 2.62 & 0.56 & 11.57 & $B$ & 2.86 \\
\hline & 3 & 8 & 3.33 & 1.26 & 7.94 & 8 & 4.5 \\
\hline
\end{tabular}


$395=13.4$

Q⿻isisio

Abundancio (N/nal, Jominancia (a2/härequencia (\%) absoiuta

e pelativa das especies seleclonadas no estagio de plantas Estadeiecidas (SPi)

Inventario continuo - 1986

\begin{tabular}{|c|c|}
\hline 918 & Andirobarana \\
\hline 255 & Afatacil \\
\hline 035 & Breis verfiselto \\
\hline 336 & Silra ieiteira \\
\hline 054 & Castantheira \\
\hline$\$ 70$ & Mut antos \\
\hline 179 & Jarica \\
\hline 185 & Pau preto \\
\hline 189 & Pente de nacaco \\
\hline 318 & And irobarana \\
\hline 025 & Arstacis \\
\hline 235 & Gren vertalho \\
\hline 038 & Bura leiteira \\
\hline 269 & Ceurarana \\
\hline 110 & Jibause vernelha \\
\hline 118 & Ings $6 i p 0$ \\
\hline 145 & Hanul \\
\hline 147 & Hapstifana \\
\hline 189 & Pente de macaco \\
\hline
\end{tabular}

$\begin{array}{ll}4 & 3 \\ 4 & 3 \\ 4 & 3 \\ 4 & 3 \\ 4 & 3 \\ 4 & 3 \\ 4 & 3 \\ 4 & 3 \\ 4 & 3 \\ 4 & 4 \\ 4 & 4 \\ 4 & 4 \\ 4 & 4 \\ 4 & 4 \\ 4 & 4 \\ 4 & 4 \\ 4 & 4 \\ 4 & 4 \\ 4 & 4\end{array}$

$8 \quad 3.35$

$0.52 \quad 2.93$

$\$ 2 \quad 5.90 \quad 0.56 \quad 3.12$

$12 \quad 5.03 \quad 1.15 \quad 6.45$

$8 \quad 3.33 \quad 9.02 \quad 0.13$

$\begin{array}{llll}4 & 4.67 & 4.12 & 23.97\end{array}$

$\begin{array}{llll}8 & 3.33 & 1.25 & 10.37\end{array}$

$\begin{array}{llll}64 & 26.67 & 0.17 & 0.94\end{array}$

$46 \quad 16.67 \quad 3.93 \quad 21.98$

$4 \quad 1.67 \quad 6.51 \quad 2.83$

ló $4.94 \quad 0.86 \quad 50.85$

$62.4 T$

$12 \quad 3.73$

$40 \quad 12.35$

if 4.54

68 20.99

$9.34 \quad 4.26$

$.97 \quad 12.27$

$4.11 \quad 2.40$

0.8010 .65

$9.26 \quad 3.31$

$28 \quad 8.64$

$0.68 \quad 0.96$

$32 \quad 9.69$

$0.26 \quad 2.07$

$4 \quad . .23$

L.t. 14.91

$8 \quad 2.47$

$0.67 \quad 8.63$

$\begin{array}{rr}8 & 4.55 \\ 12 & 6.82 \\ 12 & 6.82 \\ 8 & 4.55 \\ 4 & 2.27 \\ 4 & 2.27 \\ 24 & 15.64 \\ 24 & 13.64 \\ 4 & 2.27 \\ 16 & 6.86 \\ 4 & 4.51 \\ 12 & 4.55 \\ 36 & 13.64 \\ 12 & 4.55 \\ 49 & 45.15 \\ 24 & 9.49 \\ 24 & 9.69 \\ 4 & 4.51 \\ 8 & 3.63\end{array}$

x* Total $3 x$

$112641999.6168 .471167 .2 \quad 4476 \quad 965.69$ 


\section{APENDICE 3}

Abundancia (n/ta), Dominaricie (mª)

Frequencia $\{\%$ absoluta e relativas das especies selecionadas no estagio de crescimento varas (SF2). Inventario continas 1596. 
PB: 4.:

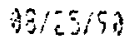

Huncancia (W/ha), Ooninancia (me/ha), Frecuencia $(y)$ aboluta

e relat ive das egoecies selecionzeas nó estagio de

crescinento de vares (SP2).

inveritar io continuo - 1986.

Codspp ive cosuta

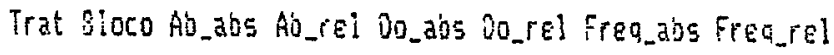

\begin{tabular}{|c|c|}
\hline 004 & Asula vermeitho \\
\hline 922 & Aที⿰彳ฺ \\
\hline 825 & Arataciu \\
\hline 831 & Bacurpari \\
\hline 835 & Ersu vertalino \\
\hline 047 & Eàterana \\
\hline 684 & Envira preta \\
\hline 185 & Grao de cachorro \\
\hline 139 & Eopro cravo \\
\hline 931 & 3acuripari \\
\hline 835 & Brel vermelto \\
\hline 958 & Cartin \\
\hline 984 & Ervira preta \\
\hline 905 & 4) \\
\hline $63 !$ & Bacuripari \\
\hline 935 & 3reu verneitio \\
\hline 0.47 & Ca?erana \\
\hline 953 & Conela te jacaninim \\
\hline 130 & Jaeo hole \\
\hline 658 & Capitiu \\
\hline 694 & Erivira preta \\
\hline 1200 & Inga peilido \\
\hline 130 & Loao mole \\
\hline 166 & Harure \\
\hline 239 & Ueuubarana \\
\hline$\{68$ & láauba branca \\
\hline 110 & Intaluba vernelia \\
\hline 110 & Inga cipo \\
\hline$\{2\}$ & Inga pretinio \\
\hline 131 & Jurubeba \\
\hline 140 & Louro preto \\
\hline$\$ 78$ & Parapara \\
\hline 179 & arica \\
\hline 958 & fapitiu \\
\hline 679 & Curupita \\
\hline 110 & Iabauba oranca \\
\hline 131 & Jurubeba \\
\hline 137 & Louro amarelo \\
\hline 205 & Saboeiro \\
\hline $016^{\circ}$ & finescia branca \\
\hline 108 & Japauba branca \\
\hline 435 & Lacre \\
\hline 178 & Parapara \\
\hline 179 & Parica \\
\hline 205 & Saboeiro \\
\hline
\end{tabular}

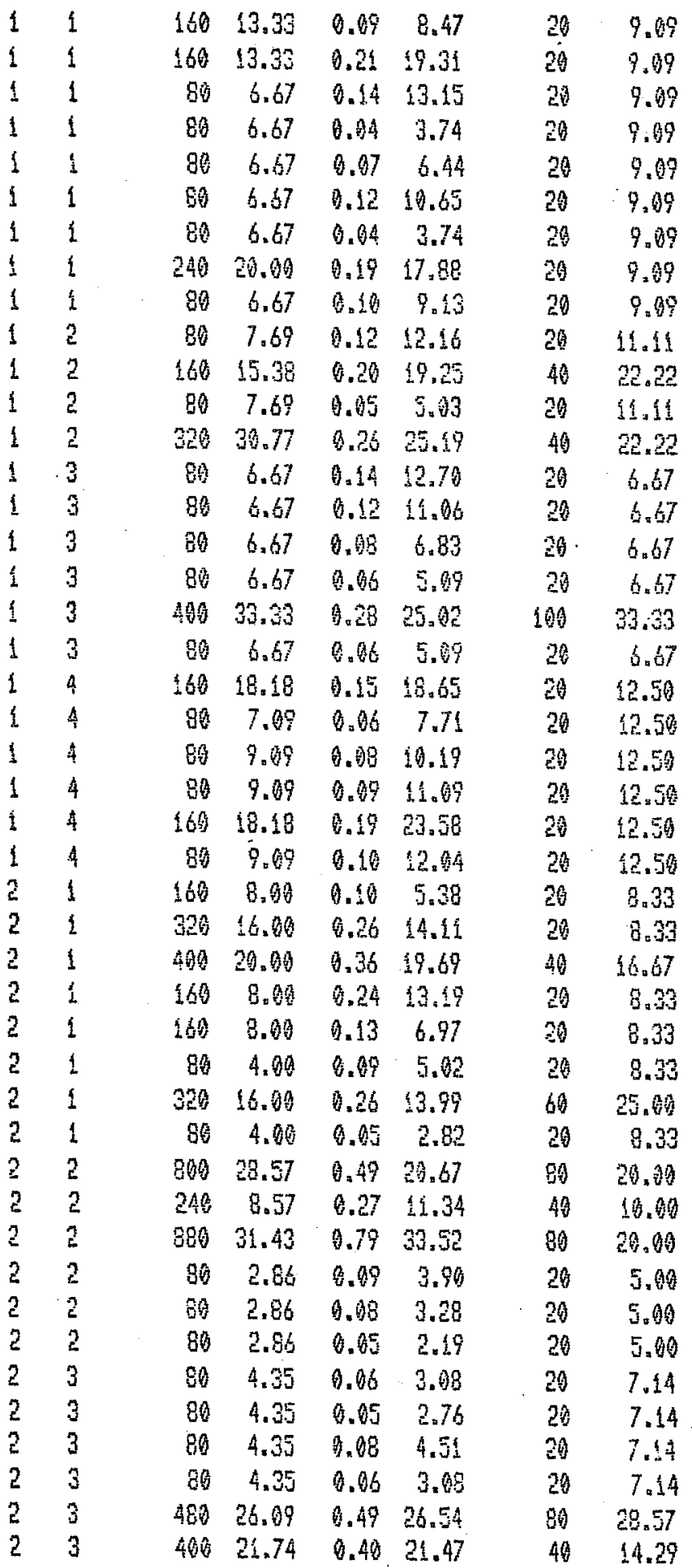


Paje to.

bi: $=273$

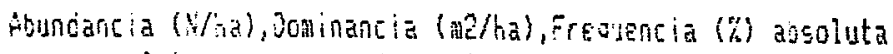

e reiativa cas esoecies selectonatas nin estajio de crescuanto re varas (S?2). inventar io continuso - 1906.

\begin{tabular}{|c|c|}
\hline 052 & Conotiu \\
\hline 079 & Surupita \\
\hline 110 & Enoalog ver welha \\
\hline 120 & nga peludo \\
\hline 189 & Pente de macaco \\
\hline 205 & Saboeiro \\
\hline 018 & Anci : rojar ana \\
\hline 035 & Breu ver melho \\
\hline 6.58 & Capitiu \\
\hline 964 & Envira preta \\
\hline 122 & Inga vernelho \\
\hline 137 & Eouro anarelo \\
\hline 035 & Brel vermelho \\
\hline 653 & Cancia de jacanial \\
\hline 094 & Envira preta \\
\hline 166 & Wurure \\
\hline 006 & Asiurana folha grande \\
\hline 835 & 3rau vernelho \\
\hline 99 & gurza iefteira \\
\hline 047 & Caferana \\
\hline 097 & Espetorana \\
\hline 147 & inge chato \\
\hline 140 & Louro preto \\
\hline 194 & Periquiteira \\
\hline 004 & Assiu verneltho \\
\hline 384 & Envira preta \\
\hline 007 & Espetorana \\
\hline$\$ 94$ & Perioutiteira \\
\hline 050 & Cajucara \\
\hline 058 & Capitiu \\
\hline 108 & Intaliba branca \\
\hline 110 & Intaúba vermeltha \\
\hline 118 & Inga cipg \\
\hline 028 & Axixa \\
\hline 837 & Espetorzna \\
\hline 997 & Freijo branco \\
\hline 110 & Intababa ver welha \\
\hline 118 & Inga cipo \\
\hline 121 & Inga pretinho \\
\hline 241 & Urucuraina \\
\hline 938 & Burra leiteira \\
\hline 058 & Capitiu \\
\hline 179 & Parica \\
\hline 185 & Pau preto \\
\hline 218 & Tantanqueira \\
\hline
\end{tabular}

$\begin{array}{ll}2 & 4 \\ 2 & 4 \\ 2 & 4 \\ 2 & 4 \\ 2 & 4 \\ 2 & 4 \\ 3 & 1 \\ 3 & 1 \\ 3 & 1 \\ 3 & 1 \\ 3 & 1 \\ 3 & 1 \\ 3 & 2 \\ 3 & 2 \\ 3 & 2 \\ 3 & 2 \\ 3 & 3 \\ 3 & 3 \\ 3 & 3 \\ 3 & 3 \\ 3 & 3 \\ 3 & 3 \\ 3 & 3 \\ 3 & 3 \\ 3 & 4 \\ 3 & 4 \\ 3 & 4 \\ 3 & 4 \\ 4 & 1 \\ 4 & 1 \\ 4 & 1 \\ 4 & 1 \\ 4 & 1 \\ 4 & 2 \\ 4 & 2 \\ 4 & 2 \\ 4 & 2 \\ 4 & 2 \\ 4 & 2 \\ 4 & 2 \\ 4 & 3 \\ 4 & 3 \\ 4 & 3 \\ 4 & 3 \\ 4 & 3\end{array}$

\begin{tabular}{|c|c|c|c|c|c|}
\hline 160 & 2.90 & 0.10 & 2.69 & 20 & 10.00 \\
\hline 86 & $\frac{6}{1.45}$ & 0.13 & 2.30 & 20 & 10.80 \\
\hline 3690 & 65.22 & 3.88 & 66.62 & 100 & 50.60 \\
\hline 86 & 1,45 & 0.35 & 0.79 & 20 & 10.90 \\
\hline 320 & 5.80 & 6.32 & 5.46 & 20 & 10.00 \\
\hline 280 & 23.19 & 1.35 & 23.15 & 23 & 19.90 \\
\hline 160 & 15.38 & 0.11 & 11.02 & 20 & 2.5 \\
\hline 80 & 7.69 & 0.05 & 5.21 & 20 & 27.50 \\
\hline 260 & 15.38 & 0.15 & 14.99 & 20 & 12.50 \\
\hline 160 & 15.30 & 0.23 & 23.48 & 20 & 1250 \\
\hline $8 \hat{\theta}$ & 7.69 & 0.00 & 7.79 & $2 \hat{y}$ & 12.50 \\
\hline 69 & 7.69 & 0.04 & 4.12 & 2 & $\{2.50$ \\
\hline 160 & 8.60 & 0.12 & 8.32 & 40 & 16.67 \\
\hline 89 & 4.60 & 0.34 & 2.76 & 20 & 8.33 \\
\hline 940 & 52.06 & 0.74 & 49.97 & 80 & 33.33 \\
\hline 86 & 4.60 & $\hat{y} .94$ & 2.76 & 20 & 8.33 \\
\hline 89 & 3.33 & 0.08 & 3.62 & 20 & 6.67 \\
\hline 406 & 36.67 & 0.39 & 16.91 & 49 & 13.33 \\
\hline 640 & 26.67 & 8.47 & 20.27 & 20 & 6.67 \\
\hline 496 & 46.67 & 0.49 & 21.11 & 60 & 20.00 \\
\hline $8 \hat{0}$ & 3.33 & 0.07 & 3.62 & 20 & 6.67 \\
\hline 80 & 3.33 & 0.04 & 1.75 & 29 & 8.67 \\
\hline 80 & 3.33 & 0.29 & 3.94 & 20 & 6.67 \\
\hline 160 & 6.67 & 9.22 & 9.47 & 29 & 6.67 \\
\hline 80 & 10.90 & 0.09 & 10.53 & 20 & 12.50 \\
\hline 243 & 30.90 & 0.16 & $\{8.53$ & 20 & 12.50 \\
\hline 86 & 10.00 & 0.10 & 11.43 & 20 & 12.59 \\
\hline 80 & 10.00 & 0.15 & 97.57 & 20 & 12.50 \\
\hline 560 & 11.11 & 0.12 & 10.72 & 48 & $\{3.18$ \\
\hline 249 & 66.67 & 0.13 & 12.97 & 28 & 9.09 \\
\hline 80 & $5.5 t$ & 0.09 & 9.96 & 26 & 9.97 \\
\hline 169 & 14.11 & 0.00 & 7.97 & 49) & 18.10 \\
\hline 160 & 11.11 & 0.13 & 12.73 & 20 & 9.69 \\
\hline 80 & 10.90 & 0.13 & $16.9 ?$ & 20 & 14.29 \\
\hline 240 & 30.30 & 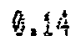 & 16.63 & 20 & 14.29 \\
\hline 160 & 29.60 & 4.25 & 29.72 & 20 & 14.29 \\
\hline 80 & 10.96 & 0.94 & 4.68 & 20 & 14.29 \\
\hline 80 & 19.90 & 0.09 & 9.22 & 20 & 14.29 \\
\hline 80 & 10.08 & 9.14 & 17.15 & 20 & 14.27 \\
\hline 89 & 19.90 & 0.95 & 5.17 & 20 & 14,29 \\
\hline 720 & 42.86 & 0.57 & 42.84 & 40 & 16.67 \\
\hline 80 & 4.76 & 6.65 & 3.85 & 20 & 8.33 \\
\hline 240 & 14.29 & 0.29 & 21.86 & 40 & 16.67 \\
\hline$\$ 60$ & 9.52 & B..11 & 8.20 & 40 & 16.67 \\
\hline 80 & $4.7 t$ & 0.65 & 3.85 & 20 & 8.33 \\
\hline
\end{tabular}




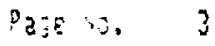

$03 / 2517$

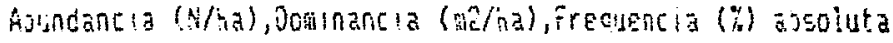

e reiativa das especies selecionadas no estagio de crescinento de varas (SP2). Inventar io continuo - $\$ 926$.

Coospp towe cons:

$029 \quad A x_{i} \times 3$

Q47 Cajerana

110 Inganba verneltha

118 Inga cipo

$\$ 89$ Pente oe macaco

218 Tamanqueira

*** Tota!
Frat Bloco Ab_abs Ab_rel Do_abs Do_re! Freq_ads Freq_rel

$\begin{array}{rrrrrrrr}4 & 4 & 30 & 6.67 & 0.09 & 10.11 & 20 & 11.11 \\ 4 & 4 & 240 & 20.00 & 0.14 & 15.87 & 20 & 11.11 \\ 4 & 4 & 160 & 13.33 & 0.16 & 17.56 & 20 & 11.11 \\ 4 & 4 & 160 & 13.33 & 0.09 & 19.13 & 20 & 11.11 \\ 4 & 4 & 90 & 6.67 & 0.12 & 12.96 & 20 & 11.11 \\ 4 & 4 & 240 & 20.09 & 1.15 & 16.01 & 20 & 11.11\end{array}$

22939 1201.9 20.41 $1005.7 \quad 2640 \quad 180.22$ 


\section{APENDICE 4}

Abundacia (n/ha), Dominancia $\left(m^{2} /\right.$ ha) $e$

Frequencia (\%) absoluta e relativas das especies selecionadas no estágio de plantas estabelecidos (SP1). Inventária continuo 1989. 


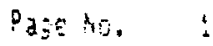

मू:

Aondancia (W/ha), Dontranc:a(me/ha), frequencia $(\%)$ absoluta

e reiativa das espectes selecionas no estagio de Diantas estabe:ecidas (GP).

inventar 10 continuo - 1980.

Codspo toge ConHA

Trat Bluco Ab_abs Ab_rel Do_abs Do_rel Freq_abs Freq_rel

\begin{tabular}{|c|c|c|c|c|c|c|c|c|c|}
\hline 816 & Amescla branca & 1 & 1 & 92 & 7.40 & 0.60 & 0.60 & 56 & 6.03 \\
\hline 017 & Asescizo & 1 & 1 & 12 & 0.96 & 2.12 & 2.12 & 12 & 1.29 \\
\hline 618 & Andirobarana & 1 & 1 & 168 & 3.68 & 1.88 & 1.88 & 60 & 6.47 \\
\hline 225 & Arataciu & 1 & 1 & 32 & 2.57 & 0.39 & 0.39 & 20 & 2.16 \\
\hline 823 & Axixa & $i$ & 1 & 16 & 1.29 & 0.79 & 0.79 & 12 & 1.29 \\
\hline 835 & Breu vergelho & 1 & 1 & 140 & 11.25 & 2.68 & 2.68 & 72 & 7.76 \\
\hline 047 & Caferana & 1 & 1 & 124 & 9.97 & 1.25 & 1.25 & 64 & 6.90 \\
\hline 069 & Cedrorana & 1 & 1 & 12 & 0.96 & 2.81 & 2.81 & 12 & 1.29 \\
\hline 109 & Injoulva da mata. & 1 & 1 & 24 & 1.93 & 1.26 & 1.26 & 12 & 1.29 \\
\hline 113 & inajarana & $\mathfrak{1}$ & 1 & 28 & 2.25 & 7.16 & 0.16 & 28 & 3.62 \\
\hline 122 & Inga vertaelho & \{ & 1 & 44 & 3.54 & 2.96 & 2.96 & 36 & 3.88 \\
\hline 130 & Load wole & 1 & 1 & 28 & 2.25 & 0.17 & 0.17 & 28 & 3.92 \\
\hline 166 & Murure & 1 & 1 & 32 & 2.57 & 0.99 & 0.99 & 28 & 3.02 \\
\hline 017 & Anescia & 1 & 2 & 16 & 1.45 & .3 .60 & 3.69 & 16 & 4.85 \\
\hline 018 & And Probarana & 1 & 2 & 84 & 7.64 & 6.72 & 0.72 & 48 & 5.56 \\
\hline 825 & fratacili & 1 & 2 & $\$ 36$ & 12.36 & $\frac{1}{2.92}$ & 1.92 & 44 & 5.99 \\
\hline 928 & Axixa & 1 & 2 & 36 & 3.27 & 4.23 & 9.28 & 36 & 4.27 \\
\hline 035 & Bren vermelho & 1 & 2 & 56 & 5.69 & 1.65 & 1.05 & 40 & 4.63 \\
\hline 047 & Caferana & 1 & 2 & 84 & 7.64 & 0.51 & 6.51 & 52 & 6.02 \\
\hline 109 & Inbauba da mata & 1 & 2 & 20 & 1.82 & 1.37 & 1.37 & 12 & 1.39 \\
\hline 113 & Inajarana & 1 & 2 & 52 & 4.73 & 0.44 & 0.44 & 52 & 6.02 \\
\hline 147 & Mapatirana & 1 & 2 & 20 & 1.82 & 1.13 & 1.13 & 16 & 1.85 \\
\hline 154 & Mataniata branco & 1 & 2 & 28 & 2.55 & 4.12 & 0.12 & 28 & 3.24 \\
\hline 166 & Hurure & 1 & 2 & 32 & 2.91 & 6.46 & 0.46 & 28 & 3.24 \\
\hline 017 & Amesclao & 1 & 3 & 44 & 4.55 & 4.86 & 4.86 & 32 & 4.76 \\
\hline 018 & Andirobarana & 1 & 3 & 48 & 4.96 & 1.06 & 1.96 & 32 & 4.76 \\
\hline 025 & Aratacin & 1 & 3 & 176 & 18.18 & 2.62 & 2.82 & 69 & 8.93 \\
\hline 035 & Bfeu ver aitho & 1 & 3 & 132 & 13.64 & 2.30 & 2.30 & 76 & 11.31 \\
\hline 047 & Caferana & 1 & 3 & 190 & 10.33 & 1.09 & $\frac{1}{3.60}$ & 64 & 9.52 \\
\hline 053 & Canela de jacanit & 1 & 3 & 48 & 4.96 & 0.18 & 0.18 & 28 & 4.17 \\
\hline 064 & Castanheira. & 1 & 3 & 8 & 0.63 & 7.07 & 7.07 & 8 & 1.19 \\
\hline 113 & Inajarana & 1 & 3 & 32 & 3.31 & 0.19 & 0.19 & 32 & 4.76 \\
\hline 166 & Murure & 1 & 3 & 20 & 2.07 & 0.33 & 0.33 & 20 & 2.98 \\
\hline 185 & Pau preto & 1 & 3 & 72 & 7.44 & 3.67 & 3.67 & 44 & 6.55 \\
\hline 018 & Andirobarana & 1 & 4 & 44 & 4.33 & 0.48 & 8.48 & 46 & 5.59 \\
\hline 025 & Arataciu & 1 & 4 & 204 & 20.08 & 3.03 & 3.03 & 80 & 11.17 \\
\hline 928 & Axixa & 1 & 4 & 56 & 5.51 & 1.44 & $\{.44$ & 44 & 6.15 \\
\hline 035 & Êreu ver melho & 1 & 4 & 52 & 5.12 & 2.42 & 2.42 & 24 & 3.35 \\
\hline 047 & Caferana & 1 & 4 & 48 & 4.72 & 0.44 & 0.44 & 28 & 3.91 \\
\hline 949 & Caju de janeiro & 1 & 4 & 4 & 0.39 & 1.29 & 1.29 & 4 & 9.56 \\
\hline 053 & Canela de jacamin & 1 & 4 & 72 & 7.09 & 0.29 & 0.29 & 32 & 4.47 \\
\hline 969 & Cedrorana & 1 & 4 & 8 & 0.79 & 3.42 & 3.42 & 8 & 1.12 \\
\hline 130 & Joao mole & 1 & 4 & 28 & 2.76 & 0.14 & 0.14 & 20 & 2.79 \\
\hline 147 & Mapatirana & 1 & 4 & 48 & 4.72 & 0.63 & 0.63 & 32 & 4.47 \\
\hline 154 & Mataniata branco & 1 & 4 & 12 & 1.18 & 1.73 & 1.73 & 12 & $\{.68$ \\
\hline
\end{tabular}




\begin{tabular}{|c|c|}
\hline 8 & Enrra leiteira \\
\hline 164 & Castantieira \\
\hline 965 & Canacu \\
\hline 369 & Cedrorana \\
\hline 109 & inbanda branca \\
\hline 110 & iguădia vermeiha \\
\hline 116 & inga cipo \\
\hline 121 & Inga pretinho \\
\hline 131 & jurubeja \\
\hline 135 & Lacre \\
\hline 145 & Mamui \\
\hline 179 & Parica \\
\hline 189 & Pente de macaco \\
\hline 205 & Saboeiro \\
\hline 216 & Tanianqueira \\
\hline 224 & Tatapiririca \\
\hline 938 & Jurre leiteira \\
\hline 864 & Castaineira \\
\hline 065 & Cauacu \\
\hline 366 & Cauctio \\
\hline 979 & Curupits. \\
\hline 064 & Envira preta \\
\hline 100 & Inbauba branca \\
\hline 110 & Jabauba vermelha \\
\hline 116 & Inga branco \\
\hline 118 & Inga cipo \\
\hline 121 & Inga pretioho \\
\hline 131 & Surubeba \\
\hline 135 & Lacre \\
\hline 145 & Manui \\
\hline 179 & Parica \\
\hline 489 & Pente de arcaco \\
\hline 205 & Saboeiro \\
\hline 218 & Tamanque ira \\
\hline 038 & Burra leiteira \\
\hline 684 & Castanheira \\
\hline 665 & Cauacu \\
\hline 069 & Cedrorana \\
\hline 679 & Curupita \\
\hline $9 B 4$ & Envira preta \\
\hline 110 & inbaita branca \\
\hline$\$ 18$ & inga cipo \\
\hline 135 & Lacre \\
\hline 145 & Ma船证了 \\
\hline 179 & Parica \\
\hline
\end{tabular}

\begin{tabular}{|c|c|c|c|c|c|c|c|}
\hline 2 & 1 & 64 & 4.07 & 8.56 & 0.56 & 36 & 7.44 \\
\hline 2 & 1 & 4 & 0.25 & 0.22 & 3.22 & 4 & 0.83 \\
\hline 2 & 1 & 4 & 0.25 & 0.01 & 8.01 & 4 & 9.83 \\
\hline 2 & 1 & 8 & f. & 0.02 & 9.02 & 4 & 0.83 \\
\hline 2 & 1 & 92 & 5.85 & 9.99 & 0.99 & 32 & 6.61 \\
\hline 2 & 1 & 928 & 59.03 & 7.32 & 7.32 & 100 & 20.66 \\
\hline 2 & 1 & 72 & 4.58 & 0.43 & 0.43 & 44 & 9.69 \\
\hline 2 & 1. & 72 & 4.58 & 6.47 & 0.47 & 44 & 9.09 \\
\hline 2 & 1 & 28 & 1.78 & 8.18 & 0.18 & 20 & 4.13 \\
\hline 2 & 1 & $B$ & 9.51 & 0.92 & 0.02 & 4 & 0.83 \\
\hline 2 & 1 & 80 & 5.69 & 0.93 & 0.93 & 44 & 9.89 \\
\hline 2 & 1 & 12 & 0.76 & 0.10 & 8.10 & $\{2$ & 2.48 \\
\hline 2 & 1 & 8 & 0.51 & 0.64 & 0.04 & $g$ & 1.65 \\
\hline 2 & 1. & 59 & 3.82 & 0.32 & 0.32 & 20 & 4.13 \\
\hline 2 & 1 & 4 & 0.25 & $6.9 ?$ & 0,02 & 4 & $\frac{n}{v} .83$ \\
\hline 2 & 1 & $A$ & 0.25 & 0.03 & 9.63 & 4 & 0.83 \\
\hline 2 & 2 & $\{4$ 公 & 7.93 & 0.63 & 0.63 & 72 & 11.92 \\
\hline 2 & 2 & 4 & 0.22 & 9.42 & v. 42 & 4 & 0.66 \\
\hline 2 & 2 & ib & 0.88 & 9.68 & 0.60 & if & 2.65 \\
\hline 2 & 2 & 12 & $\theta .66$ & 习.13 & 0.10 & 8 & 1.32 \\
\hline 2 & 2 & 24 & 1.32 & 0.15 & 0.25 & 16 & 2.65 \\
\hline 2 & 2 & 8 & 0.44 & 0.92 & 0.92 & 8 & 1,32 \\
\hline 2 & 2 & 20 & 1.40 & 0.27 & 0.27 & 16 & 2.65 \\
\hline 2 & 2 & 1616 & $55 . \%$ & 10.02 & 19.02 & 196 & 16.56 \\
\hline 2 & 2 & 16 & 0.88 & 9.98 & 0.08 & 12 & 1.79 \\
\hline 2 & 2 & 56 & 3.68 & 0.46 & 9.40 & 44 & 7.28 \\
\hline 2 & 2 & 28 & 1.54 & 0.19 & 0.19 & 24 & 3.97 \\
\hline 2 & 2 & 26 & 1.54 & 0.22 & 9.22 & 20 & 3.31 \\
\hline 2 & 2 & 8 & 0.44 & 0.65 & 0.85 & 8 & 1.32 \\
\hline 2 & 2 & 108 & 5.95 & 1.71 & 1.71 & 48 & 7.95 \\
\hline 2 & 2 & 8 & 0.44 & 0.63 & 6.63 & B & 1.32 \\
\hline 2 & 2 & 28 & 1.54 & 0.11 & 0.11 & 29 & 3.31 \\
\hline 2 & 2 & 40 & 2.20 & 0.25 & 0.25 & 12 & 1.99 \\
\hline 2 & 2 & 28 & $\{.54$ & 0.20 & 0.20 & 8 & 1.32 \\
\hline 2 & 3 & 359 & 29.62 & 1.72 & 1.72 & 88 & 20.18 \\
\hline 2 & 3 & 4 & 0.32 & 2.18 & 2.18 & 4 & 9.92 \\
\hline 2 & 3 & 4 & 0.32 & 0.02 & 0.02 & 4 & 8.92 \\
\hline 2 & 3 & 4 & 0.32 & 0.02 & 0.01 & 4 & 0.92 \\
\hline 2 & 3 & 4 & 0.32 & 0.03 & 0.03 & 4 & 0.92 \\
\hline 2 & 3 & 24 & 1.89 & 0.09 & 0.09 & 24 & 5.50 \\
\hline 2 & 3 & 52 & 4.10 & 0.72 & 9.72 & 36 & 8.26 \\
\hline 2 & 3 & 4 & 0.32 & 0.01 & 0.01 & 4 & 0.72 \\
\hline 2 & 3 & 4 & 6.32 & 0.92 & 0.02 & 4 & 0.92 \\
\hline$?$ & 3 & 32 & 2.52 & 0.47 & 0.47 & 16 & 3.67 \\
\hline 2 & 3 & 228 & 17.98 & 1.09 & 1.67 & 92 & 21.10 \\
\hline
\end{tabular}




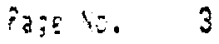

2525100

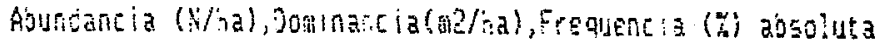

E relativ das especies seigcionas no estagio de

plantas estagelecidas (EPM).

inventario continuo - 1998.

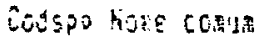

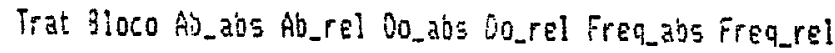

189 Fente de pã̃aco

23

205 Sazoeiro

224 iatapiririca

033 Eurra leiteira

064 Castanneira

. D66 Cancho

079 Cupupita

0.4 Envira preta

Lee Iniauga branca

190 ingauba verteliha

116 inga branco

¿13 inga cipo

121 Enga pretinno

179 Parica

¿89 ?ente de adacaco

205 Sazosiro

218 Tatenoueira

Q:6 Amescla branca

018 Andirobarana

028 Axika

035 Breu vernelho

047 Gaferana.

064 Castanizira

097 Espetorana

113 Inajarana

954 Katamata branco

bib Arescla branca

Q18 Andirobarana

ges Arataciu

028 Axika

935 3ren vernelho

Q47 Caferana

053 Canela de jacamin

099 Gema de ovo

$\$ 13$ inajarana

154 iatamata branco

198 ?urui

Q18 Andirobarana

025 Arataciu

028 Axixa

035 Ôreu ver helho

047 Caf́zrana

Q64 Castangeira

113 Inajarana

\begin{tabular}{|c|c|c|c|c|c|c|c|}
\hline & 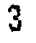 & 4 & 0.32 & 0.02 & 0.02 & 4 & 0.92 \\
\hline & 3 & 428 & 33.75 & 3.04 & 3.04 & 78 & 22.62 \\
\hline & 3 & 12 & 0.95 & 0.86 & 0.06 & 8 & 1.83 \\
\hline & 4 & 20 & 0.76 & 0.13 & 0.13 & 20 & 7.94 \\
\hline & 4 & 4 & 0.14 & 0.96 & 0.06 & 4 & 1.59 \\
\hline & 4 & 8 & 0.28 & 0.06 & 0.06 & 4 & 1.59 \\
\hline & 4 & 16 & 0.55 & 0.68 & 0.68 & 12 & 4.76 \\
\hline & 4 & 4 & 0.14 & 0.31 & 0.01 & 4 & 1.59 \\
\hline & 4 & 16 & 0.56 & 0.18 & 0.18 & 16 & 6.35 \\
\hline & 4 & 2668 & 93.42 & 24.89 & 24.89 & 100 & 39.68 \\
\hline & 4 & 4 & 0.14 & 0.02 & 0.62 & 4 & 1.59 \\
\hline & 4 & 36 & 1.26 & 0.21 & 0.21 & 28 & 11.11 \\
\hline & 4 & 4 & 0.54 & 0.01 & 0.92 & 4 & 1.59 \\
\hline & 4 & 20 & 0.70 & 0.24 & 0.24 & 8 & 3.17 \\
\hline & 4 & 16 & 0.56 & 0.23 & 0.23 & 16 & 6.35 \\
\hline & 4 & 8 & 0.28 & 0.64 & 9.84 & 8. & 3.17 \\
\hline & 4 & 4 & $0.1 \frac{1}{1}$ & 0.02 & 0.62 & 4 & 1.59 \\
\hline & 4 & 12 & 9.42 & 0.50 & 9.50 & 8 & 3.17 \\
\hline & 1 & 64 & 4.49 & 6.74 & 6.74 & 40 & 3.53 \\
\hline & 1 & 132 & 9.27 & 1.84 & 1.34 & 68 & 6.91 \\
\hline & 1 & 52 & 3.65 & 0.46 & 0.49 & 44 & 3.99 \\
\hline & 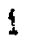 & 68 & 4.78 & 1.85 & $\{.85$ & 44 & 3.89 \\
\hline & 1 & 96 & 6.74 & 0.92 & 0.92 & 692 & 5.36 \\
\hline & 1 & 20 & 1.40 & 1.99 & 1.09 & 0 & 1.77 \\
\hline & 1 & 72 & 5.86 & 6.30 & 0.30 & 52 & 4.59 \\
\hline & 1 & 72 & 5.06 & 7. .33 & 0.33 & 56 & 4.95 \\
\hline & 1 & 32 & 2.25 & 0.96 & 0.96 & 32 & 2.83 \\
\hline & 2 & 40 & 3.08 & 6.38 & 7. .38 & 28 & 3.12 \\
\hline & 2 & $\$ 04$ & 8.00 & 1.08 & 1.68 & 69 & 7.59 \\
\hline & 2 & 44 & 3.38 & 0.45 & 0.45 & 16 & 1.79 \\
\hline & 2 & 16 & 1.23 & 9.52 & 9.52 & 16 & 1.79 \\
\hline & $?$ & $\{60$ & $\{2.34$ & 2.56 & 2.56 & 72 & 8.04 \\
\hline & 2 & 42 & 8.62 & 0.98 & 0.90 & 60 & 6.70 \\
\hline & 2 & 52 & 4.00 & 0.24 & 0.24 & 20 & 3.12 \\
\hline & 2 & 100 & 7.69 & 1.14 & 1.14 & 44 & 4.91 \\
\hline & 2 & 68 & 5.23 & 0.54 & 0.54 & 44 & 4.91 \\
\hline & 2 & 44 & 3.38 & 2.06 & 2.06 & 32 & 3.57 \\
\hline & 2 & 28 & 2.15 & 0.85 & 0.85 & 20 & 3.12 \\
\hline & 3 & 24 & 1.97 & 1.12 & 1.12 & 20 & 2.73 \\
\hline & 3 & 328 & 26.89 & 3.93 & 3.73 & 190 & 93.66 \\
\hline & 3 & 8 & 0.66 & 0.32 & 0.32 & 3 & 1.09 \\
\hline & 3 & 116 & 9.51 & 3.65 & 3.65 & 52 & 7.10 \\
\hline & 3 & 56 & 4.57 & 0.46 & 0.46 & 40 & 5.46 \\
\hline & 3 & 4 & 0.33 & 4.33 & 4.33 & 4 & 0.55 \\
\hline & 3 & 28 & 2.29 & 0.12 & 0.12 & 16 & 2.19 \\
\hline
\end{tabular}


Pass is: 4

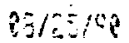

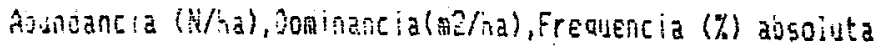

E reiativa dáa esoecies selecionas no estagio oe

piantas etaveleridas ( $(5 ?)$.

inventario continuo - 1988.

Cedspp hose corng

Trat Bloco Ab_ais Ab_rel OO_abs Do_rei Freq_ados Freq_el

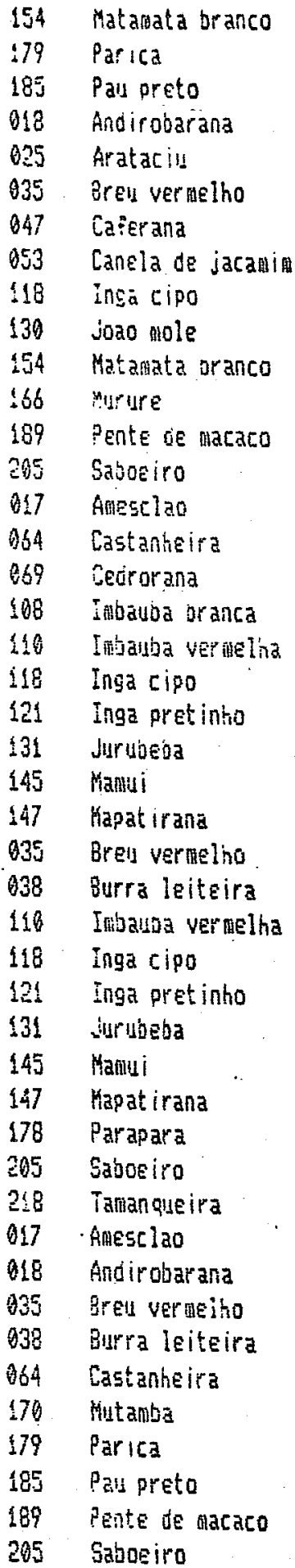

\begin{tabular}{|c|c|c|c|c|c|c|c|}
\hline 3 & 3 & 20 & 1.64 & 0.48 & 0.40 & 16 & 2.19 \\
\hline 3 & 3 & 68 & 5.57 & 0.61 & 0.61 & 28 & 3.82 \\
\hline 3 & 3 & 36 & 2.95 & 1.83 & 1.83 & 32 & 4.37 \\
\hline 3 & 3 & 40 & 5.26 & 0.37 & 0.37 & 32 & 5.41 \\
\hline 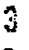 & 4 & 124 & 16.32 & 1.92 & 1.92 & 60 & 10.13 \\
\hline & 4 & 64 & 8.42 & 1.24 & 1.24 & 32 & 5.41 \\
\hline & 4 & 16 & 2.50 & 0.20 & 0.28 & 16 & 2.70 \\
\hline & 4 & $E$ & 1.05 & 0.93 & 0.83 & B & 1.35 \\
\hline & 4 & 32 & 4.21 & 0.89 & 0.89 & 16 & 2.70 \\
\hline & 4 & 28 & 3.68 & 0.37 & 0.37 & 24 & 4.65 \\
\hline & 4 & 32 & 4.21 & 9.63 & 0.63 & 23 & 4.73 \\
\hline & 4 & 29 & 3.66 & 0.77 & 9.77 & 28 & 4.73 \\
\hline 3 & 4 & 12 & 1.58 & 0.47 & 0.47 & 12 & 2.03 \\
\hline 3 & 4 & -46 & 2.11 & 9. 19 & 0.19 & 16 & 2.70 \\
\hline 4 & 1 & 8 & 0.69 & 1.75 & 1.75 & 8 & 1.64 \\
\hline$\frac{4}{4}$ & 1 & $\bar{E}$ & 0.69 & 24.72 & 21.92 & 8 & 1.64 \\
\hline 4 & 1 & 20 & 1.72 & 0.73 & 0.73 & 12 & 2.46 \\
\hline 4 & 1 & 64 & 5.52 & 9.44 & 9.44 & 44 & 9.02 \\
\hline 4 & 1 & 504 & 43.45 & 5.16 & 5.16 & $9 t$ & 19.67 \\
\hline 4 & 1 & 72 & 6.21 & 6.41 & 0.41 & 52 & 10.66 \\
\hline 4 & 1 & 100 & 3.62 & 0.49 & 0.49 & 56 & 11.48 \\
\hline 4 & 1 & 36 & 3.10 & 6.53 & 0.53 & 24 & 4.92 \\
\hline 4 & $\mathfrak{i}$ & 44 & 3.79 & 0.49 & 0.49 & 29 & 4.10 \\
\hline 4 & 1 & 28 & 2.41 & 0.32 & 0.32 & 12 & 2.46 \\
\hline 4 & 2 & $2 \frac{2}{2}$ & 3.99 & 4.58 & 1.58 & 20 & 4.90 \\
\hline 东 & 2 & 40 & 6.17 & 0.35 & 0.35 & 36 & 8.82 \\
\hline 4 & 2 & 92 & 14.26 & 1.55 & 1.55 & 52 & 12.75 \\
\hline 4 & 2 & 184 & 16.05 & 1.07 & 1.67 & 48 & 11.76 \\
\hline 4 & 2 & 52 & 8.02 & 0.46 & 0.48 & 28 & 6.86 \\
\hline 4 & 2 & 16 & 2.47 & 0.09 & 0.09 & 12 & 2.94 \\
\hline 4 & 2 & 124 & 19.14 & 1.67 & 1.67 & 52 & 12.75 \\
\hline 4 & 2 & 16 & 2.47 & 6.11 & 0.11 & 8 & 1.96 \\
\hline 4 & 2 & 26 & 3.69 & 0.12 & 0.12 & 16 & 3.92 \\
\hline 4 & 2 & 12 & 1.85 & 9.69 & 0.69 & 12 & 2.94 \\
\hline 4 & 2 & 16 & 2.47 & 0.07 & 0.97 & 16 & 3.92 \\
\hline 4 & 3 & 8 & 2.33 & 1.28 & 1.28 & 8 & 3.45 \\
\hline 4 & 3 & 8 & 2.33 & $0.5 \frac{4}{7}$ & 0.54 & 8 & 3.45 \\
\hline 4 & 3 & 12 & 3.49 & 1.18 & 1.18 & 12 & 5.17 \\
\hline 4 & 3 & 48 & 13.95 & 0.22 & 0.22 & 24 & 10.34 \\
\hline 4 & 3 & 4 & 1.16 & 4.15 & 4.15 & 4 & 1.72 \\
\hline 4 & 3 & 8 & 2.32 & 1.87 & 1.87 & 4 & 1.72 \\
\hline 4 & 3 & 72 & 25.74 & 9.58 & 0.58 & 32 & 13.79 \\
\hline 4 & 3 & $40^{2}$ & 11.63 & 4.27 & 4.29 & 24 & 10.34 \\
\hline 4 & 3 & 4 & 1.16 & 0.58 & 0.58 & 4 & 1.72 \\
\hline 4 & 3 & E & 2.32 & 0.02 & 0.02 & 8 & 3.45 \\
\hline
\end{tabular}


Jige ho, 5

$03 / 2=193$

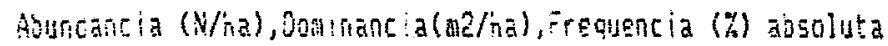

E relativa das especies geieclonas no estagio de piaitas estadelectdas (GP:).

Inventar 10 continuo - 1989.

Coc $3 \geqslant$, tore conus?

018 Andirobarana

azs jes verneltio

038 Eurra levteira

Q69 Cedrorana

116 mauba veruelha

1 if inga cipo

¿2! inga pretinino

$\$ 45$ Manui

178 Parapara

189 Jente de nacaco

218 Tamangieira

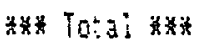

Trat jloco Ab_aos Aó_el Do_abs Do_el Freq_abs Freq_el

$\begin{array}{ll}4 & 4 \\ 4 & 4 \\ 4 & 4 \\ 4 & 4 \\ 4 & 4 \\ 4 & 4 \\ 4 & 4 \\ 4 & 4 \\ 4 & 4 \\ 4 & 4 \\ 4 & 4\end{array}$

12
12
16
19
144
2
2
3
29
29

$\begin{array}{lll}12 & 1.78 & 0.79\end{array}$

Q.79

.79
.98

$2 \quad 1.78$

$84 \quad 12.43$

$16 \quad 2.37$

1.80

$0.62 \quad 0.62$

$1.20 \quad 1.20$

$1.79 \quad 1.79$

$\begin{array}{llll}144 & 21.30 & 1.01 & 1.01 \\ 28 & 4.14 & 0.13 & 0.13\end{array}$

$\begin{array}{llll}28 & 4.14 & 9.13 & 0.13\end{array}$

$28 \quad 4.14 \quad 1.32 \quad 0.32$

$\begin{array}{llll}26 & 2.96 & 9.14 & 0.14\end{array}$

$\begin{array}{lllll}20 & 2.96 & 0.84 & 0.84\end{array}$

$\begin{array}{llll}28 & 4.14 & 0.12 & 0.12\end{array}$

$14232 \quad 124.2233 .61233 .61$

$6918 \quad 980.76$ 


\section{APENDICE 5}

Abundancia (n/ha), Dominarcia $\left(\mathrm{m}^{2} / \mathrm{ha}\right) \mathrm{E}$

Frequencia (\%) absoluta e relativas das especies selecianadas no estigio de creseimento varas (SPZ). Inventario contínuo 1998. 


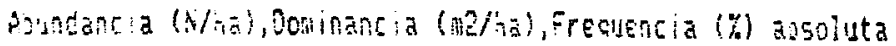

e relativa cas ejpecies seiectionacas no estag:0 de cresconerto ce varas (G?2).

inventar io continio - 1908 .

Trat Sioco Ab_abs Aórel Do_ans 0o_rel Freqaads Freq_el

\begin{tabular}{|c|c|c|}
\hline 834 & GJu vertelino & ! \\
\hline ta? & $A-3 n_{1}$ & 4 \\
\hline $8: 5$ & Arataciu & 1 \\
\hline 047 & Caterana & 1 \\
\hline$g=4$ & Erviea preta & 1 \\
\hline .95 & Erao te cachorro & 1 \\
\hline 139 & Lossec cravo & 1 \\
\hline 984 & Ajiu verhelho & 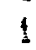 \\
\hline 818 & Andirobarana & 1 \\
\hline 335 & Ereu veratho & 1 \\
\hline 058 & Cagitiul & 1 \\
\hline 083 & Envira cana & $\mathfrak{1}$ \\
\hline 984 & Envira prota & 1 \\
\hline 116 & Inga uranco & 1 \\
\hline 024 & Aoiu vermelno & 1 \\
\hline 025 & Arataciu & 1 \\
\hline 031 & bacupipar & 1 \\
\hline 247 & Lajerana & $\underline{1}$ \\
\hline 053 & Canele de jacamin & 1 \\
\hline 664 & Castanineira & 1 \\
\hline 130 & Jo20 fols & $\mathfrak{1}$ \\
\hline 143 & Nacueu de sangue & $i$ \\
\hline 384 & Abiu vernelino & 1 \\
\hline a.j & Aratacia & $\mathfrak{i}$ \\
\hline 047 & Capitiu & 1 \\
\hline 056 & Capitiu & 1 \\
\hline 083 & Envira cana & 1 \\
\hline 130 & Soao nole & 1 \\
\hline 166 & Kurure & 1 \\
\hline 958 & Capitiu & 2 \\
\hline 110 & Imbausa verwelha & 3 \\
\hline 148 & Inga cipo & 2 \\
\hline 178 & Parapara & 2 \\
\hline 189 & Pente de macaco & 2 \\
\hline 015 & Ainaparana & 2 \\
\hline 036 & Burra leiteira & 2 \\
\hline 646 & Cafe oravo & 2 \\
\hline 958 & Capitiu & 2 \\
\hline 984 & Envira preta & 2 \\
\hline 110 & I pabauba vergalia & 2 \\
\hline 117 & Inga chato & 2 \\
\hline 154 & Haterata branco & 2 \\
\hline 179 & Parica & 2 \\
\hline 255 & Ucuuba da foltra peluda & 2 \\
\hline 038 & Gurra leiteira & .2 \\
\hline
\end{tabular}

\begin{tabular}{|c|c|c|c|c|c|}
\hline 160 & 20.60 & 0.10 & 11.41 & 20 & 14.29 \\
\hline 80 & 10.00 & 0.07 & 8.21 & 20 & 14.29 \\
\hline 80 & 10.00 & 0.56 & 19.06 & 20 & 14.2 \\
\hline 80 & 10.93 & 0.12 & 13.57 & 20 & 14.29 \\
\hline 89 & 10.00 & 0.04 & 4.77 & 20 & 14.29 \\
\hline 240 & 39.09 & 9.27 & 31.35 & 26 & 14.29 \\
\hline 80 & 10.00 & 0.10 & 11.63 & 20 & 14.29 \\
\hline 89 & 6.25 & 0.12 & 19.33 & 20 & 7.14 \\
\hline 160 & 12.50 & 0.14 & 11.86 & 40 & 14.28 \\
\hline 240 & 18.75 & 9.26 & 21.77 & 60 & 21.42 \\
\hline 80 & 6.25 & 0.06 & 4.72 & 20 & 7.14 \\
\hline 320 & 25.90 & 0.22 & 18.08 & 49 & $\{4.28$ \\
\hline 80 & 6.25 & 0.05 & 4.27 & 20 & 7.14 \\
\hline 80 & 6.25 & 0.14 & 14.86 & 20 & 7.14 \\
\hline 160 & 10.60 & 0.23 & 14.78 & 20 & 6.25 \\
\hline 160 & 10.80 & 0.20 & 13.11 & 40 & 12.50 \\
\hline 80 & 5.60 & 0.65 & 2.99 & 20 & 6.25 \\
\hline 160 & 20.89 & 0.14 & 8.82 & 30 & 6.25 \\
\hline 568 & 35.9 & $\frac{2}{4} .44$ & 28.76 & $\{00$ & 31.25 \\
\hline 80 & 5.60 & 0.35 & 3.35 & 20 & 6.25 \\
\hline 80 & 5.90 & 0.14 & 8.82 & 20 & 5.25 \\
\hline 560 & 19.90 & 0.12 & 7.99 & 49 & $12=3$ \\
\hline 160 & 11.76 & 0.12 & 3.65 & 40 & 15.38 \\
\hline 160 & 14.76 & 9.10 & 7.74 & 20 & 7.69 \\
\hline 80 & 5.80 & 0.85 & 3.87 & 20 & 7.69 \\
\hline 960 & 11.76 & 0.22 & $16.2 \mathrm{~J}$ & 20 & 7.69 \\
\hline 160 & 11.76 & 0.10 & 7.74 & 20 & 7.69 \\
\hline 30 & 5.88 & 0.13 & 10.05 & 20 & 7.69 \\
\hline 160 & 11.76 & 0.22 & 16,26 & 20 & 7.69 \\
\hline 89 & 8.33 & 9.65 & 4.70 & 20 & 12.50 \\
\hline 320 & 33.33 & 0.54 & 50.91 & 40 & 25.00 \\
\hline 249 & 25.60 & 0.22 & 20.77 & 40 & 25.00 \\
\hline 160 & 16.67 & 0.15 & 14.64 & 20 & 12.50 \\
\hline 80 & 8.35 & 9.95 & 4.90 & 20 & 12.50 \\
\hline 80 & 2.22 & 0.68 & 2.09 & 20 & 5.60 \\
\hline 320 & 8.89 & 0.29 & 7.99 & 49 & 10.00 \\
\hline 86 & 2.22 & 0.94 & 1.11 & 20 & 5.00 \\
\hline 940 & 28.89 & 0.95 & 25.78 & 80 & 23.90 \\
\hline 80 & 2.22 & 0.14 & 3.89 & 20 & 5.06 \\
\hline$\$ 360$ & 37.78 & 1.52 & 41.17 & 80 & 20.00 \\
\hline 94 & 2.22 & 0.06 & 1.73 & 20 & 5.00 \\
\hline 80. & 2.22 & 0.45 & 1.40 & 20 & 5.00 \\
\hline 80 & 2.22 & 0.11 & 2.92 & 20 & 5.00 \\
\hline 80 & 2.22 & 0.04 & 1.11 & 20 & 5.0 \\
\hline 1040 & 56.52 & 1.11 & 61.40 & 60 & $a$ \\
\hline
\end{tabular}


Page :10. ?

\begin{tabular}{|c|c|}
\hline 869 & Cecrorana \\
\hline$\llbracket: 0$ & : Jausa veraelha \\
\hline 116 & inga tranco \\
\hline 036 & Gurra leiteira \\
\hline 059 & Capitiu \\
\hline 110 & Iabauna veraelha \\
\hline 116 & Inça branco \\
\hline 117 & inga chato \\
\hline 118 & inga cipo \\
\hline 135 & Lacre \\
\hline 154 & Matariata branco \\
\hline 979 & Parica \\
\hline 189 & Pente de macaco \\
\hline 014 & Amapai \\
\hline Aft & Anescla branca \\
\hline 018 & Andirobarana \\
\hline 635 & Sreu vermelino \\
\hline 658 & Capitiu \\
\hline 684 & Envira oreta \\
\hline 117 & Inga chato. \\
\hline 136 & Joan nole \\
\hline 228 & Tento da tolka niuda \\
\hline 014 & Antapai \\
\hline 016 & Anesic branca \\
\hline 025 & Arataciu \\
\hline 835 & Breu vermelho \\
\hline 053 & Canela de jacanin \\
\hline 083 & Envira cana \\
\hline 178 & Parabara \\
\hline 018 & Andirobarana \\
\hline 025 & Arataciu \\
\hline 635 & greu veratho \\
\hline ถ马ว & Burra leiteira \\
\hline 947 & Caferana \\
\hline 053 & Canela de jacania \\
\hline 683 & Envira cana \\
\hline 117 & Inga chato \\
\hline 912 & Aq⿴囗十⺝ a anargoso \\
\hline 025 & Arataciu \\
\hline 935 & Breu veraeito \\
\hline 083 & Envira cana \\
\hline 116 & Inga oranco \\
\hline 130 & Joao nole \\
\hline $\begin{array}{l}014 \\
858\end{array}$ & Amapai \\
\hline
\end{tabular}

$\begin{array}{ll}2 & 3 \\ 2 & 3 \\ 2 & 3 \\ 2 & 4 \\ 2 & 4 \\ 2 & 4 \\ 2 & 4 \\ 2 & 4 \\ 2 & 4 \\ 2 & 4 \\ 2 & 4 \\ 2 & 4 \\ 2 & 4 \\ 3 & 1 \\ 3 & 1 \\ 3 & 1 \\ 3 & 1 \\ 3 & 1 \\ 3 & 1 \\ 3 & 1 \\ 3 & 4 \\ 3 & 1 \\ 3 & 2 \\ 3 & 2 \\ 3 & 2 \\ 3 & 2 \\ 3 & 2 \\ 3 & 2 \\ 3 & 2 \\ 3 & 3 \\ 3 & 3 \\ 3 & 3 \\ 3 & 3 \\ 3 & 3 \\ 3 & 3 \\ 3 & 3 \\ 3 & 3 \\ 3 & 4 \\ 3 & 4 \\ 3 & 4 \\ 3 & 4 \\ 3 & 4 \\ 3 & 4 \\ 4 & 1 \\ 4 & 1 \\ & \\ 2\end{array}$

\begin{tabular}{|c|c|c|c|c|c|}
\hline 80 & 4.35 & 0.12 & 6.89 & 20 & 10.00 \\
\hline 80 & 4.35 & 0.04 & 2.25 & 20 & 10.09 \\
\hline 269 & 8.70 & 8.09 & 5.10 & 20 & 10.00 \\
\hline 80 & 2.70 & 0.06 & 1.82 & 20 & 6.25 \\
\hline 480 & 46.22 & 0.37 & 11.50 & 90 & 12.50 \\
\hline 1449 & 48.65 & $\$ .97$ & 63.03 & 80 & 25.00 \\
\hline 90 & 2.70 & 0.11 & 3.41 & 20 & 6.25 \\
\hline 80 & 2,70 & 0.12 & 3.96 & 20 & 6.25 \\
\hline 80 & 2.70 & 0.95 & 1.29 & 20 & 6.25 \\
\hline 89 & 2.70 & 0.86 & 2.92 & 20 & 6.25 \\
\hline 160 & 5.41 & 0.11 & 3.49 & 20 & 6.25 \\
\hline 80 & 2.70 & 9.05 & 1.46 & 6 & 6.25 \\
\hline 249 & 8.11 & 0.17 & 5.37 & 20 & 3.25 \\
\hline 80 & $7 . \frac{1}{2} 4$ & 0.04 & 4.37 & 20 & 10.00 \\
\hline 80 & 7.14 & 0.95 & 5.54 & 20 & 10.00 \\
\hline 80 & 7.14 & 0.05 & 5.54 & 20 & 10.00 \\
\hline 80 & 7.14 & 9.95 & 5.54 & 20 & 10.00 \\
\hline 160 & 14.28 & 0.17 & $\{7.77$ & 20 & 19.98 \\
\hline 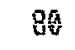 & $7.1 \frac{1}{7}$ & 0.14 & $15 \times 38$ & 20 & 10.90 \\
\hline 86 & 7.14 & 3.85 & 5.54 & 20 & 10.00 \\
\hline 160 & 14.28 & 0.98 & 8.75 & 29 & 10.00 \\
\hline 249 & 21.43 & 0.17 & 18.18 & 20 & 19.90 \\
\hline 90 & 4.55 & 9.94 & 3.64 & 20 & 7.69 \\
\hline 160 & 9.69 & 0.17 & 14.42 & 40 & 15.38 \\
\hline 240 & 13.64 & 0.18 & 13.45 & 20 & 7.69 \\
\hline 80 & 4.55 & 0.08 & 5.75 & 20 & 7.69 \\
\hline 80 & 4.55 & 0.04 & 3.64 & 20 & 7.69 \\
\hline 890 & 59.06 & 0.64 & 47.65 & 80 & 30.77 \\
\hline 83 & 4.55 & 0.64 & 3.64 & 20 & 7.69 \\
\hline 39 & 3.23 & 0.88 & 3.22 & 26 & 5.26 \\
\hline 240 & 9.68 & 0.22 & 8.97 & 40 & 10.53 \\
\hline 323 & 12.90 & 0.24 & 9.96 & 60 & 15.79 \\
\hline 880 & 35.40 & 0.95 & 39.80 & 46 & 10.53 \\
\hline 160 & 6.45 & 0.13 & 5.53 & 40 & 19.53 \\
\hline 80 & 3.23 & 0.95 & 2.26 & 20 & 5.26 \\
\hline 80 & 3.23 & 0.05 & 2.16 & 20 & 5.26 \\
\hline 80 & 3.23 & 0.68 & 3.22 & 20 & 5.26 \\
\hline$\$ 60$ & 13.34 & 9.20 & $\{8.33$ & 20 & 10.00 \\
\hline 80 & 6.67 & 0.12 & 11.33 & 20 & 10.06 \\
\hline 80 & 6.67 & 0.11 & 9.77 & 20 & 10.00 \\
\hline 484 & 40.00 & 0.35 & 34.36 & 40 & 20.00 \\
\hline 80 & 6.67 & 0.65 & 4.68 & 20 & 10.69 \\
\hline 80 & 6.67 & 0.04 & 3.70 & 20 & 10.63 \\
\hline $\begin{array}{r}89 \\
400\end{array}$ & $\begin{array}{r}4.76 \\
23.8 \frac{1}{2}\end{array}$ & $\begin{array}{l}0.65 \\
0.25\end{array}$ & $\begin{array}{r}3.70 \\
17.85\end{array}$ & 20 & 7.14 \\
\hline
\end{tabular}




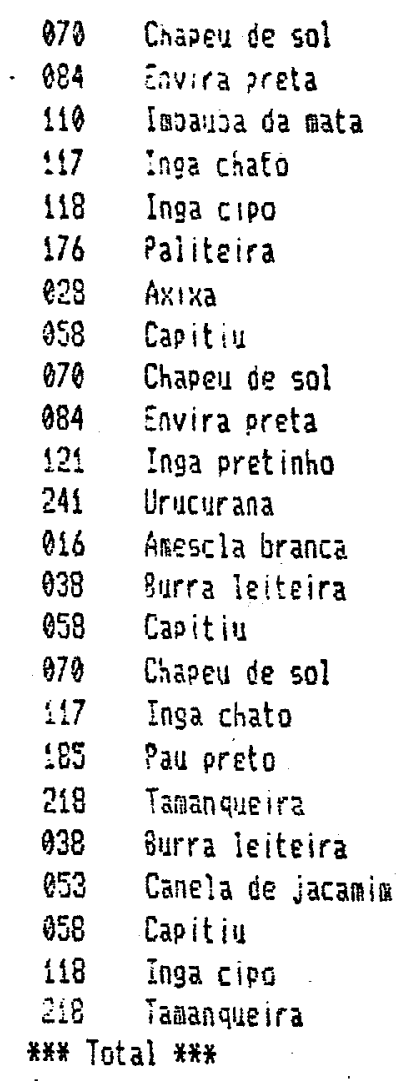

\begin{tabular}{|c|c|c|c|c|c|}
\hline 80 & 4.76 & 0.08 & 5.55 .5 & 29 & 7.14 \\
\hline 80 & 4.76 & 0.04 & 2.93 & 20 & 7.14 \\
\hline 80 & 4.76 & 0.09 & 6.63 & 20 & 7.14 \\
\hline 90 & 4.76 & 9.85 & 3.31 & 20 & 7.14 \\
\hline 160 & 9.52 & 9.99 & 6.25 & 40 & 14.28 \\
\hline 320 & 19.05 & 9.27 & 19.78 & 20 & 7.14 \\
\hline 90 & 5.88 & 4.15 & 12.41 & 20 & 14.27 \\
\hline 240 & 17.65 & $\frac{a}{8.17}$ & 14.95 & 20 & 14.29 \\
\hline 248 & 17.65 & 0.35 & 28.27 & 20 & 14.29 \\
\hline 80 & 5.88 & 0.85 & 4.18 & 20 & 14.29 \\
\hline 160 & 11.76 & 0.13 & 10.33 & 40 & 28.58 \\
\hline 560 & 41.18 & 0.38 & 30.79 & 20 & 14.29 \\
\hline 8 8f & 3.45 & 0.60 & 3.15 & 20 & 6.47 \\
\hline 800 & 34.48 & 0.97 & 39.66 & 80 & 25.67 \\
\hline 160 & 3.98 & 0.23 & 9.24 & 20 & 6,67 \\
\hline 80 & 3.45 & 9.84 & 1.67 & 20 & 6.67 \\
\hline 160 & 6.90 & 0.18 & 7.53 & 20 & 6.67 \\
\hline 560 & 24.14 & 4.51 & 20.94 & 40 & 13.34 \\
\hline 90 & 3.45 & 0.69 & 3.75 & 28 & 6.67 \\
\hline 80 & 7.14 & 0.09 & 8.78 & 20 & 14.29 \\
\hline 320 & 28.57 & 0.30 & 27.08 & 49 & 28.57 \\
\hline 80 & 7.14 & 0.09 & 8.78 & 26 & 14.29 \\
\hline 80 & 7.14 & 6.66 & 5.50 & 20 & 14.27 \\
\hline 550 & 57.20 & 9.50 & 47.86 & 40 & 28.5 \\
\hline & & & & & \\
\hline
\end{tabular}




\section{APENDTCE 6}

Abundancia (n/ha) das esfocies no estagio de regeneraçăo natural (SF3). Inventario continuo 1986. 


\begin{tabular}{|c|c|c|c|c|c|c|c|c|c|c|c|c|c|c|c|c|}
\hline \multirow{2}{*}{$\begin{array}{l}\text { Houe } \\
\text { eng } \\
\text { Estécie }\end{array}$} & \multicolumn{4}{|c|}{ Iratamento 01} & \multicolumn{4}{|c|}{ Tratamento Ge } & \multicolumn{4}{|c|}{ Tratarento 83} & \multicolumn{4}{|c|}{ Trat astento 04} \\
\hline & 1 & 2 & 3 & 4 & 1 & 2 & 3 & 4 & 1 & 2 & 3 & 4 & 1 & 2 & 3 & 4 \\
\hline Ahis vermel ho & & & & & & & 328 & & & 320 & & & & & & \\
\hline Abiarna folina & & & & & & & 969 & & & & & & & & 2240 & \\
\hline hcarignaida & & & & & 1280 & & & & & & & & & & & \\
\hline Anescla branca & 4169 & 1680 & & & 968 & 329 & 320 & 968) & 960 & 2889 & 3840 & 320 & 4850 & 1920 & 649 & 328 \\
\hline Andirobarana & & & 649 & 328 & & 3201 & & 329 & 328 & & 649 & & 1288 & & & \\
\hline Bactripari & 320 & & 648 & & & 329 & & & & 329 & & 329 & 640 & & & 329 \\
\hline Srea verthello & 320 & 329 & 5760 & 649 & & & 329 & & 329 & 969 & 960 & 329 & 328 & & 1929 & 329 \\
\hline Cacau la wata & & & & & & & & & & 320 & 328 & & & 649 & & \\
\hline caferana & 648 & 969 & 640 & 320 & 968 & 320 & & 2246 & 966 & 960 & 2868 & & 1289 & .320 & 2358 & 1668 \\
\hline Cajucara & & & & & & 320 & & 328 & & & & & & 320 & $\therefore$ & \\
\hline Canela jacanili & 328 & 2248 & 5120 & 969 & 320 & & 649 & 1280 & 320 & 960 & 4899 & 640 & 328 & 320 & 1689 & 328 \\
\hline Capitiu & & & & & 648 & 1280 & & 2249 & 649 & & & & 3526 & 326 & 1600 & 1609 \\
\hline Caraiverana & & & 320 & 649 & & & 649 & & & & 328 & & & & . & \\
\hline Chapél de sol & & & & & & 640 & & & & & & & & & 329 & \\
\hline Corapita & & & & & & 320 & 329 & & & & & & & & & 320 \\
\hline Envira casa & & & & 320 & 320 & 329 & & & & 960 & 328 & & & 320 & 649 & \\
\hline Envira preta & 6720 & 7848 & 2249 & 16568 & & 2248 & & 5120 & 8326 & 3649 & 3520 & 9668 & 5449 & 2249 & 4494 & 1289 \\
\hline Espetorana & 320 & & 326 & 320 & & 320 & & 320 & - & & & 649 & 326 & & & \\
\hline Freijó branco & & & & & & & & & & & & & 649 & & & \\
\hline Goiabarana & & 320 & 320 & & & & 960 & & & & & & & & & \\
\hline Gojabinha & 320 & 960 & 320 & & & 329 & 320 & & & & & & & & & \\
\hline liebagia branca & & & & & 529 & 320 & & & & & & & 649 & & & \\
\hline Imbansa veru. & & & & & 960 & 2800 & 640 & 7948 & & & & & 1289 & 328 & & $32 \overline{8}$ \\
\hline Inajarana. & & & & 968 & & & & & & & & & & & & \\
\hline Ingà branco & 320 & & & & & 648 & & 960 & & . & 1280 & 960 & & & 320 & 320 \\
\hline Ingá chato & & & 649 & & & & 1290 & & & 960 & 960 & 1280 & & 960 & 1920 & 969 \\
\hline Ingà cipó & & & & 320 & & & & 320 & & & & & 320 & 649 & 1660 & 320 \\
\hline Ingá pelado & 329 & & & & & $?$ & & 640 & & 320 & 649 & 326 & 1280 & 960 & & 320 \\
\hline Inga gretinho & & & & & 640 & 329 & 6490 & 640 & 328 & & & & & 649 & & \\
\hline Ingà veraeliho & & & & 320 & & & & & & & & & 320 & & 649 & \\
\hline Ingarana & 320 & & & 326 & & & 1289 & 320 & & & 329 & & & & & \\
\hline Intare & & & & & & & 640 & & 1929 & & 320 & & 329 & 320 & 328 & \\
\hline Jo\%o vole & & & & & & 648 & & 649 & & & & 329 & & 320 & & \\
\hline Jarabeba & & & & & 960 & & & & & & & & & & & 320 \\
\hline Lacre & & & & & & & 646 & & & & & & & & & \\
\hline Loaro ararelo & & & & & 1280 & 1660 & & & & & & & & & & \\
\hline Lowro zreto & 320 & & & & 320 & & & & & & 956 & 329 & & & 320 & \\
\hline กัตับi & & & & & & & 329 & & 329 & & & & & 329 & & \\
\hline Mapatirana & & & & & & & & & & & 329 & 320 & & & 326 & \\
\hline hat atat i branco & 648 & 329 & & 320 & 329 & 1929 & & 329 & & 1260 & 329 & & & 320 & & \\
\hline
\end{tabular}




\begin{tabular}{|c|c|c|c|c|c|c|c|c|c|c|c|c|c|c|c|c|}
\hline \multirow{2}{*}{$\begin{array}{l}\text { Home } \\
\text { da } \\
\text { Especie }\end{array}$} & \multicolumn{4}{|c|}{ Irataento 1} & \multicolumn{4}{|c|}{ Iratamento 22} & \multicolumn{4}{|c|}{ Tratamento 03} & \multicolumn{4}{|c|}{ Iratapento 94} \\
\hline & 1 & 2 & 3 & 4 & 1 & 2 & 3 & 4 & 1 & 2 & 3 & 4 & 1 & 2 & 3 & 4 \\
\hline far & & & & & & & & & & 320 & & 329 & & 320 & & 1600 \\
\hline Laricá & & & & & & & 1668 & & & & & & 320 & & 640 & \\
\hline Far de cobro & 328 & & & & & & & & & 32 & & & & & & \\
\hline Pan de serra & & & & & 1289 & & & & & & & & & & & \\
\hline Pan preto & & & & & & & 328 & & & & & & & & 960 & \\
\hline Pente de acaco & & & & & 320 & 320 & & & & & & & & & 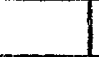 & \\
\hline Pigenta de jacui & 328 & 320 & & & 328 & & & & 640 & 968 & 329 & 320 & 320 & & . & \\
\hline Periquiteira & & & & & & & 640 & & & & 329 & & & & 329 & \\
\hline Pitoria & & & & & & & & & & & & 320 & . & & 329 & \\
\hline Parai & & & & & & & 320 & & & & & & & & 320 & \\
\hline Saboeiro & & & & & & & 649 & & & & & & & & & \\
\hline Tabanqueira & & & & & & 320 & $\ldots$ & & & & & & 320 & & & 969 \\
\hline Tatapiririca & & & & & & & & & & & & & 649 & & & \\
\hline Ueruha f.peluda & & & & & & & & & & & 320 & 329 & & & & \\
\hline Ulanuha t.firte & 320 & & & & & 328 & & 320 & & & & 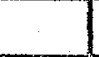 & & 328 & & \\
\hline Ucugharana & & & 320 & & & & $\cdot$ & 320 & 320 & & 329 & 325 & & 329 & & \\
\hline Urucurane & & . & & & & & & 320 & & & & & & & & 327 \\
\hline hairapinita & & 640 & & & & & & & & & & & & & & \\
\hline 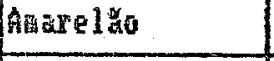 & & & & & & & & & & & & & 329 & & & \\
\hline Cedrorana & & & & & & & & & & & & & & 320 & & \\
\hline Parapara & & & & & & & 320 & & & & & & & 2 & & \\
\hline Hesconbecido & 1920 & 968 & 969 & 3260 & 1600 & 649 & 2568 & 648 & 969 & 3526 & 3848 & 2568 & 1286 & & 2560 & 3528 \\
\hline
\end{tabular}




\section{APENDICE 7}

Abundancia (n/ha) das espories no estagio de regeneraçzo natural (SF3). Inventario continuo 1989. 


\begin{tabular}{|c|c|c|c|c|c|c|c|c|c|c|c|c|c|c|c|c|}
\hline \multirow{2}{*}{$\begin{array}{c}\text { Hoge } \\
\text { da } \\
\text { Especie }\end{array}$} & \multicolumn{4}{|c|}{ irat anento 01} & \multicolumn{4}{|c|}{ Iratamento 62} & \multicolumn{4}{|c|}{ Iratasento 83} & \multicolumn{4}{|c|}{ Iratanento 4} \\
\hline & 1 & 2 & 3 & 4 & 1 & 2 & 3 & 4 & 1 & 2 & 3 & 4 & 1 & 2 & 3 & 4 \\
\hline Álig catite & 326 & & & & & & & & & & & & & & & \\
\hline Abia seco & & & 328 & & & 320 & 328 & & & 320 & & & & & & \\
\hline Abia veraelto & 960 & & & & & & & & & & & & & & 329 & \\
\hline Abiorana & 1280 & & & & & & 640 & & 960 & & & & & 960 & & \\
\hline Abingana f fina & & & & & & & 328 & & & & & & & & & \\
\hline Acariquara & 648 & & & & & & & & & & & & & & & \\
\hline Axapd amargoso & & & & & & & & & & & 328 & & & & & \\
\hline Arapai & & & & & & & & 326 & 328 & 320 & & & 649 & 646 & & \\
\hline Afuescla branca & 2568 & 989 & 2246 & 1280 & 1600 & 329 & 320 & 320 & 1280 & 3520 & 2880 & 328 & 1289 & 2249 & 3209 & 968 \\
\hline Andirolarana & 960 & 329 & 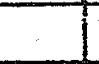 & 320 & & & 320 & 649 & 320 & 329 & 326 & 328 & 649 & 640 & 648 & \\
\hline Anani & & & 648 & 640 & 329 & & 1285 & & & & & 329 & 326 & 326 & & \\
\hline Arat aciú & 1288 & 960 & 884 & 1280 & & 320 & & 1699 & & 968 & 1680 & 3849 & & & 320 & 4160 \\
\hline Aroeira & & & 648 & & & 326 & & & & & & & & 32 & & \\
\hline Axixa & & & & 1680 & & & & & & & & & & & & \\
\hline $9 a c a b a$ & & & & & & & & & & & 320 & & & & & \\
\hline Eacuripari & & & 328 & & & & $\cdot$ & & & & & 329 & & & 329 & 640 \\
\hline Ireu preto & & & & & & & & & & & 329 & & & & & \\
\hline Bren yermelho & 960 & & 649 & & & & & & 329 & & 329 & 649 & 2569 & & & \\
\hline Eerra leiteira & & & & & & & & 640 & & & & & & & & \\
\hline Cacan da mata & & & & & & & 329 & & & & 328 & 329 & & 640 & & \\
\hline Cachá & & & & . & & & & & & & & & 379 & & & \\
\hline Gaterana & 3526 & 1920 & 328 & 1609 & & 1929 & 649 & 1606 & 2566 & 3528 & 1606 & 328 & 4869 & 648 & 1928 & 960 \\
\hline Caja & & & & & & & 328 & & & & & & & & & \\
\hline Cajingara & & & & & & & . & & & & & & & 329 & & \\
\hline Canela jacania & 646 & 1280 & 4896 & 640 & 1289 & 3201 & 969 & 9601 & 329 & 9601 & 2249 & 648 & 329 & 329 & 2249 & \\
\hline caneleiro & & & & 328 & & & & & & & & & & 326 & & \\
\hline Eanitiu & 320 & 328 & & & & 2560 & & 329 & 329 & & 320 & & 1280 & 6401 & & 649 \\
\hline Caraiperana & & & & & 1280 & & 320 & 320 & & & & & & & & \\
\hline Canagu & & & & & & 320 & & & & & & & & & & \\
\hline Chapéll de sol & & & & & 640 & & & & & & & & 960 & & & \\
\hline furupita & & & & & & & & 329 & & & & & & & & \\
\hline Envira branca & & & & & & & & & & 649 & & & & & & \\
\hline Envira cana & 2248 & 3269 & 1286 & 4160 & & 4809 & 960 & 4480 & 6468 & 6729 & 1280 & 8320 & 5449 & 969 & 3268 & 960 \\
\hline Envira preta & 9280 & 320 & & 5129 & & & 328 & & & & 329 & & 960 & 329 & 329 & \\
\hline Envira taia & & & & 320 & & 320 & & & & 649 & & & & & & 320 \\
\hline Espetoriba & 1280 & & & & & & & & & & & & 3528 & & & \\
\hline fava f.fina & & & & & & & & 329 & & & & & & & & 328 \\
\hline fera le ovo & & & & & & & & & & 1289 & & & & & & \\
\hline foiaba brava & & & & & & & & & & & 320 & & & & & \\
\hline foiaba lranca & & 1289 & & & & 328 & 329 & & & & & & & & 969 & \\
\hline
\end{tabular}




\begin{tabular}{|c|c|c|c|c|c|c|c|c|c|c|c|c|c|c|c|c|}
\hline \multirow{2}{*}{$\begin{array}{c}\text { Home } \\
\text { da } \\
\text { Especie }\end{array}$} & \multicolumn{4}{|c|}{ Tratamento 01} & \multicolumn{4}{|c|}{ Trat aluento 02} & \multicolumn{4}{|c|}{ Iratanento 3} & \multicolumn{4}{|c|}{ Iratarento 64} \\
\hline & 1 & 2 & 3 & 4 & 1 & 2 & 3 & 4 & 1 & 2 & 3 & 4 & 1 & 2 & 3 & 4 \\
\hline Inajarana & & 320 & & 649 & & & & & & 329 & 328 & & 1288 & & & \\
\hline Inga beanco & & & & & & 329 & 646 & 328 & & & 968 & & & & 320 & \\
\hline Inga costo & & & & & 1280 & & 1608 & 328 & & & 1286 & 320 & 968 & 1289 & 2249 & 329 \\
\hline Ingá ezpó & 648 & & & & & & 648 & 320 & 328 & & 320 & 649 & & 648 & 1288 & 649 \\
\hline $\operatorname{lnga} 1$ ac áo & & & 646 & & 1600 & & & & 320 & 320 & & & & & & \\
\hline Ingá pelado & & & & 320 & 329 & & & & & & 328 & & 326 & 328 & & 320 \\
\hline Ingi pretinto & & & & & 320 & & 640 & & & 649 & & 329 & 969 & 648 & 1920 & \\
\hline Ingà yermelso & & & & & & & & 320 & & & & 648 & & & & 648 \\
\hline Inga xiraica & 320 & & & & & & & & & & & & & & & \\
\hline Ingarana & 2248 & & & & & & & 320 & & 3281 & 329 & & 1928 & & & \\
\hline Intare & 320 & & & & & 320 & & & 1669 & 640 & & & 320 & & 328 & \\
\hline Josa gole & 328 & & & & & 320 & & & & & & 1690 & & 648 & & \\
\hline Lacre & & & & & & & 320 & 320 & & & & & & & & \\
\hline Lonro ararelo & & & & 320 & & & & 326 & & 328 & 320 & & & & & \\
\hline lowro branco & & 328 & 329 & & & 329 & & & & 328 & & & & 649 & & \\
\hline Lonro preto & & & & & & & & & & & 329 & & & & 320 & \\
\hline Lomro rosa & & & & & & 3201 & & & & & & & & & & \\
\hline facuca sangue & & & 328 & & & & 329 & & & & 649 & & & & & \\
\hline hasorana & & & & & 368 & & & & & & & & & & & \\
\hline Kavatirana & 960 & 320 & & & 328 & & & & & & & & & & 649 & \\
\hline trassaranduba & & & & & & & & & & & 328 & & & & & \\
\hline Hata a ata amarel & & & & 648 & & & & & 640 & & & & & & & 648 \\
\hline hatakata hranco & & 328 & & & 960 & 2560 & 320 & & 320 & 320 & 329 & & 1299 & & & \\
\hline marachiobe. & & & & & & & & & & & 320 & & & & & \\
\hline nu irat inga & & & & & & & & 329 & & & & & & & & \\
\hline Wrirat inga yel. & & & & & & & & 320 & & & & & & & & \\
\hline hargré & & & & & & & & & & & & & & & & 960 \\
\hline Futaba & & & & & & & 2240 & & & & & & & & 328 & \\
\hline Butati daro & & & & & & & & & & & & 320 & 320 & & 320 & \\
\hline Paliteira & & & & & & 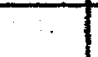 & & & & & & & 329 & & & \\
\hline Papo de antan & & & & & 329 & 328 & & 640 & & & & & & 640 & & \\
\hline Farica & & & & & & 320 & & & & & & & & & & \\
\hline Fam doce & & 320 & & & & & & & & & & & & & 328 & \\
\hline Sau greto & & & & & & & 320 & & & & 4160 & & & 649 & 2849 & \\
\hline Rente de acaco & 640 & & 1280 & & & & & 320 & & & & & & & 329 & 320 \\
\hline Pitoriona & & & & & & 649 & & 320 & & 328 & & & & & 320 & 320 \\
\hline Parui & & & & 329 & & 969 & 1288 & & & 1609 & 649 & 648 & & & 649 & \\
\hline Tachi branco & & & & & & & & & & & 320 & & & & & \\
\hline Tachi yreto & & & & & & & & 320 & & & & & & & & \\
\hline Tschi vermel to & 320 & & & & & & & & & & & & & & & \\
\hline
\end{tabular}




\begin{tabular}{|c|c|c|c|c|c|c|c|c|c|c|c|c|c|c|c|c|}
\hline \multirow{2}{*}{$\begin{array}{c}\text { Hone } \\
\text { ta a } \\
\text { Stecie }\end{array}$} & \multicolumn{4}{|c|}{ Iratasento 81} & \multicolumn{4}{|c|}{ Iratamento 62} & \multicolumn{4}{|c|}{ Iratamento 13} & \multicolumn{4}{|c|}{ Irat amento 64} \\
\hline & 1 & 2 & 3 & 4 & 1 & 2 & 3 & 4 & 1 & 2 & 3 & 4 & 1 & 2 & 3 & 4 \\
\hline Taguari & & & & & & & & 328 & & & & & 320 & & & \\
\hline Tartus & & & & & & & & & & & 329 & & & & & \\
\hline Tanari lifina & & & & 328 & & & & & & & & & & & & \\
\hline Tento f.aida & & & & & & & 328 & & & & & & & & & \\
\hline Tento preto & & & & & 320 & & & & & & & & 320 & & 320 & \\
\hline Hounba A.pelada & & 1288 & & & & & 329 & & & 320 & & & & & & \\
\hline benala t.firae & 648 & & & & & & & & & & & 640 & & & & \\
\hline Heuba preta & & & & & & & & & & & 328 & & & & & \\
\hline Ucuabaraha & & & 649 & & & & & & & & 960 & 640 & & & & \\
\hline Urucarana & 328 & 320 & & & & & & & 329 & & 320 & & 640 & & & \\
\hline Kairapiniad & 328 & 640 & & & & & & & & & & & & & & \\
\hline Desconbecido & & & & & & & & & & & & & 328 & & & \\
\hline
\end{tabular}

